\title{
Exemplary Design Envelope Specification for Standard Modular Hydropower Technology
}

Approved for public release. Distribution is unlimited.
Adam Witt

Brennan T. Smith

Achilleas Tsakiris

Thanos Papanicolaou

Kyutae Lee

Kevin M. Stewart

et al.

February 2017 


\title{
DOCUMENT AVAILABILITY
}

Reports produced after January 1, 1996, are generally available free via US Department of Energy (DOE) SciTech Connect.

Website http://www.osti.gov/scitech/

Reports produced before January 1, 1996, may be purchased by members of the public from the following source:

\author{
National Technical Information Service \\ 5285 Port Royal Road \\ Springfield, VA 22161 \\ Telephone 703-605-6000 (1-800-553-6847) \\ TDD 703-487-4639 \\ Fax 703-605-6900 \\ E-mail info@ntis.gov \\ Website http://classic.ntis.gov/
}

Reports are available to DOE employees, DOE contractors, Energy Technology Data Exchange representatives, and International Nuclear Information System representatives from the following source:

Office of Scientific and Technical Information

PO Box 62

Oak Ridge, TN 37831

Telephone 865-576-8401

Fax 865-576-5728

E-mail reports@osti.gov

Website http://www.osti.gov/contact.html

This report was prepared as an account of work sponsored by an agency of the United States Government. Neither the United States Government nor any agency thereof, nor any of their employees, makes any warranty, express or implied, or assumes any legal liability or responsibility for the accuracy, completeness, or usefulness of any information, apparatus, product, or process disclosed, or represents that its use would not infringe privately owned rights. Reference herein to any specific commercial product, process, or service by trade name, trademark, manufacturer, or otherwise, does not necessarily constitute or imply its endorsement, recommendation, or favoring by the United States Government or any agency thereof. The views and opinions of authors expressed herein do not necessarily state or reflect those of the United States Government or any agency thereof. 
Environmental Sciences Division

\title{
EXEMPLARY DESIGN ENVELOPE SPECIFICATION FOR STANDARD MODULAR HYDROPOWER TECHNOLOGY
}

\author{
Oak Ridge National Laboratory \\ Adam Witt \\ Brennan T. Smith \\ Kyutae Lee \\ Kevin M. Stewart \\ Scott DeNeale \\ Mark Bevelhimer \\ Jason L. Pries \\ Timothy A. Burress \\ Brenda Pracheil \\ Ryan McManamay \\ Shelaine Curd \\ University of Tennessee-Knoxville \\ Achilleas Tsakiris \\ Thanos Papanicolaou \\ Kivanc Ekici \\ Benjamin Kutz
}

Knight Piésold and Co.

Norman Bishop

McKeown and Associates LLC

Alisha R. Fernandez

US Department of Energy

Timothy Welch

Daniel Rabon

Revision 1

Date Published: February 2017

Prepared by

OAK RIDGE NATIONAL LABORATORY

Oak Ridge, TN 37831-6283

managed by

UT-BATTELLE, LLC

for the

US DEPARTMENT OF ENERGY

Contract DE-AC05-00OR22725 



\section{CONTENTS}

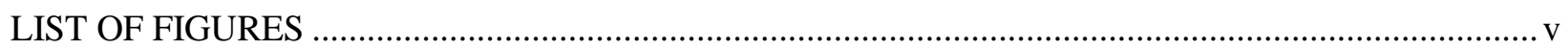

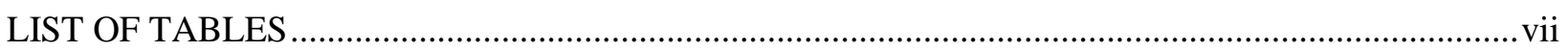

ABBREVIATIONS, ACRONYMS, AND INITIALISMS …......................................................... ix

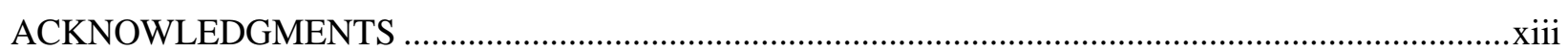

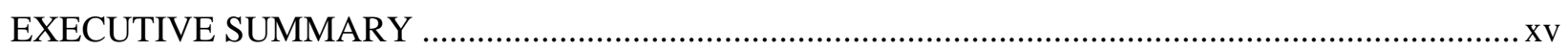

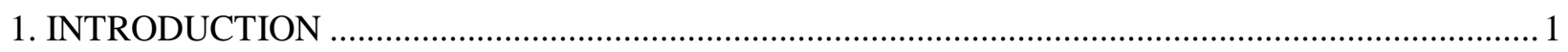

2. EXEMPLARY DESIGN PRINCIPLES AND CONCEPTS …...................................................... 3

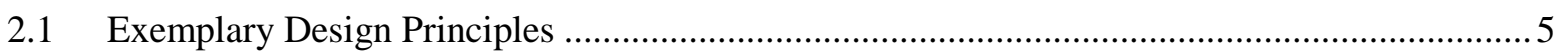

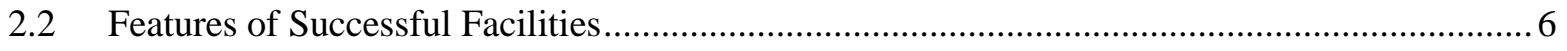

2.3 Implementation Through Functional Decomposition.......................................................... 7

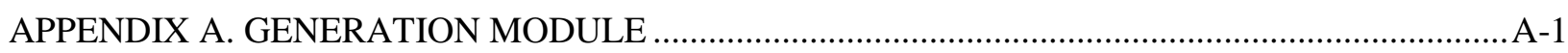

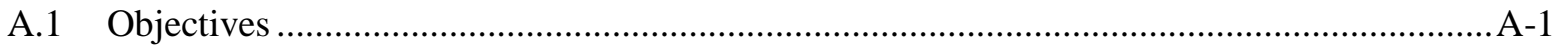

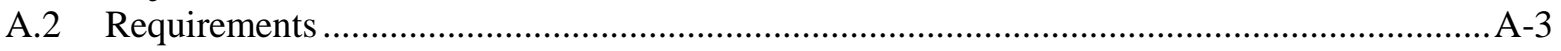

A.3 Inputs, Functional Relationships, and Processes .......................................................

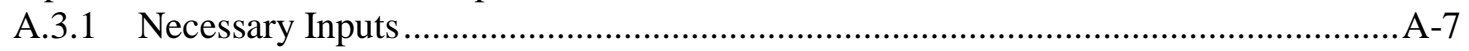

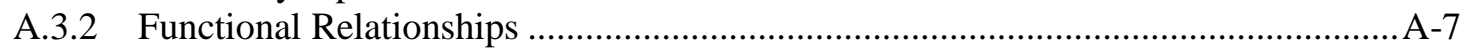

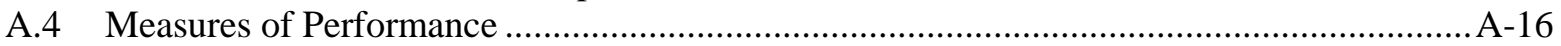

A.4.1 Module Unit Efficiency Characteristics ............................................................. A-16

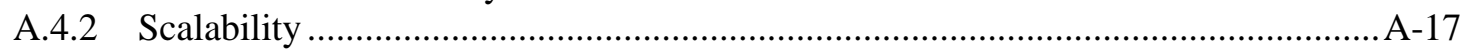

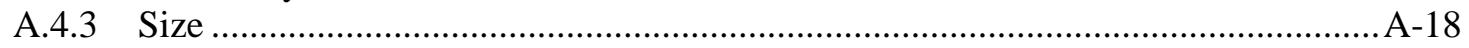

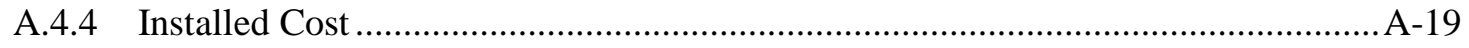

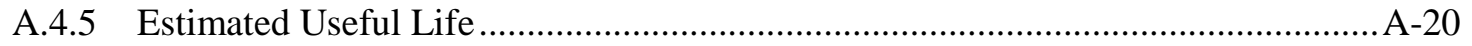

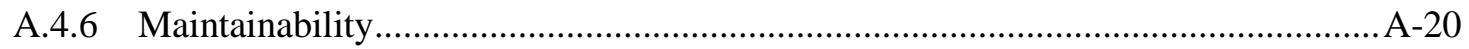

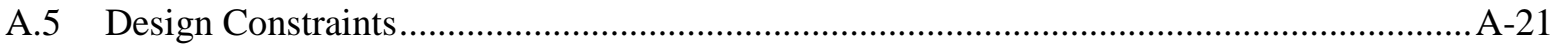

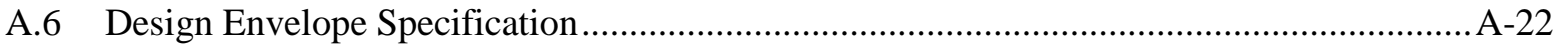

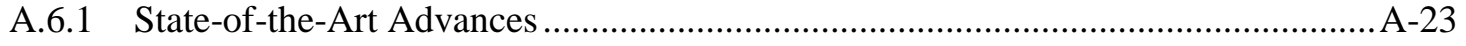

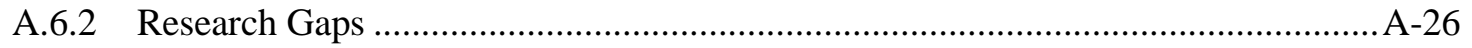

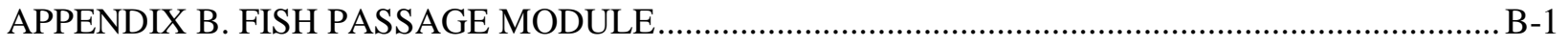

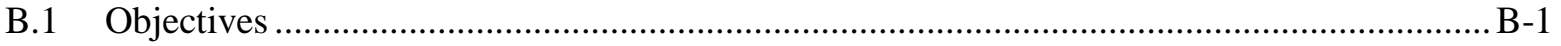

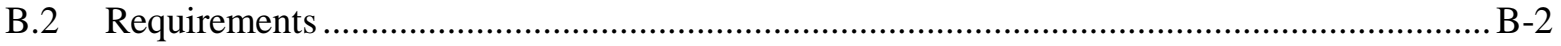

B.3 Inputs, Processes, Functional Relationships …….................................................................. B

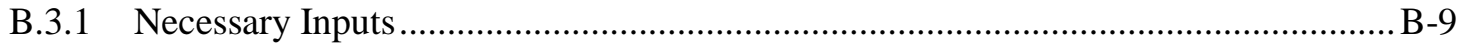

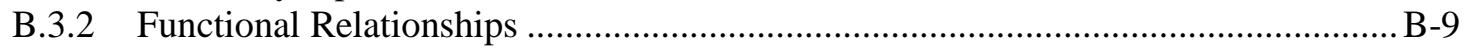

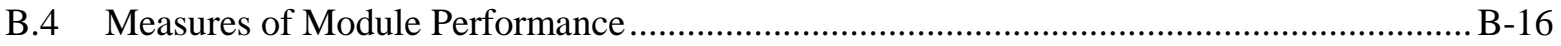

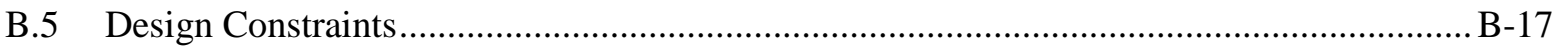

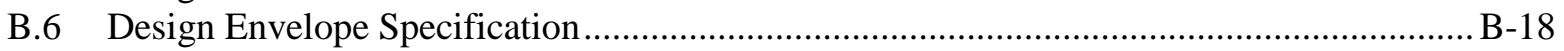

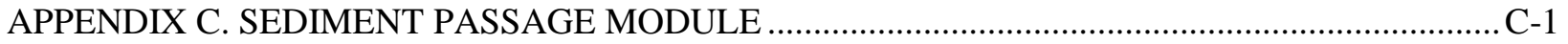

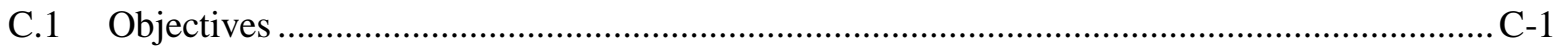

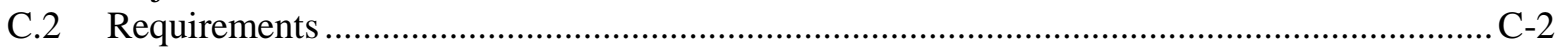

C.3 Inputs, Functional Relationships and Processes …......................................................... -5

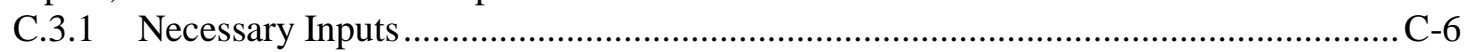

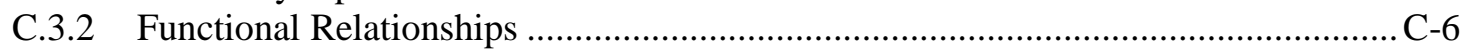

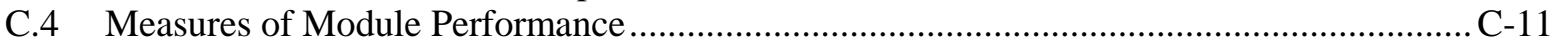

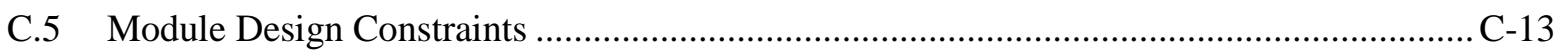




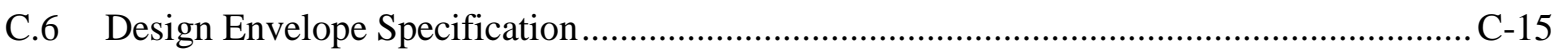

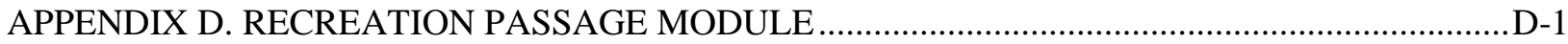

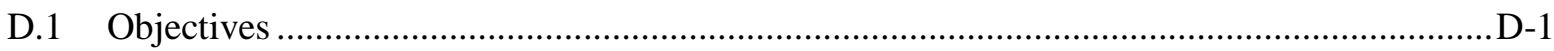

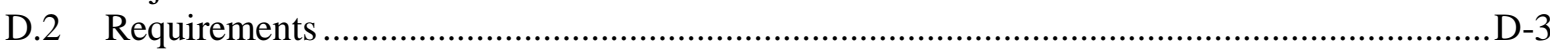

D.3 Inputs, Functional Relationships and Processes ..............................................................

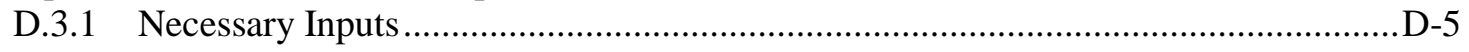

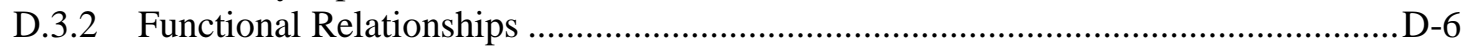

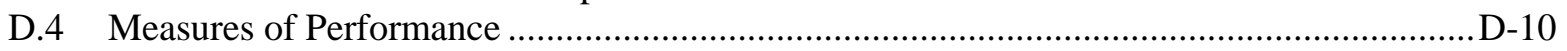

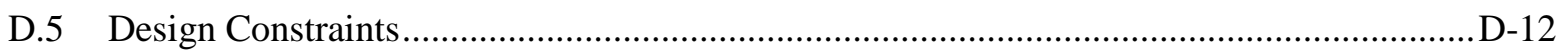

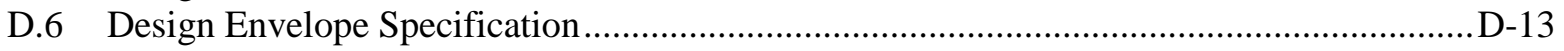

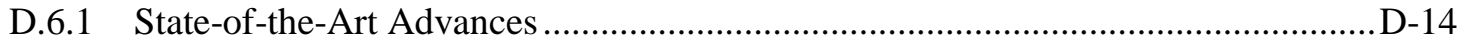

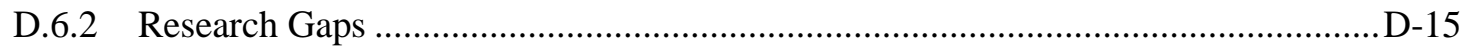

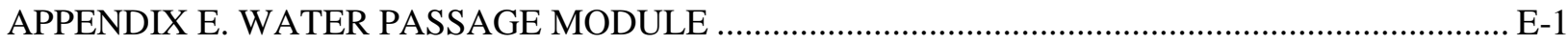

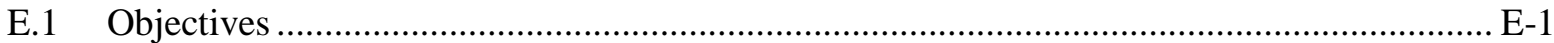

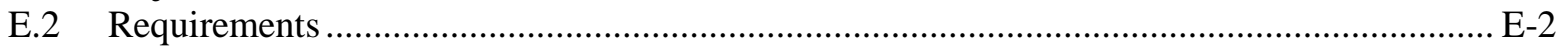

E.3 Inputs, Functional Relationships and Processes ….............................................................. E-7

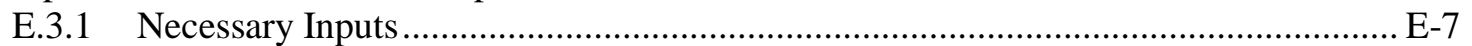

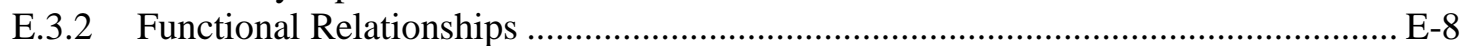

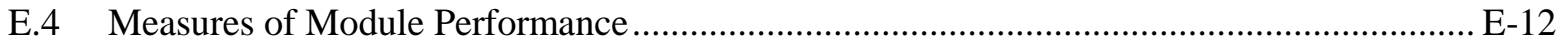

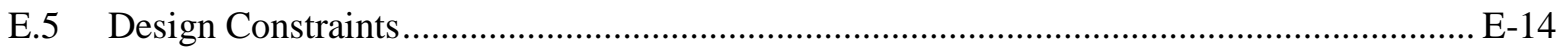

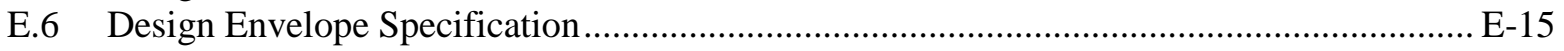

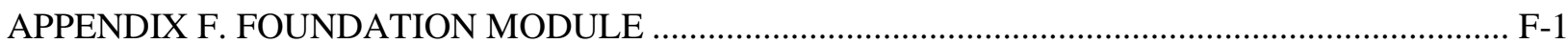

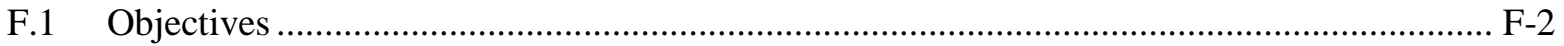

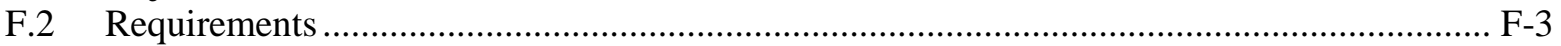

F.3 inputs, Functional Relationships, and Processes ……....................................................... F-7

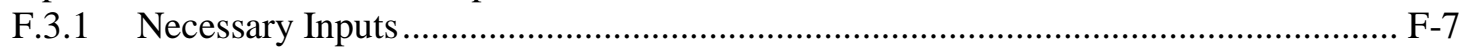

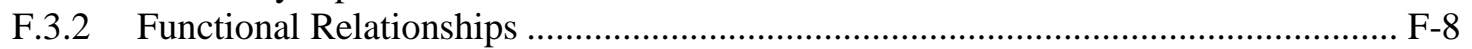

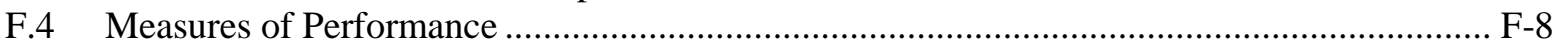

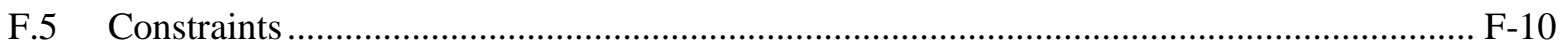

F.6 Design Envelope Specification ........................................................................... F-11

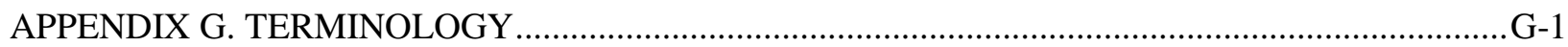

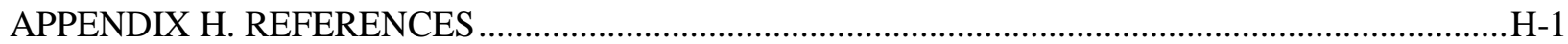




\section{LIST OF FIGURES}

Figure 1. Conceptual schematic of an SMH facility and constituent modules as "black boxes." ............... 2

Figure 2. Hierarchical structure of natural stream environments and hydropower systems. ....................... 4

Figure 3. Conceptual schematic of the specific objectives of a generation module. ............................... A-2

Figure 4. Specific objectives from Figure 3 mapped on a conventional run-of-river hydropower

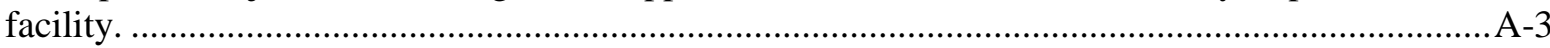

Figure 5. Example flow duration curve with important flow design parameters.................................A-10

Figure 6. A hill chart documenting the hydraulic efficiency (shown as labeled contours) of a

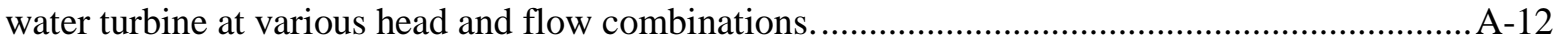

Figure 7. Optimum runner blade geometry for a given specific speed. .......................................... A-13

Figure 8. Idealized generator system power-speed characteristics for wide speed range operation........ A-14

Figure 9. Turbine efficiency for different turbine types at constant speed as a function of

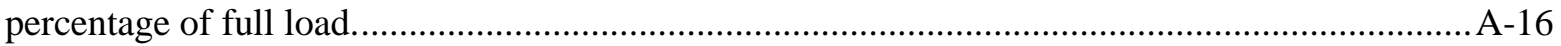

Figure 10. Example of the performance improvement expected from variable-speed turbines with

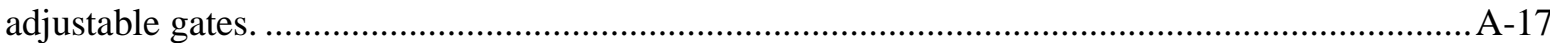

Figure 11. Single runner diameter for small, low-head $(<10 \mathrm{~m})$ conventional hydropower turbines (bulb Kaplan, vertical Kaplan, Francis) and embedded generator designs (Amjet, VLH, StreamDiver).

Figure 12. Project cost estimates for new stream-reach hydropower developments in the United States provided during the planning, engineering, and construction phases of project development.

Figure 13. Average power output of the new VSD and PMG system compared with the former induction generator.

Figure 14. Net real power efficiency of the new VSD and PMG system compared with the former induction generator.

Figure 15. Amjet Turbine Systems low-head turbine with embedded permanent magnet generator and variable-speed electronic flow control that eliminates the need for conventional peripheral equipment.

Figure 16. VLH turbine technology (right) eliminates powerhouse superstructure associated with more conventional technologies (left).

Figure 17. Installed unit (left) and cutaway sketch (right) of the Turbinator turbine-generator integrated technology installed without a powerhouse.

Figure 18. Conceptual schematic of the specific objectives of a fish passage module. B-2

Figure 19. Swimming speeds for various species of fish: (left) adult individuals, (right) juvenile individuals.

Figure 20. Fish endurance (vertical axis) as function of fish swimming speed (horizontal axis) for different fish species and water temperatures (after Ficke et al. 2011)....................................... B-11

Figure 21. Relationship between the flow discharge, bed slope, and flow depth (Katopodis 1992)...... B-13

Figure 22. Geometries of different fish passage modules and the expected flow patterns................... B-13

Figure 23. Relationship between the flow velocity (vertical axis) and discharge (horizontal axis) in the fish passage module (Katopodis 1992).

Figure 24. Flow patterns in fish passage modules of different geometry........................................... B-15

Figure 25. Conceptual schematic of the specific objectives of a sediment passage module. .................. C-2

Figure 26. Correlation of the bedload transport rate (vertical axis) with the excess bed shear stress (horizontal axis).

Figure 27. Critical shear stress as a function of the grain Reynolds number for different degrees of grain protrusion, denoted as $(\mathrm{p} / \mathrm{D})$, in relation to the flow and different grain shapes.

Figure 28. Percentage of sediment transported as bed load and suspended load as a function of the ratio of sediment fall velocity to friction velocity. 
Figure 29. Relationship of suspended sediment load (vertical axis) to the flow discharge and watershed steepness (horizontal axis).

Figure 30. Threshold values of (a) the index for sediment aggradation and degradation and (b) the index of incision potential for various hydropower facilities.....

Figure 31. Threshold values of (a) the index for flood magnitude reduction and (b) the index of incision potential for various hydropower facilities.

Figure 32. Thresholds of the morphologic change indices of Grant et al. (2003) where the effects of hydropower facilities on river morphology are subtle.

Figure 33. Conceptual schematic of the specific objectives of a recreation passage module..................D-2

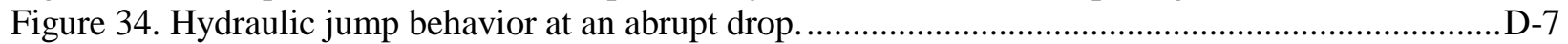

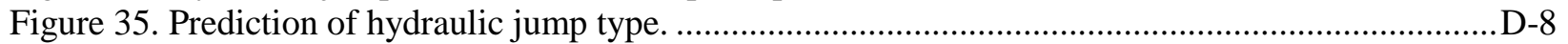

Figure 36. Inlet control structure designed with a slotted apron that creates an undular hydraulic

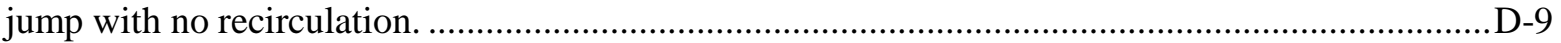

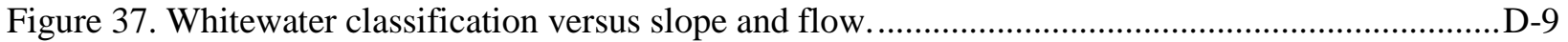

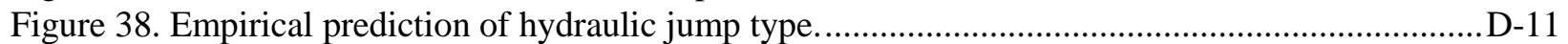

Figure 39. Suggested depth and velocity criteria for canoeing and kayaking.................................... D-11

Figure 40. Combined canoe and fish pass in the United Kingdom....................................................

Figure 41. Canoe/kayak slide adjacent to a fish passage structure located at a gated weir. .................. D-15

Figure 42. Conceptual schematic of the specific objectives of a water passage module........................ E-2

Figure 43. Dependence of the bankfull discharge on the watershed drainage area for different hydrologic units in New York state. (Mulvihill and Baldigo 2012) .............................................. E-9

Figure 44. (a) Example of a typical hydrograph indicating the flow response (blue curve) to precipitation (gray bars)................................................................................................... E-10

Figure 45. Relationship between the weir discharge coefficient (vertical axis) and the available water head (horizontal axis) for an ogee-shaped weir. (USBR 1977) ........................................... E-11

Figure 46. Conceptual schematic of the imposed loads a foundation module must resist....................... F-2

Figure 47. Conceptual schematic of the environmental mechanics a foundation module must resist. 


\section{LIST OF TABLES}

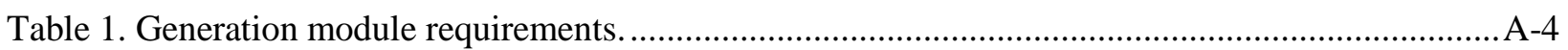

Table 2. Necessary inputs for generation module design ................................................................

Table 3. Functional relationships governing the generation module operation ...................................... A-7

Table 4. US hydrologic classification (McManamay et al. 2013) ….................................................. A-11

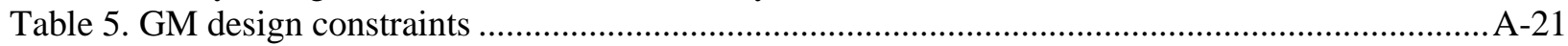

Table 6. Classification of barriers with respect to fish movement (adapted from the California

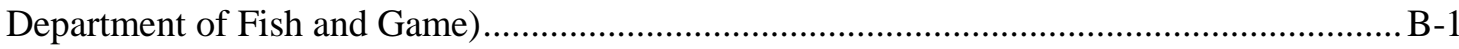

Table 7. Fish passage module functional requirements: objective 1 -attract fish to the module............. B-4

Table 8. Fish passage module functional requirements: objective 2-allow fish to cross SMH

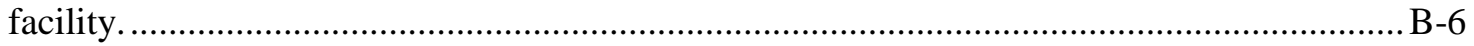

Table 9. Fish passage module functional requirements; objective 3-allow fish to exit safely into the

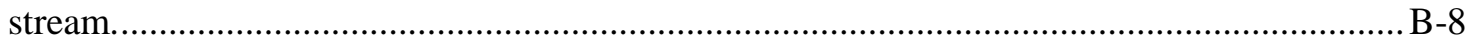

Table 10. Key inputs for the function of the fish passage module .................................................... B-9

Table 11. Functional relationships governing fish passage module operation ...................................... B-9

Table 12. Key physiological characteristics for common freshwater fish species (Meixler et al.

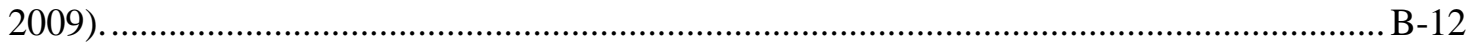

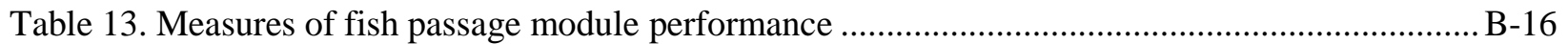

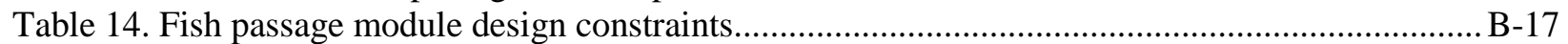

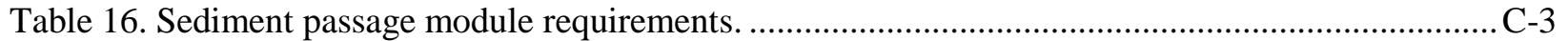

Table 17. Key inputs for the function of the sediment passage module …............................................ C-6

Table 18. Summary of the key functional relationships relevant to operation of the sediment passage

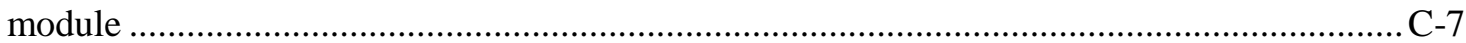

Table 19. Sediment passage module measures of performance ........................................................ -11

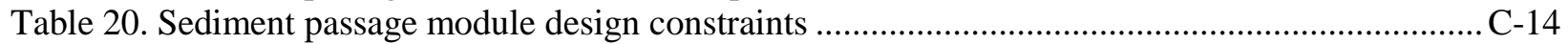

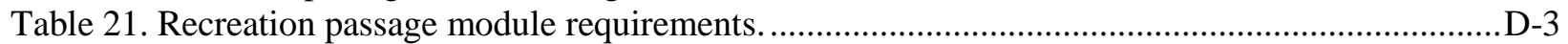

Table 22. Recreation passage module necessary inputs for hydraulic design ....................................... D-5

Table 23. Summary of key functional relationships necessary for recreation passage module design ....D-6

Table 24. Recreation passage module measures of performance ....................................................... D-10

Table 25. Recreation passage module design constraints .............................................................. D-12

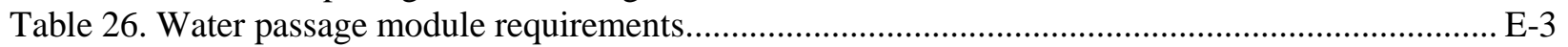

Table 27. Water passage module functional requirements. ............................................................... E-5

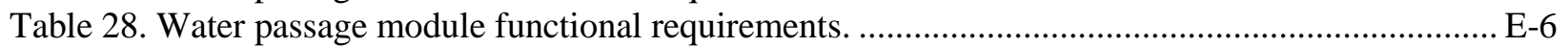

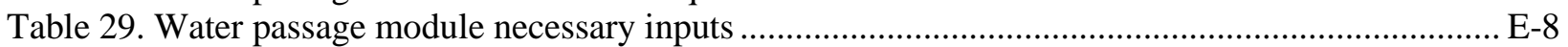

Table 30. Functional relationships governing water passage module operation.................................... E-8

Table 31. Water passage module measures of performance ........................................................... E-13

Table 32. Water passage module design constraints....................................................................... E-14

Table 33. Foundation module requirements. In the fourth column: $\mathrm{F}=$ Functional; $\mathrm{P}=$ Performance; $\mathrm{I}=$ Interaction; $\mathrm{O}=$ other. In columns 6-11, an " $\mathrm{X}$ " denotes a relationship to the river

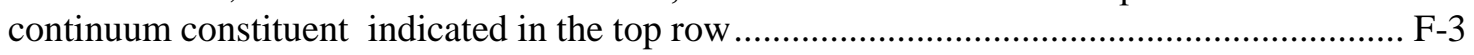

Table 34. Foundation module necessary inputs for module design ..................................................... F-7

Table 35. Functional relationships governing foundation module operation...................................... F-8

Table 36. Foundation module measures of performance ............................................................ F-9

Table 37. Foundation module design constraints............................................................................ F-10 



\section{ABBREVIATIONS, ACRONYMS, AND INITIALISMS}

AC alternating current

cfs cubic feet per second

DC direct current

EDES Exemplary Design Envelope Specification

EDF energy dissipation function

FM foundation module

GM generation module

IHA Indicators of Hydrologic Alteration

MYRP Multi-Year Research Plan

PM passage module

PMG permanent magnet generator

R\&D research and development

SMH standard modular hydropower

TKE turbulent kinetic energy

VSD variable-speed drive 



\section{ACKNOWLEDGMENTS}

The authors would like to acknowledge and express their appreciation to all the following individuals and programs for their review, comments, and support of this report and support of Standard Modular Hydropower research efforts.

\section{Oak Ridge National Laboratory}

- Deborah Counce, Technical Writer/Editor

- Kathy Jones, Electronic Media Specialist

- Rose Raney, Technical Writer/Editor

- Priscilla Henson, Publications Manager

- Andy Sproles, Graphic Artist

- Dami Rich, Graphic Artist

- Douglas Edwardson, Web Developer

- Shih-Chieh Kao, Statistical Hydrologist

- Nicole Samu, Geospatial Data Coordinator/Cartographer

- Christopher DeRolph, GIS Analyst and Aquatic Ecologist

- Missy Miller, Administrative Assistant

- Greg Zimmerman, Group Leader, Human Health Risk and Environmental Analysis

- Patrick O’Connor, Energy Analyst

\section{New Mexico Institute of Mining and Technology}

- Rebecca Brink, Science Undergraduate Laboratory Intern

\section{University of Minnesota}

- The authors extend their gratitude to Professor John Gulliver of the Civil, Environmental, and Geo- Engineering Department at the University of Minnesota for his meaningful insights and detailed review of this report.

\section{Small Hydropower Stakeholders}

The authors would like to thank the many stakeholders with whom we have engaged to elicit feedback on the opportunities and challenges associated with developing and deploying standard modular hydropower technologies. Ongoing engagement with these technology innovators, commercial service/equipment providers, project developers, and environmental stewards has yielded insight into the myriad perspectives and experiences that shape the current hydropower landscape and inform standard modular hydropower research.

\section{Copyright Holders}

In addition, the authors would like to thank the many publishers, organizations, and individuals who have granted Oak Ridge National Laboratory permission to reuse various figures, graphics, and information that aid in communicating and illustrating key research concepts. 



\section{EXECUTIVE SUMMARY}

Hydropower is an established, affordable renewable energy generation technology supplying nearly $18 \%$ of the electricity consumed globally. A hydropower facility interacts continuously with the surrounding water resource environment, causing alterations of varying magnitude in the natural flow of water, energy, fish, sediment, and recreation upstream and downstream. A universal challenge in facility design is balancing the extraction of useful energy and power system services from a stream with the need to maintain ecosystem processes and natural environmental function. On one hand, hydroelectric power is a carbon-free, renewable, and flexible asset to the power system. On the other, the disruption of longitudinal connectivity and the artificial barrier to aquatic movement created by hydraulic structures can produce negative impacts that stress fresh water environments. The growing need for carbon-free, reliable, efficient distributed energy sources suggests there is significant potential for hydropower projects that can deploy with low installed costs, enhanced ecosystem service offerings, and minimal disruptions of the stream environment.

The Exemplary Design Envelope Specification (EDES) for Standard Modular Hydropower (SMH) Technology offers a new paradigm for small hydropower technology development, based on the premise that standardization, modularity, and preservation of stream functionality must become essential and fully realized features of next-generation hydropower technologies and project designs. As documented in this report, a module is an independently deployable and operable unit with explicit objectives, requirements, and constraints governed by the natural stream environment. A generation module transforms incoming water flow into an energy output and outgoing water flow. A downstream passage module transfers water, fish, sediment, or boats safely through a facility. An upstream passage module enables fish to transit upstream safely. A foundation module provides a stable platform that enables itself and other modules to maintain location, orientation, and stability. A multiplicity of these modules function in complementary and coupled ways within a facility to produce energy and minimize disruptions to natural stream functions.

The EDES provides a framework for technology-neutral conceptual design. It documents the functionalities that are necessary for successful module operation, independent of how these functionalities are accomplished. The general structure of this document is the identification of the objectives, requirements, constraints, and performance of exemplary modules. An effort is made to identify functional relationships that describe the system and module performance attributes needed to minimize disruptions of the river continuum. Both state-of-the-art advances and research gaps and challenges are identified, offering perspective on the evolution of SMH technologies.

This document represents Revision 1 of the SMH Exemplary Design Envelope Specification and will be updated periodically. 



\section{INTRODUCTION}

Hydropower has been a reliable renewable energy generation technology for more than 100 years, producing valuable energy and non-energy benefits. In that time, the state of the art for facility design and operation, including generation technology, civil engineering works, and environmental mitigation technology, has been refined for both large- and small-scale development. As with other critical infrastructure designs, hydropower design philosophies have emphasized the safety and long-term reliability of energy production through incremental advancements in technology and process. However, as the science of complex aquatic, riparian, and terrestrial ecosystems and their vulnerability to disturbance has been revealed (Trussart et al. 2002; Renöfölt et al. 2010; Poff and Zimmerman 2010; Kao et al. 2014), new design and operating constraints to protect or restore ecological function have emerged as essential concepts in the hydropower project development process. So, too, has the inherent worth of the recreational and aesthetic functions of streams become an important consideration in hydropower siting and engendered new constraints in project design. As with most design endeavors, the addition of new constraints to the traditional hydropower design paradigm either increases costs or eliminates sites from consideration where the totality of constraints cannot be satisfied. In either case, the result is fewer opportunities for which traditional design paradigms are feasible - this is the challenge faced by developers of new hydropower projects.

The Exemplary Design Envelope Specification (EDES) presents a new paradigm for small hydropower technology development based on progressive concepts put forth by hydropower developers (Bishop et al. 2015) and global hydropower consortiums and organizations (IEA 2000; TN SHP 2005; ICPDR 2013). The Multi-Year Plan for Research, Development, and Prototype Testing of Standard Modular Hydropower Technology (MYRP; Smith et al. 2016) describes the context for the EDES. Within the standard modular hydropower (SMH) project, the EDES details the hypothesis that standardization, modularity, and ecological function as principal design concepts can enable hydropower technology to deploy and operate with minimal environmental impact and greater public acceptance at reduced costs. This new design paradigm encompasses more than the hydroelectric powertrain; it calls for standardization and modularity of every aspect of a hydropower facility so as to enable efficiency of design, safety review, environmental protection, manufacture, installation, operation, maintenance, replacement, and removal.

The concept of modularity can be understood in two ways. First, modularity within the facility refers to the use of different module types to assemble an entire SMH facility. For example, a site may require several module types:

- a generation module that encompasses all hydraulic and electric machines, equipment, and systems necessary for hydroelectric power generation

- passage modules that enable the consistent and predictable passage of fish (upstream and downstream), sediment, water, and recreational craft

- and foundation modules that provide structural resistance and reliably interface with the streambed to support generation and passage modules

All these modules can be assembled to form an SMH facility that matches the scale, environmental attributes, and watershed context of the site selected for development. The second concept of modularity refers to scalability at many sites through multiple modules of the same type. An upstream fish passage module may be applicable at many sites within a watershed region. A cost-optimized, compact generation module designed with wide operational flexibility could be applied at multiple sites throughout the country. This report is a first step toward gaining consensus within the broader hydropower stakeholder community on how a future based on modularity in hydropower design can be realized. 
To address the vast range of module specification possibilities, the EDES describes the functionality that modules and facilities must provide, but not how they provide that functionality. It explicitly specifies the hydraulic, structural, electrical, and environmental requirements and constraints for physical modules. The "how" of module design and functionality is the province of the inventor and innovator, and there may ultimately be many designs that are validated as satisfying design constraints and meet specifications for functionality (these many designs are the "envelope" in the EDES title). An important requirement within the specifications is interoperability of modules to enable multiple-module facility design that also provides the required functionality. Ultimate success in this rigorous design paradigm will be the acceptance of validated, pre-certified modules for multiple deployments, and a significant reduction in the burden and uncertainty of site-specific design, safety, and environmental review for all stakeholders.

The goal of this report is to converge on a validated set of objectives, requirements and constraints that establish a bounded envelope of design for SMH modules. It is critical to note that the EDES does not propose an ideal design for an SMH facility or for an individual module. The goal is to develop a technology-agnostic framework in the early design phase and remain uncommitted to specific designs, arrangements, components, or technologies. Before an innovative design can be realized, or before an existing design can be evaluated, there must be a common understanding that certain functionalities are key to successful operation, independent of how these functionalities are accomplished. This report outlines the framework for navigating through this process for generation, passage, and foundation modules and defines the objectives, requirements, constraints, and performance that define exemplary module designs. To frame this line of thinking, the SMH facility concept is shown in Figure 1 with modules depicted as "black boxes," that is, without defined shape, form, or configuration.

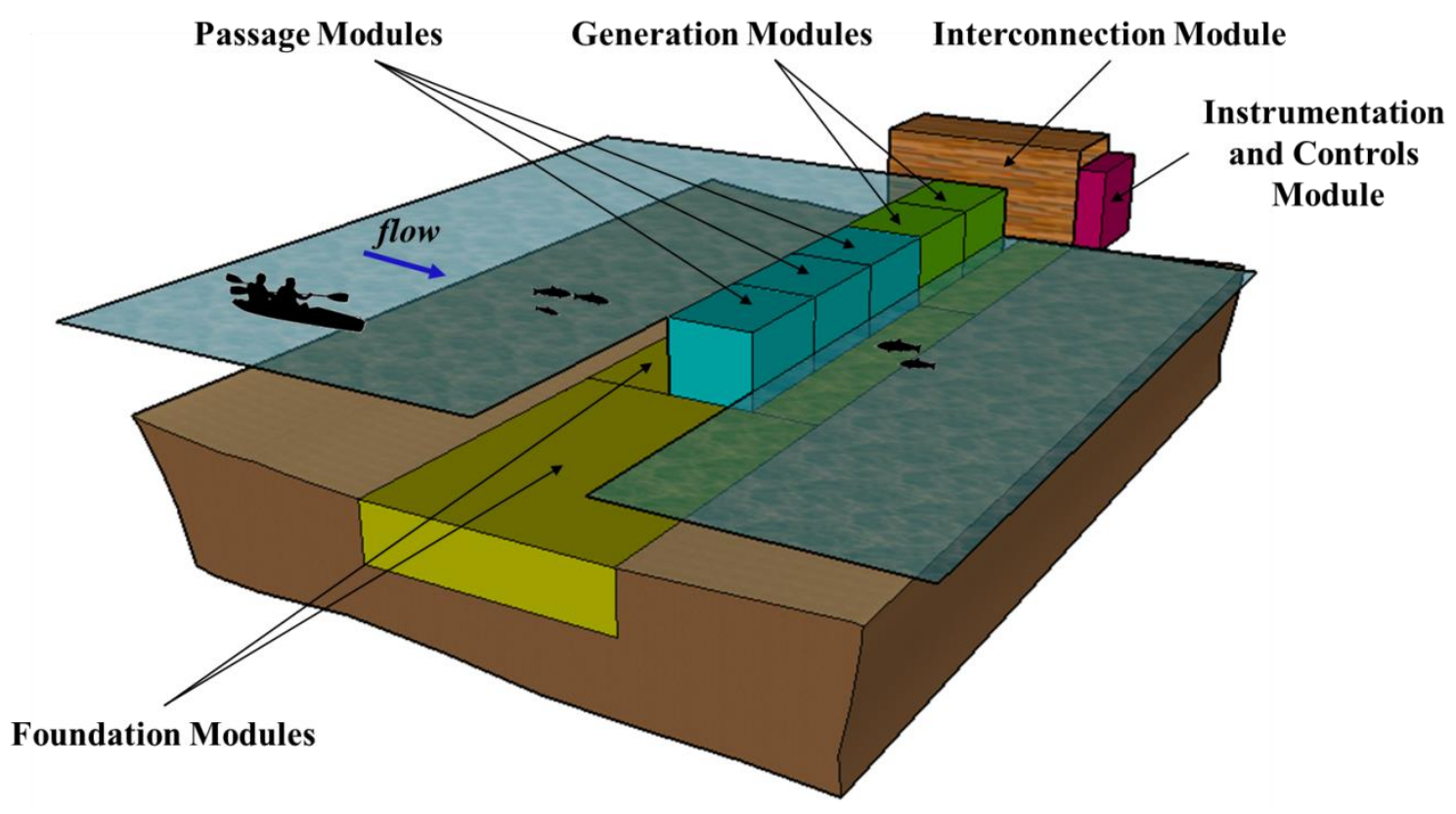

Figure 1. Conceptual schematic of an SMH facility and constituent modules as "black boxes." Generation, passage, and foundation modules will be explored in this report. 


\section{EXEMPLARY DESIGN PRINCIPLES AND CONCEPTS}

Hydropower development at a site where no structures have existed before is a complex undertaking with uncertain outcomes. In the balance are the essential and highly-valued functions of the stream, the benefits of the renewable energy to be produced, and the costs of creating and deploying technology that can sustain these stream functions and produce energy concomitantly. Development that does not sustain stream functions is neither acceptable nor possible in modern regulatory contexts. However, creating and deploying technology capable of sustaining stream functions while producing power engenders costs that must be balanced by the revenue and other benefits of power production. This is the essential and existential challenge for new hydropower technology. The focus of this section is on the hierarchy, principles, and implementing concepts of SMH functional design that address this challenge.

Traditional hydropower design hierarchy includes components (for example, gates, valves, and switches) combining to form units (for example, a single turbine-generator) combining to form hydropower facilities. Multiple hydropower facilities exist in series and parallel within a river and its tributaries and may be designed, modeled, and operated with greater value to the power system as a combination of plants than as individual uncoordinated installations. A natural stream environment can also be viewed as exhibiting a distinct hierarchy_-sediment, water, fish, and habitat at a site are constituent elements of a broader stream network that sustains spatially and temporally diverse ecosystem processes. The stream, with its flowing water, allocates its power to natural functions: transporting sediment to form the stream channel; creating habitat for plants and animals; rushing over rocks and boulders to create the rapids, riffles, and pools that boaters enjoy; providing a riverscape with pleasing aesthetics; and providing drinking water, to name a few. These natural functions are supported by the lateral inflow of water and nutrients from a multitude of catchment areas nested within a watershed. Adjacent watersheds and streams are nested within broader multi-level hierarchical watershed systems.

The broad organizing principle of SMH conceptual design is the acknowledgement of hierarchical order in streams and hydropower plants and the alignment of stream and module functionality, as depicted in Figure 2. A module is an independently deployable and operable unit with explicit objectives, functionality, inputs, and outputs governed by the stream. For example, a generation module transforms incoming water flow into an energy output and outgoing water flow. A downstream passage module transfers water, fish, sediment, or boats safely through a facility. An upstream passage module enables fish to transit upstream safely. A foundation module provides a stable platform that enables itself and other modules to maintain location and orientation.

A multiplicity of these modules function in complementary and coupled ways within a facility to produce energy and minimize disruptions to natural stream functions. An SMH facility may include multiple modules of one type, or different types of modules, to achieve the requisite multi-functionality and scale for the facility. Facilities in the SMH context exist because electric power from a stream may be possible and useful, either because of the market value of the energy and power system services made available, or because the desirable non-power functionality of a facility may be supported or enhanced by the availability of energy and services. 


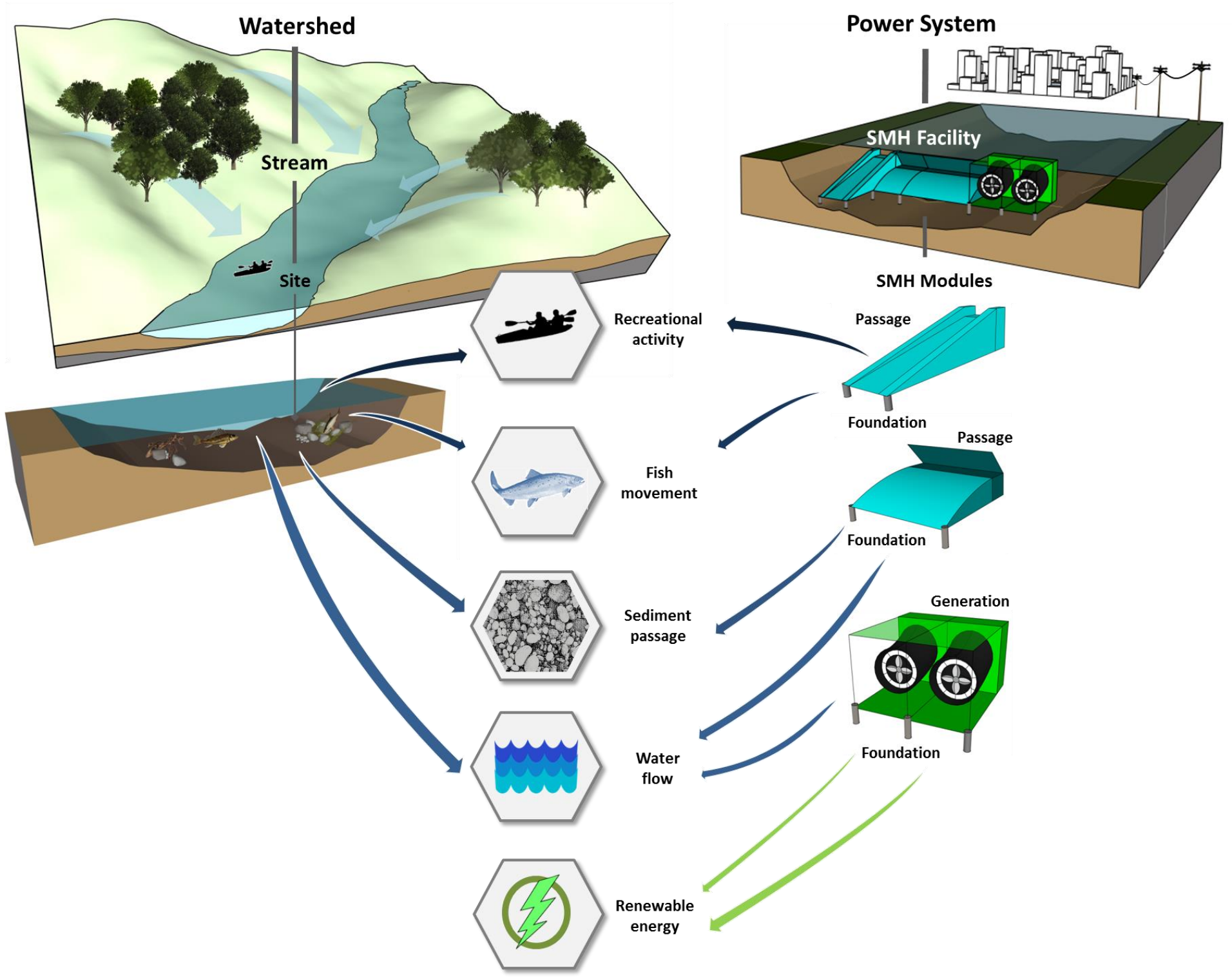

Figure 2. Hierarchical structure of natural stream environments and hydropower systems. The organizing principle of SMH exemplary design is the alignment of module and stream functionality. 


\subsection{EXEMPLARY DESIGN PRINCIPLES}

The design of an SMH facility does not begin solely with a determination of the energy generation potential and economic feasibility. It should incorporate concepts of environmental function, energy and energy services, economics, and risk to be robust and successful in the long term. The following design principles emphasize this concept:

\section{Principle 1: The Exemplary Design Envelope Specification prescribes functionality rather than} detail or methodology. The EDES addresses only a portion of the aforementioned hierarchy of infrastructure and environment, demanding that stream and power functionality be provided at the modular and facility levels by fixing explicitly the objectives, requirements, constraints, and performance that modules and facilities must address. It is not explicit as to which components must combine into a working module, nor is it explicit as to how multiple SMH facilities interact in series or parallel in a river system. The requisite multi-functionality of a facility may be wholly specified through the functionality of the modules and module interdependencies - the detailed design of the modules, including the internal components, need not be specified for the facility as long as they act to meet the objectives, functional requirements, and design constraints for modules and facilities.

The EDES does influence, indirectly or implicitly, the component-level specifics and river system outcomes through the module and facility objectives, requirements, and constraints. It is technologyagnostic in this way, with no a priori bias toward a specific design; nor is it the one and only design of a specific facility. Put another way, the EDES indicates what facilities and modules should do rather than what they should be or how they should accomplish their functions. Multiple designers can create multiple designs that adhere to the specification and thus are within the envelope. The EDES does not examine intra-modular functions or component interactions, but instead treats the module as a black box that meets needs by transforming or transferring inputs of many forms (water, energy, fish, sediment, boats) into outputs. Multiple unique module designs may achieve the identical and requisite functionality for a site. The innovation of new components and new combinations of components into these unique designs is the task of the inventor or designer working in response to the EDES and using the simulation and testing tools that will be developed under the SMH Simulation and Modeling Plan, the Testing Capability Plan, and the Multi-Year Research Plan.

Principle 2: Functionality demanded by the Exemplary Design Envelope Specification follows from the functionality existing in natural streams. This includes basic functionality, such as the transport of mass and energy; more complex functions, such as provision of habitat; and human uses, such as recreation and water supply. Figure 2 depicts the commonality of function and correspondence of hierarchy between the stream resource and SMH technology. Research to develop the SMH Site Classification Scheme will provide insight into characterization and classification of streams by their basic and more complex functions and attributes (for example, bed slope, sediment transport, species presence). The EDES demands that SMH modules and facilities preserve and enhance those functions and attributes of streams even as they produce electric power and power system services and enable other human uses. In so doing, it references site characteristics such as gross hydraulic head and flow-duration or other hydrograph characteristics. This principle provides the essential link between the SMH EDES research pillar and the SMH Site Classification Scheme pillar. These two research pillars share a common context of multi-scale hierarchical functionality - from the scale of river basins that transport mass, energy, and biota, down to the scale of organisms and sediment particles and their interaction with the internal components of modular technology. 
Principle 3: The Exemplary Design Envelope Specification parameterizes the functionality of modules and facilities so as to enable evaluation of cost and feasibility. Feasibility here means environmental, energy, and economic feasibility and acceptability. This principle requires that the EDES incorporate sufficient understanding and quantification of functionality, based on available or emerging science, to enable the designer to design - the EDES must be complete. This principle also requires the designer to parameterize a specific design so as to couple design choices and attainment of EDES compliance to costs and feasibility. In other words, designs of SMH modules and facilities must be explicit and transparent in how they provide stream functionality and in how their costs vary with functional requirements.

\subsection{FEATURES OF SUCCESSFUL FACILITIES}

The siting of a hydropower facility in a stream engenders continuous interaction with the environment, potentially altering the movement of water, energy, fish, sediment, and recreation upstream and downstream. While there are many potential impacts of hydropower development on stream functionality that vary with regional and context, the disruption of connectivity is a universal challenge. Practical mitigation strategies and technologies, and the methodologies to evaluate their success, are the subject of much research and debate (Bratrich et al. 2004; Poff and Zimmerman 2010; LIHI 2014). Nowhere in the Exemplary Design Envelope Specification is there a requirement for a dam to completely impound a stream into a reservoir or pond, nor is there a requirement for an array of modules to span the width of a stream and entirely disrupt connectivity. This impoundment feature of traditional facility design arises from two motivations. First, there is value in storing water for flood reduction, water supply, or flexible power dispatch during peak energy demand periods. It is unlikely that the SMH paradigm can accommodate these storage-related objectives because they necessarily alter the timing of streamflowSMH facilities are run-of-river facilities that do not store water or appreciably alter the inflow hydrograph. The second motivation for impoundment features is to maximize hydraulic head, thereby maximizing turbine capacity, enabling streamlined intake design, maximizing hydraulic efficiency, and maximizing energy production from the available water. The SMH design paradigm addresses this motivation through tradeoffs between sufficient energy production and functional, but perhaps not maximum, connectivity of the affected stream.

Success of the Exemplary Design Envelope Specification will be the stimulation of innovative designs that achieve concomitant functionality of streams and power generation at costs that are feasible. These designs would use the aforementioned design principles to yield physical arrangements of modules acting in complementary and functionally-compliant ways to generate head and partition flows to the generation and passage modules. Ideally, metrics for the functionality of installed modules and facilities would be available from the outset of SMH design efforts, and many are found in literature and in regulatory proceedings (Santucci et al. 2005; Schramm et al. 2016; ), reviews (Smith and Jager 2008; Renofalt et al. 2010; Poff and Zimmerman 2010), surveys of plant owners (Trussart et al. 2002), analyses of existing plant designs (ESHA 2004, Schwartz and Shahidehpour 2006), and best practices frameworks (LIHI 2014; Bishop et al. 2015). Within this body of information, an initial list of features exhibited by facilities that have achieved broad acceptance and feasibility includes:

- predictable and somewhat regular production of electricity;

- minimal alteration of the inflow hydrograph (and minimal impoundment);

- environmental mitigation technology (functionality) inherent within and integral to the facility design (including fish passage, water quality, and sediment management design);

- minimal disruption to the aesthetics of the natural stream and streamscape;

- minimal fluctuations of water surface elevation; and

- enabling of safe recreational passage through and activity around the project. 
However, there is, at best, incomplete consensus on which metrics and which thresholds are appropriate for development across a range of sites and how to address differing priorities for functionality and features in facility designs. This is an area where more research and development (R\&D) of consensus among stakeholders will be necessary.

\subsection{IMPLEMENTATION THROUGH FUNCTIONAL DECOMPOSITION}

The Exemplary Design Envelope Specification decomposes site and stream functionality into facility level functions, module level functions, and module interdependencies. This functional decomposition ensures that the stream and site functionality identified through the SMH Site Classification Scheme is provided by a combination of modules. All facilities must have one or more foundation modules to prevent physical modules from sliding and overturning. All facilities must have at least one generation module to produce electric power. All facilities must have at least one passage module to accommodate flood flows and minimum flows, but most will require additional passage modules to handle combinations of water, fish, sediment, boats, and debris. These are the primary SMH modules described in detail in the appendices. The presence of multiple primary modules in a facility requires that the designer understand and accommodate module interdependencies between water levels, flow, passage capacity, and power generation. Facilities will also require an interconnection module, a monitoring and controls module, and an installation/retrieval module. These secondary SMH modules will be addressed in future appendices to this Exemplary Design Envelope Specification document.

The three design principles of Section 2.1 and the features of successful projects in Section 2.2 are made explicit within functional decomposition through four design concepts:

Objectives: the primary function to be achieved as a result of deploying and operating a module or facility. Examples of design objectives are fish passage and power production.

Requirements: a feature of a module or facility that (1) is essential to achieving the primary objective, (2) is verifiable through testing, measurement, or observation, and (3) in combination with other requirements indicates that the module or facility is achieving its primary objective. Examples of requirements are convert hydraulic power into mechanical power with a hydraulic turbine runner (generation module), or minimize sediment deposition downstream of the SMH facility (sediment passage module). Requirements are prescribed as functional, performance, interface, or a combination thereof. Functional requirements relate to the actions a module must perform, performance requirements are quantified by how well a module must perform a function, and interface requirements involve interactions with other modules. When prescribed in this way, requirements can be assessed on both an individual module scale and a holistic facility scale.

Measures of Performance: a set of quantifiable indices or metrics that enable the evaluation of a module with respect to how well it accomplishes specific and primary technical objectives. Measures of performance include proportion of fish passing through a module (upstream or downstream fish passage module), unit efficiency (generation module), or an index of incision potential (sediment passage).

Constraints: a limitation on the value of a design parameter or a limitation on an effect of deployment or operation that must be satisfied and verifiable to ensure feasibility of a module or facility. Constraints include avoid creating a recirculating hydraulic jump under normal conditions (recreation passage module), and must be run-of-river and operate within natural variations of head and flow (generation module).

These concepts define the design challenge for facility and module technology developers. Each of Appendices A through $\mathrm{G}$ specify the design concepts for a module type, along with supporting rationale 
for those concepts. Technology developers will undertake research efforts to iteratively design, simulate, fabricate, and test the performance of their equipment until it satisfies the design concepts, including design constraints for installed cost. The input/output specifications for a specific module design will be required to evaluate module interdependencies and establish the exact arrangement of modules in a facility design. 
APPENDICES
A. GENERATION MODULE
B. FISH PASSAGE MODULE
C. SEDIMENT PASSAGE MODULE
D. RECREATION PASSAGE MODULE
E. WATER PASSAGE MODULE 



\section{APPENDIX A. GENERATION MODULE}

The generation module is envisioned as a complete hydroelectric generation machine, meaning the module contains all equipment and systems for safe and reliable water power generation, it is preengineered to accommodate a host of potential sites, the internal component configuration is predictable and scalable, performance characteristics meet preconceived expectations, and the module can be relied upon to produce a regular supply of hydropower. The generation module is the only module designed to produce electricity and is a module that will be deployed at all SMH facilities.

\section{A.1 OBJECTIVES}

The primary objective of the generation module is to generate hydroelectric power from flowing water under pressure.

Generation Module Primary Objective

To generate hydroelectric power from flowing water under pressure

The following specific objectives need to be accomplished to achieve the primary objective:

\section{Take in flow}

a. Receive a flow of water driven by a pressure gradient.

2. Direct the flow to the hydraulic turbine chamber

a. Pass flow through to the hydraulic water turbine.

b. Adjust the direction of the flow for optimal power extraction. The adjustment typically takes place with stay vanes and/or fixed or adjustable inlet guide vanes.

3. Convert hydraulic power to mechanical power

a. Water flow does work on the runner as the force of moving water acts across the runner blades.

b. The runner blades rotate about a fixed axis, generating torque (either on a shaft or through torque-transmitting connections between turbine runner blades and the generator rotor) with a magnitude that is a function of the hydraulic forces and distances they occur from the axis of rotation. Runner blades can have a fixed or adjustable pitch.

4. Convert mechanical power into electrical power

a. The mechanical work derived from the runner is used to spin the generator's rotor, which carries a static magnetic field produced by either permanent magnets or windings (electromagnets).

b. The rotational motion creates a time-varying magnetic field in stationary conductors surrounding the rotor. The time-varying fields induce electric fields, which ultimately cause electric current to flow. In many cases, power electronics converters are used to control the generator with respect to various flow conditions, power demand, and optimal operation.

5. Prepare electrical power for distribution to the customer

a. The power produced by the generator is made compatible with the specifications and power quality requirements of the customer. In many cases, this involves power electronics converters that synchronize with the grid and provide sufficient filtering for power quality requirements.

6. Release flow

a. The residual flow kinetic and pressure energy carries water out of the hydraulic turbine chamber and out of the module. For some arrangements, a draft tube helps recover kinetic 
energy by diffusing the flow and slowing the water flow velocity into the tailwater, effectively increasing head across the turbine.

\section{Integrate structurally into the foundation module}

a. The entire generation module must integrate structurally and functionally into the foundation module to transmit forces directly into the ground and ensure module stability.

The specific module objectives are shown in Figure 3, and Figure 4 maps these objectives onto a schematic of a conventional hydropower facility. The upstream and downstream module boundaries will intake and release flow, respectively, and the conversion of hydraulic power to mechanical power and finally into electrical power will occur inside the module. The requirement to prepare electric current for distribution is ambiguously placed at the module boundary. An interconnection module will be used to distribute electrical power to the customer, whose requirements will dictate the inner workings and functionality of the interconnection module. It is possible that a generation module will consist simply of conductors at the generator terminals that send raw electrical power to the interconnection module.

Another possibility is the inclusion of power electronics and other auxiliary electrical equipment within the generation module itself.

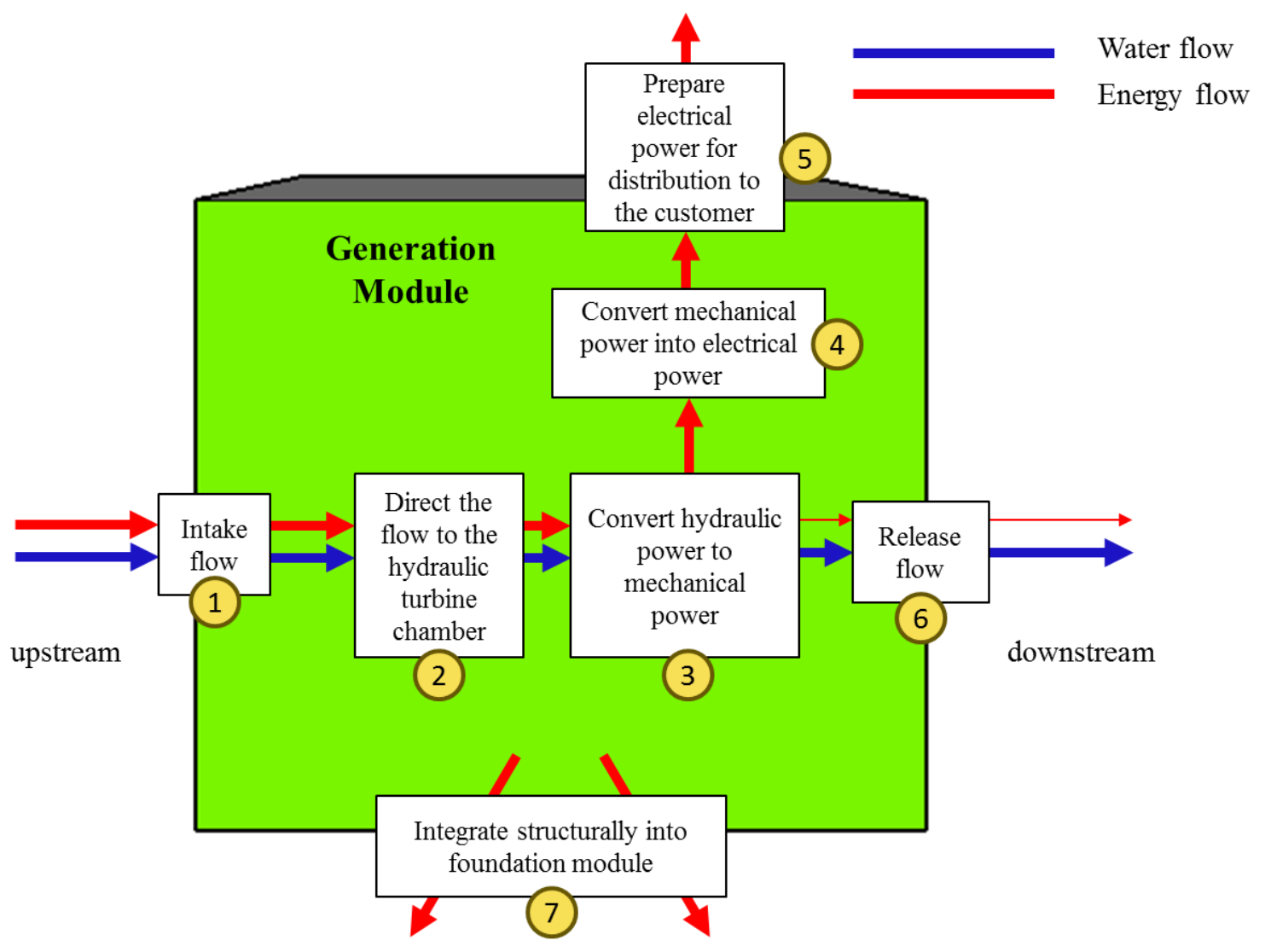

Figure 3. Conceptual schematic of the specific objectives of a generation module. 


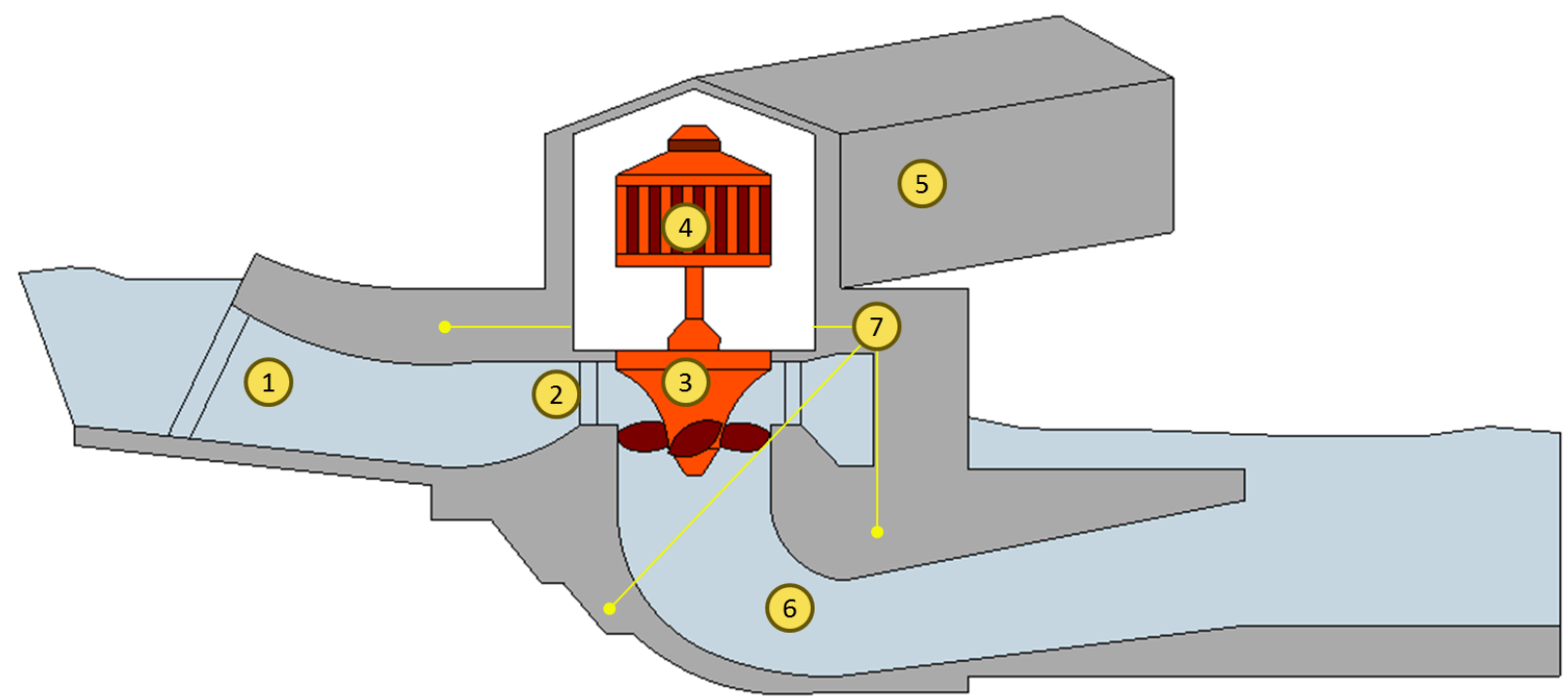

Figure 4. Specific objectives from Figure 3 mapped on a conventional run-of-river hydropower facility.

\section{A.2 REQUIREMENTS}

Generation module requirements state the conditions that must be met to accomplish the generation module primary objective. Stated simply, requirements describe what the module has to do. They include specific objectives, as well as additional sub-requirements that enable the specific objectives. In the conventional sense, hydroelectric generation is achieved through the mechanical coupling of a turbine runner to a generator; the turbine runner is placed in a hydraulic chamber within a water conveyance, and the generator is placed in a powerhouse. Hundreds to thousands of additional interacting components are incorporated into the design, each with a dedicated functionality and well-defined requirements. These components are engineered and optimized to achieve maximum hydraulic, mechanical, and electrical efficiency. The goal of generation module conceptual design is to remain uncommitted to these specific components, arrangements, technologies, and design decisions in the early stages of design thinking and consider the module as technology-agnostic. Regardless of design or generation technology, generation modules must exhibit certain functionalities to ensure successful operation. Multiple module designs may achieve the same functionality through physically and structurally unique technologies and configurations. The intent of this section is to identify these functionalities through the specification of requirements, rather than structure, components, configuration, and technology.

The generation module functional requirements are stated succinctly in Table 1 and described with a formal definition. 
Table 1. Generation module requirements. In the fourth column: $\mathrm{F}=$ Functional; $\mathrm{P}=$ Performance; $\mathrm{I}=$ Interaction; $\mathrm{O}=$ other. In columns $6-11$, an " $\mathrm{X}$ " denotes a relationship to the river continuum constituent indicated in the top row

\begin{tabular}{|c|c|c|c|c|c|c|c|c|c|}
\hline & & Requirement & $\begin{array}{c}\text { Type } \\
\text { (F/P/I/O) }\end{array}$ & Formalization/rationale & 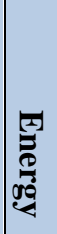 & 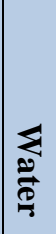 & 臤 & 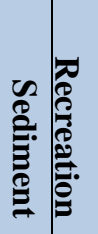 & 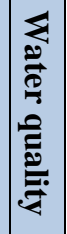 \\
\hline 1 & & Intake flow & & & & & & & \\
\hline & $\mathrm{a}$ & $\begin{array}{l}\text { Guide upstream flow to the } \\
\text { generation module intake }\end{array}$ & $\mathrm{F}, \mathrm{P}, \mathrm{I}$ & $\begin{array}{l}\text { The intake is the primary point } \\
\text { of entry for power production. } \\
\text { Improper intake design runs } \\
\text { the risk of reducing installed } \\
\text { capacity by introducing } \\
\text { unnecessary head losses and } \\
\text { increasing down time and } \\
\text { operations and maintenance } \\
\text { effort by allowing trash and } \\
\text { debris to accumulate at the } \\
\text { entrance. Key intake design } \\
\text { considerations include location } \\
\text { and orientation, type of intake, } \\
\text { hydraulic convergence and } \\
\text { head losses, and depth of } \\
\text { submergence }\end{array}$ & $\mathrm{X}$ & $\mathrm{X}$ & & & \\
\hline & $\mathrm{b}$ & Provisions for shutoff & F, P & $\begin{array}{l}\text { A generation module should } \\
\text { incorporate a mechanism to } \\
\text { stop flow through the runner. } \\
\text { This may include a gate at the } \\
\text { module intake or the use of } \\
\text { adjustable blades }\end{array}$ & $\mathrm{X}$ & $\mathrm{X}$ & & & \\
\hline & c & Provisions for trash racks & $\mathrm{F}, \mathrm{P}$ & $\begin{array}{l}\text { Any trash or debris allowed } \\
\text { through the intake into the } \\
\text { hydraulic chamber has the } \\
\text { potential to damage equipment, } \\
\text { disrupt operations, and require } \\
\text { downtime and maintenance } \\
\text { expense. Debris larger than the } \\
\text { spacing between runner blades } \\
\text { may remain lodged in the } \\
\text { module unless the blades rotate } \\
\text { with sufficient force to } \\
\text { dislodge it or chop it into } \\
\text { smaller segments. A trash rack } \\
\text { will mitigate this issue, though } \\
\text { it will introduce additional } \\
\text { head losses and design } \\
\text { considerations with respect to } \\
\text { placement, bar spacing, } \\
\text { cleaning ability, weight, and } \\
\text { extent of mechanical } \\
\text { complexity }\end{array}$ & $\mathrm{X}$ & $\mathrm{X}$ & & & \\
\hline
\end{tabular}


Table 1. Generation module requirements (continued)

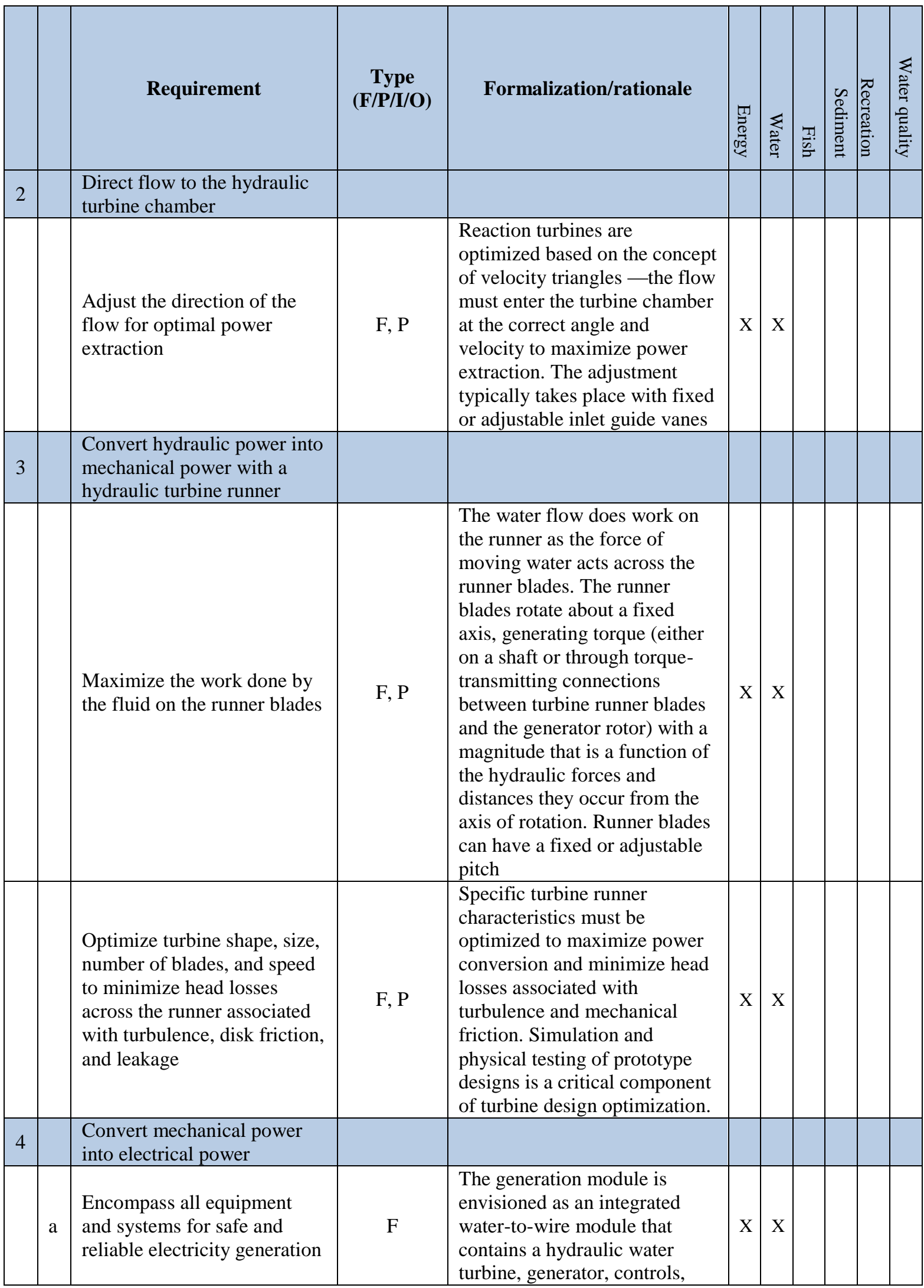


Table 1. Generation module requirements (continued)

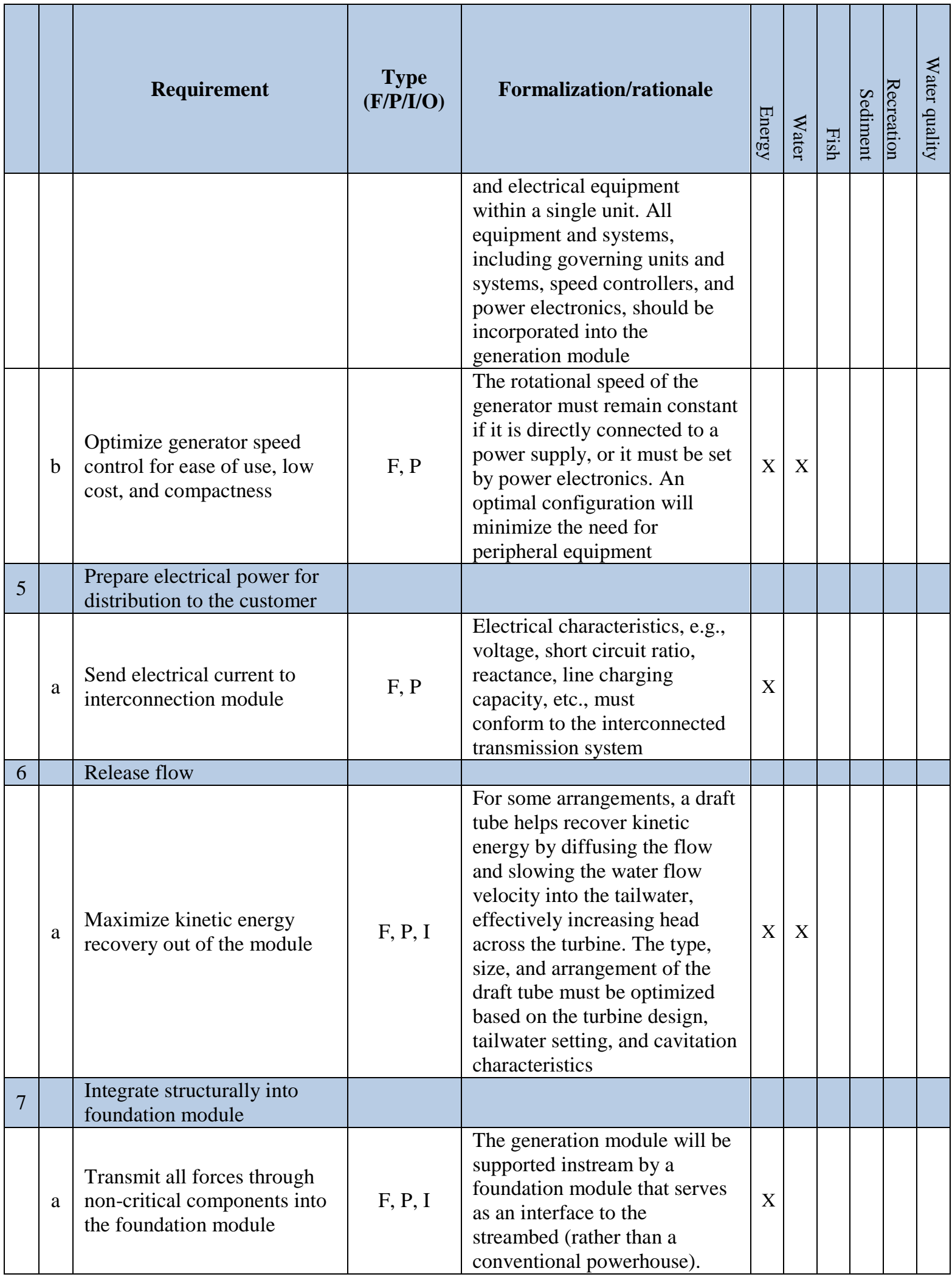




\section{A.3 INPUTS, FUNCTIONAL RELATIONSHIPS, AND PROCESSES}

In this section, we identify the key processes and relationships related to the conversion of inflow hydraulic power to electrical power. Many basic relationships are available in textbooks and manuals on hydropower design (for example, see Gulliver and Arndt 1991; ASME PTC 1993; Leyland 2014). Because the hydropower turbine is the primary revenue-generating mechanism in any hydro project, functional relationships that govern specific runner and generator types, shapes, and operating characteristics are often proprietary, developed and optimized based on years of detailed laboratory and computational studies. To strike a balance between common knowledge and proprietary information, this section broadly discusses the most important processes for generation module design.

\section{A.3.1 Necessary Inputs}

The key processes identified in the previous section rely on necessary site inputs and variables that must be known by a technology designer and developer. A summary of these inputs is outlined in Table 2 .

Table 2. Necessary inputs for generation module design

\begin{tabular}{|l|l|}
\hline \multicolumn{1}{|c|}{$\begin{array}{c}\text { Identification of } \\
\text { key inputs }\end{array}$} & \multicolumn{1}{c|}{ Formalization } \\
\hline River discharge & $\begin{array}{l}\text { Flow duration curve, mean annual flow, minimum environmental flow } \\
\text { requirements }\end{array}$ \\
\hline Head & $\begin{array}{l}\text { Range of gross head available (headwater and tailwater high and low } \\
\text { elevations), net head, tailwater submergence }\end{array}$ \\
\hline River geometry & Wetted perimeter, width, bottom width \\
\hline Electrical frequency of customer & $\begin{array}{l}\text { AC frequency of the customer to which generation module must be } \\
\text { synchronized }\end{array}$ \\
\hline Desired power quality & $\begin{array}{l}\text { Total harmonic distortion, power factor } \\
\text { The output voltage desired at the grid or customer connection prior to } \\
\text { high voltage transformers for transmission. }\end{array}$ \\
\hline
\end{tabular}

\section{A.3.2 Functional Relationships}

The functional relationships that govern generation module operation, along with a brief summary of their importance, are described in Table 3.

Table 3. Functional relationships governing the generation module operation

\begin{tabular}{|c|l|l|}
\hline Relationship of & \multicolumn{1}{|c|}{ To } & \multicolumn{1}{c|}{ Rationale/Importance } \\
\hline Site characteristics & $\begin{array}{l}\text { Range of head and } \\
\text { flow }\end{array}$ & $\begin{array}{l}\text { The conventional approach to small, low-head hydropower relies } \\
\text { on an impoundment model, which assumes a dam is placed across } \\
\text { a stream to create sufficient head or a pool for power generation. } \\
\text { New functional relationships are necessary to determine how } \\
\text { head and flow may vary at a site with a modular facility that does } \\
\text { not use an impoundment. }\end{array}$ \\
\hline
\end{tabular}


Table 3. Functional relationships governing the generation module operation (continued)

\begin{tabular}{|c|c|c|}
\hline Relationship of & To & Rationale/Importance \\
\hline $\begin{array}{l}\text { Range of head and } \\
\text { flow }\end{array}$ & $\begin{array}{l}\text { 1. Performance } \\
\text { characteristics } \\
\text { 2. Rotational speed } \\
\text { 3. Turbine runner } \\
\text { diameter } \\
\text { 4. Cost }\end{array}$ & $\begin{array}{l}\text { 1. Relationships between design head and flow and important } \\
\text { turbine performance characteristics are necessary to establish how } \\
\text { a generation module will operate at a given site. These include } \\
\text { power output vs. head and flow, torque vs. head and flow, and } \\
\text { hydraulic efficiency vs. head and flow. } \\
\text { 2. The rotational speed of the turbine can be derived from the } \\
\text { specific speed, once the head, flow, and power potential of a site } \\
\text { are known. } \\
\text { 3. The turbine runner diameter is specific to the manufacturer and } \\
\text { runner design, and it may be developed empirically based on } \\
\text { physical testing. Relationships defining how generation module } \\
\text { runner diameter varies with head and flow are necessary to } \\
\text { standardize module development. } \\
\text { 4. Standardized and scalable cost estimates will be necessary to } \\
\text { determine if a module design is economically feasible. }\end{array}$ \\
\hline Module scaling & $\begin{array}{l}\text { Hydrologic statistics } \\
\text { and module } \\
\text { performance } \\
\text { characteristics }\end{array}$ & $\begin{array}{l}\text { The traditional approach to determining how many hydropower } \\
\text { turbines are necessary at a site is based largely on the flow } \\
\text { duration curve, annual hydrograph or other flow statistics, and } \\
\text { turbine performance characteristics. This will be a starting point } \\
\text { for assessing generation module scalability. }\end{array}$ \\
\hline Specific speed & Turbine shape & $\begin{array}{l}\text { In conventional turbine design, specific speed, a function of head, } \\
\text { flow, and rotational speed, determines the type of turbine that is } \\
\text { most appropriate at a given site. A new relationship for } \\
\text { generation modules may be necessary if turbine runners do not } \\
\text { conform to conventional geometries. }\end{array}$ \\
\hline $\begin{array}{l}\text { Input hydraulic } \\
\text { power }\end{array}$ & $\begin{array}{l}\text { Shaft power and } \\
\text { output electrical } \\
\text { power }\end{array}$ & $\begin{array}{l}\text { Turbine efficiency describes how well a module turbine converts } \\
\text { input hydraulic power to shaft power, while unit characteristics } \\
\text { describe the efficiency in converting input hydraulic power to } \\
\text { electrical power. Both of these efficiency estimates of generation } \\
\text { modules must be known for a wide range of head and flow to } \\
\text { inform techno-economic models of site feasibility. }\end{array}$ \\
\hline
\end{tabular}

The generation module primary objective can be partitioned into three main concepts: generate power, flowing water, and pressure. The first is a function of the latter two, that is, the power output of the module, $P$, is a function of the water flowing through the module, $Q$, and the pressure available to the module from the flowing water, generally referred to as hydraulic head, $H$. Power is also a function of the energy losses sustained during conversion of hydraulic power to mechanical power and the conversion of mechanical power to electrical power:

$$
P(t)=\frac{Q H \eta_{t} \eta_{g}}{11,814}
$$

where $P(t)$ is electrical power output of a generation module in $\mathrm{MW}, Q$ is flow discharge through the turbine in cfs, $H$ is hydraulic head in $\mathrm{ft}, \eta_{t}$ is the hydraulic turbine efficiency, $\eta_{g}$ is the generator efficiency, and 11,814 is a conversion constant for English units. The four variables on the right hand side of the equation are all a function of the surrounding environment, module component structure and architecture, and numerous other uncontrollable and external inputs that vary as a function of time. To provide a more standardized approach to generation module functional analysis, the important relationships describing the flow of water to the module, the conversion of power in the module, and the flow of water out of the module will be presented. 


\section{A.3.2.1 Flow of water to the module}

A holistic approach to generation module design must begin with an assessment of the local hydrologic regime, namely the duration, magnitude, and frequency of river discharge and the flow available for power generation. Flow availability is most commonly expressed using a flow duration curve, a function that represents the percentage of time a certain volumetric flow rate has been observed at a specific point in space over a previous time period. The flow duration curve can be plotted with the estimated gross head available to provide a clear picture of the variability in power generation potential at a given site (Figure 5). The flow duration curve provides a range of discharges that are important to generation module design:

- The minimum observed flow provides a baseline to what has historically been observed in the stream.

- The design flow represents the point where a generation module or modules are optimized for cost and energy production.

- The minimum technical flow reflects the point where a generation module cannot technically operate because of low efficiency and potentially equipment damage from off-design operation. The minimum technical flow will vary by number of generation modules and the efficiency characteristics of each module.

It is assumed the generation module will not have access to the full river discharge, as the module(s) will occupy a total width that is less than the total width of the stream. When the use of passage modules is necessary, the river discharge must be partitioned among passage and generation modules in a way that accommodates the objective of each module. The greater the flow needs of the passage modules, the closer the minimum technical flow line moves toward the design flow line, and the smaller the design range becomes. The optimum design flow will be less than the largest magnitude of observed flow-if the generation module(s) are sized based on a discharge that occurs only $1 \%$ of the time, they will be idle or operating under potentially damaging off-design conditions for extended periods of time, and there is little economic payoff in sizing a turbine for $1 \%$ of the time.

As shown in Figure 5, the flow of water available to the module will be closely related to the gross head at a given location, with a relationship determined by the geometry of the stream and the characteristics of upstream or downstream hydraulic structures, among other factors. The flow and head interdependencies are particularly important for the design of low-head generation modules. At most low-head run-of-river sites, the tailwater elevation generally rises twice as fast as headwater elevation when river flow increases, leading to a significant reduction in available gross head (Kinloch 2015). As a result, low-head sites with high variability in flow and head often lead to operating conditions beyond the acceptable performance and efficiency limits of the hydraulic turbine. 


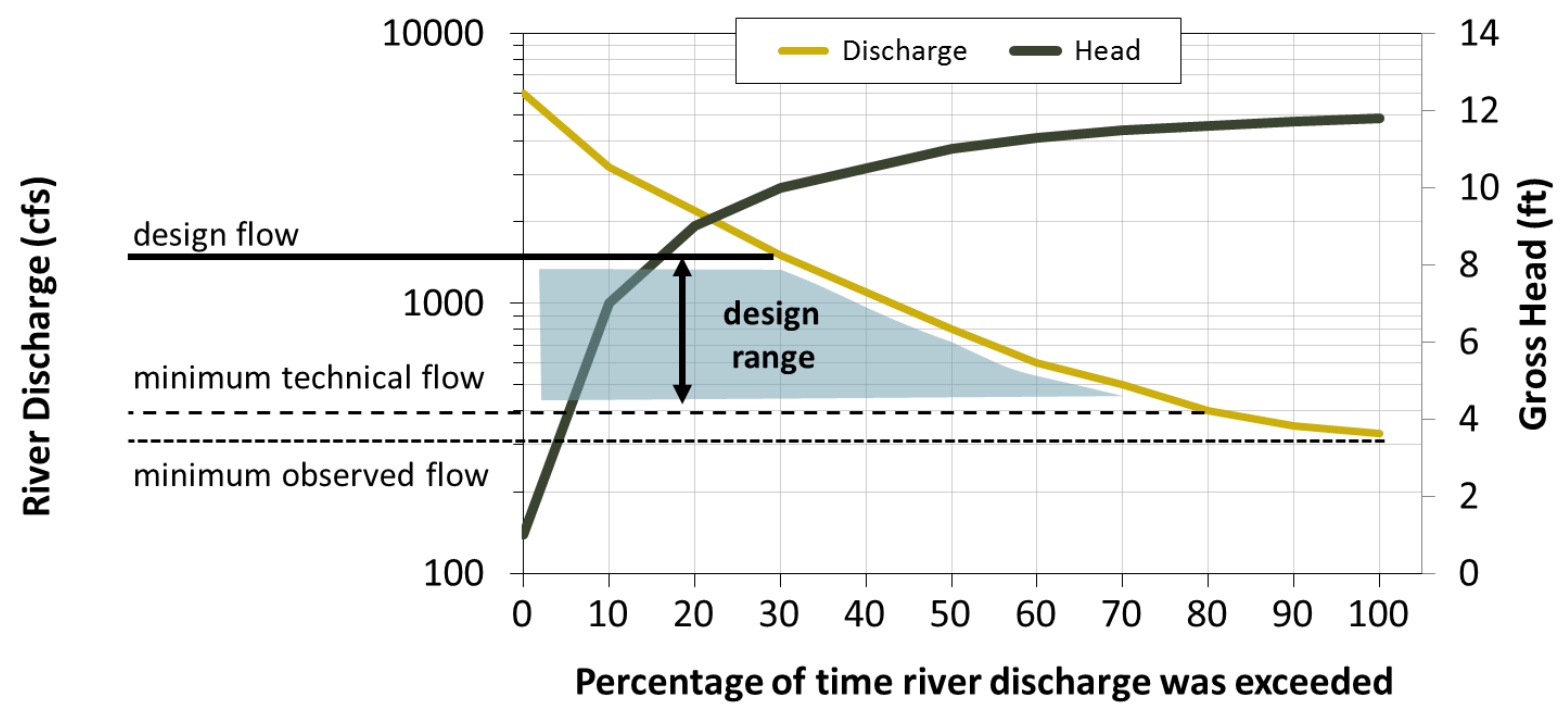

Figure 5. Example flow duration curve with important flow design parameters.

Variability at low head presents a significant design challenge for both conventional turbines and generation modules. The following are some of the major obstacles to success.

- Turbine runner diameters must be larger to accept larger volumetric flow rates and produce an equivalent power as head is decreased. Larger diameters require more material to resist the internal forces and stresses of operation, increasing the weight of the machine and the structural support (i.e., civil works) requirements. The result is a lower power output per unit weight of material and per site cost, which is economically unappealing.

- Generating units must maintain high efficiency over a wide range of possible head and flow combinations to achieve economic feasibility and to avoid operating in off-design conditions that may increase the likelihood of premature machine failure or damage. From a hydraulic perspective, this can be accomplished by adding adjustable guide vanes and adjustable turbine blades that rotate based on flow and head to provide the optimum velocity angles for the hydraulic turbine runner. This arrangement requires additional mechanical complexity and cost, and the flow and head characteristics of a given site must be analyzed to determine if the additional efficiency gains justify the added cost. From an electrical perspective, higher overall efficiencies can be achieved through the use of power electronics that allow the turbine to operate at variable speeds, although additional costs and electrical complexity may also be incurred.

A standardized approach to characterizing water flow to modules has been embodied in the hydrologic classification work of McManamay et al. (2013), who classified 12 hydrologic regimes throughout the US based on flow statistics (Table 4). 
Table 4. US hydrologic classification (McManamay et al. 2013)

\begin{tabular}{|l|l|l|}
\hline \multicolumn{1}{|c|}{ Name } & \multicolumn{1}{c|}{ Code } & \multicolumn{1}{c|}{ Characteristics } \\
\hline Intermittent flashy & IF & High intermittency, long high-flow duration \\
\hline Perennial runoff 1 & PR1 & Similar to SHBF but lower base flows, semi-stable \\
\hline Perennial runoff 2 & PR2 & Similar to PR1, but lower base flows, higher runoff than PR1 \\
\hline Unpredictable intermittent 1 & UI1 & $\begin{array}{l}\text { Moderate intermittency, low predictability, and semi-flashy } \\
\text { flows }\end{array}$ \\
\hline Stable high base flow & SHBF & $\begin{array}{l}\text { High base flows (smaller than SSGW), stable and relatively high } \\
\text { runoff }\end{array}$ \\
\hline Snowmelt 1 & SNM1 & $\begin{array}{l}\text { Distinct and consolidated periods of runoff, stable and relatively } \\
\text { high base flows, early annual minimum (winter freeze) }\end{array}$ \\
\hline Super-stable groundwater & SSGW & Very high base flow, high stability, not necessarily high runoff \\
\hline Coastal high runoff & CHR & $\begin{array}{l}\text { High runoff, very late annual maximum, and very early annual } \\
\text { minimum; slightly high reversals (potential tide effects) }\end{array}$ \\
\hline Unpredictable intermittent 2 & UI2 & $\begin{array}{l}\text { Moderate intermittency, low predictability, and semi-flashy } \\
\text { flows (different timing and runoff from UI1) }\end{array}$ \\
\hline Snowmelt 2 & SNM2 & Less stable and lower base flow than SNM; otherwise similar \\
\hline Western Coastal high runoff & WCHR & $\begin{array}{l}\text { Distinct wet/dry seasons, lower base flow than PR streams, but } \\
\text { very high runoff, early annual maximum }\end{array}$ \\
\hline Harsh intermittent & HI & $\begin{array}{l}\text { Very long periods of intermittency, punctuated by episodic } \\
\text { flows }\end{array}$ \\
\hline
\end{tabular}

\section{A.3.2.2 Converting hydraulic power to mechanical power}

Inflow hydraulic power is converted to mechanical power through runner blades, which rotate about a fixed axis generating torque, either on a shaft or through torque-transmitting connections between turbine runner blades and the generator rotor. It is anticipated that the generation modules (based on both new and traditional designs) will be fully immersed in water, which necessitates the use of a reaction-type turbine design in which the runner blades are profiled to create a lift force that generates torque. Therefore, the inflow hydraulic power available to the generation module is

$$
P_{h}=\frac{Q H}{11,814},
$$

which is the same as Eq. (A.1) without the efficiency terms. In this case, $P_{h}$ is hydraulic power in MW and represents the maximum theoretical power available from the stream. The mechanical power delivered to the generator by the turbine is

$$
P_{t}=P_{h} \eta_{t}=\omega T,
$$

where $P_{t}$ is turbine power, $\eta_{t}$ is turbine efficiency, $\omega$ is the rotational speed of the turbine shaft in $\mathrm{rad} / \mathrm{s}$, and $T$ is the torque provided by the turbine shaft.

To optimize turbine power, i.e., the generation of torque, the turbine runner diameter and rotational speed must be suited to the design head and flow. The relationship between these two variables at a given head is

$$
N_{t} \propto \frac{1}{D_{t}},
$$


where $N_{t}$ is the rotational speed of the runner in $\operatorname{rpm}$ and $D_{t}$ is the turbine diameter. This inverse relationship indicates an increase in rotational speed is correlated with smaller-diameter turbines, and larger turbines have a slower rotational speed. This tradeoff has several implications for module design:

- A reduction in runner diameter will decrease material costs, increase runner rotational speed, and decrease generator size and cost. However, disadvantages are manifest in increased fluid velocitieswhich require specific cavitation avoidance techniques, including a lower unit elevation setting and concomitant increased excavation burden - and high runaway speeds, which exert substantial mechanical forces that must be sustained safely by the turbine. Smaller-diameter turbines also pass less flow, generate less torque, and produce less power per unit than larger-diameter turbines.

- A larger turbine size will increase material costs and may require the use of a speed increaser or gear box to drive the generator at a faster speed than that of the runner. The gear box will result in additional efficiency losses, noise, vibration, and cost; but the overall cost may be offset by the use of a standard or off-the-shelf generator that would otherwise be unsuitable without the gear box. Higher civil works costs may result from the larger runner.

To obtain the efficiency characteristics of a generation module, that is, to know how well the module converts hydraulic power to mechanical power, it is necessary to conduct model or prototype testing under a range of different operating conditions. Statistical formulae describing optimal module dimensions and performance characteristics must be developed based on iterative testing procedures that measure turbine efficiency over a range of head and flow. High efficiency is required to ensure favorable hydrodynamic behavior, which must be maintained to maximize both the turbine life and annual energy production, and minimize the negative impacts of cavitation and vibration. In general, water turbines have some optimum range of head and flow within which they should operate, and some boundary of head and flow within which they must operate to avoid off-design conditions that may damage equipment and systems. An example of these turbine characteristics is shown as a hill chart in Figure 6. For this particular turbine, the optimum efficiency can be obtained over a range of heads within a relatively narrow band of expected unit discharges. The goal of exemplary design is not to maximize the peak efficiency but to obtain a broad and tall optimum efficiency band that indicates good performance under a range of conditions.

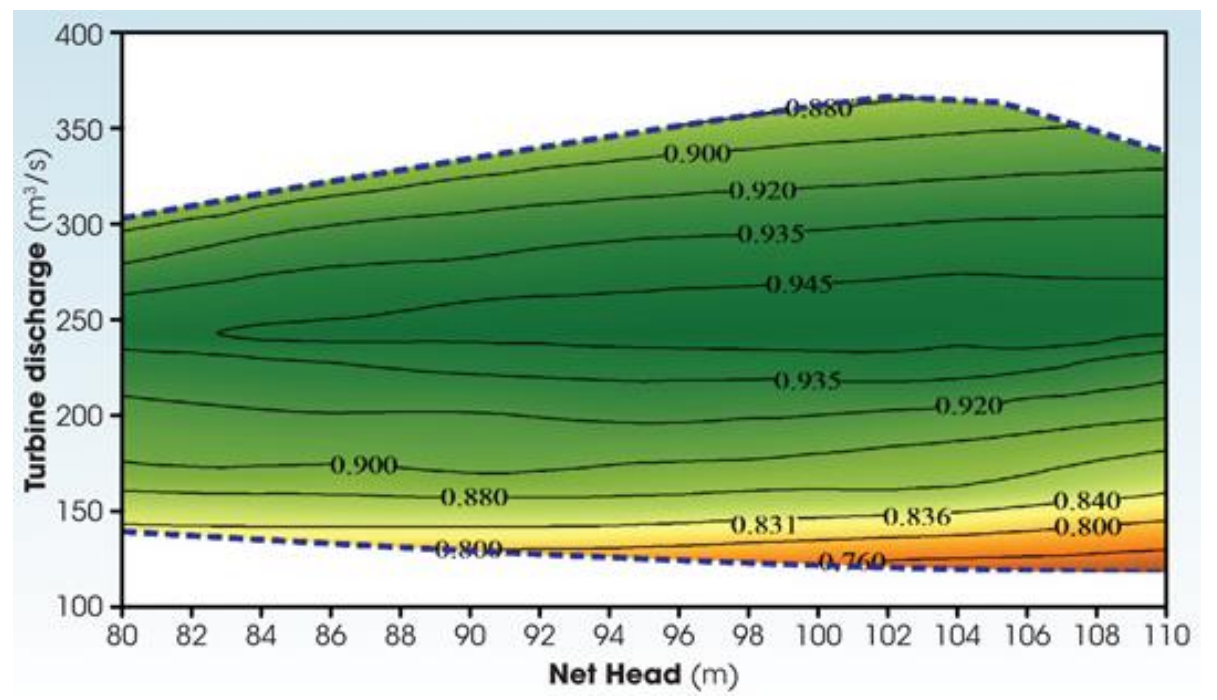

Figure 6. A hill chart documenting the hydraulic efficiency (shown as labeled contours) of a water turbine at various head and flow combinations. The dashed lines represent a forbidden zone within which it is inefficient and potentially damaging to operate the turbine. (Cordova et al. 2013) 
There are two concepts associated with turbines and speed: rotational speed and specific speed. "Rotational speed" refers to the number of revolutions per minute the runner will make under given inflow conditions. The rotational speed of the runner is proportional to head and flow and must be synchronized, either directly by mechanical means or indirectly through power electronics, to the frequency of the grid, which is $60 \mathrm{~Hz}$ in the United States. "Specific speed" refers to the nondimensional number used to classify turbines based on their performance and proportions. There are numerous mathematical representations of specific speed, each of which incorporates some combination of head, flow, rotational speed, diameter, and power output. Engineering experience has proved that different shapes and orientations of runner blades will result in optimum performance at particular specific speeds (Figure 7). A generation module employed at low head will have a relatively high specific speed, correlating with a conventional axial flow type machine.

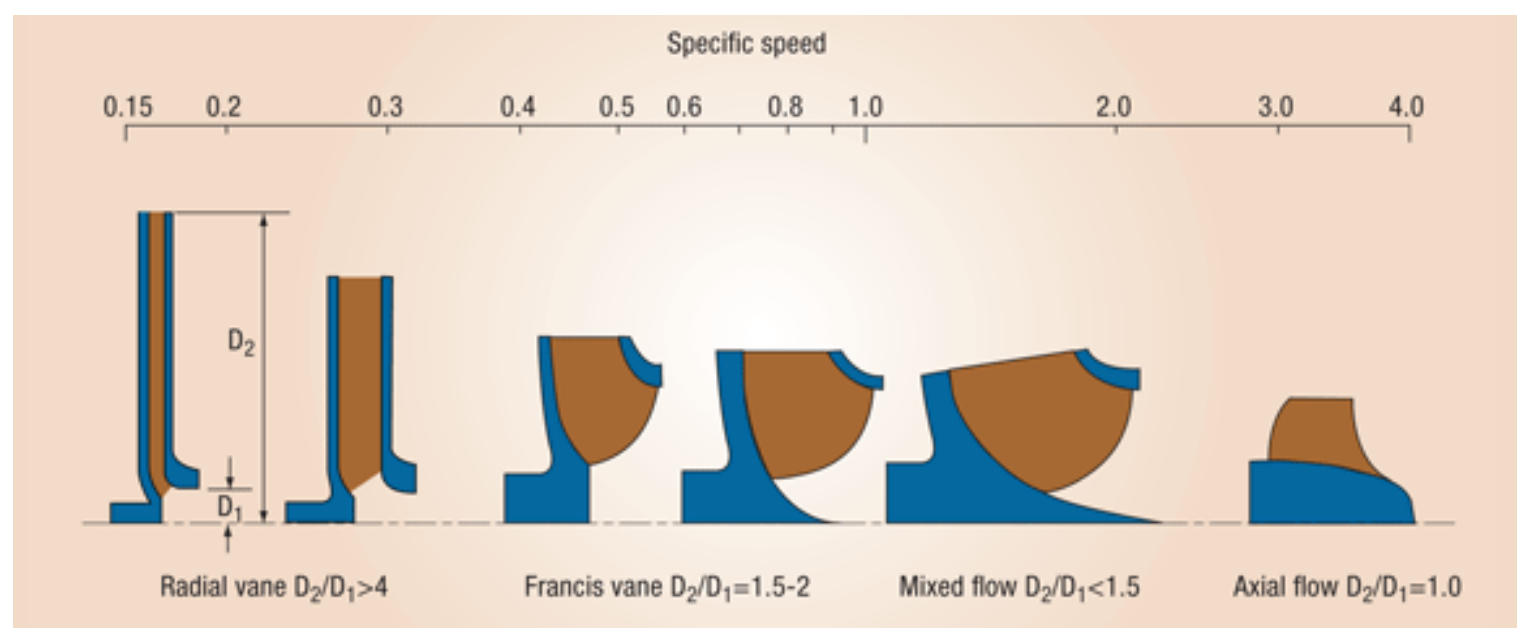

Figure 7. Optimum runner blade geometry for a given specific speed. (Baines 2010)

\section{A.3.2.3 Converting mechanical power to electrical power}

Just as flow across turbine blades produces a torque that spins the turbine, electric current through the generator stator windings produces a torque on the generator's rotor. To convert the mechanical power captured by the turbine into electric power, the electromagnetic torque opposes the hydraulic torque. That is, hydraulic currents will tend to increase the rotor speed, whereas electrical currents will tend to decrease the rotor speed. A quasi-steady state is reached when these two forces come into equilibrium. Therefore, special attention must be given to the generator design for variable head and flow, as is the case for the turbine design. Moreover, the turbine and generator design must be matched to a certain degree, as it is the intersection of their feasible torque/speed operational ranges that produces the unit level power and efficiency characteristics. The generator real power output is given as

$$
P_{g}=P_{h} \eta_{t} \eta_{g}
$$

where $\eta_{g}$ is the generator efficiency and $P_{g}$ is generator power in kilowatt. Generator apparent power in $\mathrm{kVA}$ is expressed as $P_{g} / p f$, where $p f$ is the power factor, a value that conveys how efficiently the generator transfers energy to a load.

The generator must rotate at a certain speed to produce electrical power with a voltage and frequency that match the power system of the customer. The required speed range of the generator will depend to a great extent on choices made upstream in the generation module. Adjustment of the flow at the inlet of the module, or adjustable turbine vanes that attempt to mechanically govern the speed of the turbine/generator, will reduce the speed range required by the generator, allowing it to be more highly 
optimized for a specific operating condition. On the other hand, a generator system with an inherently wide speed range may obviate the need for mechanical governing mechanisms, resulting in lower-cost turbines. If both mechanical and electrical speed regulating mechanisms are present, the design and control of the turbine and generator become tightly coupled. This gives the potential for high-performance designs at the risk of increasing the cost of the overall system. The goal of the designer will be to assess the tradeoffs between performance and cost in optimizing the module behavior.

Generators require a minimum speed to produce their rated power, sometimes called the "base speed." The power output will generally drop linearly below this speed. For a given generator topology, the generator size is determined by the ratio of maximum power to base speed. Higher base speeds and lower power ratings lead to smaller generators.

There are three main considerations in designing a generator for wide speed range operation. First, the generator voltage should be controlled within the designed limits over the entire speed range. Second, the generator - and any associated power electronics - must supply power to the grid at a fixed frequency. Third, because they are made of steel and windings, generators are inherently inductive in nature and tend to have a lagging power factor if special attention is not paid to this fact. For a generator to produce its rated power over a wide speed range, it is desirable for the power factor to be as close to unity as possible. The addition of a magnetic field produced on and carried by the rotor moves the power factor from lagging toward unity. The method of producing and controlling the rotor field is the main difference between different generator topologies and their power electronics requirements. These topologies include wound field synchronous generators, permanent magnet synchronous generators, and various types of induction generators (Skvarenina and DeWitt 2004; Hughes 2009). Figure 8 shows the power-speed characteristics of an idealized generator achieving a constant power speed range of 5:1.

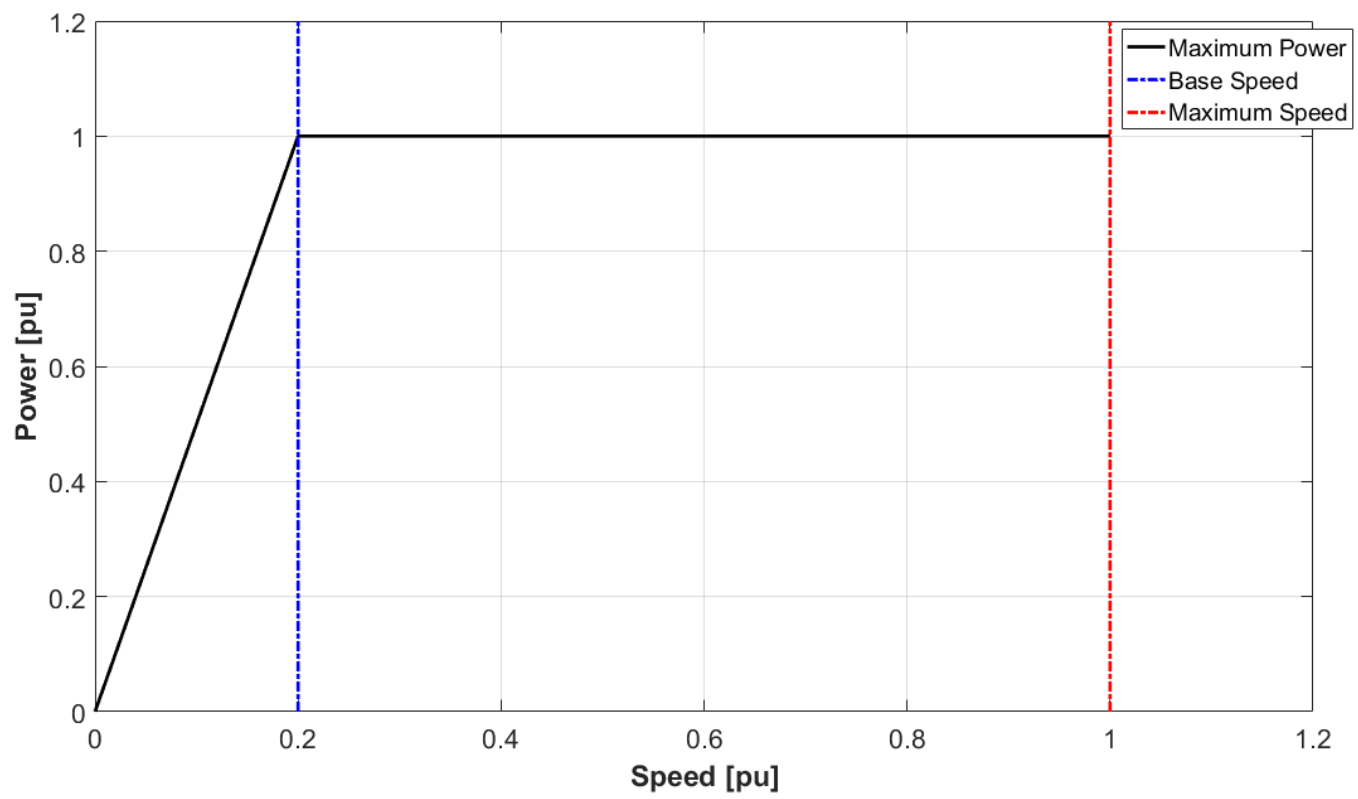

Figure 8. Idealized generator system power-speed characteristics for wide speed range operation. Units are displayed in pu (per unit), a fraction of an arbitrary base unit quantity.

For generators with wound field rotors with DC excitation and slip rings, the rotor field is proportional to the applied voltage; and the field can be reduced to allow higher-speed operation within the voltage limitations of the generator. In this case, however, the generator frequency is proportional to the rotor speed, and some form of AC-AC conversion is necessary to supply power at the grid frequency. It is 
possible to adjust the rotor field to regulate and operate at a fixed speed, thereby permitting direct connection to the grid without power electronics. However, doing so will often result in lower power density and efficiency than other arrangements.

Synchronous generators are so named because they produce electrical power at a frequency directly proportional to the rotor speed. Types of generators in this category include surface-mounted permanent magnet, synchronous reluctance, and interior permanent magnet generators (PMGs). AC-to-AC conversion is necessary for supplying power to the grid if they are not operated at a fixed speed. Widespeed-range operation is accomplished in PMGs by creating a field in the stator that actively cancels a portion of the field setup by the rotor. This has a similar effect to reducing the rotor excitation in a DC generator. Because of bulky windings and conduction losses in the rotors of wound field and induction generators, PMGs are often more efficient with smaller, lighter rotors.

Rotor field generation occurs naturally in singly-fed induction generators because of a difference between the mechanical speed of the rotor and the rotational speed of the electric field produced by the stator. When directly connected to the grid, induction generators can supply power synchronously to the grid with a variable rotor speed, although the peak efficiency/power region can be quite small. With the inclusion of power electronics and a suitable control algorithm, their performance can be quite robust over a wide speed range.

Doubly-fed induction generators accomplish wide-speed-range operation by supplying variable AC frequency excitation to the rotor. The frequency is controlled so that the power produced by the generator is at the grid frequency. Therefore, the generator is able to supply power directly to the grid without power electronics, while the power electronics exciting the rotor need only be rated at a fraction of the output power.

The inclusion of power electronics to perform a frequency conversion between the generator and the grid allows a decoupling of the generator operation from the grid frequency. This can result in significant volume, weight, and cost reductions if the generator can be designed to operate at a higher speed than would otherwise be dictated by the grid frequency. Of course, this advantage is offset by the cost and complexity of the power electronics system, which must be rated at full power. Since the inverter is connected to the rotor of a doubly fed induction generator, it must still operate (nominally) at synchronous speed; and no generator sizing benefit results from the inclusion of the power electronics. However, the inverter for a doubly fed induction generator is sized relative to the required speed range and can be rated at a much lower level than the maximum generator power.

\section{A.3.2.4 Flow of water out of the module}

The generation module must recover as much energy as possible from the flow as it is discharged from the hydraulic turbine chamber, while maintaining sufficient pressure head to overcome the pressures exerted by the tailwater. This is generally accomplished using a draft tube, which works to diffuse or slow the linear and rotational velocity of the water, increasing the pressure head and the overall head across the turbine. This is especially important for reaction-type turbines at very low heads, during which the velocity head of water leaving the runner may increase to $80 \%$ of the net head available to the runner (ESHA 2004).

The draft tube allows a turbine runner to be placed above the tailwater elevation, allowing ease of access for maintenance and reduced excavation burden during construction. These features are preferred in module design. At a certain elevation, cavitation may occur when the local absolute pressure in the turbine or draft tube drops below the vapor pressure of water. Thus, the tailwater setting must be optimized for efficiency, cavitation prevention, and cost. According to Bishop et al. (2015), the current 
practice in hydropower design is to lower the turbine centerline and use a long, wide draft tube to optimize efficiency, although trading off efficiency for more economical configurations with lower civil costs is a viable strategy.

\section{A.4 MEASURES OF PERFORMANCE}

The primary generation module performance measure is the ability to generate revenue to support development of the SMH project. From an equipment perspective, this measure requires simultaneous knowledge of the module unit efficiency characteristics, scalability, size of the module, and installed cost per module, in addition to estimates of module useful life and maintainability. A single value cannot be specified for any of these categories, but general targets are offered that should be achieved by generation modules.

\section{A.4.1 Module Unit Efficiency Characteristics}

\begin{tabular}{|l|l|}
\hline Standard of measurement & Target \\
\hline $\begin{array}{l}\text { How well the module converts hydraulic } \\
\text { input power to electrical power }\end{array}$ & $\begin{array}{l}\text { High unit efficiency over a wide range of heads and flows. A lower } \\
\text { peak efficiency may be acceptable if overall generation module costs } \\
\text { are reduced for the same estimated useful life, but the efficiency } \\
\text { must still remain high at partial load }\end{array}$ \\
\hline
\end{tabular}

Hydraulic water turbine and generator peak efficiencies are generally greater than $85-90 \%$ with modern small hydropower technologies. The range of turbine efficiencies at different flow rates for a given head is highly dependent on the module configuration. Reaction-type axial flow turbines with adjustable blades and gates can achieve high efficiencies from partial load to greater than full load, while propeller type turbines with fixed blades and gates have a sharp peak efficiency that quickly falls off at loads below and beyond the design load (Figure 9). For the low-head and run-of-river types of applications targeted by $\mathrm{SMH}$, some adjustment of gates or blades is necessary to ensure efficient operation at partial load.

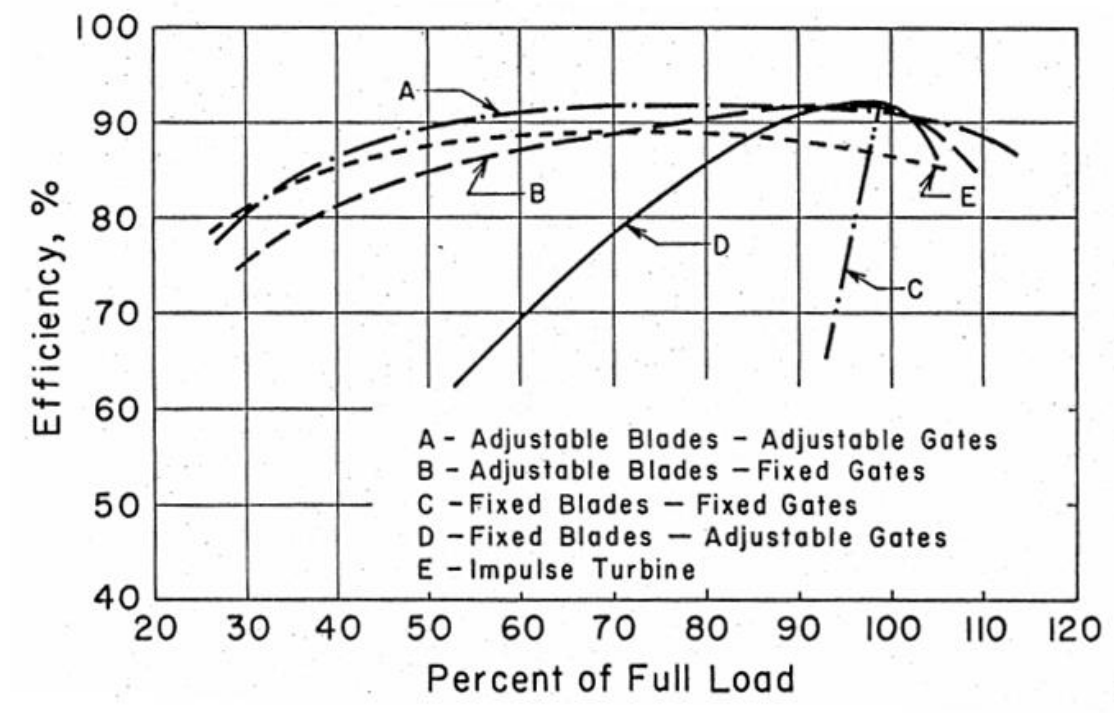

Figure 9. Turbine efficiency for different turbine types at constant speed as a function of percentage of full load. (Farell et al. 1983)

An additional influence on module unit efficiency is the speed of operation. Fixed-speed turbines and generators must mechanically synchronize to the grid using the head and flow available at the site. If head 
or flow is increased or reduced, the turbine unit must compensate by adjusting the flow rate if possible, or by stopping generation completely, resulting in a narrow range of operation and efficiency (turbine type $\mathrm{C}$ in Figure 9). Variable-speed operation is enabled by power electronics, which decouple the turbine and generator from the grid. The turbine is allowed to rotate at an optimal speed, and a series of rectifiers and inverters act to maintain a constant output frequency and voltage. The result is both an increase in efficiency over a range of heads, and an expansion of the effective operating range of the unit (Figure 10).

Although it is expected that a generation module should achieve peak efficiencies similar to those of existing technologies, it is possible that a lower-peak-efficiency turbine with lower overall installed cost, reduced operating and maintenance costs, and low replacement costs could prove economically viable. However, the peak efficiency should be maintained under the variable heads and flows that are to be expected at low-head sites. This operation would require the use of advanced turbine control or double regulation.

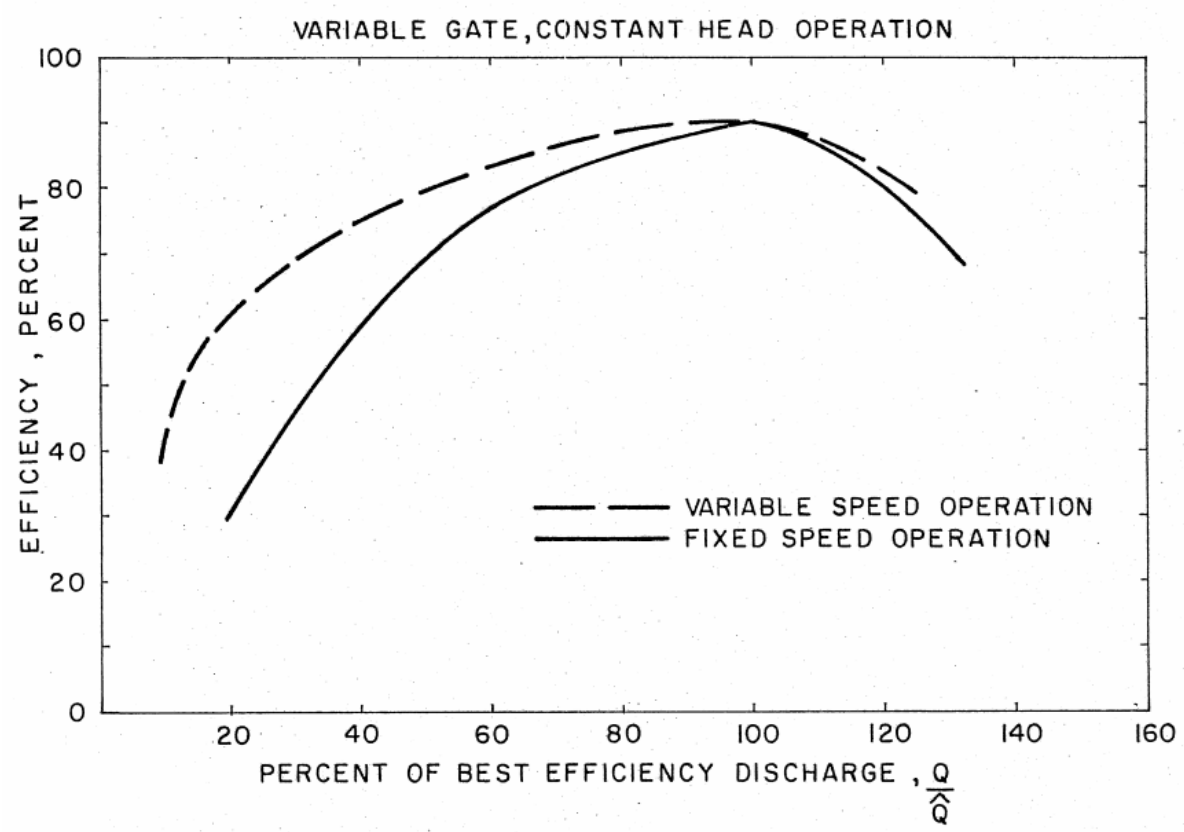

Figure 10. Example of the performance improvement expected from variable-speed turbines with adjustable gates. (Farell et al. 1983)

\section{A.4.2 Scalability}

\begin{tabular}{|l|l|}
\hline Standard of measurement & Target \\
\hline $\begin{array}{l}\text { How well the module can be applied at a } \\
\text { variety of sites with different flow } \\
\text { regimes }\end{array}$ & $\begin{array}{l}\text { Module consists of a standard turbine runner and generator available } \\
\text { in a range of installed capacities }\end{array}$ \\
\hline
\end{tabular}

Most small hydropower turbine manufacturers offer a range of standard turbine runner diameters, while fewer incorporate the generator directly into the design or offer a combined turbine and generator package. To provide a standard approach to site analysis, a generation module should incorporate both the turbine runner and diameter in a variety of standard sizes. This enables scalability to be addressed in two ways - the generation module can be applied at many different locations, and multiple generation modules can be applied at a single site. When turbines are designed in this fashion, module service, replacement, refurbishment, and spare part service and administration can be streamlined and made costeffective. 


\section{A.4.3 Size}

\begin{tabular}{|l|l|}
\hline Standard of measurement & Target \\
\hline $\begin{array}{l}\text { Overall dimension of a fully operating } \\
\text { module }\end{array}$ & $\begin{array}{l}\text { Modules or sub-modules are amenable to standard transportation } \\
\text { methods and facilitate ease of installation and minimized civil works }\end{array}$ \\
\hline
\end{tabular}

Module size is largely influenced by generator type and arrangement. A smaller turbine may be less expensive to manufacture, but it will accept lower volumetric flow rates, generate less power, and may require a speed increaser (gear box or belt drive) to use a standard and compact generator. This additional equipment will increase the overall module size and nominally reduce module unit efficiency, although it generally will lead to an overall reduction in project costs. Larger turbines will accept more flow and produce more power at the same head. A larger turbine may not require a speed increaser, although its increased size will generally require additional structural support and civil works.

The use of an embedded generator design, in which the generator is configured either in a hub on the nose of the runner or on the runner blades as a rim-rotor type unit, can reduce the overall footprint of the turbine and generator configuration, resulting in reduced civil work, simplified electrical configurations, and reduced installation times. These turbines generally exhibit larger diameters than conventional designs with an equivalent rated power (Figure 11). However, all three embedded designs in Figure 11 use PMGs with the option of variable-speed technology, reducing the balance of auxiliary equipment associated with excitation systems and the number of rotating parts while increasing the operating range of the unit. They are also fully submersible, eliminating the need for a powerhouse and additional civil works to protect a conventional generator. This produces cost benefits as well as aesthetic value-the reduction in size of the superstructures improves the integration of the entire facility into the surrounding environment.

Although no target size is set for a generation module, the following guidelines are offered:

- Modules must be amendable to standard transportation methods - a single module or sub-modules should not be larger than the carrying capacity of a standard semi-trailer.

- Designs should enable quick and efficient assembly and disassembly of modules or sub-modules.

- Ease of installation should be a priority - thus compact modules or sub-modules that can be lifted into and out of place within a day are preferred.

- Modules that limit the need for civil works are preferred. 


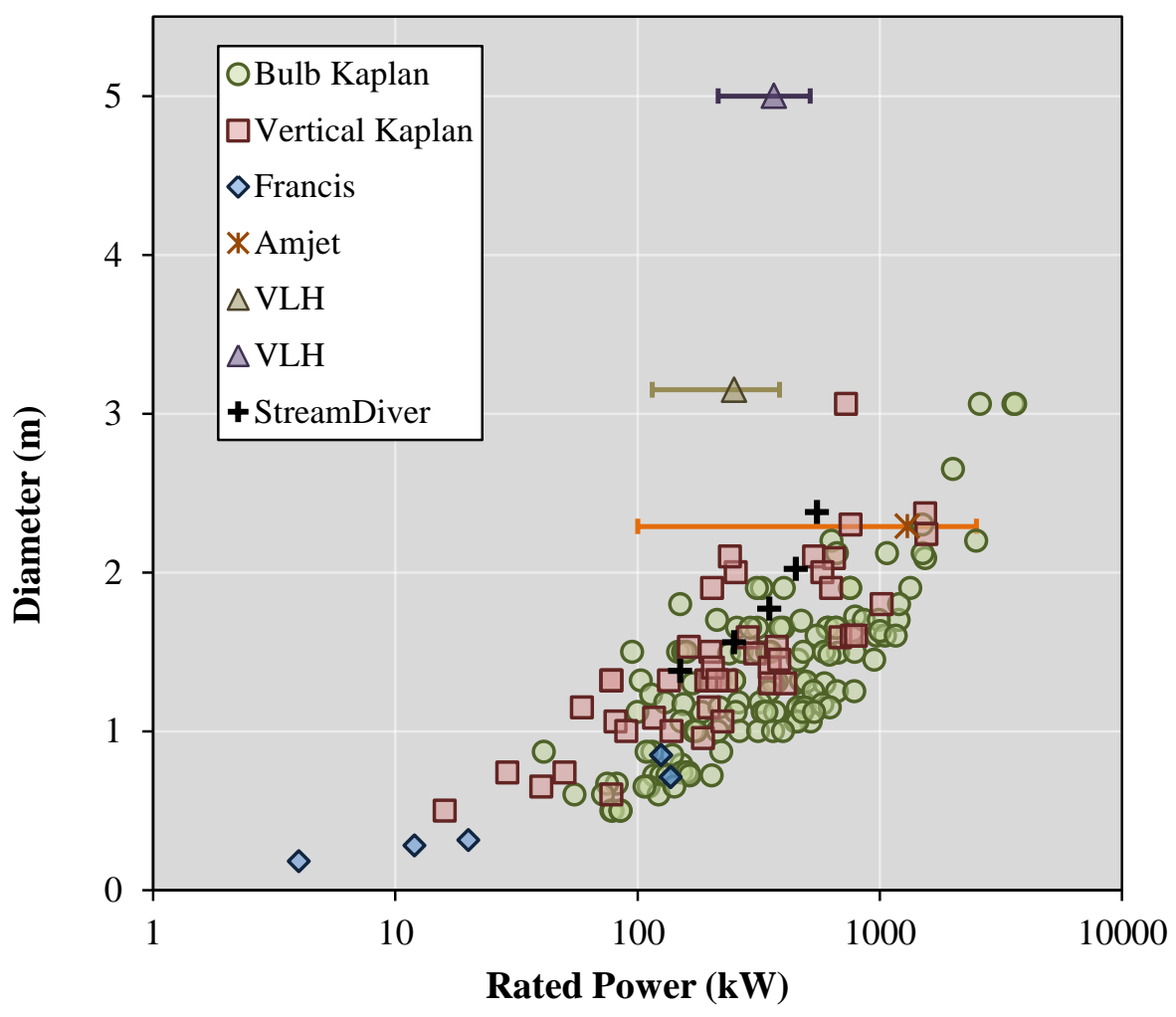

Figure 11. Single runner diameter for small, low-head $(<10 \mathrm{~m})$ conventional hydropower turbines ${ }^{1}$ (bulb Kaplan, vertical Kaplan, Francis) and embedded generator designs (Amjet ${ }^{2}, \mathrm{VLH}^{3}$, StreamDiver $\left.^{4}\right)$.

\section{A.4.4 Installed Cost}

\begin{tabular}{|l|l|}
\hline Standard of measurement & Target \\
\hline $\begin{array}{l}\text { How much it costs to manufacture, } \\
\text { deliver, and install the module }\end{array}$ & $\begin{array}{l}\text { The immediate target for an SMH project should be less than } \\
\$ 6,000 / \mathrm{kW}, \text { including all modules necessary at a site. Over time, this } \\
\text { number should be reduced as module deployment increases. }\end{array}$ \\
\hline
\end{tabular}

There is a large degree of uncertainty in setting a specific target installed cost for a generation module:

- A site may consist of a generation module and a foundation module, or it may require several passage modules and foundation modules. The acceptable installed cost of generation equipment will be different in each case.

- The cost to procure, deliver, and install a generation module may be greater than the cost of existing technologies, but the modular development of a project may reduce civil works and other project soft costs, improving project feasibility.

- A generation module manufactured and tested offsite, delivered as a complete unit skid-mounted to the project location, and installed in roughly a day is expected to yield significant cost savings for a project, but this theory is largely untested in the market.

\footnotetext{
${ }^{1}$ Data obtained from http://www.koessler.com/en/kaplan-turbines and http://www.koessler.com/en/francis-turbines

${ }^{2}$ Data obtained from http://amjethydro.com/products.html

${ }^{3}$ Data obtained from http://www.vlh-turbine.com/gamma

${ }^{4}$ Data obtained from http://voith.com/ca-fr/t_3390_StreamDiver_screen.pdf
} 
- The first modular generating units developed and installed may reflect higher R\&D, design, and engineering costs; but as economies of scale are achieved, cost savings will be realized.

Based on these uncertainties, it is most instructive to set an upper bound on the installed cost under which a generation module should strive to achieve. This can be estimated by looking at installed capital costs of new stream-reach development projects in the United States (O'Connor et al. 2015), as these best reflect what is currently economically feasible. Small, low-head hydropower projects in the planning, engineering, and construction phases exhibit installed capital costs between $\$ 2,000 / \mathrm{kW}$ and $\$ 11,000 / \mathrm{kW}$, with planning stage projects reflecting higher costs owing to contingencies and low-accuracy cost data (Figure 12). The majority of low-head engineering stage projects are in the range of $\$ 2,000 / \mathrm{kW}$ to $\$ 7,000 / \mathrm{kW}$. The immediate target for an $\mathrm{SMH}$ project should be less than $\$ 6,000 / \mathrm{kW}$, including all modules necessary at a site. Over time, this number should be reduced as module deployment increases.
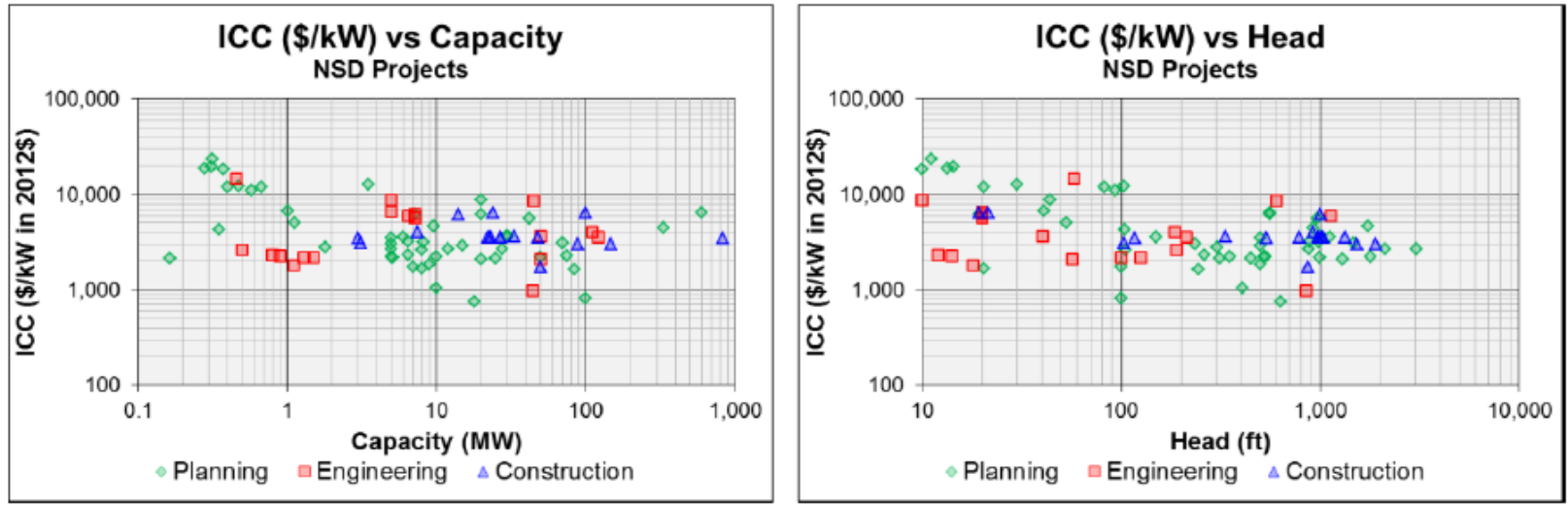

Figure 12. Project cost estimates for new stream-reach hydropower developments in the United States provided during the planning, engineering, and construction phases of project development.

(O’Connor et al. 2015)

\section{A.4.5 Estimated Useful Life}

\begin{tabular}{|l|l|}
\hline Standard of measurement & Target \\
\hline $\begin{array}{l}\text { How long a module is expected to remain } \\
\text { in operation before needing replacement }\end{array}$ & $\begin{array}{l}\text { Employ fit-for-purpose, environmentally compatible module designs } \\
\text { that trade off cost, efficiency, durability, and modular replacement }\end{array}$ \\
\hline
\end{tabular}

Conventional hydropower plants can last over 100 years. The SMH strategy is to maximize the useful life of modules, although fit-for-purpose, environmentally compatible module designs are expected to trade off cost, efficiency, durability, and modular replacement to improve deployment opportunities. When designed in this way, a generation module, on average, may fail more frequently than conventional designs, although it can be replaced inexpensively without jeopardizing public or worker safety as a result of catastrophic failure and without severe facility performance degradation. Ultimately, this trade-off must be explored in depth through techno-economic cost models.

\section{A.4.6 Maintainability}

\begin{tabular}{|l|l|}
\hline Standard of measurement & Target \\
\hline $\begin{array}{l}\text { How many man-hours does it take for } \\
\text { routine average maintenance }\end{array}$ & $\begin{array}{l}\text { Minimize the need to remove nonessential equipment during repairs } \\
\text { and enable complete removal of a module from the foundation } \\
\text { module in a single day }\end{array}$ \\
\hline
\end{tabular}


Maintainability is determined by the complexity of the module and the specific module design. An exemplary design will reduce module complexity so that isolated repairs can be made on individual components. Project downtime can be minimized if a module can be easily removed without the need to dewater or dismantle auxiliary equipment and systems. Several state-of-the art turbines can be lifted out of a bay and replaced or repaired in one day.

\section{A.5 DESIGN CONSTRAINTS}

Generation module design constraints describe limitations on how the module must operate, restrictions on what the module must produce, or conditions that must be met for an effective generation module design (Table 5). These limitations and conditions are derived by considering the current small, low-head hydropower potential in the United States as outlined in the MYRP, and the desired characteristics of an exemplary generation module. They bound the design of modules to ensure environmentally conscious decisions are incorporated into the development of new technologies. The design constraints are characterized as "local" when they pertain specifically to the generation module and "global" when their validity can be extended to the other modules of the SMH facility.

Table 5. GM design constraints

\begin{tabular}{|c|c|c|}
\hline Constraint & Formalization/rationale & $\begin{array}{c}\text { Scale } \\
(\mathrm{L}=\text { local } \\
\mathbf{G}=\text { global })\end{array}$ \\
\hline $\begin{array}{l}\text { Must be run-of-river and operate } \\
\text { within natural variations of head } \\
\text { and flow }\end{array}$ & $\begin{array}{l}\text { To minimize environmental disturbances at a site, an } \\
\text { SMH facility cannot appreciably alter the quantity, } \\
\text { timing, or duration of natural flow regimes. This } \\
\text { constraint requires the generation module to operate as } \\
\text { run-or-river, meaning the sum of inflows into the } \\
\text { upstream region of the facility must equal the sum of } \\
\text { outflows into the downstream reach of the facility }\end{array}$ & $\mathrm{L}, \mathrm{G}$ \\
\hline $\begin{array}{l}\text { Must maintain safe operation of } \\
\text { equipment and systems within the } \\
\text { generation module during all } \\
\text { operational scenarios (normal } \\
\text { operations, flood, drought, special } \\
\text { hydraulic operations, emergency } \\
\text { shutdown, startup, and ramping up } \\
\text { and down) }\end{array}$ & $\begin{array}{l}\text { The generation module is fixed instream and will } \\
\text { encounter both design and off-design conditions during } \\
\text { normal conditions and during extreme events. The } \\
\text { module itself must include all equipment and systems to } \\
\text { guarantee safe operation under all expected conditions; to } \\
\text { ensure public health and safety are not at risk; and to } \\
\text { protect the module from water, electrical, and structural } \\
\text { damage }\end{array}$ & G \\
\hline $\begin{array}{l}\text { Must produce 3-phase power at } \\
60 \mathrm{~Hz}\end{array}$ & $\begin{array}{l}\text { The US power system operates at a frequency of } 60 \mathrm{~Hz} \text {. } \\
\text { This constraint has implications for the rotational speed } \\
\text { of the runner and generator, which must either } \\
\text { independently, via a mechanical speed increaser, or } \\
\text { deliver electricity at the appropriate frequency through } \\
\text { power electronics }\end{array}$ & $\mathrm{L}$ \\
\hline $\begin{array}{l}\text { Must accommodate heads of less } \\
\text { than } 30 \mathrm{ft} \text { and flows less than } \\
4,000 \mathrm{cfs}\end{array}$ & $\begin{array}{l}\text { The US new stream-reach hydropower development } \\
\text { potential addressed through SMH research is broadly } \\
\text { characterized as low-head and low power. To accommodate } \\
\text { a large majority of these sites, a generation module must } \\
\text { operate under a maximum head and flow limit }\end{array}$ & $\mathrm{L}, \mathrm{G}$ \\
\hline $\begin{array}{l}\text { Must not appreciably increase the } \\
\text { temperature of water as it moves } \\
\text { through the module }\end{array}$ & $\begin{array}{l}\text { Some generators (e.g., those encapsulated in bulb type } \\
\text { turbines) may rely on the flow of water through the } \\
\text { module to dissipate heat from generation. The thermal } \\
\text { regime of the river is an important water quality } \\
\text { characteristic that cannot be altered appreciably from the } \\
\text { natural state }\end{array}$ & $\mathrm{L}$ \\
\hline
\end{tabular}


Table 5. GM design constraints (continued)

\begin{tabular}{|c|c|c|}
\hline Constraint & Formalization/rationale & $\begin{array}{c}\text { Scale } \\
(\mathrm{L}=\text { local } \\
\text { G= global })\end{array}$ \\
\hline $\begin{array}{l}\text { Must use biodegradable oil and } \\
\text { lubricants or water-lubricated } \\
\text { bearings }\end{array}$ & $\begin{array}{l}\text { A generation module may require the use of oil or } \\
\text { lubricants in hydraulic systems that regulate gate openings, } \\
\text { turn blades or guide vanes, or lubricate bearings. These oils } \\
\text { and lubricants cannot be released into the flow. The use of } \\
\text { water-lubricated bearings or biodegradable oil and } \\
\text { lubricants is preferred }\end{array}$ & $\mathrm{L}$ \\
\hline Cannot kill or injure fish & $\begin{array}{l}\text { Traditional approaches to downstream fish passage either } \\
\text { exclude fish from turbines with screens or racks at the } \\
\text { intake, or allow them to pass through the turbines. If fish } \\
\text { are excluded from the intake they must be provided with } \\
\text { another means of downstream transport, either through a } \\
\text { dedicated passage facility or through a trap and truck } \\
\text { approach. Allowing fish to pass through the turbine } \\
\text { requires additional constraints on turbine design to } \\
\text { account for the effects of rapid pressure fluctuations, } \\
\text { blade strikes, shear stresses, mechanical grinding, } \\
\text { cavitation, and turbulence on fish survivability. This } \\
\text { constraint also requires consideration of fish attracted to } \\
\text { the outflow of water from the module that may try and } \\
\text { swim up through the module }\end{array}$ & $\mathrm{L}$ \\
\hline Must not be excessively loud & $\begin{array}{l}\text { Loud hydropower plants are audibly disruptive to the } \\
\text { surrounding environment and socially unacceptable. The } \\
\text { generation module must remain within acceptable limits } \\
\text { of noise }\end{array}$ & $\mathrm{L}$ \\
\hline $\begin{array}{l}\text { Must conform with all relevant } \\
\text { standards and codes for hydropower } \\
\text { generators }\end{array}$ & $\begin{array}{l}\text { Standards and codes applicable to hydraulic turbines and } \\
\text { generators must be met, including ANSI, IEEE, and } \\
\text { NERC specifications relating to the acceptance of new } \\
\text { electrical equipment and apparatus }\end{array}$ & $\mathrm{L}$ \\
\hline
\end{tabular}

ANSI = American National Standards Institute; IEEE = Institute of Electrical and Electronics Engineers; NERC $=$ North American Electric Reliability Corporation.

\section{A.6 DESIGN ENVELOPE SPECIFICATION}

To fully tap into the potential of small hydropower, development of a compact fit-for-purpose turbine runner and generator- a generation module - is crucial. The generation module is envisioned as a hydropower generation technology that spans $100 \mathrm{~kW}-2 \mathrm{MW}$ of power generation (per turbine) and is designed based on cost effective run-of-river designs that eliminate the need for dam storage or employ only a small barrage to create a low head. The requirements, constraints, and measures of performance laid out above are intended to create a bounded envelope for generation module design innovation. Their implications can be summarized as follows:

- A generation module must receive upstream flows at an intake, pass them through the module, and discharge them downstream.

- It is anticipated that the generation modules will be fully immersed in water, which necessitates the use of a reaction-type turbine design in which the runner blades are profiled to create a lift force and generate torque based on the principle of a "propeller" that runs in reverse.

- A generation module must encompass all equipment and systems for safe and reliable water power generation. 
- The generation module should accommodate design flows of less than 4,000 cfs per unit and design heads of less than $30 \mathrm{ft}$ per unit.

- Run-of-river type operation is expected, with a generation module operating within the natural variation of head and flow.

- The module must minimize environmental disturbance-it cannot kill or injure fish, release oil or lubricants into the flow, appreciably increase the temperature of water, or emit loud and obtrusive noise during operation.

- Design decisions - including type of turbine, type of generator, mechanical turbine-generator coupling, turbine-generator configuration, number of turbine runner blades, speed control system, and necessary peripheral equipment - are to be determined by individual generation module manufacturers with consideration of the requirements, constraints, and measures of performance outlined herein.

Many of these specifications are met by existing technologies, although the concept of a fit-to-purpose generation module that incorporates all specifications and conforms to the SMH facility concept is new.

\section{A.6.1 State-of-the-Art Advances}

Advanced small hydropower designs have been identified that embody exemplary characteristics and improve the generation module conception. There is high uncertainty with respect to their cost, as most solutions are proprietary and detailed cost data are not provided. Thus, it is unclear if their inclusion in a generation module design will improve the overall feasibility of the SMH concept. However, they are briefly described here to further characterize an exemplary generation module.

\section{A.6.1.1 Variable-speed power electronics coupled with permanent magnet generators}

A recent US Department of Energy-funded project (Kinloch 2015) replaced an induction generator at a low-head small hydropower site with a variable-speed drive (VSD) and a PMG. A VSD and PMG use one power converter box to adjust the output voltage and frequency of the generator, allowing the turbine to spin at the optimum speed for the given input hydraulic power. This technology eliminates the need for a contactor, exciter, voltage regulator, auto-synchronizer, speed increaser, and speed-matching controls. The system is considered off-the-shelf, as it is already in use for wind turbines.

The original fixed-blade runner and supporting civil works were left intact, allowing for an exact performance improvement evaluation of the new generator and power electronics. The new technology resulted in reduced complexity and fewer components than the existing induction generator (and a comparable synchronous generator), and is expected to produce $96 \%$ more energy per year than the previous generator system. The major improvements came from (1) operating the fixed-blade turbine at optimum speed over a full range of head and (2) operating the turbine at optimum speed at the maximum design head (as the old induction system was unintentionally mismatched and the generator was running at a speed that was too high, resulting in poor performance). The overall improvement in real power and efficiency over a range of heads is shown in Figure 13 and Figure 14, respectively. Although the project principal investigator stated it is not possible to isolate the performance improvements due solely to the VSD and PMG system (i.e., due to the technology and not to correcting the turbine-generator speed mismatch), it is clear that coupled VSD and PMG technologies reduce complexity, increase flexibility, enable more compact designs, and have the potential to improve efficiency over a wide range of heads and flows.

The cost of equipment and supplies for the project totaled $\$ 64,105$, or $\$ 2,331 / \mathrm{kW}$ based on the roughly $27 \mathrm{~kW}$ output at the approximate design head of $8.55 \mathrm{ft}$, with an estimated payback period of roughly 7 years. The power output of this site is fairly low, although the concept can be applied at larger sites; and the principal investigator suggests this technology applied on larger streams with more variation in head 
would see increased benefits. The VSD technology can also be added without a PMG at roughly half the cost of the current project. This approach would also yield benefits for a module designed with a conventional generator.

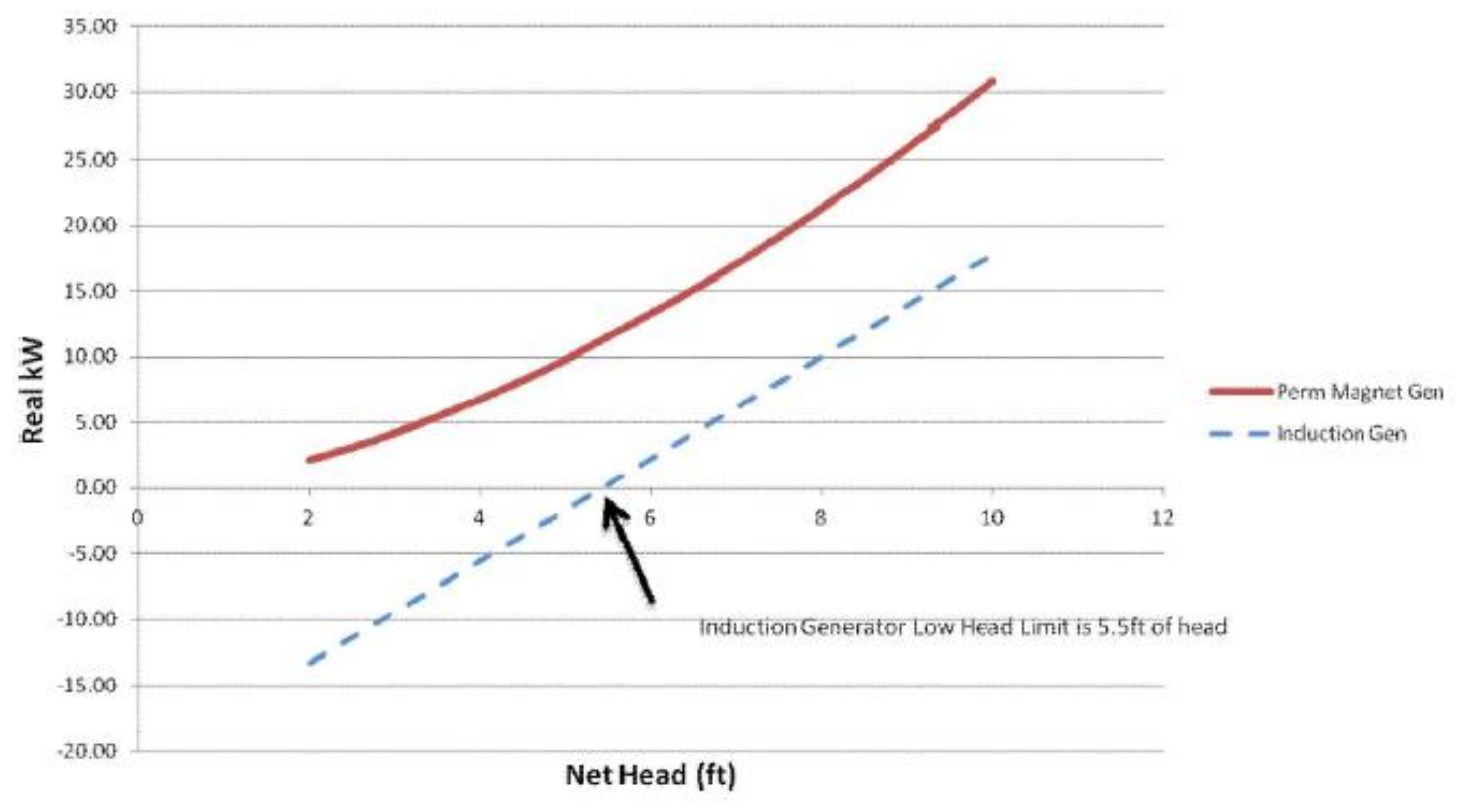

Figure 13. Average power output of the new VSD and PMG system compared with the former induction generator. (Kinloch 2015)

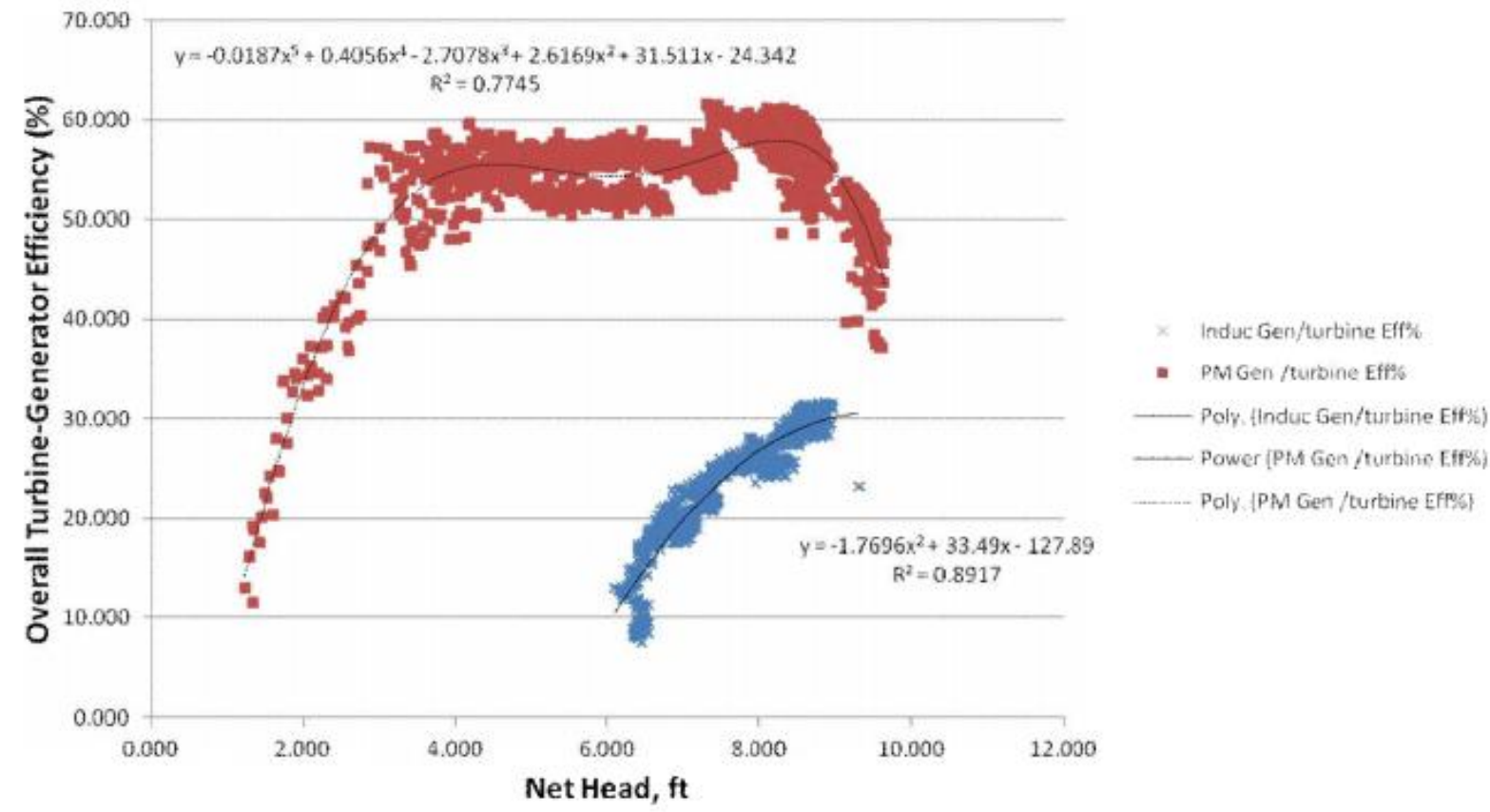

Figure 14. Net real power efficiency of the new VSD and PMG system compared with the former induction generator. (Kinloch 2015) 


\section{A.6.1.2 Fully submersible turbine and generator assembly}

A fully submersible generation module incorporating the entire turbine and generator assembly into a single compact design has been introduced in the past several years. One recent example is the Amjet Turbine $^{5}$ (Figure 15), a $5 \mathrm{ft}$ long and $8 \mathrm{ft}$ wide rim-rotor hydropower turbine unit. The unit uses variablespeed technology and a PMG to eliminate the need for mechanical controls. It can operate at multiple power ranges to match varying heads; a composite turbine housing reduces overall unit weight; it can be installed in-line at existing structures without the need for a foundation; and it includes only one rotating part, the rotor, minimizing the overall footprint and complexity of interoperating components. Installation design and Federal Energy Regulatory Commission approval are currently in progress. Other examples include the Voith StreamDiver and the ANDRITZ HydroMatrix, bulb-type turbines that incorporate the generator into a hub on the upstream nose of the unit.

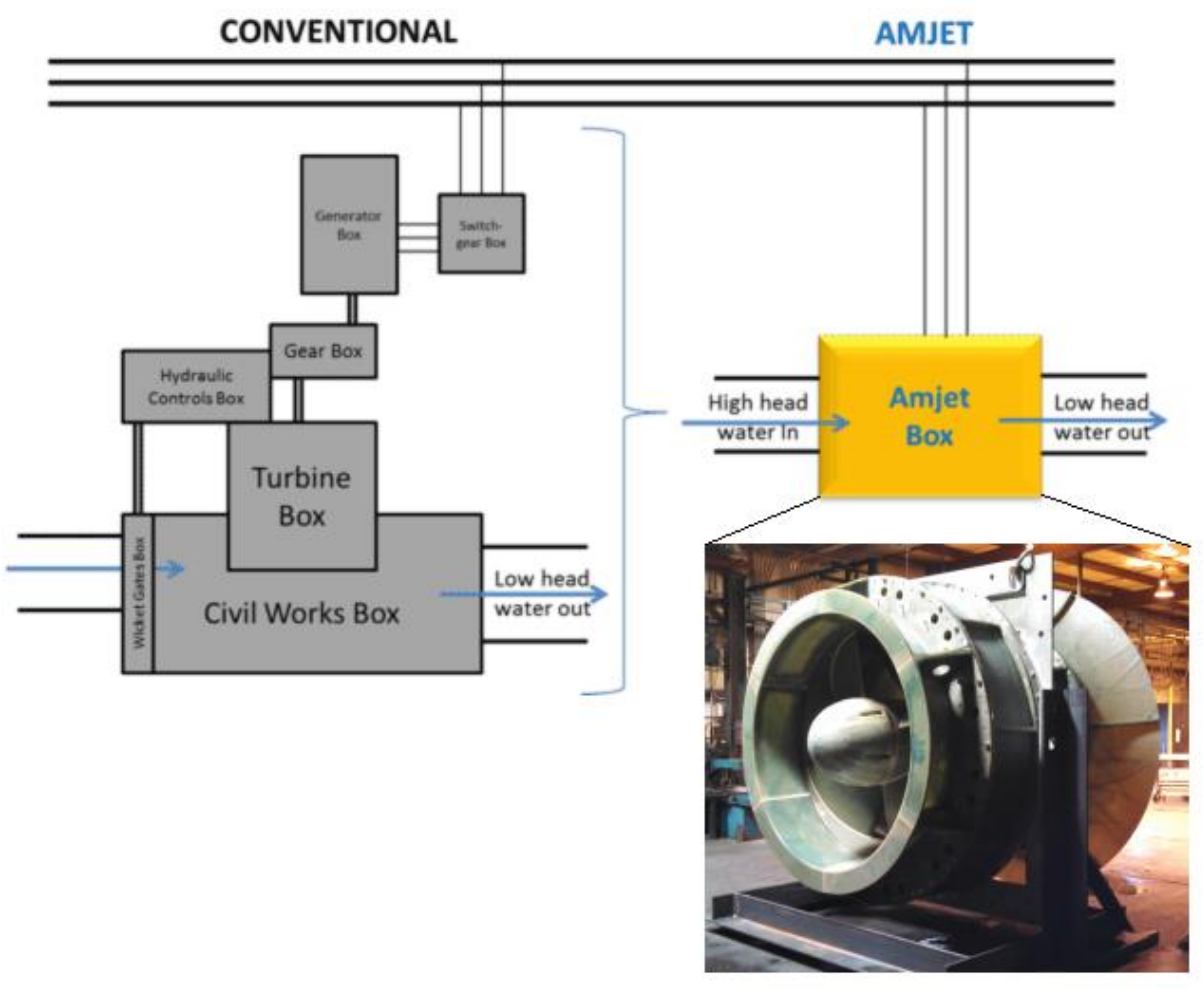

Figure 15. Amjet Turbine Systems low-head turbine with embedded permanent magnet generator and variable-speed electronic flow control that eliminates the need for conventional peripheral equipment. (Personal communication between S. DeNeale, Oak Ridge National Laboratory, and P. Roos, Amjet Turbine Systems, LLC, March, 23, 2016)

An additional benefit of fully submersible units is they may eliminate the need for a conventional powerhouse (Figure 16 and Figure 17). An acute issue at low-head sites is the volume of concrete necessary for a powerhouse. Low-head turbines have larger diameters to accommodate higher discharges, increasing the structural stability requirements. Incorporating the generation equipment and systems into a fully submersible and compact unit can reduce the cost of civil works, the overall project complexity, and project construction times.

\footnotetext{
${ }^{5}$ http://amjethydro.com/
} 


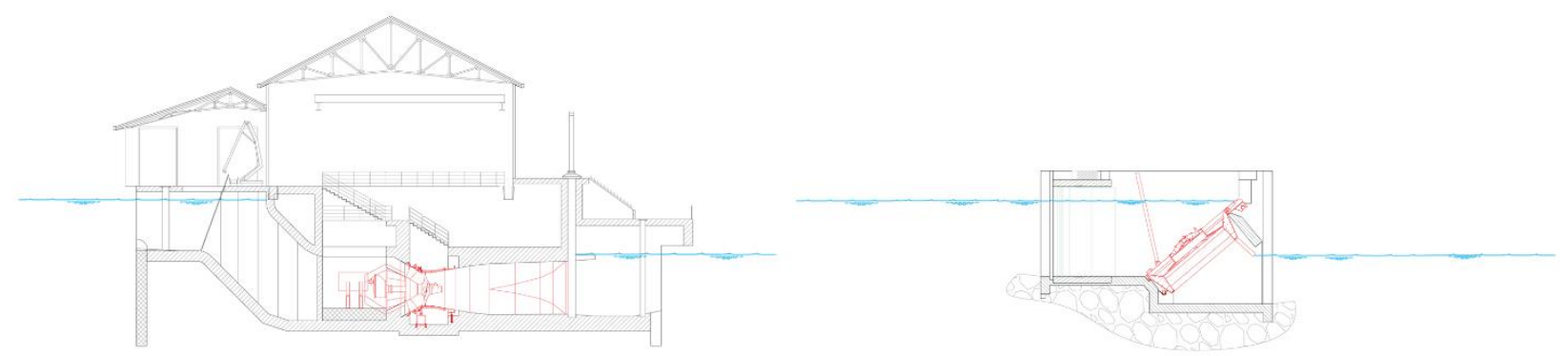

Figure 16. VLH turbine technology (right) eliminates powerhouse superstructure associated with more conventional technologies (left). (Source: MJ2 Technologies North America. Used by permission.)
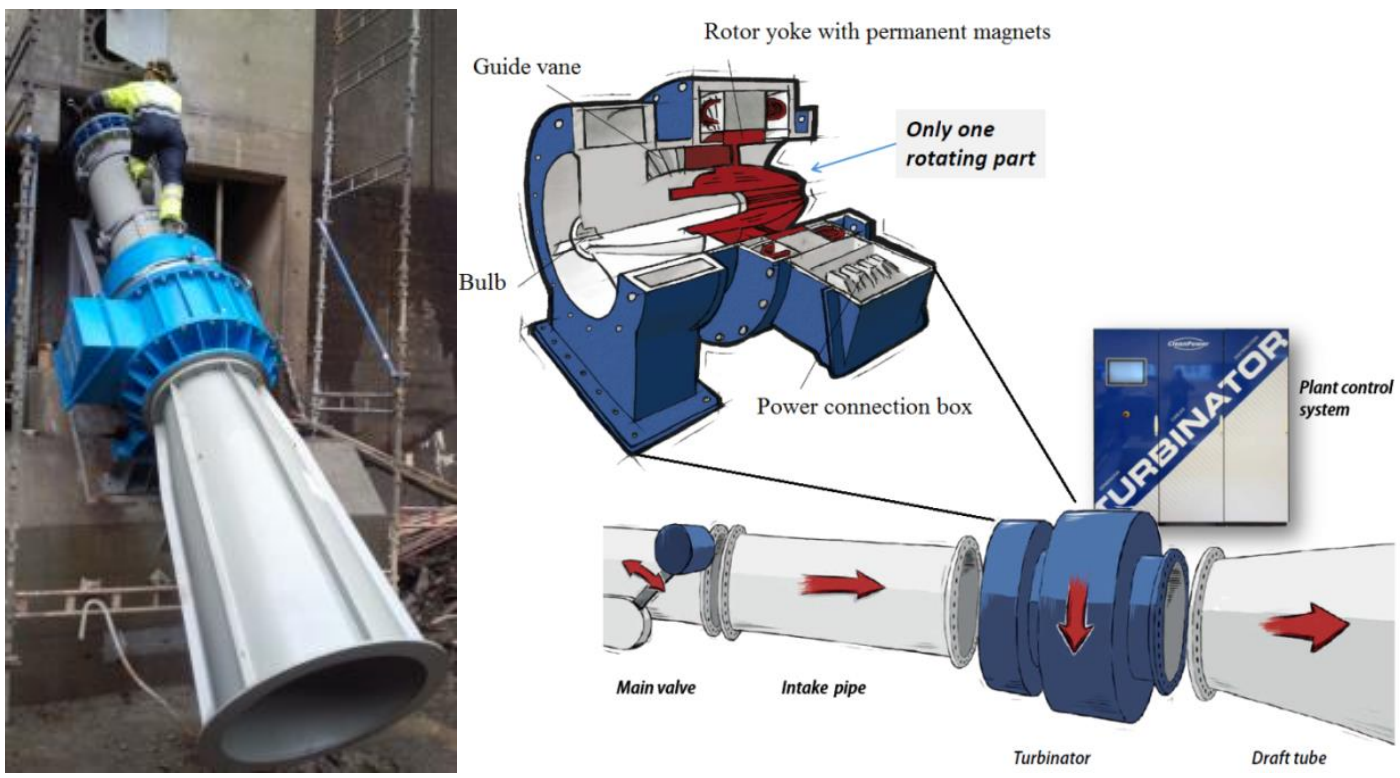

Figure 17. Installed unit (left) and cutaway sketch (right) of the Turbinator turbine-generator integrated technology installed without a powerhouse. (Opsahl 2013)

\section{A.6.2 Research Gaps}

\section{A.6.2.1 Techno-economic tradeoffs}

All generation module design decisions have specific economic implications that challenge the inclusion of exemplary technologies. New designs and technologies are more expensive when first introduced, and they require adoption at scale before the economics become attractive. The biggest research unknown is whether the costs of new exemplary designs can be competitive while ensuring favorable long-term environmental and technical performance. Specific techno-economic tradeoffs to be researched include

- Advanced flow control

- Flow available for generation with respect to other module uses

\section{A.6.2.2 Structural integration into a foundation module}

The generation module is required to embed or anchor into the foundation module at a site. This concept represents the largest departure from conventional thinking, and a current research gap with respect to 
where and how these kinds of assemblies can be installed. The authors have identified two emerging lowhead hydropower technologies, the VLH turbine ${ }^{6}$ and the Ossberger movable powerhouse ${ }^{7}$, which secure an integrated runner and generator unit into place on top of a modular-type foundation structure. In both cases, the foundation consists of two vertical parallel side-walls and a bottom foundation that is either stepped (VLH) or sloped (Ossberger). Both units are inclined with respect to the bottom wall and do not require a powerhouse, reducing the excavation required to secure the unit in place.

\section{A.6.2.3 Module performance characteristics relative to traditional impoundment designs}

To minimize the environmental footprint of hydropower operations and limit the disruption of flow regimes, the generation module must operate without an impoundment, akin to conventional run-of-river type operation. The extent to which a module design may be situated in a stream without any sort of impoundment, or with a partial impoundment that leaves a portion of the stream undisturbed, is currently unknown.

\section{A.6.2.4 Use of advanced materials and manufacturing techniques in module design}

The turbine runner is usually made of cast iron or steel, durable metals with high cycle fatigue and limited susceptibility to cavitation, erosion, and corrosion. Modern composites have strength and stability comparable to those of steel at a fraction of the total weight. A few emerging small hydro technologies are incorporating carbon fiber materials in turbine runners and runner blades to produce lightweight, modular, mass-producible designs. Applied research has shown that systematic assembly of composite turbines could lead to reduced labor costs and substantial weight reductions (Whitehead and Albertani 2015). The use of thermoset plastics, sintered metals, and ceramic coatings is frequently proposed as a target for small hydropower R\&D, although these materials have yet to be incorporated into generation technology on a large scale (Zhang et al. 2012). Although composite turbine blades are seeing increased adoption in wind turbine designs and marine hydrokinetic installations, very little research has been carried out on the performance or benefits of hydropower turbines fabricated with composite materials.

Additive manufacturing, or the 3-dimensional printing of components in layers, enables fabrication of composite components with fewer bolted connections, reduced manufacturing labor costs, and higher throughput. These features have led to significant cost reductions for mass-produced components in other industrial sectors, namely pumps and pump impellers. A significant challenge to widespread use of this technique is the relatively slow pace of small hydropower development in the United States.

\section{A.6.2.5 Use of permanent magnet generators with non-rare earth materials}

Although PMGs with rare earth magnets offer high torque/power density, alternatives with reduced or no use of rare earth materials are possible. Alternative magnet types include AlNiCo, ferrite, and samarium cobalt. AlNiCo and ferrite magnets, in particular, have a much smaller energy product than rare earth permanent magnets. A lower energy product indicates lower magnet strength, which necessitates an overall increase in magnet volume. This poses difficulties for the mechanical design of the rotor. Because of their low coercivity, AlNiCo and ferrite magnets are more susceptible to demagnetization in a surfacemounted configuration. The low remnant flux density of ferrite magnets makes it difficult, if not impossible, for them to achieve power densities similar to those of that of a rare earth magnet, surfacemounted PMG. Some of the difficulties of using low-cost magnets can be ameliorated by combining them with the reluctance generator topology to increase the overall output. Reluctance generators can also operate without magnets entirely, but they may be disadvantaged by a worse power factor.

\footnotetext{
${ }^{6}$ http://www.vlh-turbine.com/

7 http://owa.ca/assets/files/presentations/FINALOssbergerPresentation.pdf
} 


\section{APPENDIX B. FISH PASSAGE MODULE}

Hydropower facilities can work as total, partial, and/or permanent temporal barriers (Table 6) or a combination of these with regard to the movement of native (anadromous, catadromous, amphidromous, and residential) fish species (Larinier 2000; Schilt 2007; Noonan et al. 2012; Fuller et al. 2015). In addition to being total, partial, or temporal barriers to fish movement, hydropower facilities often impair the natural sense of direction of fish by creating low-flow-velocity regions, which are not natural to fish (Cada 1997; Larinier 2000; Katopodis 1992). The disruption of the connectivity of fish movement impedes fish lifecycles, including spawning/feeding purposes. In a nutshell, this disruption has impacts on fish survival, mortality rates, health, biodiversity, and habitat.

Table 6. Classification of barriers with respect to fish movement (adapted from the California Department of Fish and Game)

\begin{tabular}{|l|l|l|}
\hline \multicolumn{1}{|c|}{ Barrier category } & \multicolumn{1}{|c|}{ Definition } & \multicolumn{1}{c|}{ Potential impacts } \\
\hline Temporal & $\begin{array}{l}\text { Impassable to all fish at certain flow } \\
\text { conditions (based on run timing and } \\
\text { flow conditions) }\end{array}$ & $\begin{array}{l}\text { Delay in movement beyond the } \\
\text { barrier for some period of time }\end{array}$ \\
\hline Partial & $\begin{array}{l}\text { Impassable to some fish species } \\
\text { during part or all life stages at all } \\
\text { flows }\end{array}$ & $\begin{array}{l}\text { Exclusion of certain species during } \\
\text { their life stages from portions of a } \\
\text { watershed }\end{array}$ \\
\hline Total & Impassable to all fish at all flows & $\begin{array}{l}\text { Exclusion of all species from } \\
\text { portions of a watershed }\end{array}$ \\
\hline
\end{tabular}

\section{B.1 OBJECTIVES}

To minimize the barriers posed by an SMH facility to migratory fish movement upstream and downstream in a river, and thus preserve the connectivity of migratory fish population and habitat, the SMH facility includes a fish passage module. The primary technical objective of the fish passage module is to allow the unimpeded and safe passage (upstream or downstream) of fish through an SMH facility.

Fish Passage Module Primary Technical Objective

To allow the unimpeded and safe passage (upstream and downstream) of fish through a SMH facility

To succeed in its primary technical objective, the fish passage module must possess favorable geometry and create hydraulic conditions such that fish are encouraged to cross the SMH facility in a safe manner by minimizing fish fatigue, disorientation, and injury. These objectives are shown for both upstream and downstream passage in Figure 18. A key prerequisite for the passage of fish across the SMH facility is that fish must enter the fish passage module inlet. The modification of the natural river flow conditions by the presence of the SMH facility causes fish disorientation, which could, in turn, prevent fish from finding the fish passage module entrance that allows them to cross the facility. Thus, fish need to be guided toward the module inlet before they can use the fish passage module. Although fish guidance is generally required for both upstream and downstream fish passage, downstream fish passage may additionally require minimizing the likelihood of fish entering the generation module. It is recognized that fishfriendly turbine designs have recently been developed (Cada 2001; Pracheil et al. 2016) that limit fish injury and achieve high survival rates of fish passing through the turbine (Ferguson et al. 2006). However, the generation module is still considered the route that results in higher rates of fish injury, as well as direct and indirect mortality, especially for adult fish (Cada 2001; Schilt 2007). Therefore, fish may need to be deterred from entering the generation module of an SMH facility and guided to the fish passage 
module, which ensures safe passage. Finally, the fish passage module outlet configuration must minimize fish injuries and disorientation and allow fish to exit safely into the waterway to resume their migration.

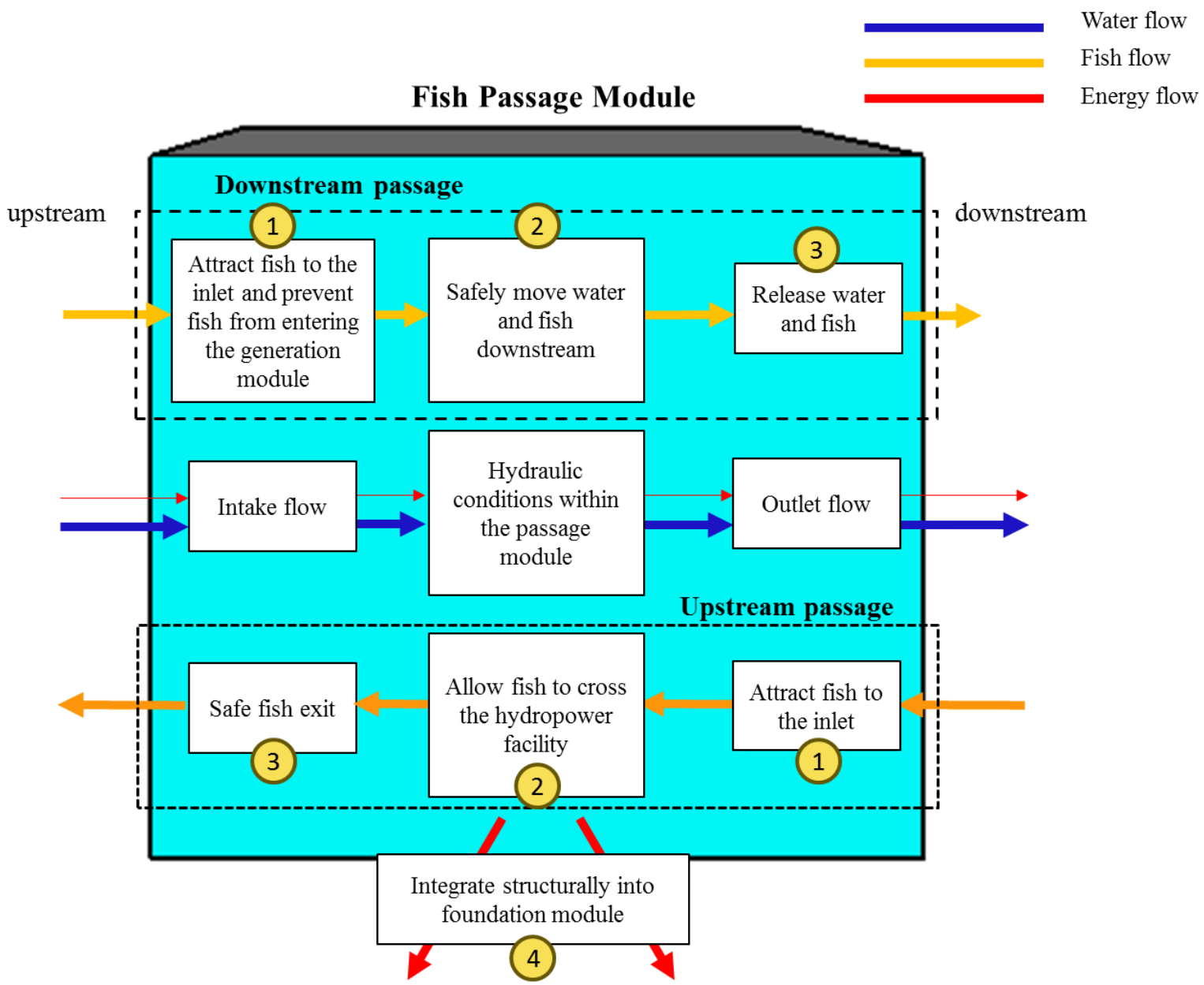

Figure 18. Conceptual schematic of the specific objectives of a fish passage module. Note that downstream and upstream passage of fish are shown together on the same module because of the shared requirements of attraction, safe passage, and release, and their relationship to hydraulic conditions in and around the module. Separate upstream and downstream passage modules may be required.

In summary, to achieve its primary objective, the fish passage module must accomplish the following specific objectives:

1. Attract fish to the module inlet. Specifically for downstream fish passage, the fish passage module should also deter fish from entering the generation module.

2. Allow fish to cross the SMH facility.

3. Allow fish to exit safely into the river (downstream or upstream) of the SMH facility.

4. Integrate structurally into the foundation module.

\section{B.2 REQUIREMENTS}

The requirements of the fish passage module are a series of quantifiable characteristics or behaviors that the module must exhibit to accomplish each one of its specific objectives. In turn, by fulfilling its specific objectives, the fish passage module will achieve its primary objective of allowing the unimpeded and safe 
passage of fish across the SMH facility. Fish passage module requirements are presented in Table 7 , Table 8, and Table 9 and characterized as Functional, Performance, Interface and Other, based on the following criteria:

- Functional requirement: The requirement is a behavior or function that needs to be performed for successful module operation.

- Performance requirement: The requirement is quantified by how well a function is accomplished.

- Interface requirement: The requirement involves interaction of the fish passage module with other modules, e.g., water passage, generation.

- Other: There is a lack of knowledge regarding the requirement at present.

Achieving the passage module requirements aims to minimize disruption of the connectivity in the river continuum in terms of its five constituents: water, sediment, energy, organisms, and water quality. It is therefore pertinent to identify the relationship(s) of each requirement of the fish passage module with one or more of the environmental constituents, as indicated in the five rightmost columns of Table 7, Table 8 , and Table 9. Identifying these relationships further allows isolating interactions between the fish passage module and other modules by considering the requirements of the various modules that relate to the same constituent. Note that these requirements pertain to both upstream and downstream fish passage modules, unless one of the two is specifically identified.

A key prerequisite for ensuring the passage of fish through the SMH facility, and thus accomplishing the primary objective of the fish passage module, is to guide fish to the fish passage inlet (see Table 7). Fish that cannot enter the fish passage module, which is the key conveyor of fish across the SMH facility, are likely to become trapped upstream or downstream of the SMH facility (OTA 1995). Their entrapment not only impedes their migration, thus disrupting fish connectivity along the river continuum, but also increases fish exposure to predators and thus fish mortality rates (Larinier 2000; Schilt 2007). However, detection of the fish passage module entrance by the fish is not straightforward. Previous research has suggested that migratory fish possess complex biological mechanosensory systems that detect water motion against their bodies (Coombs et al. 1989; Montgomery et al. 1997; Schilt 2007). Using water motion to guide them, fish sense their direction of travel and avoid obstacles.

As a result, complex flow patterns - including regions of strong acceleration, deceleration, and recirculation - in the vicinity of the fish passage module entrance are likely to disorient fish. A key requirement for the fish passage module is to limit flow patterns unfavorable to fish movement (OTA 1995) and provide for a consistent flow stream that will guide fish toward the fish passage module entrance. In addition, the flow depth near the fish passage module entrance must exceed a minimum threshold to allow fish to swim (OTA 1995). The interaction of the approaching river flow typically leads to elevated turbulence levels, through the creation of shear layers and mixing between slow and fastmoving fluid in the river and in the fish passage, respectively. Elevated levels of turbulence may cause disorientation and excessive fatigue to fish and therefore should be limited. 
Table 7. Fish passage module functional requirements: objective 1 -attract fish to the module. In the fourth column: $\mathrm{F}=$ Functional; $\mathrm{P}=$ Performance; $\mathrm{I}=$ Interaction; $\mathrm{O}=$ other. In columns $6-11$, an " $\mathrm{X}$ " denotes a relationship to the river continuum constituent indicated in the top row

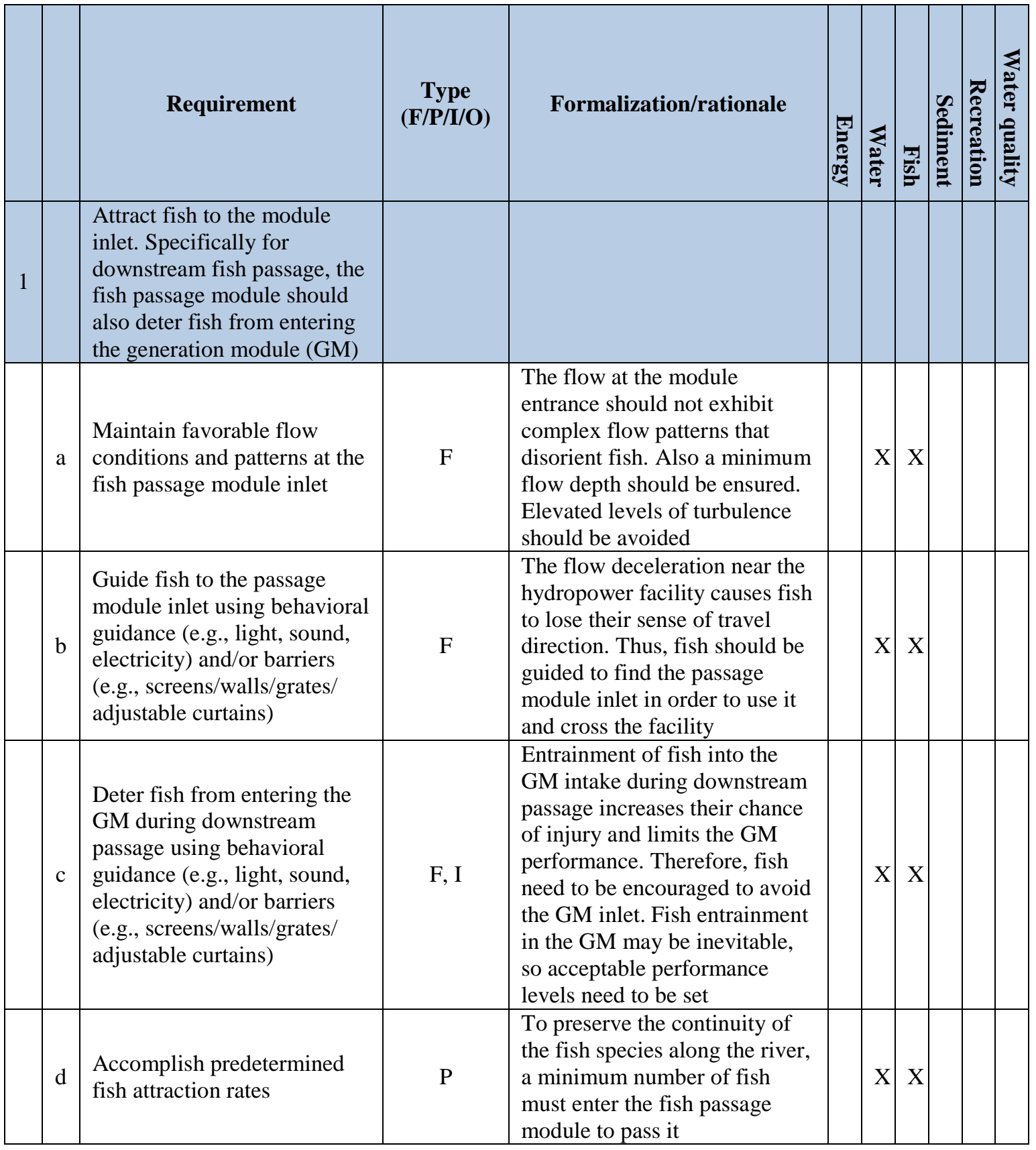

The deceleration of the river flow, particularly upstream but also downstream of an SMH facility, also prevents fish from sensing the water flow and causes disorientation. To prevent fish disorientation and encourage fish to enter the fish passage module, the module must feature guidance devices (Table 8). There are two broad categories of guidance devices: barriers and behavioral guidance devices (Larinier 2000; Schilt 2007; CNRA 2013). Barriers include various types of fixed or movable screens (e.g., Eicher screens, vertical and inclined fixed flat-plate screens), structures (e.g., angled and "louver" racks), as well as movable barrier nets and curtains (OTA 1995; Schilt 2007; CNRA 2013). The barrier guidance devices 
prevent fish from crossing them and allow fish to move only along their length, thus delineating a path for fish movement. The fish passage module will need to include such barrier guidance devices to delineate a path that guides fish to the module entrance. Behavioral attraction devices, on the other hand, use stimuli such as light, sound, or turbulence to generate fish movement toward or away the devices. However, these behavioral attraction devices are relatively new technologies; to date, they have seen limited testing and application and should be used with caution in the fish passage module (Schilt 2007 CNRA 2013). Note the requirement of attracting fish to the fish passage module inlet is common for both downstream and upstream passage, to allow crossing of the SMH facility by catadromous and anadromous fish, respectively.

An additional requirement for downstream migrating fish is that the fish passage module must discourage the entrainment of fish into the inlet of the generation module. Despite improvements made in the design of turbines to make them more fish-friendly and improve the survival chances of fish entrained through the turbines, passage of fish through the turbines is the least safe passage or escape route with the highest chances of fish injury (Cada 2001; Schilt 2007). Further, the increased pressure and turbulence generated in the generation module turbines could disorient fish, which has implications for fish mortality (Cada 2001; Schilt 2007). To minimize the likelihood of fish entrainment into the generation module, the fish passage module may need to employ fish guidance devices (barriers or behavioral guidance devices such as curtains) that direct downstream migrating fish away from the generation module and into the fish passage module.

Finally, the fish passage module must achieve a predetermined minimum rate of fish attraction to its inlet. The fish attraction rate is typically quantified by the ratio of migrating fish entering the fish passage module to the total number of migrating fish (Roscoe and Hinch 2010; Cooke and Hinch 2013).

Satisfying a minimum fish attraction rate to the fish inlet ensures that a minimum number of migrating fish will use the fish passage module and eventually pass through the SMH facility, thus minimizing the disruption caused by the SMH facility to the continuity of existing fish species in the river. The minimum threshold for fish attraction rate needs to be determined based on an assessment of the specific river conditions and thus is a measure of the fish passage module performance, as will be discussed in detail in Appendix B.4.

Perhaps the most important specific objective/utility of the fish passage module is to allow downstream and upstream migrating fish to safely and consistently cross the SMH facility. To do so, a portion of the river flow must be diverted into the fish passage module, and the portion of the flow routed through the fish passage module should be kept within relatively well-defined bounds even under changing hydrologic conditions for the river. To retain the diverted flow within the fish passage module within this predetermined range, it is necessary for the fish passage module to interface with the water passage module. This interface can make provisions for directing additional water volume to the fish passage module at low-flow conditions and for excess water removal during flood conditions, so that favorable conditions for fish movement are sustained within the fish passage module. 
Table 8. Fish passage module functional requirements: objective 2-allow fish to cross SMH facility. In the fourth column: $\mathrm{F}=$ Functional; $\mathrm{P}=$ Performance; $\mathrm{I}=$ Interaction; $\mathrm{O}=$ other. In columns 6-10, an "X" denotes a relationship to the river continuum constituent indicated in the top row

\begin{tabular}{|c|c|c|c|c|c|c|c|c|c|c|}
\hline & & Requirement & $\begin{array}{l}\text { Type } \\
(\mathbf{F} / \mathbf{P} / \mathbf{I} / \mathbf{O})\end{array}$ & Formalization/rationale & 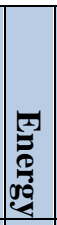 & 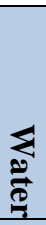 & ב⿳⺈冂大 & 离 & 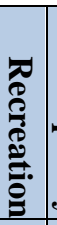 & 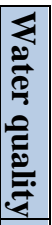 \\
\hline 2 & & $\begin{array}{c}\text { Allow fish to cross the } \\
\text { SMH facility }\end{array}$ & & & & & & & & \\
\hline & $\mathrm{a}$ & $\begin{array}{l}\text { Divert a sufficient } \\
\text { portion of the river } \\
\text { flow }\end{array}$ & $\mathrm{F}, \mathrm{I}, \mathrm{O}$ & $\begin{array}{l}\text { A portion of the river flow should be } \\
\text { diverted in the passage module to allow fish } \\
\text { to swim in the passage. This portion is thus } \\
\text { not used by the generation module and must } \\
\text { be supplied by the water passage module }\end{array}$ & $\mathrm{X}$ & $\mathrm{X}$ & & & & \\
\hline & $\mathrm{b}$ & $\begin{array}{l}\text { Sustain appropriate } \\
\text { flow conditions and } \\
\text { flow patterns }\end{array}$ & $\mathrm{F}$ & $\begin{array}{l}\text { Fish require flow velocities below a } \\
\text { threshold to prevent excessive fatigue- } \\
\text { especially for upstream passage, a minimum } \\
\text { flow depth to be able to swim, and low-flow- } \\
\text { velocity resting regions. Also, turbulence } \\
\text { levels must be retained below a threshold. } \\
\text { These thresholds are specific to fish species } \\
\text { and age }\end{array}$ & $\mathrm{X}$ & $\mathrm{X}$ & $\mathrm{X}$ & & & \\
\hline & $\mathrm{c}$ & $\begin{array}{l}\text { Retain } \\
\text { passage/structure } \\
\text { dimensions to levels } \\
\text { manageable by the fish }\end{array}$ & $\mathrm{F}, \mathrm{P}$ & $\begin{array}{l}\text { The fish passage structure elements (e.g., } \\
\text { baffles, steps) need to be smaller than the } \\
\text { fish jump height to allow fish crossing. Also, } \\
\text { the passage structure length should be as } \\
\text { short as possible to minimize fish fatigue } \\
\text { during crossing }\end{array}$ & & $X$ & $\mathrm{X}$ & & & \\
\hline & $\mathrm{d}$ & $\begin{array}{l}\text { Guide fish toward the } \\
\text { module exit }\end{array}$ & $\mathrm{F}$ & $\begin{array}{l}\text { Fish may lose their sense of direction in an } \\
\text { artificial passage structure and be unable to } \\
\text { swim toward its exit }\end{array}$ & & $\mathrm{X}$ & $\mathrm{X}$ & & & \\
\hline & $\mathrm{e}$ & $\begin{array}{l}\text { Prevent excessive } \\
\text { sediment accumulation } \\
\text { in the passage }\end{array}$ & $\mathrm{F}, \mathrm{P}$ & $\begin{array}{l}\text { Excessive sediment deposition in the passage } \\
\text { module may alter its flow patterns, thus } \\
\text { reducing its efficiency in passing fish }\end{array}$ & $\mathrm{X}$ & $\mathrm{X}$ & & $\mathrm{X}$ & & \\
\hline & $\mathrm{f}$ & $\begin{array}{l}\text { Maintain dissolved } \\
\text { oxygen and bubble } \\
\text { entrainment within } \\
\text { levels manageable by } \\
\text { fish }\end{array}$ & $\mathrm{F}, \mathrm{P}$ & $\begin{array}{l}\text { Excessive turbulence generated in the } \\
\text { structures may lead to increased dissolved } \\
\text { oxygen levels and/or bubble entrainment, } \\
\text { which impair fish health }\end{array}$ & & $\mathrm{X}$ & $\mathrm{X}$ & & & $\mathrm{X}$ \\
\hline
\end{tabular}

Sustaining favorable conditions within the fish passage module entails ensuring that mean flow patterns are favorable to fish, without regions of weak or strong flow acceleration, deceleration, and swirling motion (Table 9). Favorable flow conditions within the fish passage module further entail sustaining a minimum flow depth so that the encountered migrating fish species are able to swim. Furthermore, the flow velocity within the fish passage module must be retained below thresholds manageable by the fish that encounter it (Katopodis 1992; OTA 1995; Larinier 2000; Dermisis and Papanicolaou 2009; CNRA 2013). If not, strong currents will lead to excessive fish fatigue and injury, thereby preventing fish from safely crossing the SMH facility. This is particularly relevant to upstream fish passage, where fish swim against the flow direction and must therefore exert a larger effort to overcome higher flow velocities. Also, the turbulence within the fish passage module should be maintained below certain limits, as excessive turbulence increases fish fatigue and the probability that fish become disoriented. 
An additional requirement for the fish passage module (Table 9) is that its geometry is manageable by the fish species encountered in the stream. This requirement, which is more important for upstream migrating fish, entails that the height of the fish passage module elements - including steps, baffles and weirs-be within the jumping ability of the prevalent fish species encountered. If not, these elements will become a permanent barrier to fish, making the SMH facility impassable to them. In addition, the fish passage module geometry should minimize areas with intense flow acceleration, deceleration, and recirculation, as well as areas with pronounced turbulence, such as shear layers and downwelling. Overall the fish passage module geometry should contribute to maintaining favorable flow conditions for fish. The length of the fish passage module must be kept as short as possible so that delays in fish migration through the SMH facility are minimized. At the same time, however, the fish passage module should not be too steep and must not cause high flow velocities within the passage.

The complex flow patterns within the fish passage module may disorient fish, which base their orientation on their interaction with the flow (Coombs et al. 1989; Montgomery et al. 1997; Schilt 2007). To prevent fish disorientation within the fish passage, which could lead to delays in fish migration, fatigue, and injury, the fish passage module needs to feature barriers or behavioral guidance devices for ensuring that fish find the exit.

Especially at higher flows, river sediment may be entrained into the fish passage module (OTA 1995). Because the flow within the fish passage decelerates to maintain flow conditions manageable by fish, incoming sediment could deposit within the fish passage module. Sediment accumulation could alter the geometric characteristics of the fish passage module and, in turn, the flow characteristics in the module. For instance, sediment deposition could reduce the flow depth, creating shallow but fast flow regions that are not manageable by fish. To prevent sediment accumulation within the module, the flow conditions in the fish passage module should be competent to transport the sediment material supplied from upstream.

Finally, increased turbulence resulting from the interaction of the incoming flow with the fish passage structure can lead to excessive air bubble entrainment in the flow (Chanson 2009). Elevated levels of air bubbles are known to cause "gas bubble trauma" to fish, which can ultimately lead to fish death (OTA 1995). Enhanced air entrainment also causes fish to become disoriented. To prevent such a condition, the fish passage module must minimize turbulence production and gas bubble entrainment into the flow.

At its exit, the fish passage module should exhibit characteristics that allow the safe exit of the fish into the river (Table 9). A key prerequisite for safe exit from both the upstream and downstream passage is to maintain flow conditions and patterns that prevent fish from being disoriented. At the exit of the downstream passage, enhanced turbulence from the mixing of the water moving in the fish passage with the low-speed water downstream of an SMH facility can result in increased turbulence levels and recirculating patterns that disorient the exiting fish, therefore effectively trapping them near the exit. As upstream-migrating fish exit the upstream passage, they can experience nearly stagnant water upstream of the SMH facility, which could also disorient them. Therefore, for both downstream and upstream passage, the flow conditions should neither delay fish migration downstream nor increase indirect fish mortality from predators (OTA 1995; Cada 2001; CNRA 2013). The maintenance of flow conditions that minimize fish disorientation at the fish passage module exit should be complemented with guidance devices. Specifically for downstream passage, the exit of the fish passage module must not be located at a much higher elevation than the water surface. 
Table 9. Fish passage module functional requirements; objective 3-allow fish to exit safely into the stream. In the fourth column: $\mathrm{F}=$ Functional; $\mathrm{P}=$ Performance; $\mathrm{I}=$ Interaction; $\mathrm{O}=$ other. In columns 6-10, an "X" denotes a relationship to the river continuum constituent indicated in the top row

\begin{tabular}{|c|c|c|c|c|c|c|c|c|c|c|}
\hline & & Requirement & $\begin{array}{c}\text { Type } \\
(\mathbf{F} / \mathbf{P} / \mathbf{I} / \mathbf{O})\end{array}$ & Formalization/rationale & 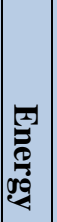 & 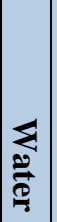 & $\frac{3}{\frac{3}{2}}$ & 里 & 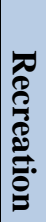 & 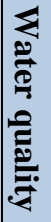 \\
\hline 3 & & $\begin{array}{l}\text { Allow fish to exit safely into } \\
\text { the river }\end{array}$ & & & & & & & & \\
\hline & $\mathrm{a}$ & $\begin{array}{l}\text { Minimize fish disorientation } \\
\text { from mean flow and } \\
\text { turbulence }\end{array}$ & $\mathrm{F}, \mathrm{I}, \mathrm{O}$ & $\begin{array}{l}\text { The enhanced turbulence and } \\
\text { exit flow patterns may } \\
\text { disorient fish, effectively } \\
\text { trapping them in the vicinity of } \\
\text { the hydropower facility }\end{array}$ & $X$ & $X$ & & & & \\
\hline & $\mathrm{b}$ & $\begin{array}{l}\text { Retain exit structure height } \\
\text { to levels manageable by fish }\end{array}$ & $\mathrm{F}, \mathrm{P}$ & $\begin{array}{l}\text { The fish passage outlet } \\
\text { structures should not allow } \\
\text { fish to drop or jump more than } \\
\text { their jumping height }\end{array}$ & $X$ & $X$ & $X$ & & & \\
\hline & $\mathrm{c}$ & $\begin{array}{l}\text { Keep air bubble entrainment } \\
\text { within levels manageable by } \\
\text { fish }\end{array}$ & $\mathrm{F}, \mathrm{P}, \mathrm{I}$ & $\begin{array}{l}\text { Flows plunging into the river } \\
\text { at the passage module exit } \\
\text { could lead to increased air } \\
\text { bubble entrainment, which can } \\
\text { disorient fish exiting the } \\
\text { facility }\end{array}$ & & $\mathrm{X}$ & $X$ & & & $\mathrm{X}$ \\
\hline & d & $\begin{array}{l}\text { Accomplish predetermined } \\
\text { fish passage rates }\end{array}$ & $\mathrm{P}$ & $\begin{array}{l}\text { To preserve the continuity of } \\
\text { the fish species along the river, } \\
\text { a minimum number of fish } \\
\text { must enter the passage module } \\
\text { to pass it safely }\end{array}$ & & & $X$ & & & \\
\hline 4 & & $\begin{array}{l}\text { Integrate structurally into } \\
\text { foundation module }\end{array}$ & & & & & & & & \\
\hline & $\mathrm{a}$ & $\begin{array}{l}\text { Transmit all forces through } \\
\text { non-critical components into } \\
\text { the foundation module }\end{array}$ & $\mathrm{F}, \mathrm{P}, \mathrm{I}$ & $\begin{array}{l}\text { The fish passage module will } \\
\text { be supported instream by a } \\
\text { foundation module that serves } \\
\text { as an interface to the } \\
\text { streambed }\end{array}$ & $X$ & & & & & \\
\hline
\end{tabular}

Finally, the fish passage module must achieve predetermined fish passage rates to preserve the continuity of the fish species in the river on which the SMH is located. The fish passage rates will need to be determined a priori following an assessment of the SMH site characteristics at different scales; this process will be discussed in more detail in Appendices B.4 and B.5.

\section{B.3 INPUTS, PROCESSES, FUNCTIONAL RELATIONSHIPS}

In this section, we identify the key processes that govern the operation of the fish passage module. These processes, and the functional relationships that quantify them, are important for understanding the function and predicting the behavior of the fish passage module. This understanding will, in turn, allow design of the fish passage module in a way that effectively minimizes disruption of the connectivity of fish along the river continuum that the SMH facility may cause under a variety of flow conditions. Before 
identifying these processes, however, it is pertinent to isolate the key variables that are the inputs to these relationships.

\section{B.3.1 Necessary Inputs}

The key inputs (or variables) relevant to the fish passage module concept are presented in Table 10. These key inputs are grouped in five categories, depending on how they relate to biological, flow, geometric, geomorphologic, or chemical processes. This categorization allows a systematic examination of the functional relationships to which these inputs relate, as is discussed in Appendix B.3.2.

Table 10. Key inputs for the function of the fish passage module

\begin{tabular}{|l|l|}
\hline \multicolumn{1}{|c|}{$\begin{array}{c}\text { Identification of } \\
\text { key inputs }\end{array}$} & \multicolumn{1}{c|}{ Formalization } \\
\hline $\begin{array}{l}\text { Fish species and accompanying } \\
\text { biological characteristics }\end{array}$ & $\begin{array}{l}\text { Species type, fish length, endurance, jump height, swimming speed, } \\
\text { fish age }\end{array}$ \\
\hline Flow variables & $\begin{array}{l}\text { Range of flow discharges encountered, watershed hydrologic } \\
\text { characteristics, flow depth, turbulence kinetic energy, turbulence } \\
\text { dissipation, characteristic eddy length, water temperature, friction } \\
\text { factor }\end{array}$ \\
\hline Geometric variables & $\begin{array}{l}\text { Type of passage module, elevation difference upstream and } \\
\text { downstream of facility, passage module slope, passage module length, } \\
\text { passage module width, passage module element (e.g., baffle, weir, } \\
\text { step/pool) height }\end{array}$ \\
\hline Geomorphologic variables & $\begin{array}{l}\text { Grain size distribution, friction factor, sediment fall velocity, sediment } \\
\text { characteristics (shape, angularity) }\end{array}$ \\
\hline
\end{tabular}

\section{B.3.2 Functional Relationships}

The functional relationships that govern the transport processes relating to the fish passage module are summarized in Table 11, along with brief descriptions of their importance. The first category involves the functional relationships among the fish biological variables. In this category is fish swimming speed (velocity), which depends on the fish species and age (Figure 19). More specifically, past work on fish swimming speed has shown that three types of fish swimming speeds can be identified: cruising, sustained, and darting (NRCS 2007; Meixler et al. 2009). Cruising speed, the slowest of the three, is the swimming speed at which a fish can travel for time periods longer than 1 hour. Sustained speed is the velocity at which a fish can travel for time periods between 1 minute and 1 hour. Darting speed, the fastest of the three velocities, is the velocity at which a fish can swim for time periods of less than 1 minute. The three types of fish velocities are specific to the fish species; larger fish, such as salmon, are capable of achieving higher cruising and sustained speeds (Figure 19). In addition, age significantly affects the swimming speeds of the various species. Typically, juvenile fish can achieve lower cruising and sustained speeds than adult fish of the same species. More important, juvenile fish may not be sufficiently developed to be capable of darting speeds, which becomes an important issue when fish are using the fish passage module.

Table 11. Functional relationships governing fish passage module operation

\begin{tabular}{|l|l|l|}
\hline \multicolumn{1}{|c|}{ Relationship of } & \multicolumn{1}{|c|}{ To } & \multicolumn{1}{c|}{ Rationale/importance } \\
\hline $\begin{array}{l}\text { Fish swimming } \\
\text { speed }\end{array}$ & Fish species and age & $\begin{array}{l}\text { The swimming speed that a fish can achieve depends on the fish } \\
\text { species and age, i.e., whether it is an adult or juvenile individual }\end{array}$ \\
\hline Fish length & Fish species and age & $\begin{array}{l}\text { The different lengths (sizes) of various fish species relate to the } \\
\text { sizes of the turbulent eddies that fish can overcome }\end{array}$ \\
\hline
\end{tabular}


Table 11. Functional relationships governing fish passage module operation (continued)

\begin{tabular}{|l|l|l|}
\hline \multicolumn{1}{|c|}{ Relationship of } & \multicolumn{1}{|c|}{ To } & \multicolumn{1}{c|}{ Rationale/importance } \\
\hline Fish endurance & $\begin{array}{l}\text { Fish species, } \\
\text { swimming speed, } \\
\text { water temperature }\end{array}$ & $\begin{array}{l}\text { The endurance of fish relates to their swimming velocity, species, } \\
\text { and age }\end{array}$ \\
\hline Fish jump height & $\begin{array}{l}\text { Fish species, water } \\
\text { temperature }\end{array}$ & $\begin{array}{l}\text { The passage cannot have obstacles with heights exceeding the } \\
\text { jumping height of the target fish species }\end{array}$ \\
\hline $\begin{array}{l}\text { Flow velocity in fish } \\
\text { passage }\end{array}$ & $\begin{array}{l}\text { Discharge, passage } \\
\text { geometry, passage } \\
\text { roughness, flow } \\
\text { depth }\end{array}$ & $\begin{array}{l}\text { Flow velocities higher than the fish swimming speed cause } \\
\text { excessive fatigue and disorientation in fish }\end{array}$ \\
\hline $\begin{array}{l}\text { Flow depth in fish } \\
\text { passage }\end{array}$ & $\begin{array}{l}\text { Discharge, passage } \\
\text { geometry, passage } \\
\text { roughness, passage } \\
\text { bed slope }\end{array}$ & $\begin{array}{l}\text { A minimum flow depth is required for each species to be able to } \\
\text { swim, which relates to the fish species }\end{array}$ \\
\hline $\begin{array}{l}\text { Turbulence } \\
\text { production and } \\
\text { dissipation }\end{array}$ & $\begin{array}{l}\text { Discharge, passage } \\
\text { roughness, passage } \\
\text { configuration/type }\end{array}$ & $\begin{array}{l}\text { Excessive turbulent kinetic energy levels may cause fish } \\
\text { displacement and disorientation. Increases in turbulence } \\
\text { dissipation are sought }\end{array}$ \\
\hline $\begin{array}{l}\text { Turbulence eddy } \\
\text { length scale }\end{array}$ & $\begin{array}{l}\text { Discharge, passage } \\
\text { geometry, passage } \\
\text { roughness }\end{array}$ & $\begin{array}{l}\text { Fish can tackle eddies with characteristic sizes comparable to or } \\
\text { smaller to their length. Hence, smaller eddies allow smaller fish } \\
\text { (e.g., juveniles) to pass }\end{array}$ \\
\hline $\begin{array}{l}\text { Sediment transport } \\
\text { friction, size } \\
\text { distribution of } \\
\text { transported material }\end{array}$ & $\begin{array}{l}\text { Sediment may be entrained into the passage module. In that case, } \\
\text { its deposition must be prevented, especially at lower-flow } \\
\text { conditions }\end{array}$ \\
\hline
\end{tabular}

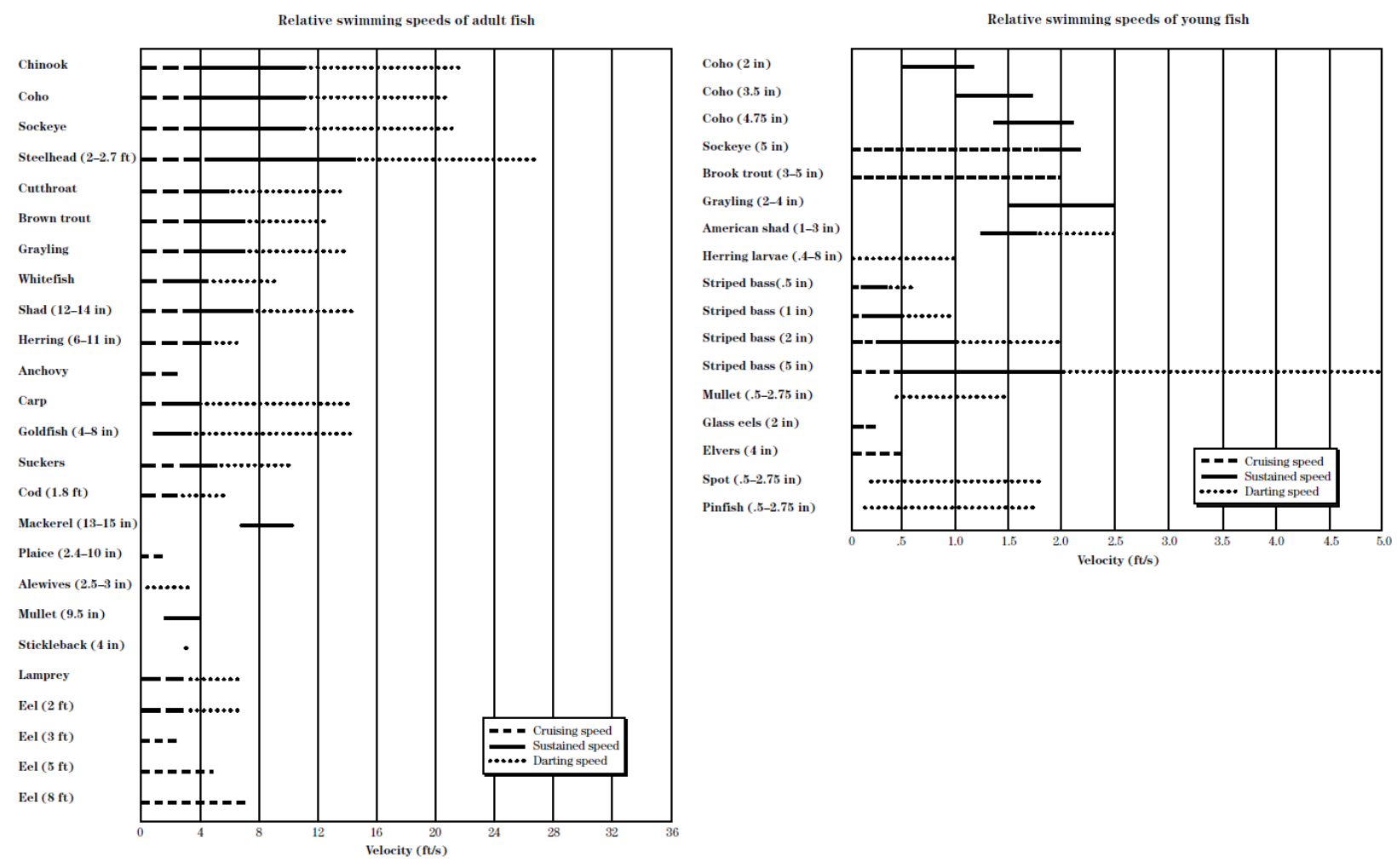

Figure 19. Swimming speeds for various species of fish: (left) adult individuals, (right) juvenile individuals.

(NRCS 2007) 
The average fish length — the length between the fish nose and the base of the tail —is also dependent on the fish species and age (Figure 20). Previous research (Papanicolaou and Maxwell 2000; Dermisis and Papanicolaou 2009) has shown that fish can withstand only those turbulent eddies that are smaller in size than their length, known also as fork length. Therefore, knowledge of the fish length for a species and the age of the fish encountered at the SMH site can determine the suitability of the fish passage in terms of turbulence characteristics.

The endurance of fish is defined as the time that a fish individually can swim at a given speed (Katopodis 1992; Ficke et al. 2011). Fish endurance is predominantly a function of the fish species, which in turn determines the type of motion (mode) that the fish makes as it swims (Katopodis 1992; Ficke et al. 2011; Meixler et al. 2009). As illustrated in Figure 20, fish endurance drops abruptly as the fish swimming velocity increases. In other words, fish can swim fast only for limited periods of time. The endurance and swimming speed can vary substantially among fish species. For instance, Figure 20 shows that brassy minnows can swim almost twice as fast as Arkansas darters for time periods of less than 1 minute. Also, water temperature can have significant impact on the swimming ability of certain fish species. As Figure 20 shows, a drop in the water temperature of $7.5^{\circ} \mathrm{C}\left(14^{\circ} \mathrm{F}\right)$ can lead to a tenfold drop in swimming velocity. Note that the product of fish endurance and swimming velocity, i.e., the area under each endurance-swimming velocity curve (Figure 20), yields the maximum distance that a fish can swim before needing to rest.
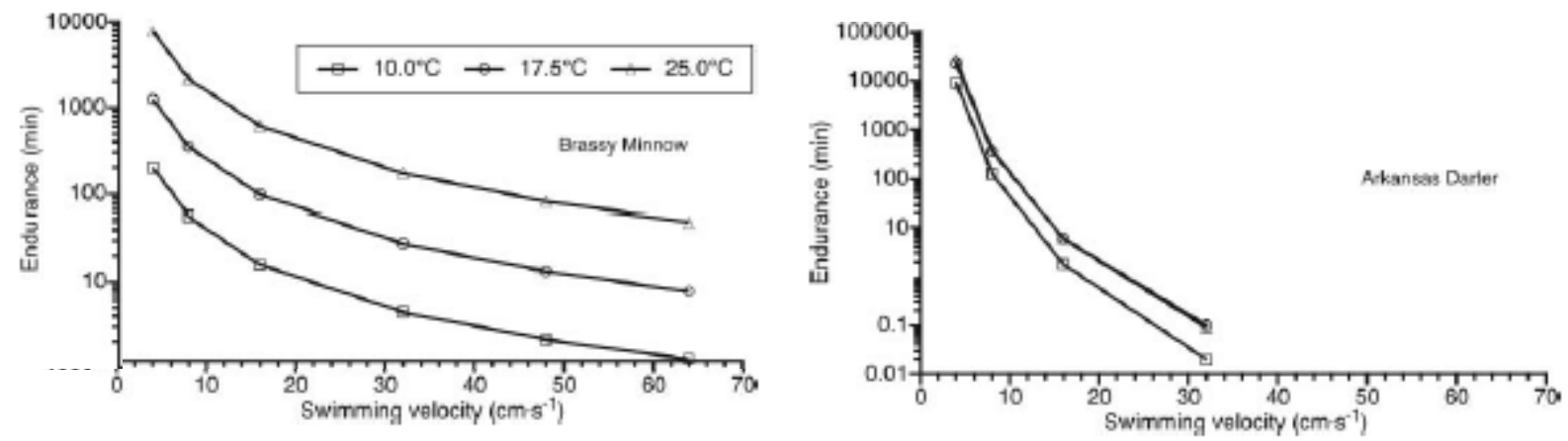

Figure 20. Fish endurance (vertical axis) as function of fish swimming speed (horizontal axis) for different fish species and water temperatures (after Ficke et al. 2011). (Reprinted by permission of Taylor \& Francis Lt. http://tandfonline.com)

In addition to the fish swimming velocity and endurance, another key characteristic that varies among different fish species is their jumping height (Table 12). As noted in Appendix B.2, the various structural elements, such as baffles, weirs and steps, of the fish passage module must be smaller than the fish jumping height to make them passable by fish. Therefore, knowledge of the jumping height for fish species is necessary for proper design of the fish passage module. Some research also suggests that the jumping height for a given fish species depends on the water temperature (Ficke et al. 2011). Specifically, a decrease in water temperature was found to cause a decrease in the fish jumping height, with extreme reductions in water temperature causing fish not to jump.

The two main characteristics of the flow in the fish passage module are flow velocity and depth. These two parameters, which are interrelated, are in general expressed as a function of the discharge flowing into the fish passage module, the fish passage module geometry and bed slope, and the fish passage module roughness (Chaudhry 2008). The discharge itself is a function of the drainage area of the watershed in which the SMH facility is located, and of watershed characteristics such as land use and land cover, soil type, and climatic conditions (Maidment 1993; Papanicolaou and Abban 2016). These dependencies are examined in more detail in Appendix E, which discusses the water passage module. 
Table 12. Key physiological characteristics for common freshwater fish species (Meixler et al. 2009). (Obtained from Creative Commons under license CC BY-NC-ND 4.0 https://creativecommons.org/licenses/by-nc-nd/4.0/)

\begin{tabular}{|l|l|c|c|c|c|}
\hline \multicolumn{1}{|c|}{ Common name } & \multicolumn{1}{|c|}{ Scientific name } & $\begin{array}{c}\text { Maximum jumping } \\
\text { height }(\mathbf{m})\end{array}$ & $\begin{array}{c}\text { Maximum darting } \\
\text { speed }(\mathbf{m} / \mathbf{s})\end{array}$ & $\begin{array}{c}\text { Average total length } \\
(\mathbf{m})\end{array}$ & Migratory season \\
\hline Alewife & Alosa pseudohar engus & 0.39 & 2.77 & 0.31 & Spring \\
\hline Alantic salmon & Salmo salar & 1.94 & 6.17 & 0.69 & Fall \\
\hline Brook trout & Salveltnus fontinalls & 0.37 & 2.70 & 0.30 & Fall \\
\hline Brown trout & Salmo trutta & 1.10 & 4.64 & 0.52 & Fall \\
\hline Chinook salmon & $\begin{array}{l}\text { Oncarhynchus } \\
\text { tshawytsch }\end{array}$ & 3.67 & 8.48 & & Summary \\
\hline Coho salmon & Oncarhynchus klsutch & 1.47 & 5.36 & 0.60 & Fall \\
\hline Creek chubsucker & Erimyzon oblongus & 0.23 & 2.13 & 0.24 & Spring \\
\hline Fantail darter & Etheostoma flaberllare & 0.01 & 0.47 & 0.05 & Spring \\
\hline Gizzard shad & Darosoma cepedianum & 0.34 & 2.59 & 0.29 & Spring \\
\hline Iowa darter & Etheostoma exile & 0.01 & 0.49 & 0.05 & Spring \\
\hline Johnny darter & Etheostoma nigrum & 0.01 & 0.39 & 0.04 & Spring \\
\hline Northern hog sucker & Hypenteltum nigricans & 0.37 & 2.68 & 0.30 & Spring \\
\hline Northern pike & Esox luctus & 1.49 & 5.40 & 0.60 & Spring \\
\hline Shorthead redhorse & Maxostoma \\
macrolepidotum & 0.57 & 3.36 & 0.37 & Spring \\
\hline Smallmouth bass & Micropterus dolomieu & 0.60 & 3.42 & 0.38 & Spring \\
\hline Spottail shiner & Notropis hudsonius & 0.04 & 0.85 & 0.09 & Summer \\
\hline Steelhead & Rainbow trout & 1.03 & 4.50 & 0.50 & Spring \\
\hline Walleye & Sander vitreus & 1.21 & 4.86 & 0.54 & Spring \\
\hline White perch & Morone americana & 0.0 .09 & 1.36 & 0.15 & Spring \\
\hline White sucker & $\begin{array}{l}\text { Catostomus commer } \\
\text { Sonill }\end{array}$ & 0.68 & 3.66 & 0.41 & Spring \\
\hline Yellow perch & Perca flavescens & 0.22 & 2.06 & 0.23 & Spring \\
\hline
\end{tabular}

Note, however, that the complex interactions between watershed characteristics and climate can cause significant variability in the flow discharge at the SMH facility over time. This would lead to variability in the flow discharge entering the fish passage module.

For typical types of fish passage, empirical relationships expressing the dependencies of flow velocity and depth parameters upon discharge, fish passage module geometry, and slope have been developed (Katopodis 1992). Experimental work has shown that the flow discharge expressed in dimensionless form is related to the dimensionless flow depth in a linear fashion for different types of fish passage modules (Figure 21). Considering the discharge and the flow depth in dimensionless form allows scaling of these relationships between experiment and prototype, while also accounting for the bed slope effects on discharge. Different fish passage module geometries (Figure 22) yield different slopes in the curves relating the discharge and the flow depth (Figure 21).

Similar relationships have been developed for predicting the flow velocity from the flow discharge in the fish passage module, as indicated in Figure 23. In this case, a power relationship between the flow velocity and the discharge was determined (Figure 23). The bed surface roughness may also affect the flow velocity and depth in the fish passage module (Chaudhry 2008). Its role is not as critical in artificial structures that are made of concrete and have rather smooth surfaces, but roughness may become important in nature-like fish passage modules with beds consisting of river sediment. In such cases, the increased bed roughness causes a larger energy loss in the approach flow and decelerates the flow velocity in the fish passage module. The flow velocity deceleration is larger as the roughness increases, which is positively related to the size of the bed material. 


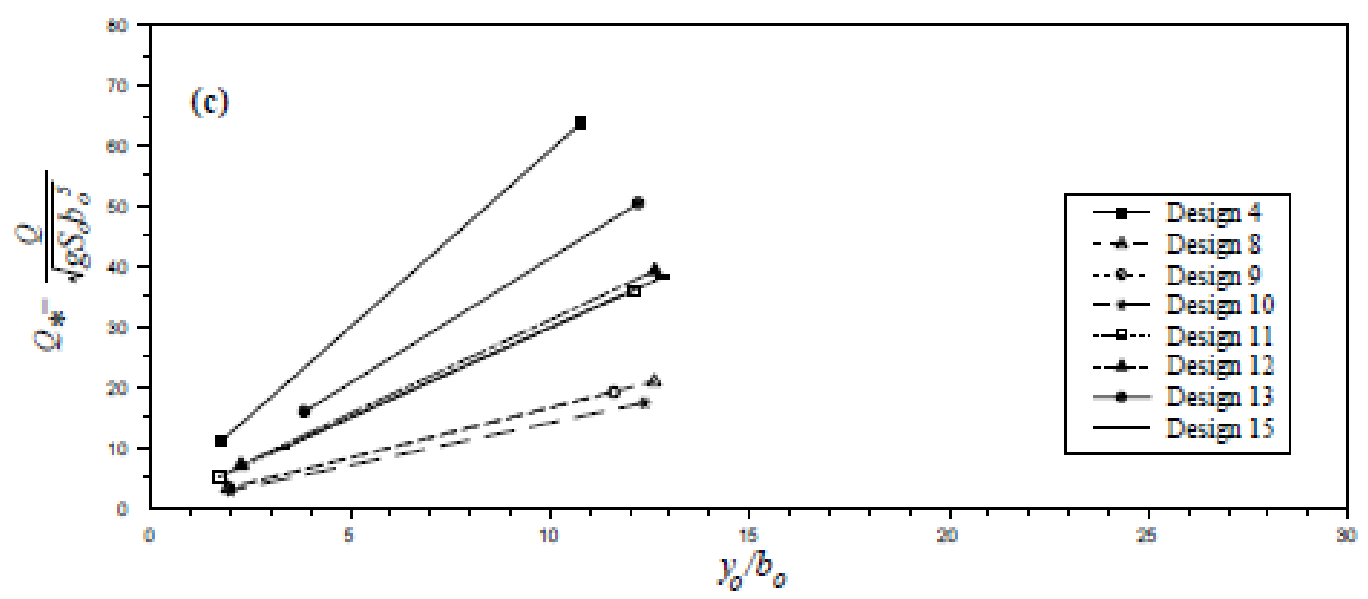

Figure 21. Relationship between the flow discharge, bed slope, and flow depth (Katopodis 1992). (Credit: Chris Katopodis, P. Eng. Freshwater Institute: Central and Artic Region) ${ }^{8}$
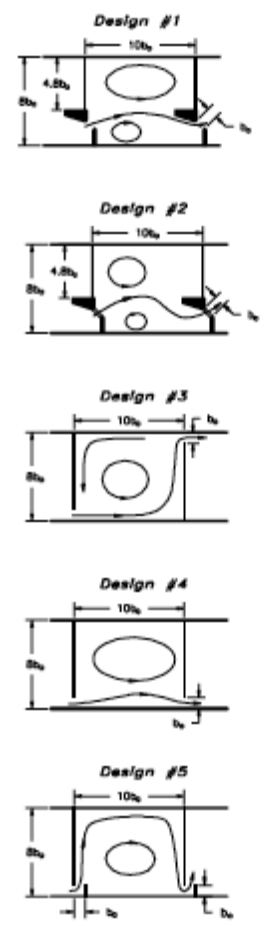
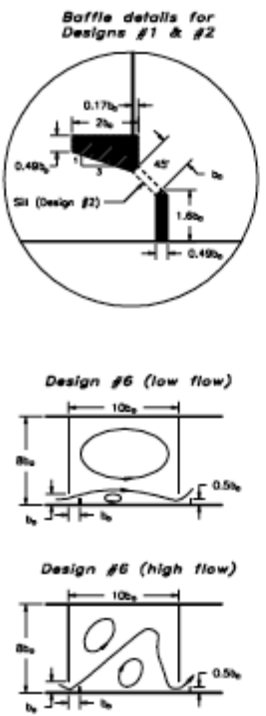

Dasign 17

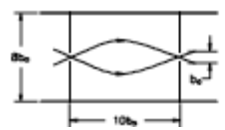

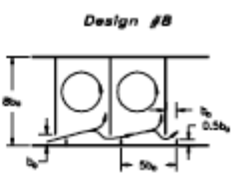

Deslon as

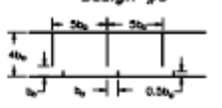

Destgn 10
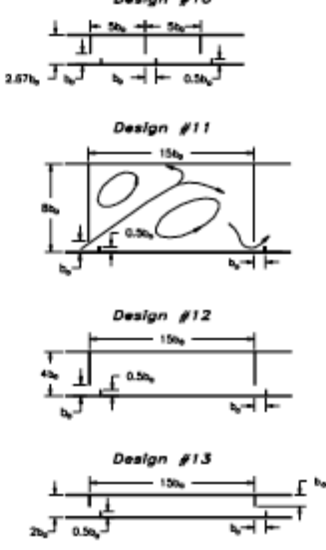
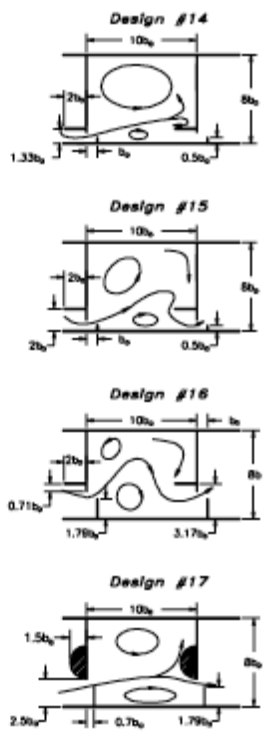

Deslgn 118

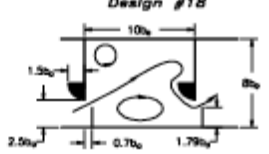

Figure 22. Geometries of different fish passage modules and the expected flow patterns. (Katopodis 1992). (Credit: Chris Katopodis, P. Eng. Freshwater Institute: Central and Artic Region) ${ }^{9}$

\footnotetext{
${ }^{8}$ This reproduction is a copy of an official work that is published and owned by the Government of Canada and has not been produced in affiliation with, or with the endorsement of the Government of Canada.

${ }^{9}$ This reproduction is a copy of an official work that is published and owned by the Government of Canada and has not been produced in affiliation with, or with the endorsement of the Government of Canada.
} 


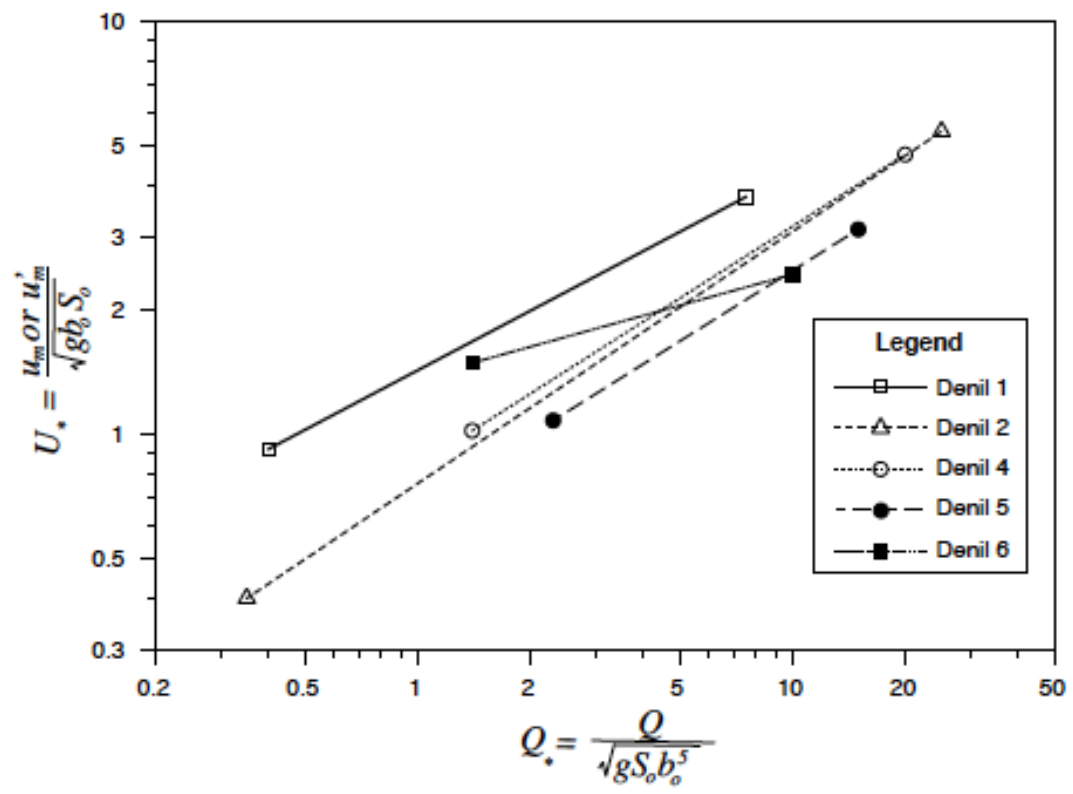

Figure 23. Relationship between the flow velocity (vertical axis) and discharge (horizontal axis) in the fish passage module (Katopodis 1992). (Credit: Chris Katopodis, P. Eng. Freshwater Institute: Central and Arctic Region) ${ }^{9}$

Note that the empirical relationships between velocity and flow discharge in the fish passage module predict a characteristic or average velocity within the passage module. Such relationships, however, do not provide an insight into the flow patterns within the fish passage module. The flow patterns in the module may become complex, with adverse consequences for fish orientation (Puertas et al. 2004; Liu et al. 2006; Tarrade et al. 2008; Wang et al. 2010; Marriner et al. 2014). As illustrated in the left panels of Figure 24, the fish passage module geometry can have a profound impact on the flow patterns, creating regions of high- and low-velocity fluid as well as recirculating flow. These flow features can lead to fish disorientation and excessive fatigue and will need to be minimized (OTA 1995).

Turbulence is another phenomenon that plays a key role in the hydraulics of the fish passage module. The level of turbulence is often quantified by the turbulent kinetic energy (TKE), with higher TKE indicating more turbulent flow. In general, the interaction of high-speed fluid with low-speed fluid, or the interaction of fluid with structures, leads to elevated levels of turbulence and higher TKE. For instance, turbulence is elevated at the entrances of fish passage modules (Figure 24), where the flow streamlines are constricted and high-speed fluid, represented by the darker regions in the center panels of Figure 24, interacts with low-speed fluid, represented with the lighter colors in the center panels of Figure 24.

At the same time, the fluid turbulence is dissipated by the friction of the fluid with the bed and among the fluid particles themselves. The dissipation of turbulence is quantified in an average sense over the volume of the fish passage module by the energy dissipation function (EDF) (Liu et al. 2006; Wang et al. 2010). It has been shown that the EDF is related to the flow discharge in the fish passage module, the slope of the module, and its plan view geometry, i.e., its length and width (Liu et al. 2006; Tarrade et al. 2008). Alternately, it has been shown that the EDF is a function of the velocity in the fish passage module and its length (Wang et al. 2010). The turbulent dissipation and hence EDF is related to the characteristic turbulent eddy length scales (Liu et al. 2006; Marriner et al. 2014). Therefore, some studies consider the turbulent eddy length scales, in place of the EDF, as comparison of the characteristic eddy length scale with the fish length offers a direct assessment of the suitability of a fish passage module in terms of turbulence (Papanicolaou and Maxwell 2000; Liu et al. 2006; Dermisis and Papanicolaou 2009). 

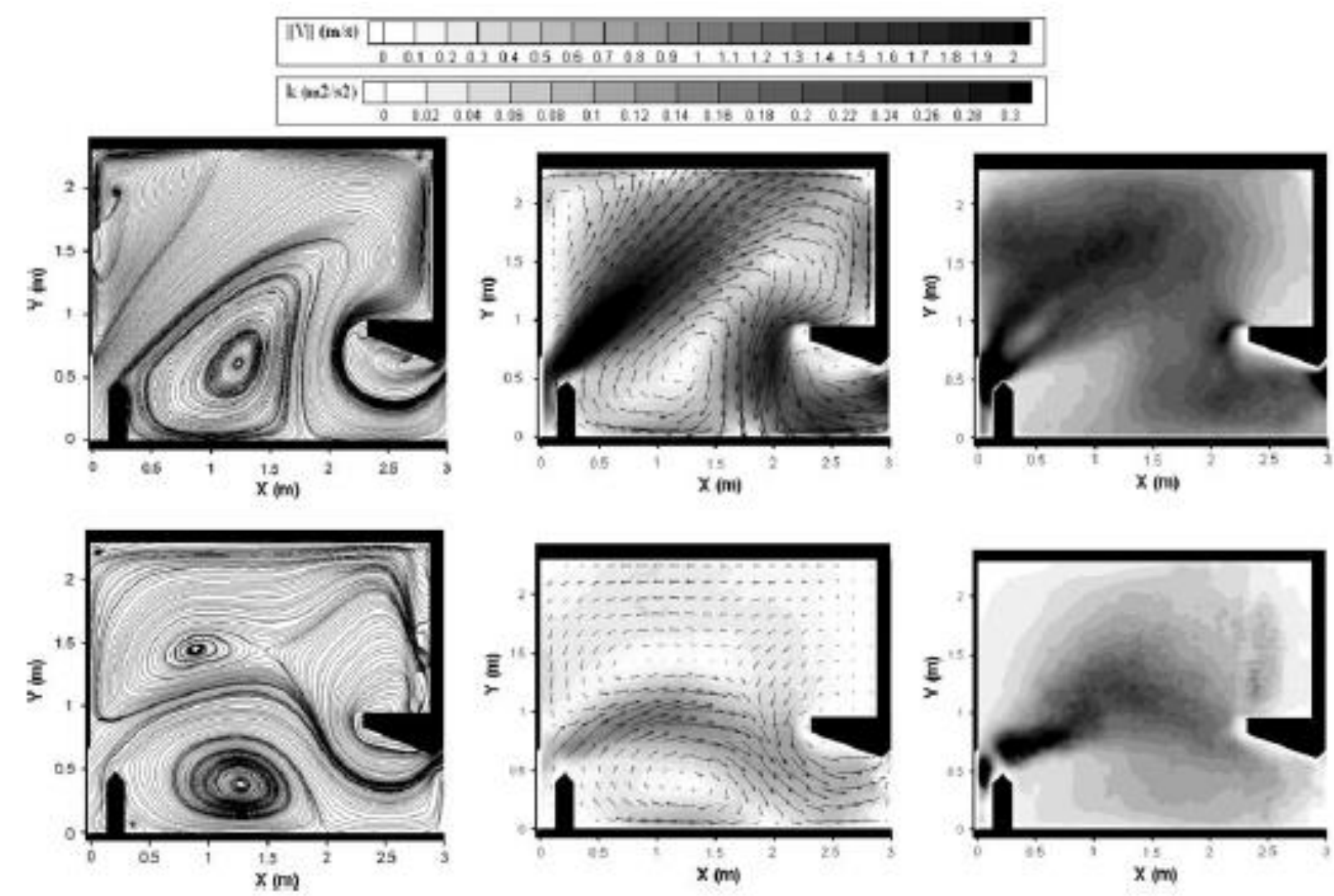

Figure 24. Flow patterns in fish passage modules of different geometry. The left panels illustrate the flow streamlines, the center panels the velocity magnitude, and the right panels the turbulent kinetic energy (TKE) within the fish passage module. Darker gray shades represent higher magnitudes of velocity and TKE. The top and bottom rows correspond to fish passage modules with bed slopes of 5 and $15 \%$, respectively. Flow enters from the bottom left and exits at the bottom right of each panel. (Tarrade et al. 2008; Copyright: Springer Science+Business Media

BV and FAO 2008; With permission of Springer)

Although an SMH facility might have a devoted sediment passage module, it is possible that sediment may enter into the fish passage module (OTA 1995). It is pertinent, therefore, to examine the key functional relationships that govern the transport of sediment, to the extent that they relate to sediment transported and deposited within the fish passage module. In general, coarser sediment that is transported in proximity to the bed is deposited when the flow transport capacity is smaller and the sediment supply from upstream exceeds the flow transport capacity (Yalin 1977). The sediment transport capacity is typically expressed as a function of the difference between the force applied by the flow and the threshold force that is required to set a coarse sediment grain of given size in motion (Yalin 1977). The applied flow force, also termed the "bed shear stress," is a function of the flow depth, the slope of the fish passage module bed, and the density and size of the sediment grains to be transported. The threshold stress, also known as the "critical bed shear stress for incipient motion," is broadly dependent on the heterogeneity of the bed material grains, their packing density, their shape, and their degree of protrusion into the flow (Yalin 1977; Wiberg and Smith 1987; Papanicolaou et al. 2002). On the other hand, finer sediment is typically transported in suspension. The suspended sediment is considered to settle out of suspension and deposit when a characteristic velocity length scale of the flow, termed the "friction velocity" is less than the settling velocity of the suspended sediment. The flow shear velocity is dependent on the flow depth and bed slope, whereas the fall velocity is determined from the sediment size and water temperature 
(Raudkivi 1998). These relationships inform fish passage module design, though if significant sediment issues are observed at a site they should be addressed with a sediment passage module.

\section{B.4 MEASURES OF MODULE PERFORMANCE}

Assessing the efficiency of the fish passage module in meeting the requirements listed in Appendix B.2 requires a set of quantifiable indices. Such indices will allow, in turn, evaluation of the efficiency with which the fish passage module accomplishes its specific and primary technical objectives.

To assess the performance of the fish passage module in terms of its primary technical objective of consistently and safely passing fish across an SMH facility, a key index is the fish passage rate, which indicates the proportion of fish (Table 13) that safely pass the SMH facility (Noonan et al. 2012). In addition, it is necessary to know the survival rate of the fish that do not pass through the module to identify features of the fish passage module or the flow patterns that contribute to fish mortality (Larinier 2000; CNRA 2013). The fish survival rate can be a useful index for assessing causes of indirect mortality once fish have passed the SMH facility as well, e.g., from predation of disoriented fish. Examination of the passage rates in conjunction with fish mortality rates can be helpful for identifying potential causes of fish disorientation and entrapment within the fish passage module. This assessment could also be assisted by examining the time delay (Table 13) that the fish passage module causes in fish migration (Katopodis 1992; OTA 1995; Larinier 2000; Schilt 2007).

Table 13. Measures of fish passage module performance

\begin{tabular}{|l|l|}
\hline \multicolumn{1}{|c|}{ Index } & \multicolumn{1}{c|}{ Status } \\
\hline Proportion of fish passing the module & More research needed \\
\hline Fish survival rate & More research needed \\
\hline Passage time delay & More research needed \\
\hline Fish injury & More research needed \\
\hline Proportion of fish entering fish passage entrance & More research needed \\
\hline Flow depth & Limits available \\
\hline Flow velocity & Limits available \\
\hline Fish passage module bed slope & Limits available \\
\hline Flow acceleration & More research needed \\
\hline Turbulent kinetic energy & Limits available \\
\hline Energy dissipation function & Limits available \\
\hline Turbulent eddy length scale & More research needed \\
\hline Fish passage module bed elevation change & More research needed \\
\hline
\end{tabular}

An additional index - which is important for quantifying the performance of the fish passage module in accomplishing the safe passage of fish - is injuries to exiting fish (Deng et al. 2005; Pracheil et al. 2016), where a correlation between fish injury and flow acceleration patterns has been shown.

For evaluating the performance of fish attraction devices, a quantitative index is the proportion of fish entering the fish passage module (Bunt 2001; Bunt et al. 2012; Cooke and Hinch 2013). This index can help identify which attraction techniques, e.g., barriers, vs. behavioral attraction devices, are optimal for the fish species encountered at the SMH facility.

Such indices aim at quantifying the performance of the fish passage module in terms of its primary technical objective of consistently and safely passing fish through the SMH facility. As alluded to in Appendices B.2 and B.3, however, the passage of fish through an SMH facility is intimately related to the hydraulics of the fish passage module. For this line of thinking, additional indices quantifying the 
performance of the fish passage module are also valuable (Katopodis 1992; OTA 1995). For instance, the flow depth and velocity within the fish passage module are known to relate to the quality of fish passage. Similarly, the bed slope of the fish passage module is known to influence the quality of fish passage (Dermisis and Papanicolaou 2009; Noonan et al. 2012). Research has shown that the flow acceleration, which is a surrogate of the flow patterns within the fish passage module, is related to fish injury (Deng et al. 2005; Richmond et al. 2009). In addition, indices characterizing the turbulence levels in the fish passage module are needed. The best-known indices for assessing the levels of turbulence are the TKE of the flow and the EDF. However, recent work has established a relationship of the EDF to the turbulent eddy characteristic length, which has thus gained popularity as a way of assessing the hydraulic performance of the fish passage. The main reason for the increasing popularity of the turbulent eddy characteristic length as a fish passage performance index is that it offers a tangible measure of the flow, which is directly comparable to fish length, which is a species-specific attribute (Liu et al. 2006; Dermisis and Papanicolaou 2009).

A simple but reliable measure of the fish passage module performance in terms of managing sediment is its bed surface elevation and size fraction. Deposition of sediment, which could affect the hydraulic performance of the fish passage module, would lead to a change in the elevation of the fish passage module bed. In addition, monitoring of changes in the bed elevation of the bed surface topography over time could allow estimation of the amount of incoming sediment and evaluation of countermeasures to sediment deposition.

\section{B.5 DESIGN CONSTRAINTS}

An examination of the fish passage module requirements (Appendix B.2) and functional relationships (Appendix B.3) allows the specification of design constraints for the fish passage module. The design constraints can be viewed as the behaviors and features that the fish passage module must exhibit to accomplish its primary technical objective of consistently and safely allowing the passage of fish across the SMH facility. These behaviors and features, summarized in Table 14, are derived by mapping the identified module requirements onto the functional relationships expressing the dominant processes that govern the fish passage module function. At present, we do not specify strict quantitative criteria for each of the design constraints, as the development of such criteria is beyond the scope of the present document. Instead, identification the fish passage module performance measures outlined in Appendix B.4 provides a basis for developing such quantitative criteria in the future. The design constraints examined in Table 14 are characterized as local when they pertain specifically to the fish passage module, and global when their validity can be extended to the other modules of the SMH facility.

Table 14. Fish passage module design constraints

\begin{tabular}{|l|l|c|}
\hline \multicolumn{1}{|c|}{ Constraint } & \multicolumn{1}{|c|}{ Formalization/rationale } & $\begin{array}{c}\text { Scale (L= local, } \\
\text { G = global) }\end{array}$ \\
\hline $\begin{array}{l}\text { Module elements cannot create } \\
\text { barriers or drops higher than } \\
\text { the jumping ability of } \\
\text { encountered fish species }\end{array}$ & $\begin{array}{l}\text { Module elements (e.g., steps, weirs) taller than the fish } \\
\text { jumping ability create a permanent barrier to fish movement. } \\
\text { Conversely, drops in elevation higher than the jumping } \\
\text { ability of fish may lead to fish injury or death }\end{array}$ & $\mathrm{L}$ \\
\hline $\begin{array}{l}\text { The module must create } \\
\text { favorable flow conditions at its } \\
\text { inlet for fish to enter }\end{array}$ & $\begin{array}{l}\text { The flow velocity, flow depth, and turbulence levels at the } \\
\text { module inlet are constrained by the swimming and } \\
\text { orientation ability of the encountered fish species }\end{array}$ & $\mathrm{L}$ \\
\hline $\begin{array}{l}\text { The fish passage module inlet } \\
\text { should feature fish attraction } \\
\text { devices }\end{array}$ & $\begin{array}{l}\text { The fish passage module should allow disoriented fish to find } \\
\text { its entrance }\end{array}$ & $\mathrm{L}$ \\
\hline $\begin{array}{l}\text { The fish passage module } \\
\text { should prevent fish from } \\
\text { entering the generation module }\end{array}$ & $\begin{array}{l}\text { The fish passage module should prevent disoriented fish from } \\
\text { entering the generation module }\end{array}$ & $\mathrm{L}, \mathrm{G}$ \\
\hline
\end{tabular}


Table 15. Fish passage module design constraints (continued)

\begin{tabular}{|c|c|c|}
\hline Constraint & Formalization/rationale & $\begin{array}{l}\text { Scale }(\mathrm{L}=\text { local, } \\
\mathrm{G}=\text { global })\end{array}$ \\
\hline Fish passage module slope & $\begin{array}{l}\text { The fish passage slope is constrained by the swimming } \\
\text { ability of fish }\end{array}$ & $\mathrm{L}, \mathrm{G}$ \\
\hline Flow velocity & $\begin{array}{l}\text { The velocity within and at the exit of the fish passage module } \\
\text { is constrained by the swimming ability of the encountered } \\
\text { fish species }\end{array}$ & \\
\hline Flow depth & $\begin{array}{l}\text { The flow depth within and at the exit of the fish passage } \\
\text { module is constrained by the minimum required flow depth } \\
\text { for the encountered fish species }\end{array}$ & $\mathrm{L}$ \\
\hline Fish passage module length & $\begin{array}{l}\text { The length of the fish passage module is constrained by the } \\
\text { endurance of the encountered fish species }\end{array}$ & $\mathrm{L}$ \\
\hline $\begin{array}{l}\text { Fish passage module flow } \\
\text { patterns }\end{array}$ & $\begin{array}{l}\text { The flow patterns within and at the exit of the fish passage } \\
\text { module are constrained by the susceptibility of fish to injury }\end{array}$ & $\mathrm{L}$ \\
\hline $\begin{array}{l}\text { Turbulence levels in the fish } \\
\text { passage module }\end{array}$ & $\begin{array}{l}\text { The turbulent kinetic energy, energy dissipation function, or } \\
\text { turbulent eddy characteristic length scale within and at the } \\
\text { exit of the fish passage module are constrained by the } \\
\text { tolerance of the fish for these quantities }\end{array}$ & $\mathrm{L}$ \\
\hline $\begin{array}{l}\text { Sediment accumulation within } \\
\text { fish passage module }\end{array}$ & $\begin{array}{l}\text { The accumulation of sediment within the fish passage } \\
\text { module is constrained by the maintenance of the required } \\
\text { flow velocity, depth, and pattern constraints }\end{array}$ & $\mathrm{L}$ \\
\hline $\begin{array}{l}\text { Air bubble concentration } \\
\text { within fish passage module }\end{array}$ & $\begin{array}{l}\text { The air bubble concentration in the fish passage module is } \\
\text { constrained by the tolerance of fish for the air bubbles }\end{array}$ & $\mathrm{L}$ \\
\hline $\begin{array}{l}\text { Module components cannot be } \\
\text { heavier than the lift capacity of } \\
\text { available cranes and transport } \\
\text { vehicles or vessels }\end{array}$ & $\begin{array}{l}\text { The module components must not exceed the capacity of } \\
\text { transport vehicles or vessels and available cranes, so that they } \\
\text { can be transported to the SMH site and placed }\end{array}$ & G \\
\hline $\begin{array}{l}\text { Module components cannot } \\
\text { exceed in size the size of } \\
\text { available transport vehicles or } \\
\text { vessels }\end{array}$ & $\begin{array}{l}\text { The module components must be smaller than the transport } \\
\text { vehicle or vessel to allow their transportation to the SMH site }\end{array}$ & $\bar{G}$ \\
\hline $\begin{array}{l}\text { Module components must be } \\
\text { compatible with one another }\end{array}$ & $\begin{array}{l}\text { The module components must connect with one another and } \\
\text { offer structural stability to the module }\end{array}$ & G \\
\hline $\begin{array}{l}\text { Module components must be } \\
\text { compatible with foundation } \\
\text { modules }\end{array}$ & $\begin{array}{l}\text { The module components must be compatible with the } \\
\text { foundation module to ensure the structural stability of the } \\
\text { module from the SMH facility foundation }\end{array}$ & G \\
\hline
\end{tabular}

It is also recognized herein that cost poses an additional design constraint, which plays a significant role in the identification of optimal designs. Cost optimization, or a balancing of the costs of implementation and operation versus the benefit of passage, must be pursued for every fish passage design to achieve objectives, requirements, and constraints that are appropriate for a site.

\section{B.6 DESIGN ENVELOPE SPECIFICATION}

This systematic examination of the fish passage module for an SMH facility has culminated in a list of design constraints for the fish passage module, the fulfillment of which ensures that the fish passage module accomplishes its primary technical objective of consistently and safely passing fish across the SMH facility. The design constraints identified in Table 14 may alternately be viewed as a design envelope for characteristics and behaviors that successful fish passage module designs must exhibit to ensure minimal disruption of the connectivity of the fish populations in a river by the SMH facility. Note that multiple fish passage module designs could fulfill these design constraints, but it is not the goal of the 
present report to identify the optimal design. To aid design, this report provides measures, identified in Appendix B.4, for evaluating the performance of potential designs and identifying the optimal one.

Specification of the fish passage module design envelope requires identifying limits for the fish passage module performance measures provided in Appendix B.4. Identification of these performance measure limits allows excluding potential fish passage module designs with performance outside the identified limits. For instance, a potential design for the fish passage module that allows flow velocities higher than the darting velocity of the fish species encountered at the SMH site should not be considered. As alluded to in Appendices B.2 and B.3, identification of such performance measure limits is subject to specific characteristics at the SMH facility site, such as the local fish species in the example just cited. It is possible to classify potential SMH sites with respect to some key, recurring characteristics that are pertinent to the design envelope specification of the fish passage module. Such a classification will allow the development of limits and designs that are applicable to a class of SMH sites with similar characteristics, thereby enhancing SMH standardization. Site classification, which is the second pillar of $\mathrm{SMH}$, is therefore of paramount importance for identifying the limits of the fish passage module design envelope, along with the other SMH pillars - simulation capability and testing capability.

To establish the exemplary design envelope, it is necessary to identify the pertinent spatial and temporal scales for the fish passage module performance measures. Identifying acceptable limits for fish passage rates for a given fish species would require identifying how far upstream and downstream from the SMH facility, and for how long, the SMH facility effects on the populations of this fish species are evident. The identification of these scales will also be aided by the other three pillars of SMH-site classification, simulation capability, and testing capability.

A limitation of the current analysis is that many of the functional relationships examined in Appendix B.3 are deterministic in nature and therefore can express the processes that they model only in a deterministic sense. The deterministic nature of these relationships implies that a given input to a process cause can have only the specific outcome predicted by the functional relationship; for example, a given discharge in the examined fish passage will lead to a given attraction rate of a particular fish species. Although a design may produce certain outcomes in an average sense, the complexity and randomness in nature may cause some variability around this predicted outcome. To account for the randomness prevalent in nature, probabilistic relationships for the studied processes should ultimately be developed. 


\section{APPENDIX C. SEDIMENT PASSAGE MODULE}

Hydropower facilities can act as barriers to the movement of sediment along a river, disrupting the connectivity of sediment transport. This disruption has important implications for the river morphology upstream and downstream of the hydropower facility (Schmidt and Wilcock 2008; Draut et al. 2011). Most commonly, sediment is trapped and deposited upstream of a facility, thus reducing the water volume and head available for power generation (Brune 1953). At the same time, entrapment of incoming sediment upstream of the hydropower facility limits the supply of sediment downstream, thus affecting the river morphology and planform geometry upstream and downstream of the hydropower facility, as well as the channel stability and aquatic habitat.

There is uncertainty surrounding the need for a sediment passage module at small hydropower facilitiessedimentation at large reservoirs has received significant attention in the literature (Kondolf et al. 2014) although few design guidelines exist for sediment passage at small, low-head hydropower facilities. This section will not provide the information necessary to determine whether a sediment passage module is necessary at a site. Rather, it assumes a sediment passage module is necessary to sustain the natural stream function of sediment transport. It is possible that sediment passage could be achieved through other modules, such as suspended load passed over a water passage module. This multi-objective approach is the subject of ongoing research.

\section{C.1 OBJECTIVES}

To minimize the effects caused by the disruption in the continuity of sediment transport along a river resulting from the presence of the SMH facility, the sediment supplied from upstream must be transported across the SMH facility (Annandale 2013; Kondolf et al. 2014; Wild et al. 2015). Thus, the transport of sediment through the SMH facility is the primary technical objective of the sediment passage module.

Sediment Passage Module Primary Technical Objective

To allow the transport of incoming sediment through a SMH facility

To achieve the primary technical objective, the sediment passage module needs to intercept incoming sediment from upstream while preventing its deposition upstream of the SMH facility (Figure 25). Furthermore, the sediment passage module must maintain hydraulic conditions that allow the transport of the supplied sediment through the SMH facility (Figure 25). The sediment routed across the SMH facility must be transported further downstream to prevent its accumulation at the downstream end of the facility, which might compromise the function of the other modules, such as the fish passage and the generation module. The amount of sediment passing the SMH facility via the sediment passage module must be sufficient to prevent degradation problems in the downstream river, such as channel incision and overdeepening, bank erosion, and river channel migration. At the same time, the sediment transport fluxes downstream of the hydropower facility must be such that fish habitat degradation, caused by these river geomorphological changes or the intermittent sediment supply, is minimized. Attention must be also given to maintaining the river water quality, which can be affected by the release and transport of finer sediments that are typically transported in suspension (Figure 25). In summary, to achieve its primary technical objective, the sediment passage module must accomplish a series of specific objectives:

1. Deliver incoming sediment supply to sediment passage module inlet.

2. Sustain conditions for transporting sediment across passage module.

3. Minimize sediment deposition downstream of the SMH facility. 
4. Minimize river geomorphic change further upstream and downstream of SMH facility.

5. Minimize fish habitat and water quality degradation due to sediment releases.

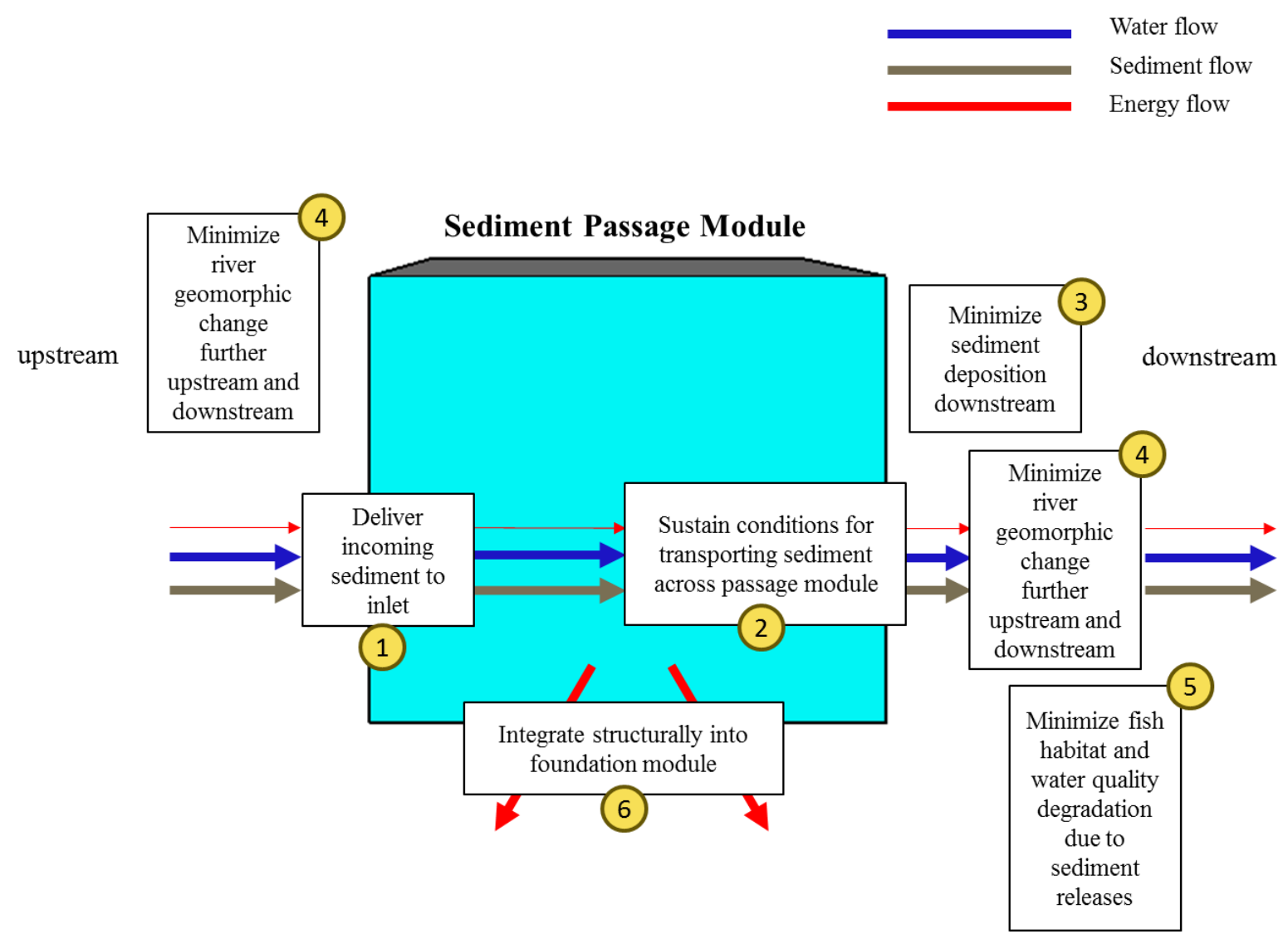

Figure 25. Conceptual schematic of the specific objectives of a sediment passage module.

\section{C.2 REQUIREMENTS}

The requirements for the sediment passage module are quantifiable characteristics or behaviors that the sediment passage module must exhibit to satisfy its specific objectives and thereby its primary technical objective. The requirements for the sediment passage module are summarized in Table 16, where they are grouped for each specific objective of the sediment passage module. This grouping highlights the connection of the requirements with the specific objectives and thereby with the primary technical objective of the sediment passage module. In Table 16, the module requirements are characterized as Functional, Performance, Interface, and Other, similar to the requirements for the fish passage and other modules (Appendix B.2). Furthermore, in Table 16 the relationship of each functional requirement for the sediment passage module to the five constituents of the river continuum-water, sediment, energy, organisms, and nutrients - is indicated in an analogous manner to the functional requirements for the fish passage module (Appendix B.2).

For the sediment passage module to be able to convey sediment downstream of the SMH facility, it is imperative that the sediment pass through the module inlet. As the flow decelerates upstream of an SMH facility, its competence to transport sediment decreases. As a result, incoming sediment is likely to deposit upstream of the SMH facility and not enter the sediment passage module, thereby not allowing the sediment passage module to accomplish its primary technical objective. The resulting sediment deposition upstream of the SMH facility, if left uncontrolled, can reduce the available head for power generation by 
the generation module, thereby limiting the generation module efficiency. In extreme cases, the sediment deposited upstream of the generation module could possibly block its intake, interrupting its operation, and/or be entrained into the generation module intake, damaging the turbines. To minimize this risk, the

Table 16. Sediment passage module requirements. In the fourth column: $\mathrm{F}=$ Functional; $\mathrm{P}=$ Performance; $\mathrm{I}=$ Interaction; $\mathrm{O}=$ other. In columns $6-11$, an " $\mathrm{X}$ " denotes a relationship to the river continuum constituent indicated in the top row

\begin{tabular}{|c|c|c|c|c|c|c|c|c|c|c|}
\hline & & Requirement & $\begin{array}{c}\text { Type } \\
(\mathbf{F} / \mathbf{P} / \mathbf{I} / \mathbf{O})\end{array}$ & Formalization/rationale & 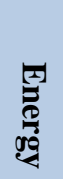 & 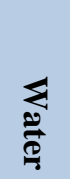 & 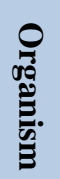 & 足: & 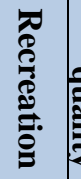 & : \\
\hline 1 & & $\begin{array}{l}\text { Deliver incoming sediment } \\
\text { supply to the sediment } \\
\text { passage inlet. }\end{array}$ & & & & & & & & \\
\hline & $\mathrm{a}$ & $\begin{array}{l}\text { Sustain appropriate hydraulic } \\
\text { conditions and flow patterns } \\
\text { to minimize sediment } \\
\text { deposition and ensure } \\
\text { transport of sediment to the } \\
\text { sediment passage module } \\
\text { inlet }\end{array}$ & $\mathrm{F}, \mathrm{P}, \mathrm{I}$ & $\begin{array}{l}\text { Upstream of the sediment } \\
\text { passage module, sediment } \\
\text { should be prevented from } \\
\text { depositing upstream of the } \\
\text { SMH facility, where } \\
\text { aggradation can reduce the head } \\
\text { used by the generation module } \\
\text { (GM) or clog the GM intakes }\end{array}$ & $\mathrm{X}$ & $\mathrm{X}$ & & $\mathrm{X}$ & & $\mathrm{X}$ \\
\hline & $\mathrm{b}$ & $\begin{array}{l}\text { Use mechanical means: } \\
\text { walls, traps, screens }\end{array}$ & $\mathrm{F}$ & $\begin{array}{l}\text { Special barriers may be } \\
\text { needed to route incoming } \\
\text { sediment to the passage } \\
\text { module inlet and prevent it } \\
\text { from entering the GM intake }\end{array}$ & & $\mathrm{X}$ & & $\mathrm{X}$ & & \\
\hline 2 & & $\begin{array}{c}\text { Sustain conditions for } \\
\text { transporting sediment across } \\
\text { passage module }\end{array}$ & & & & & & & & \\
\hline & $\mathrm{a}$ & $\begin{array}{l}\text { Divert a sufficient portion of } \\
\text { the river flow }\end{array}$ & $\mathrm{F}, \mathrm{I}$ & $\begin{array}{l}\text { A portion of the river flow } \\
\text { must be diverted into the } \\
\text { sediment passage module to } \\
\text { transport sediment } \\
\text { downstream. This portion is } \\
\text { thus not used by the GM or the } \\
\text { other modules }\end{array}$ & $\mathrm{X}$ & $\mathrm{X}$ & & $\mathrm{X}$ & & \\
\hline & $\mathrm{b}$ & $\begin{array}{l}\text { Sustain appropriate hydraulic } \\
\text { conditions and flow patterns } \\
\text { to ensure transport of } \\
\text { sediment through the module }\end{array}$ & $\mathrm{F}, \mathrm{P}$ & $\begin{array}{l}\text { The hydraulic conditions } \\
\text { within the sediment passage } \\
\text { module should correspond to } \\
\text { sufficient transport capacity } \\
\text { for the amount and sizes of } \\
\text { sediment encountered in the } \\
\text { river }\end{array}$ & $\mathrm{X}$ & $\mathrm{X}$ & & $\mathrm{X}$ & & \\
\hline 3 & & $\begin{array}{l}\text { Minimize sediment } \\
\text { deposition downstream of } \\
\text { the SMH facility }\end{array}$ & & & & & & & & \\
\hline & $\mathrm{a}$ & $\begin{array}{l}\text { Sustain appropriate hydraulic } \\
\text { conditions and flow patterns } \\
\text { to ensure transport of } \\
\text { sediment through the module }\end{array}$ & $\mathrm{F}, \mathrm{P}$ & $\begin{array}{l}\text { The flow conditions and } \\
\text { patterns at the exit of the } \\
\text { sediment passage module must } \\
\text { have the capacity to transport } \\
\text { the exiting sediment amounts } \\
\text { and sizes further downstream }\end{array}$ & & & & & & \\
\hline
\end{tabular}


Table 15. Sediment passage module requirements (continued)

\begin{tabular}{|c|c|c|c|c|c|c|c|c|c|c|}
\hline & & Requirement & $\begin{array}{c}\text { Type } \\
(\mathbf{F} / \mathbf{P} / \mathbf{I} / \mathbf{O})\end{array}$ & Formalization/rationale & 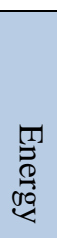 & $\sum_{\substack{\oplus \\
\oplus}}$ & 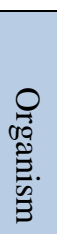 & 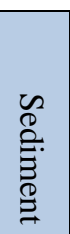 & 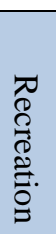 & 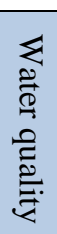 \\
\hline 4 & & $\begin{array}{l}\text { Minimize river geomorphic } \\
\text { change further upstream and } \\
\text { downstream of SMH facility }\end{array}$ & & & & & & & & \\
\hline & $\mathrm{a}$ & $\begin{array}{l}\text { Minimize channel narrowing } \\
\text { and incision }\end{array}$ & $\mathrm{F}, \mathrm{P}, \mathrm{I}$ & $\begin{array}{l}\text { When sediment supply from } \\
\text { upstream is disrupted, the river } \\
\text { flow tends to erode sediment } \\
\text { from the bed, causing channel } \\
\text { incision }\end{array}$ & & $\mathrm{X}$ & & $\mathrm{X}$ & & \\
\hline & $\mathrm{b}$ & Minimize channel armoring & $\mathrm{F}, \mathrm{P}, \mathrm{I}$ & $\begin{array}{l}\text { When sediment supply from } \\
\text { upstream is disrupted, finer } \\
\text { sediment is gradually } \\
\text { winnowed away by the flow. } \\
\text { This leaves the coarser } \\
\text { immobile sediment that creates } \\
\text { an armoring layer on the bed, } \\
\text { preventing further erosion }\end{array}$ & & $\mathrm{X}$ & & $\mathrm{X}$ & & \\
\hline & $\mathrm{c}$ & Minimize bank erosion & $\mathrm{F}, \mathrm{P}, \mathrm{I}$ & $\begin{array}{l}\text { Lack of entrainable bed } \\
\text { sediment can lead to erosion of } \\
\text { bank material }\end{array}$ & & $\mathrm{X}$ & & $\mathrm{X}$ & & \\
\hline & $\mathrm{d}$ & $\begin{array}{l}\text { Minimize changes in stream } \\
\text { planform geometry }\end{array}$ & $\mathrm{F}, \mathrm{P}, \mathrm{I}$ & $\begin{array}{l}\text { Excessive bank erosion can } \\
\text { lead to lateral river channel } \\
\text { migration and the development } \\
\text { of a meandering river plan } \\
\text { view geometry }\end{array}$ & & $\mathrm{X}$ & & $\mathrm{X}$ & & \\
\hline 5 & & $\begin{array}{l}\text { Minimize fish habitat and } \\
\text { water quality degradation } \\
\text { due to sediment releases }\end{array}$ & & & & & & & & \\
\hline & $\mathrm{a}$ & $\begin{array}{l}\text { Sustain hydraulic conditions } \\
\text { to minimize settling and } \\
\text { intrusion of fine sediment } \\
\text { into the river bed substrate }\end{array}$ & $\mathrm{F}, \mathrm{P}, \mathrm{I}$ & $\begin{array}{l}\text { Intrusion of suspended } \\
\text { sediment into the bed } \\
\text { interstices causes suffocation } \\
\text { of the fish eggs laid there }\end{array}$ & & $\mathrm{X}$ & $\mathrm{X}$ & $\mathrm{X}$ & & \\
\hline & $\mathrm{b}$ & $\begin{array}{l}\text { Sustain hydraulic conditions } \\
\text { to minimize suspended } \\
\text { sediment concentration }\end{array}$ & $\mathrm{F}, \mathrm{P}$ & $\begin{array}{l}\text { Excessive concentration of } \\
\text { suspended sediment in the } \\
\text { water degrades water quality }\end{array}$ & & $\mathrm{X}$ & $\mathrm{X}$ & $\mathrm{X}$ & & $\mathrm{X}$ \\
\hline 6 & & $\begin{array}{l}\text { Integrate structurally into } \\
\text { foundation module }\end{array}$ & & & & & & & & \\
\hline & $\mathrm{a}$ & $\begin{array}{l}\text { Transmit all forces through } \\
\text { non-critical components into } \\
\text { the foundation module }\end{array}$ & $\mathrm{F}, \mathrm{P}, \mathrm{I}$ & $\begin{array}{l}\text { The sediment passage module } \\
\text { will be supported instream by } \\
\text { a foundation module that } \\
\text { serves as an interface to the } \\
\text { streambed }\end{array}$ & $\mathrm{X}$ & & & & & \\
\hline
\end{tabular}

sediment passage module must sustain appropriate flow conditions that allow incoming sediment to be transported through its inlet. Appropriate diversion structures, such as walls, submerged vanes, or screens, can be used to constrict and accelerate the flow, allowing the movement of the incoming sediment into the sediment passage module. Also, because the proper operation of the generation module is a fundamental 
goal of the SMH facility, the generation module entrance must be protected by appropriate barriers against sediment motion, such as screens, walls, or sediment traps.

A key requirement for the sediment passage module is to keep the sediment entering in motion so that it can be transported across the SMH facility. As in the fish passage module (Appendix B.2), a portion of the river flow must be diverted in the sediment passage module to maintain a sufficient transport capacity to transport all sizes of incoming sediment. If this minimum transport capacity is not maintained, the sediment will deposit within the sediment passage module (Raudkivi 1998) and, over time, the sediment passage module may be unable to transport sediment across the SMH facility.

Because of the obstruction that the SMH facility poses to the river flow, the flow downstream of the SMH facility is significantly decelerated and may thus lack the transport capacity required to transport exiting sediment further downstream. As a result, the sediment exiting the sediment passage module may deposit in its vicinity, preventing the transport of additional sediment. More important, as sediment progressively accumulates downstream of the SMH facility, the river bed surface elevation will increase, leading to a corresponding increase in the tailwater surface elevation. The increase in the tailwater elevation will decrease the available head for production of energy by the generation module. The sediment passage module is therefore required to maintain appropriate flow conditions at its exit so that sediment exiting the sediment passage module is transported further downstream in the river.

The placement of the SMH facility disrupts the connectivity of sediment transport along the river, which limits the supply of sediment downstream of the SMH facility (Papanicolaou 2011, p. 83). In these downstream river reaches, the shortage of entrainable sediment from upstream causes an increase in the transport of sediment from the river bed, which in turn causes incision of the river channel by the flow action (Gaeuman et al. 2005; Grams et al. 2007; Magilligan et al. 2013). The channel incision can become particularly pronounced when there is a lack of lateral sediment input to the river reaches downstream of the SMH facility from the adjacent watershed, which intensifies the shortage of entrainable sediment supply. The channel incision may be accompanied by channel armoring, which occurs when most of the entrainable material has been transported downstream and only coarser material, which cannot be entrained, remains at the river bed surface. Once river bed armoring takes place, and if the lack of entrainable sediment supply persists, the river flow may accelerate the erosion of the banks, which is the only remaining erodible material. Accelerated river bank erosion can lead to lateral migration of the river channel and therefore a change in the river planform geometry with the development of river meanders. Such changes in the river planform geometry may compromise the safety and stability of structures, such as bridges and roads, that were adjacent to the original river channel. To prevent such significant geomorphological changes to the river, it is necessary that the sediment passage module provide a sufficient supply of sediment downstream of the SMH module.

\section{C.3 INPUTS, FUNCTIONAL RELATIONSHIPS AND PROCESSES}

The processes relevant to the operation and behavior of the sediment passage module are identified in the current section, along with the functional relationships that allow quantification and prediction of these processes. Knowledge of these processes and functional relationships is a key step for understanding the function and predicting the behavior of the sediment passage module so that the design of the sediment passage module minimizes the disruption of the sediment transport continuity along the river length due to the hydropower facility. The key variables, which are the inputs to these functional relationships, are identified first. 


\section{C.3.1 Necessary Inputs}

The key variables, which appear in the functional relationships for the sediment passage module, are presented in Table 17. These variables are categorized in five categories, depending on their relation to sediment, flow, geometric, and geomorphologic processes. This categorization will further allow the systematic examination of the functional relationships to which these inputs relate.

Table 17. Key inputs for the function of the sediment passage module

\begin{tabular}{|l|l|}
\hline \multicolumn{1}{|c|}{$\begin{array}{c}\text { Identification of } \\
\text { key inputs }\end{array}$} & \multicolumn{1}{c|}{ Formalization } \\
\hline Sediment characteristic variables & $\begin{array}{l}\text { Sediment grain size distribution (e.g., median grain diameter, } \\
\text { geometric standard deviation), friction factor, sediment fall velocity, } \\
\text { sediment angularity, sediment shape, relative protrusion }\end{array}$ \\
\hline Flow variables & $\begin{array}{l}\text { Range of flow discharges encountered, watershed hydrologic } \\
\text { characteristics, flow depth, turbulent shear stress, water temperature, } \\
\text { friction factor }\end{array}$ \\
\hline Geometric variables & $\begin{array}{l}\text { Geometry and shape of passage module, elevation difference upstream } \\
\text { and downstream of facility, passage module slope, passage module } \\
\text { length, stream cross-sectional geometry upstream and downstream of } \\
\text { SMH facility }\end{array}$ \\
\hline Geomorphologic variables & $\begin{array}{l}\text { River bed slope, bed topography, friction factor, channel sinuosity, } \\
\text { bank geometry, bank soil composition }\end{array}$ \\
\hline
\end{tabular}

\section{C.3.2 Functional Relationships}

The functional relationships, which express the processes that govern the transport of sediment and hence the operation of the sediment passage module, are summarized in Table 18, along with a brief rationale for the importance of each functional relationship.

To systematically investigate the functional relationships relevant to the operation of the sediment passage module, it is necessary to divide the transport of sediment into two types - bedload and suspended load (Raudkivi 1998). Bedload is the mode of transport predominantly of coarser materialssuch as coarse sand, gravel, and cobbles - which move in close proximity to the bed. In contrast, the finer sediment - including the finer sand, silt and clay — is transported in suspension within the water column and constitutes the suspended sediment load (Raudkivi 1998). The processes that govern the movement of bedload and suspended load are different; therefore, the functional relationships governing their transport are examined separately (Table 18).

Broadly, the bedload transport rate is considered a function of excess bed shear stress (Figure 26), which expresses the difference between applied bed shear stress and critical bed shear stress for incipient motion of the grains (Yalin 1977; Wong and Parker 2006; Parker 2008). The applied bed shear stress quantifies the force applied by the flow that is available to set the sediment grains in motion. 
Table 18. Summary of the key functional relationships relevant to operation of the sediment passage module

\begin{tabular}{|c|c|c|}
\hline Relationship of & To & Rationale/importance \\
\hline $\begin{array}{l}\text { Bedload transport } \\
\text { rate }\end{array}$ & $\begin{array}{l}\text { 1. Mean flow } \\
\text { characteristics and } \\
\text { patterns } \\
\text { 2. Turbulent flow } \\
\text { characteristics } \\
\text { 3. Bed morphology } \\
\text { 4. Critical bed shear } \\
\text { stress for incipient } \\
\text { motion }\end{array}$ & $\begin{array}{l}\text { 1. The main drivers of the bedload transport rate are the mean } \\
\text { flow characteristics, which are quantified by the bed shear stress } \\
\text { or stream power } \\
\text { 2. At near-incipient conditions, turbulence may increase the } \\
\text { instantaneously applied shear stress to the sediment and lead to an } \\
\text { increase in bedload rates and bedload intermittency } \\
\text { 3. Bedforms and/or other large roughness elements (e.g., } \\
\text { boulders, large woody debris) bear a portion of the applied bed } \\
\text { shear stress, hence reducing the bedload rates } \\
\text { 4. Sediment is transported as bedload as the applied bed shear } \\
\text { stress by the flow exceeds the critical shear stress for incipient } \\
\text { motion for a given sediment size }\end{array}$ \\
\hline $\begin{array}{l}\text { Critical bed shear } \\
\text { stress for incipient } \\
\text { motion }\end{array}$ & $\begin{array}{l}\text { Sediment } \\
\text { characteristics }\end{array}$ & $\begin{array}{l}\text { The critical shear stress for incipient motion is dependent on } \\
\text { sediment size, size distribution (e.g., hiding effects), and the } \\
\text { relative protrusion of the bed sediments }\end{array}$ \\
\hline $\begin{array}{l}\text { Suspended sediment } \\
\text { concentration }\end{array}$ & $\begin{array}{l}\text { 1. Mean flow } \\
\text { characteristics and } \\
\text { patterns } \\
\text { 2. Turbulent flow } \\
\text { characteristics } \\
\text { 3. Supplied } \\
\text { sediment } \\
\text { 4. Settling velocity }\end{array}$ & $\begin{array}{l}\text { 1. The mean flow velocity is the main driver for the } \\
\text { transportation of suspended sediment downstream } \\
\text { 2. Turbulence causes diffusion and mixing of the transported } \\
\text { sediment concentration } \\
\text { 3. The amount of sediment transported downstream in suspension } \\
\text { is dependent on the amount of sediment supplied from upstream } \\
\text { 4. The sediment settling velocity quantifies the tendency of } \\
\text { sediment to deposit or remain in suspension }\end{array}$ \\
\hline $\begin{array}{l}\text { River morphological } \\
\text { change }\end{array}$ & $\begin{array}{l}\text { 1. Bedload and } \\
\text { suspended sediment } \\
\text { transport capacity } \\
\text { 2. Bank properties }\end{array}$ & $\begin{array}{l}\text { 1. The transport capacity of a river determines the amount of } \\
\text { sediment that the river can transport for a given set of flow and } \\
\text { sediment conditions. Imbalances between sediment transport } \\
\text { capacity and supply result in aggradation or degradation of the } \\
\text { river } \\
\text { 2. The type of material and geometry of the river banks determine } \\
\text { how prone the river is to lateral migration and change in its } \\
\text { planform geometry }\end{array}$ \\
\hline
\end{tabular}

The applied bed shear stress is considered to be a function of the flow depth, the slope of the sediment passage module bed, and the density and the size of the sediment grains to be transported. Because the bed shear stress is a function of the flow depth, it follows that indirectly it is dependent on the variables that influence the flow depth in a river. As a result, the bed shear stress is also dependent on the flow discharge and the resistance exhibited by the river bed surface to the flowing water. As is presented in detail in Appendix $\mathrm{E}$ of this report, resistance to the river flow is, in turn, related to the size distribution of the sediment grains making up the river bed. Overall, resistance to flow, and hence the friction factor, which is a quantitative measure of resistance, increases with larger bed grain sizes. The friction factor is also a function of the relative submergence - the ratio of the flow depth to the characteristic height of the sediment making up the bed. In rivers with large roughness elements, such as large boulders, bedforms, and logs, it is possible for the flow depth to be less than the sizes of these elements. Under such conditions, the friction factor becomes an inverse function of the relative submergence, i.e., the ratio of the flow depth and the roughness element size (Millar 1999; Ferguson 2007; Rickenmann and Recking 2011). 


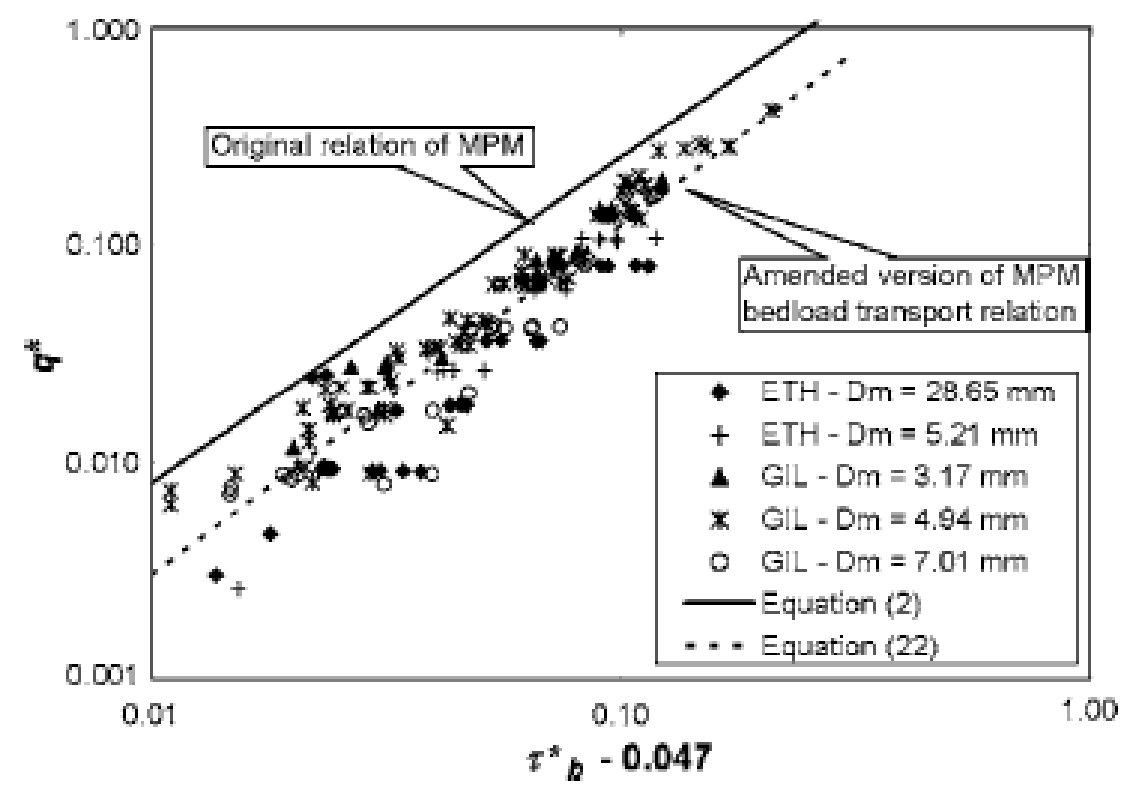

Figure 26. Correlation of the bedload transport rate (vertical axis) with the excess bed shear stress (horizontal axis). The critical bed shear stress is considered equal to 0.047. (Wong and Parker 2006; With permission from ASCE)

The critical bed shear stress for incipient motion is the minimum amount of force applied by the flow that is required to set a grain with a given size in motion. The critical bed shear stress for incipient motion is broadly dependent on the size and heterogeneity of the bed material grains, their packing density, their shape, and their degree of protrusion into the flow (Yalin 1977; Wiberg and Smith 1987; Papanicolaou et al. 2002). Clearly, larger grains are heavier and require more force applied by the flow to be entrained. At the same time, the heterogeneity of the bed material plays an important role in the critical bed shear stress for incipient motion. Specifically, when both larger and smaller grains are present atop the river bed, the larger and thus more stable grains hide the smaller grains from the flow action, thereby reducing the likelihood that smaller grains will be entrained (Parker 2008; Kleinhans and van Rijn 2002). Similarly, when the packing density of the entrainable sediment increases, it is more unlikely that sediment grains will be dislodged and transported by the flow. The shapes of sediment particles also influence their critical stress for incipient motion. More elongated grains are more stable and tend to be harder for the flow to entrain, compared with more round grains. Also, sediment grains, which are more angular, tend to interlock more strongly with the bed substrate grains and therefore require more force from the flow to be entrained. The sediment grain protrusion also plays an influential role on the entrainment of the grains. As the degree of grain protrusion decreases, the area of the grain exposed to the flow action decreases, and thus a higher force is required to entrain the grain (Figure 27) (Wiberg and Smith 1987).

Finer sediment is typically transported in suspension (Raudkivi 1998). The suspended sediment is considered to settle out of suspension and deposit when a characteristic velocity length scale of the flow called "friction velocity" is less than the settling velocity of the suspended sediment (Figure 28). The flow shear velocity is a surrogate measure of the bed shear stress and depends on the flow depth and bed slope, while the fall velocity is determined from the sediment size and water temperature (Raudkivi 1998). 


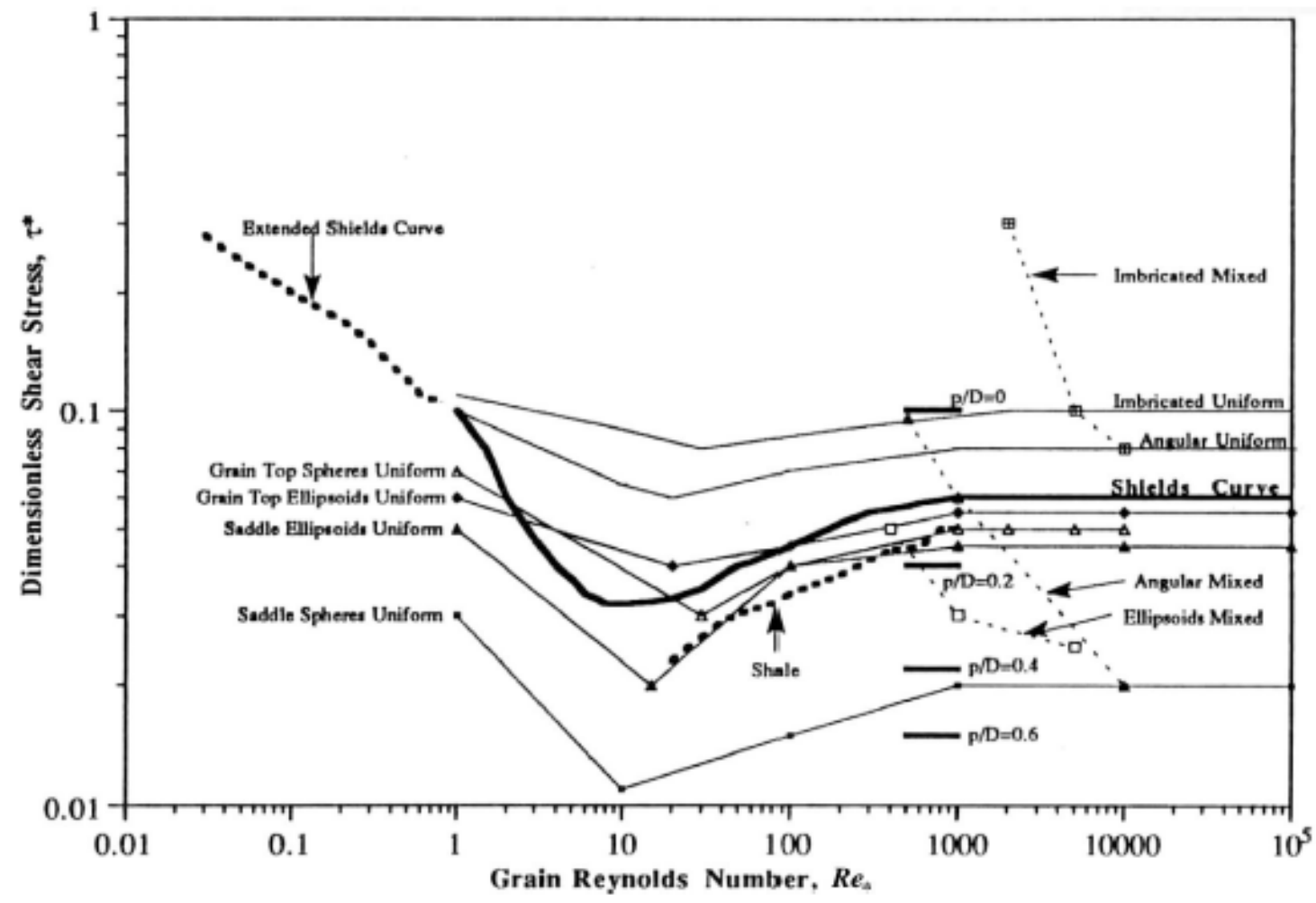

Figure 27. Critical shear stress as a function of the grain Reynolds number for different degrees of grain protrusion, denoted as (p/D), in relation to the flow and different grain shapes. (After Moore 1994 in

Papanicolaou and Abban et al. 2016)

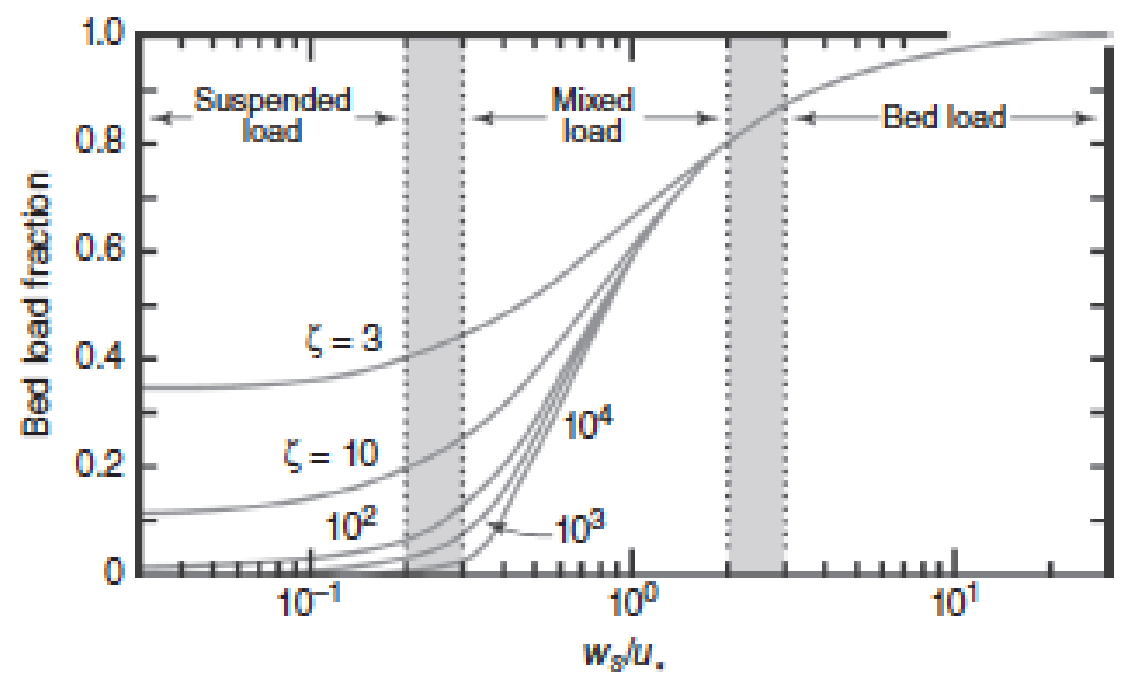

Figure 28. Percentage of sediment transported as bed load and suspended load as a function of the ratio of sediment fall velocity to friction velocity. (After Papanicolaou and Abban 2016)

The amount of suspended sediment being transported by the flow is known as the "suspended load flux." It is the product of the flow velocity and the suspended sediment concentration (Figure 29). As discussed in detail in Appendix $\mathrm{E}$ of this report, the flow velocity in the river or within the sediment passage module depends on the flow discharge, the cross-sectional geometry, the bed resistance, and the bed slope. The 
suspended sediment concentration expresses the amount of sediment in suspension in the water column, which may come from three sources: (1) sediment yield from the watershed, (2) erosion and uplift from the river bed, and (3) erosion from the river banks. These three sources are examined separately in the following paragraphs.

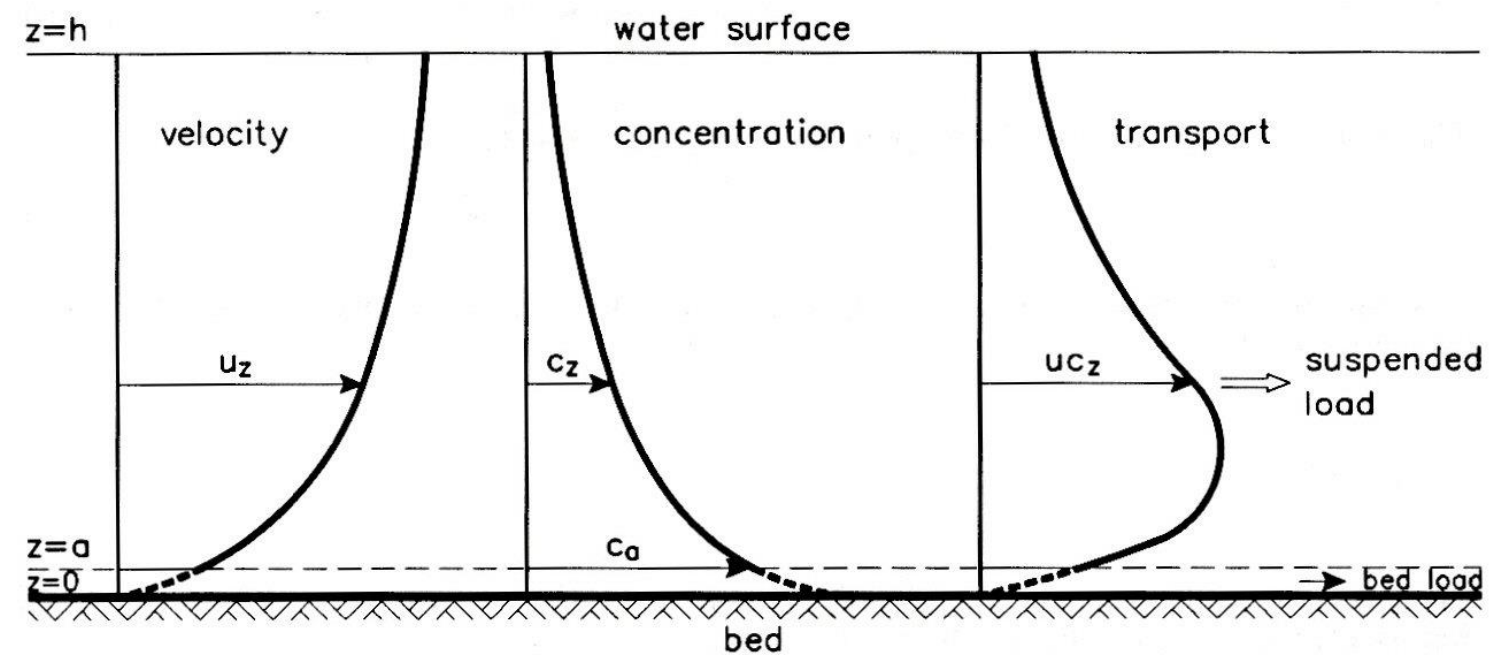

Figure 29. Relationship of suspended sediment load (vertical axis) to the flow discharge and watershed steepness (horizontal axis). (van Rijn 1993)

The supply of sediment from a watershed to its rivers is a complex phenomenon that has been studied extensively (Milliman and Farnsworth 2013; Abban et al. 2016). In short, the yield of suspended sediment from the watershed to a river depends on the watershed drainage area; the precipitation and water runoff; the watershed topographic characteristics, such as shape, size, slope and elevation; the watershed soil type; and the types of land use and land cover in the watershed. The erosion and uplift of finer sediment from the river bed into suspension is a function of the prevailing flow conditions in the river and the sediment size. As indicated in Figure 28, when the friction velocity is significantly smaller than the sediment fall velocity, then sediment tends to become suspended. The contribution of material from the erosion of the river banks is an outcome of the imbalance between the flow force acting on the river banks and the resistance to erosion offered by the bank material (Langendoen and Alonso 2008; Langendoen and Simon 2008; Sutarto et al. 2014). The flow force is quantified by the shear stress acting on the river bank, and the bank material resistance to erosion is quantified by the material erodibility and critical shear strength. These two parameters depend on the physical properties of the bank material soil (e.g., sediment type and size distribution, bulk density), along with a suite of geochemical properties (e.g., soil clay type, water chemistry) and biological properties (e.g., vegetation cover, burrowing animals). (Grabowski et al. 2011) Note that the contribution of bank material to the river may also be caused by bank mass failure, in which large sections of the bank lose their stability, fall into the river, and are eroded by the flow action (Langendoen and Alonso 2008; Sutarto et al. 2014).

Geomorphic change in a river reach is an outcome of the imbalance between the transport capacity of a river and the sediment supply to its reach from its upstream reaches. It can be shown that this imbalance is an outcome of variations in the sediment transport rate along the river, which result in changes in the river topography over time (Parker 1991; Viparelli et al. 2010). 


\section{C.4 MEASURES OF MODULE PERFORMANCE}

Assessing the efficiency of the sediment passage module in meeting the requirements listed in Appendix C.2 requires quantifiable indices (Table 19). Such indices will in turn allow evaluation of the degree to which various designs for the sediment passage module accomplish its specific and primary technical objectives and evaluation of the optimal design.

Table 19. Sediment passage module measures of performance

\begin{tabular}{|l|l|}
\hline \multicolumn{1}{|c|}{ Index } & \multicolumn{1}{c|}{ Status } \\
\hline Indices of Schmidt and Wilcock (2008) & Limits available_-modeling needed \\
\hline Indices of Grant et al. (2003) & Limits available_-modeling needed \\
\hline River width & Limits available \\
\hline River topography & Limits available \\
\hline Bedload transport rate & Limits available \\
\hline Bed slope & Limits available \\
\hline Grain size distribution & Limits available \\
\hline River planform geometry & Limits available \\
\hline Suspended sediment flux & Limits available \\
\hline
\end{tabular}

The assessment of sediment passage module performance, with respect to maintaining sufficient sediment transport capacity in the river reaches downstream of the SMH facility, needs to involve measures quantifying the river geomorphic change. Such measures are the three complementary indices proposed by Schmidt and Wilcock (2008), which quantify (1) the potential for river aggradation or degradation, (2) the bed incision potential, and (3) the magnitude of flood reduction under the conditions before and after the installation of the SMH facility. Starting from a conceptual relationship for river morphological stability proposed by Lane (1955), Schmidt and Wilcock (2008) derive an index for the potential for river aggradation and degradation, which considers the river discharge, sediment transport rate, and representative grain size in a river reach before and after the placement of the SMH facility. Because aggradation or degradation is a necessary but not sufficient condition for river incision, an index for the river bed incision potential is also proposed. The bed incision potential index for a river reach is based on a formulation similar to the bed shear stress. It is a function of the flow depth after the SMH facility placement, the river bed slope upstream of the hydropower facility installation, and the characteristic grain size at the time of the hydropower facility installation. To account for the reduction in competent flows for sediment transport following the placement of a hydropower facility, the third index of Schmidt and Wilcock (2008) considers the ratio of 2 year floods before and after the placement of the hydropower facility. Following a systematic analysis of these indices, in conjunction with observed geomorphic changes in rivers downstream of existing hydropower facilities, Schmidt and Wilcock (2008) provide ranges for the indices, which correspond to minimal changes in river geomorphology (Figure 30 and Figure 31).

In an earlier work, Grant et al. (2003) proposed a set of two indices, different from those of Schmidt and Wilcock (2008), for assessing the geomorphologic effects of dams. Specifically, Grant et al. (2003) consider (1) the ratio of the sediment supply upstream and downstream of the SMH facility and (2) the ratio of the fractions of sediment-transporting flows before and after the placement of the SMH facility. In river reaches where sediment supply is considerable lower than the transport capacity, morphologic changes such as bed erosion, incision, narrowing and armoring are expected to take place (Grant et al. 2003; Magilligan et al. 2013). This regime corresponds to the lower right area of the plot of Figure 32. In the opposite case, river reaches with limited sediment transport capacity but high sediment supply - for instance, due to lateral watershed contributions - tend to aggrade. The river morphology will experience subtle effects in reaches where sediment transport capacity and supply are nearly in balance, corresponding to the center of the graph in Figure 32. 

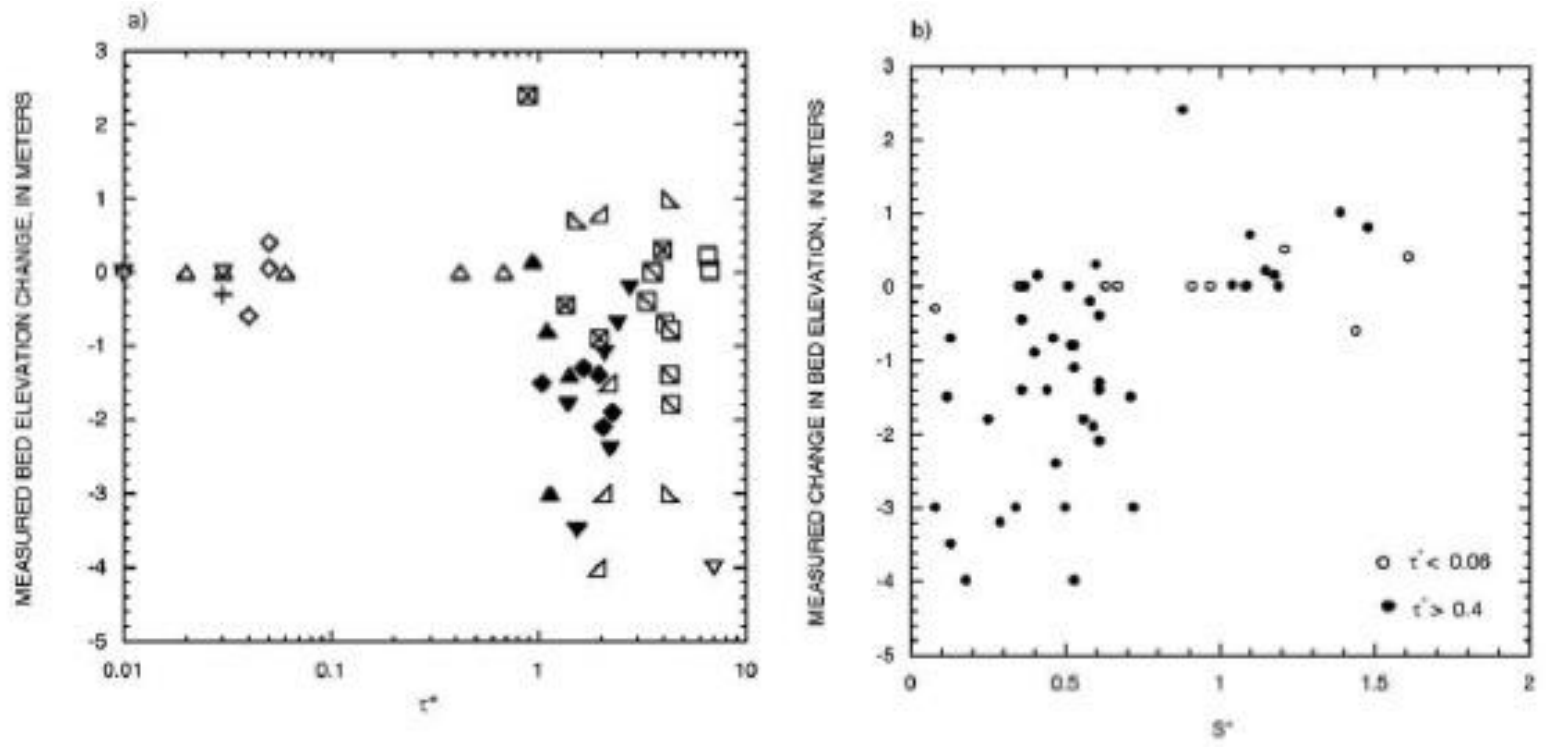

Figure 30. Threshold values of (a) the index for sediment aggradation and degradation and (b) the index of incision potential for various hydropower facilities. (Schmidt and Wilcock 2008)
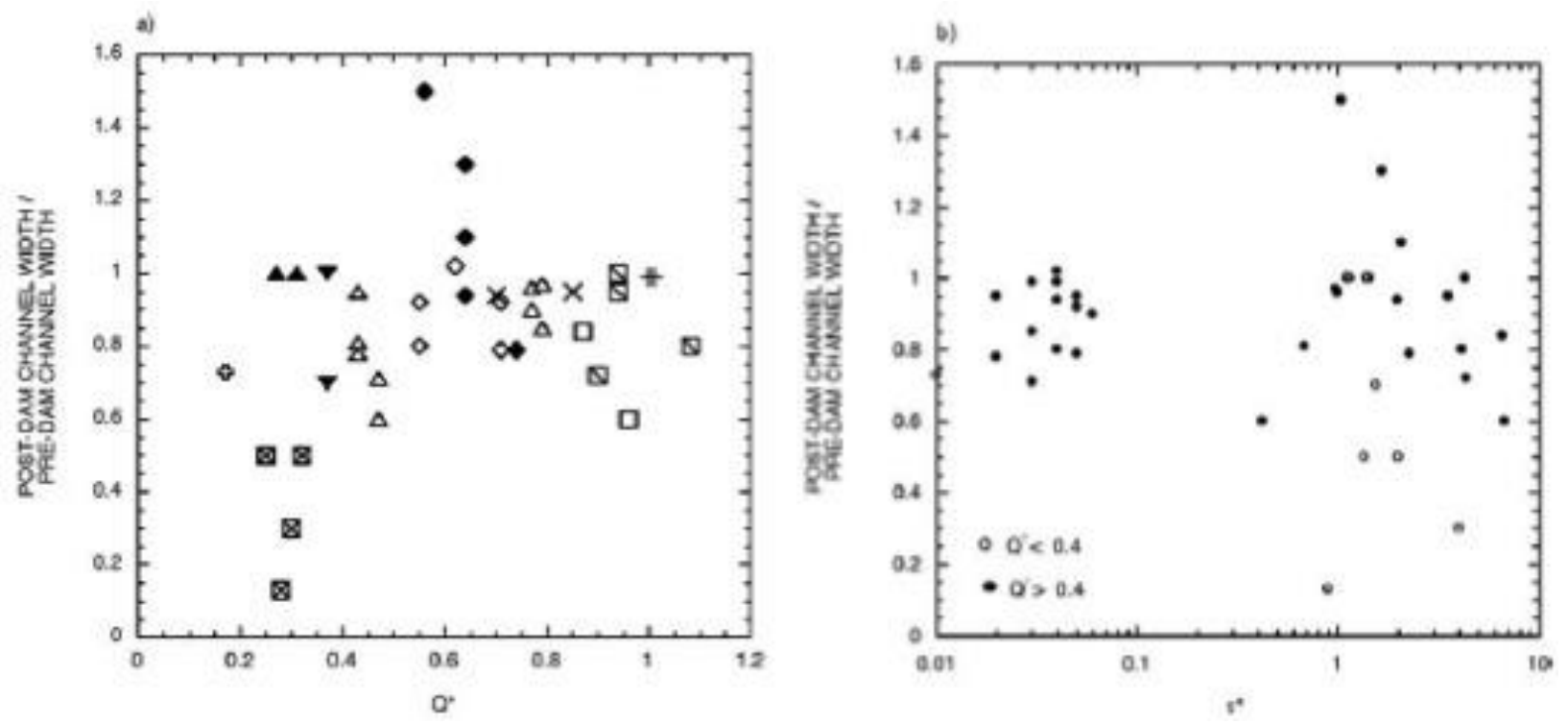

Figure 31. Threshold values of (a) the index for flood magnitude reduction and (b) the index of incision potential for various hydropower facilities. (Schmidt and Wilcock 2008) 


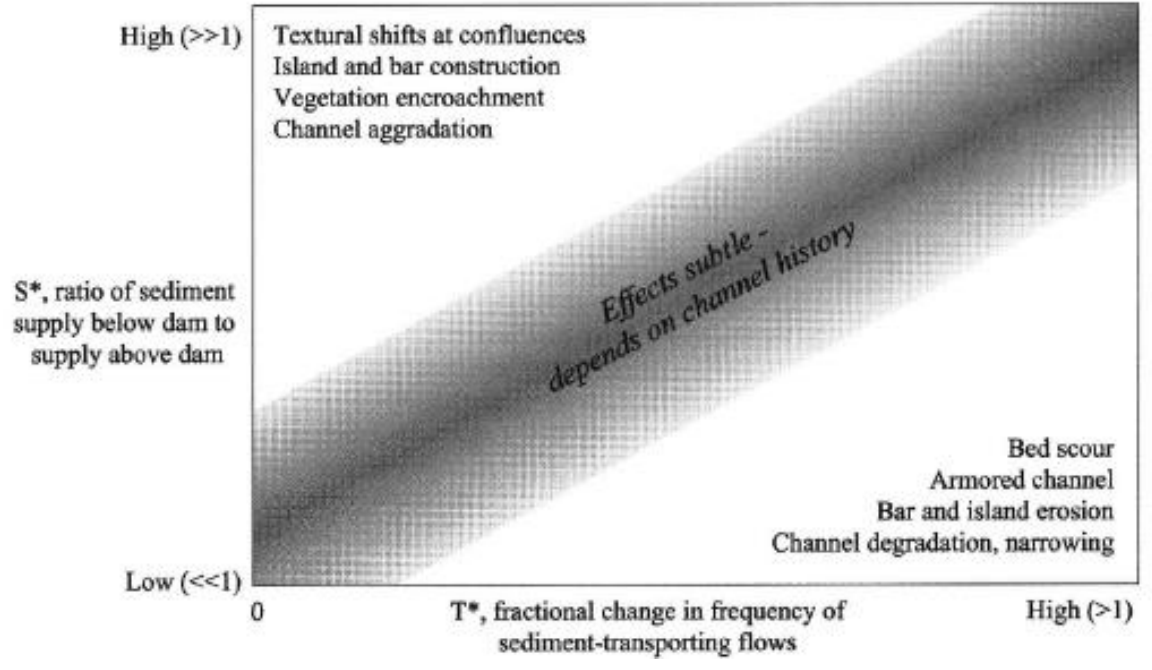

Figure 32. Thresholds of the morphologic change indices of Grant et al. (2003) where the effects of hydropower facilities on river morphology are subtle.

To fully assess the effects of an SMH facility on the downstream river morphology, a systematic survey of the river topography, width, bed slope, and planform geometry is necessary. Furthermore, monitoring the grain size distribution would allow assessment of whether armoring is taking place. In addition, assessing the efficiency of the sediment passage module in conveying sediment through the SMH facility requires monitoring of the bedload transport rate and the suspended sediment flux. At the same time, monitoring the river bed topography upstream and downstream of the SMH facility allows the evaluation of potential sediment deposition around the SMH facility.

\section{C.5 MODULE DESIGN CONSTRAINTS}

As is the case for the fish passage module, the design constraints (Table 20) for the sediment passage module are derived by mapping the sediment passage module requirements (Appendix C.2), onto the functional relationships (Appendix C.3). The design constraints can be viewed as the behaviors and features that the sediment passage module must exhibit to accomplish its primary technical objective of allowing the transport of sediment across the SMH facility. We do not specify strict quantitative criteria for each of the design constrains, as the development of such criteria is beyond the scope of the present document. Instead, the identification of the sediment passage module performance measures outlined in Appendix C. 4 provides a basis for developing such quantitative criteria in the future. For the other modules, the design constraints examined in Table 20 are characterized as local when they pertain specifically to the sediment passage module and global when their validity can be extended to the other modules of the SMH facility. 
Table 20. Sediment passage module design constraints

\begin{tabular}{|c|c|c|}
\hline Constraint & Formalization/rationale & $\begin{array}{l}\text { Scale }(\mathrm{L}=\text { local, } \\
\mathbf{G}=\text { global })\end{array}$ \\
\hline $\begin{array}{l}\text { The sediment passage module } \\
\text { must create favorable flow } \\
\text { conditions at its inlet for } \\
\text { sediment to enter }\end{array}$ & $\begin{array}{l}\text { Sediment that does not enter the sediment passage module } \\
\text { will likely deposit upstream of the SMH facility, causing } \\
\text { loss of available head for power generation and } \\
\text { interference with the operation of the other modules }\end{array}$ & $\mathrm{L}$ \\
\hline $\begin{array}{l}\text { The sediment passage module } \\
\text { inlet must prevent incoming } \\
\text { sediment from being } \\
\text { entrained into the generation } \\
\text { module (GM) and from } \\
\text { clogging the GM inlet }\end{array}$ & $\begin{array}{l}\text { Sediment entrained into the turbines will cause damages to } \\
\text { the turbines. Also, clogging of the GM intake will reduce } \\
\text { the turbine efficiency and energy production }\end{array}$ & $\mathrm{L}$ \\
\hline $\begin{array}{l}\text { The bed shear stress within } \\
\text { the sediment passage module } \\
\text { must exceed the critical bed } \\
\text { shear stress for incipient } \\
\text { motion of all encountered } \\
\text { sediment sizes }\end{array}$ & $\begin{array}{l}\text { Sediment with critical bed shear stress for incipient motion } \\
\text { higher than the applied bed shear stress will deposit within } \\
\text { the sediment passage module, preventing it from } \\
\text { accomplishing its primary technical objective }\end{array}$ & $\mathrm{L}$ \\
\hline $\begin{array}{l}\text { The sediment passage module } \\
\text { must supply sufficient } \\
\text { amounts and sizes of } \\
\text { sediment downstream to } \\
\text { minimize channel } \\
\text { morphologic change }\end{array}$ & $\begin{array}{l}\text { Failure to supply sufficient amounts and/or sizes of } \\
\text { sediment downstream of the SMH facility will lead to } \\
\text { often undesired river morphologic changes, such as } \\
\text { incision, armoring, and lateral migration }\end{array}$ & $\mathrm{L}$ \\
\hline $\begin{array}{l}\text { The sediment passage module } \\
\text { geometry should be sufficient } \\
\text { for handling all sizes and } \\
\text { amounts of sediment } \\
\text { encountered by the river }\end{array}$ & $\begin{array}{l}\text { If the geometry of the sediment passage module-i.e., } \\
\text { width, opening size - is not adequate for the size and } \\
\text { amounts of sediment required to be transported, sediment } \\
\text { will accumulate upstream and within the module, } \\
\text { preventing its transport downstream }\end{array}$ & $\mathrm{L}$ \\
\hline $\begin{array}{l}\text { The bed shear stress at the } \\
\text { exit of the sediment passage } \\
\text { module must exceed the } \\
\text { critical bed shear stress for } \\
\text { incipient motion of all } \\
\text { encountered sediment sizes }\end{array}$ & $\begin{array}{l}\text { If the shear stress applied by the flow is smaller than the } \\
\text { critical shear of the transported sediment, sediment will } \\
\text { deposit downstream of the SMH facility, decreasing the } \\
\text { available head for power generation, impairing the } \\
\text { function of the adjacent modules, and limiting the supply } \\
\text { downstream }\end{array}$ & $\mathrm{L}, \mathrm{G}$ \\
\hline $\begin{array}{l}\text { Module components need to } \\
\text { be able to withstand the } \\
\text { impact of the largest sediment } \\
\text { expected }\end{array}$ & $\begin{array}{l}\text { Impacts from incoming sediment could lead to damage to } \\
\text { the structure of the module, which must be minimized }\end{array}$ & G \\
\hline $\begin{array}{l}\text { Module components cannot } \\
\text { be heavier than the lift } \\
\text { capacity of available cranes } \\
\text { and transport vehicles or } \\
\text { vessels }\end{array}$ & $\begin{array}{l}\text { The module components must not exceed the capacity of } \\
\text { transport vehicles or vessels and available cranes, so that } \\
\text { they can be transported to the SMH site and placed }\end{array}$ & G \\
\hline $\begin{array}{l}\text { Module components cannot } \\
\text { exceed in size the size of } \\
\text { available transport vehicles or } \\
\text { vessels }\end{array}$ & $\begin{array}{l}\text { The module components must be smaller than the } \\
\text { transport vehicle or vessel to allow their transportation to } \\
\text { the SMH site }\end{array}$ & G \\
\hline $\begin{array}{l}\text { Module components must be } \\
\text { compatible with one another }\end{array}$ & $\begin{array}{l}\text { The module components must connect with one another } \\
\text { and offer structural stability to the module }\end{array}$ & $\mathrm{G}$ \\
\hline $\begin{array}{l}\text { Module components must be } \\
\text { compatible with foundation } \\
\text { modules }\end{array}$ & $\begin{array}{l}\text { The module components must be compatible with the } \\
\text { foundation module to ensure the structural stability of the } \\
\text { module from the SMH facility foundation }\end{array}$ & G \\
\hline
\end{tabular}




\section{C.6 DESIGN ENVELOPE SPECIFICATION}

This section of the report derives a list of design constraints for the sediment passage module, which are intended to guide design so that the sediment passage module will best accomplish its primary technical objective of transporting sediment across the SMH facility. Multiple sediment passage module designs could fulfill these design constraints, but the present report does not aim to identify the optimal design. Rather, we provide in Appendix C.4 a set of indices that can be used to assess the optimal design for the sediment passage module.

Specifying the design envelope for the sediment passage module requires establishing limits for the performance measures outlined in Appendix C.4. Identifying these performance measure limits allows the exclusion of potential sediment passage module designs that do not perform within the identified limits. For instance, a water passage module design allowing incoming sediment accumulation at the generation module intake cannot be considered. The identification of these limits is influenced by specific characteristics of the SMH facility site, including the hydrologic regime of the watershed where the SMH facility site is located, as well as the grain size distribution of the sediment transported along the river. It is possible to classify potential SMH sites with respect to these key, recurring characteristics that are pertinent to the design envelope specification of the sediment passage module. The outcome of such classification schemes will be to establish limits and designs that apply to a class of SMH sites with similar characteristics, thereby enhancing SMH standardization. For the other modules, site classification, the second pillar of SMH, is of paramount importance for identifying the performance limits for the sediment passage module design envelope, along with the other SMH pillars, simulation capability and testing capability.

The concept of scale is particularly important for the sediment passage module, as the sediment transported by the sediment passage module across the SMH facility and conveyed further downstream may significantly impact the morphologies of river reaches far downstream of the SMH facility. For instance, Schmidt and Wilcock (2008), in the case of larger dams, considered river reaches as far as 180 miles downstream to test their proposed indices of geomorphic change. It is necessary, therefore, to delineate the spatial and the temporal scales at which the SMH facility affects sediment supply. Of paramount importance in identifying the spatiotemporal scale are the testing capability and especially the simulation capability of the SMH concept, which can be used to simulate potential effects of the SMH facility in the river continuum.

A limitation of the current analysis is that all of the functional relationships examined in Appendix C.3 are deterministic in nature. The deterministic nature of these relationships implies that a given input to a process cause can have only a specific outcome, which is predicted by the functional relationship. However, complexities such as river turbulence and river bed surface irregularity often cause variability in the outcome of processes, which are not predicted by deterministic relationships. In the future, additional research should focus on replacing the currently used deterministic relations, such as those included in Appendix C.3, with their probabilistically based counterparts. 


\section{APPENDIX D. RECREATION PASSAGE MODULE}

By disrupting the flow of water, hydropower facilities can have significant impacts on recreation, a key activity and economic resource in many rivers (Bonnet et al. 2015). Recreational craft have three options for traversing a hydropower facility: exit the water and portage the craft around the dam, use a lock structure that mechanically raises the water level or lifts a boat from the downstream water surface elevation to the upstream water surface elevation (or vice versa), or use a passive canoe or boat chute that carries small craft through a channel-type structure built into or around the facility. When none of these three options is readily available, a boat or paddler must reverse course.

The economic and social impacts of hydropower facilities on recreation are apparent - the most common Federal Energy Regulatory Commission-mandated mitigation measure at small hydropower plants undergoing relicensing is "the preparation and implementation of plans to monitor or study recreational site usage or plan for the implementation of recreational sites and improvements" (Bevelhimer et al. 2015). A recreation passage module integrated into the facility in the design phase has the potential to create new recreation opportunities and serve as a local asset. ${ }^{10}$

At large hydropower facilities on navigable inland waterways, locks that pass commercial traffic are sometimes available for use by recreational watercraft. It is not anticipated that these types of structures meet the ecological compatibility, cost-optimized, modular approach that SMH facilities will embody, and they are not considered in this section. At small, low-head dams, passage structures for small canoes, kayaks, and whitewater rafts have been implemented over the past few decades (Caisley et al. 1999; Bombardelli et al. 2002; Colorado Water Conservation Board 2008). Caisley et al. (1999) note that few design guidelines for canoe chutes are documented, and new designs have generally required a physical model study accompanied by computational models to fully understand the chute hydrodynamics.

Furthermore, hydropower facilities could create hazardous flows, such as large eddies, sudden drops of the water surface, large surface waves, high velocities, and hydraulic jumps, that would endanger recreational craft, especially smaller craft such as canoes and kayaks. The presence of a recirculating hydraulic jump is of particular concern, as that condition has been known to cause fatalities throughout the United States. ${ }^{11}$

\section{D.1 OBJECTIVES}

To mitigate the adverse consequences of hydropower facilities on river-based recreation, provision needs to be made for a recreation passage module. The primary objective of the recreation passage module is to allow the passage of small recreational craft consistently and safely through the hydropower facility.

Recreation Passage Module Primary Technical Objective

Allow the passage of small recreational craft consistently and safely through a SMH facility

To accomplish its primary technical objective, a recreation passage module needs to accomplish the following specific objectives (Figure 33):

1. Operate within a known range of recreation performance difficulty.

2. Provide a safe and visible entrance for recreational craft into the module.

\footnotetext{
${ }^{10}$ See for example http://www.denverpost.com/2007/07/14/the-south-platte-a-rivers-rebirth/

${ }^{11} \mathrm{http} / / / \mathrm{krcp}$ roject.groups.et.byu.net/browse.php
} 
3. Allow recreational craft to safely cross the hydropower facility.

4. Allow recreational craft to exit safely into the river downstream of the module.

5. Provide for emergency rescue personnel and apparatus.

6. Integrate structurally into foundation module.

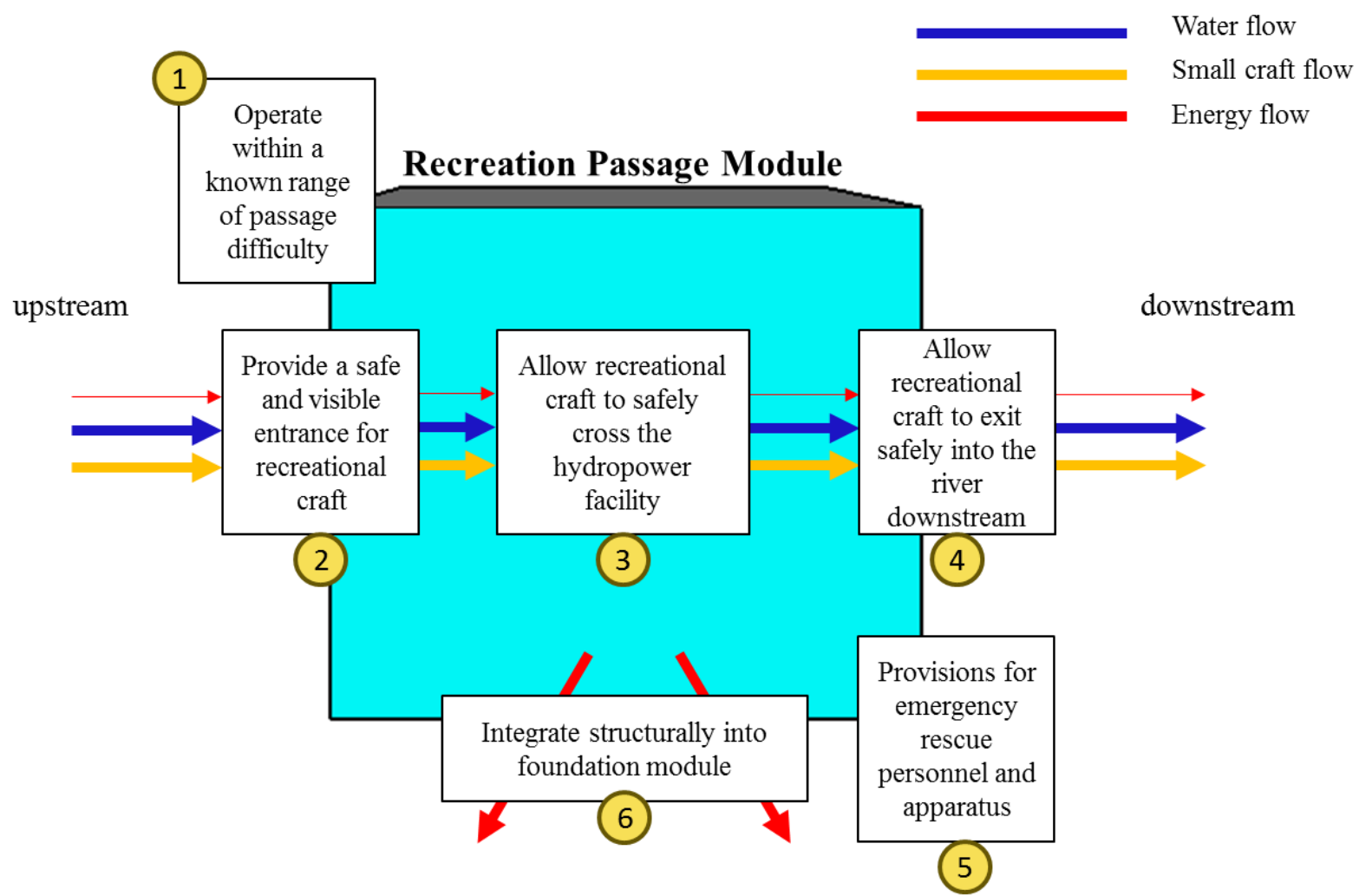

Figure 33. Conceptual schematic of the specific objectives of a recreation passage module.

It is noted that hydropower facilities could indirectly affect recreation outside their immediate vicinity. The reduction of flows downstream of hydropower facilities could make river reaches unnavigable by many types of vessels used for recreation purposes, such as boating, whitewater rafting, and fishing, thereby eliminating these activities. In addition, changes in the river geomorphology downstream of a hydropower facility - such as river bed aggradation, lateral migration, and narrowing - could impact near-stream activities, including camping, hiking, and aesthetic enjoyment. Finally, degradation of fish habitat and fish populations downstream of hydropower facilities could have significant consequences on recreational fishing. However, these indirect effects can be mitigated by the operation of the water, sediment, and fish passage modules, as covered in detail in Appendices E, C, and B, respectively, of the present document. Therefore, the indirect effects of the hydropower facility on recreation are not considered in this section.

Recreational craft may wish to travel upstream through a hydropower facility. While this is an important connectivity issue to address, contrary to upstream fish passage, recreational craft cannot be conveyed upstream without heavy mechanical equipment (i.e., a lock, lift, or onshore mechanical track). Future recreation passage modules may include this functionality, but for simplicity, cost optimization, and alignment with modern day canoe and kayak courses, the recreation passage module exemplary design only accommodates downstream movement. 


\section{D.2 REQUIREMENTS}

The requirements of a recreation passage module are derived to ensure the safety of passengers while balancing length and cost (Table 21). General requirements are referenced from Klumpp et al. (1989), Caisley et al. (1999), and Colorado Water Conservation Board (2008).

Table 21. Recreation passage module requirements. In the fourth column: $F=$ Functional; $P=$ Performance; $I=$ Interaction; $\mathrm{O}=$ other. In columns $6-11$, an " $\mathrm{X}$ " denotes a relationship to the river continuum constituent indicated in the top row

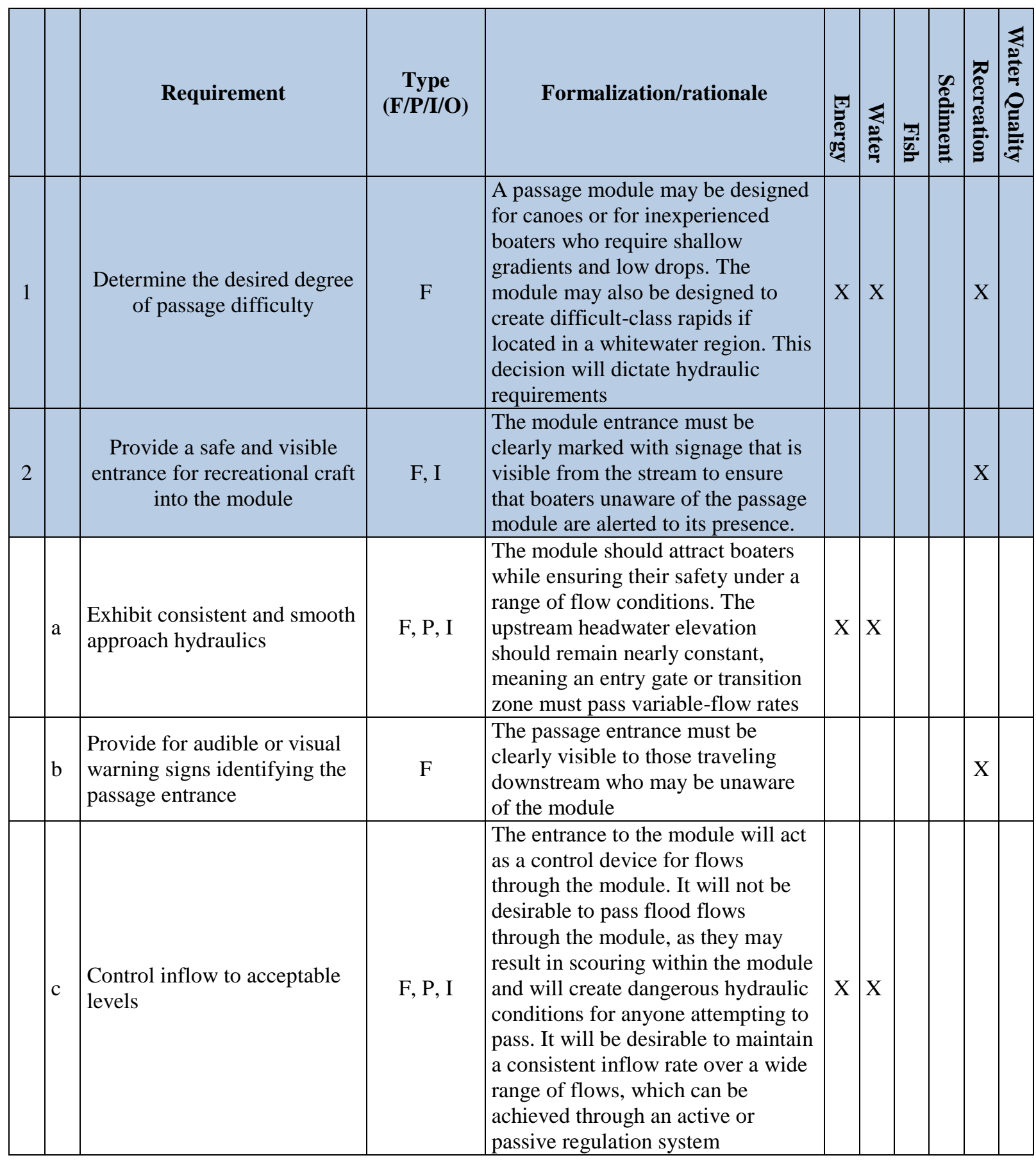


Table 20. Recreation passage module requirements (continued)

\begin{tabular}{|c|c|c|c|c|c|c|c|c|c|c|}
\hline & & Requirement & $\begin{array}{c}\text { Type } \\
(\mathbf{F} / \mathbf{P} / \mathbf{I} / \mathbf{O})\end{array}$ & Formalization/rationale & 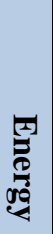 & 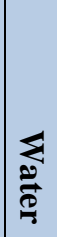 & $\frac{3}{2}$ & 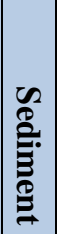 & 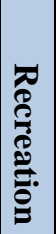 & 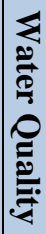 \\
\hline 3 & & $\begin{array}{l}\text { Allow recreational craft to } \\
\text { safely cross the hydropower } \\
\text { facility }\end{array}$ & F & & X & $\mathrm{X}$ & & & $X$ & \\
\hline & $\mathrm{a}$ & $\begin{array}{l}\text { Exhibit consistent and smooth } \\
\text { passage hydraulics }\end{array}$ & $\mathrm{F}, \mathrm{P}$ & $\begin{array}{l}\text { The recreation passage module } \\
\text { should be safe under all flow } \\
\text { conditions, with the module } \\
\text { smoothly and continuously sloping } \\
\text { downstream, and eddies should } \\
\text { have low velocities so a swimmer } \\
\text { can escape from them. Many boat } \\
\text { chutes include a notched "V" down } \\
\text { the center of the flow path to both } \\
\text { guide boats through the center of the } \\
\text { channel and ensure flow is } \\
\text { concentrated under low-flow } \\
\text { conditions }\end{array}$ & $\mathrm{X}$ & $\mathrm{X}$ & & & & \\
\hline & $\mathrm{b}$ & Optimize module width & $\mathrm{F}, \mathrm{P}$ & $\begin{array}{l}\text { The module should be wide enough } \\
\text { to accommodate recreational craft } \\
\text { while allowing someone to easily } \\
\text { maneuver around the craft. Sloping } \\
\text { walls are preferred to vertical walls, } \\
\text { as they mitigate the effects of } \\
\text { surging and reflected waves } \\
\text { (Simmons et al. 1977) }\end{array}$ & $X$ & $\mathrm{X}$ & & & $X$ & \\
\hline & $\mathrm{c}$ & $\begin{array}{l}\text { Optimize water velocity and } \\
\text { depth through the module }\end{array}$ & $\mathrm{F}, \mathrm{P}$ & $\begin{array}{l}\text { Velocity and depth of water flow } \\
\text { through the module are closely } \\
\text { related. A high velocity will result } \\
\text { in shallow water, sloshing, and large } \\
\text { eddies. Depth should be sufficient to } \\
\text { immerse the hull of the craft and } \\
\text { allow paddles to be effectively } \\
\text { submerged }\end{array}$ & $X$ & $\mathrm{X}$ & & & $X$ & \\
\hline & d & $\begin{array}{l}\text { Provide natural in-module } \\
\text { features }\end{array}$ & F & $\begin{array}{l}\text { The inclusion of boulders, smooth } \\
\text { natural rocks, or artificial rocks } \\
\text { should be considered. Artificial } \\
\text { obstacles with simple and smooth } \\
\text { shapes are preferred to enable } \\
\text { precast fabrication or the use of } \\
\text { forms that can be reused at multiple } \\
\text { modules }\end{array}$ & X & $\mathrm{X}$ & & & $X$ & \\
\hline 4 & & $\begin{array}{l}\text { Allow recreational craft to } \\
\text { exit safely into the river } \\
\text { downstream of the module }\end{array}$ & $\mathrm{F}, \mathrm{P}, \mathrm{I}$ & & $X$ & $\mathrm{X}$ & & & $\mathrm{X}$ & \\
\hline & $\mathrm{a}$ & $\begin{array}{l}\text { Exhibit consistent and smooth } \\
\text { exit hydraulics }\end{array}$ & $\mathrm{F}, \mathrm{P}, \mathrm{I}$ & $\begin{array}{l}\text { The downstream module exit into } \\
\text { the channel is the location where a } \\
\text { recirculating hydraulic jump or } \\
\text { "keeper" roller can form. This }\end{array}$ & $\mathrm{X}$ & $\mathrm{X}$ & & & $X$ & \\
\hline
\end{tabular}


Table 20. Recreation passage module requirements (continued)

\begin{tabular}{|c|c|c|c|c|c|c|c|c|c|c|}
\hline & & Requirement & $\begin{array}{c}\text { Type } \\
(\mathbf{F} / \mathbf{P} / \mathbf{I} / \mathbf{O})\end{array}$ & Formalization/rationale & 㽦 & 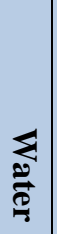 & بُ & 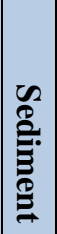 & 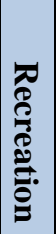 & 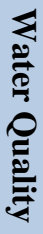 \\
\hline & & & & $\begin{array}{l}\text { condition must be mitigated under a } \\
\text { wide range of flow conditions }\end{array}$ & & & & & & \\
\hline & $\mathrm{b}$ & Provide for a recovery pool & $\mathrm{F}, \mathrm{I}$ & $\begin{array}{l}\text { Many boat chutes include a } \\
\text { recovery pool to allow the paddler } \\
\text { to perform an Eskimo roll to right a } \\
\text { capsized vessel }\end{array}$ & $X$ & $\mathrm{X}$ & & & $X$ & \\
\hline 5 & & $\begin{array}{l}\text { Provide for emergency rescue } \\
\text { personnel and apparatus }\end{array}$ & $\mathrm{F}$ & $\begin{array}{l}\text { Warning signs and audible warning } \\
\text { systems, buoys, and physical } \\
\text { separation between the recreation } \\
\text { passage module and generation } \\
\text { modules should be incorporated into } \\
\text { module design. The module design } \\
\text { must consider appropriate access for } \\
\text { emergency personnel, which may } \\
\text { include anchor points within the } \\
\text { module or on the module periphery }\end{array}$ & & & & & $X$ & \\
\hline 6 & & $\begin{array}{l}\text { Integrate structurally into } \\
\text { foundation module }\end{array}$ & & & & & & & & \\
\hline & $a$ & $\begin{array}{l}\text { Transmit all forces through } \\
\text { non-critical components into } \\
\text { the foundation module }\end{array}$ & $\mathrm{F}, \mathrm{P}, \mathrm{I}$ & $\begin{array}{l}\text { The recreation passage module will } \\
\text { be supported instream by a } \\
\text { foundation module that serves as an } \\
\text { interface to the streambed }\end{array}$ & $X$ & & & & & \\
\hline
\end{tabular}

\section{D.3 INPUTS, FUNCTIONAL RELATIONSHIPS AND PROCESSES}

\section{D.3.1 Necessary Inputs}

The variables necessary to quantify recreation passage module functional relationships are presented in Table 22. These can be categorized as relating to either the physical features and flow characteristics of the site, or the type of watercraft and passage experience to be designed for. This categorization will further allow the systematic examination of the functional relationships to which these inputs relate.

Table 22. Recreation passage module necessary inputs for hydraulic design

\begin{tabular}{|l|l|}
\hline \multicolumn{1}{|c|}{$\begin{array}{c}\text { Identification of } \\
\text { key inputs }\end{array}$} & \multicolumn{1}{c|}{ Formalization } \\
\hline Flow characteristics & $\begin{array}{l}\text { Range of discharge available under normal conditions, inflow Froude } \\
\text { number, stage-discharge relationships for headwater and tailwater at an } \\
\text { SMH-type facility }\end{array}$ \\
\hline Head & Headwater and tailwater elevations under normal conditions, depth \\
\hline Site characteristics & $\begin{array}{l}\text { Stream width, presence of boulders or other sharp or dangerous submerged } \\
\text { structures, presence of eddies, design head of SMH facility, streambed } \\
\text { elevation, bed slope }\end{array}$ \\
\hline
\end{tabular}


Table 21. Recreation passage module necessary inputs for hydraulic design (continued)

\begin{tabular}{|l|l|}
\hline \multicolumn{1}{|c|}{$\begin{array}{c}\text { Identification of } \\
\text { key inputs }\end{array}$} & \multicolumn{1}{c|}{ Formalization } \\
\hline Recreation vessel type & Type (canoe, kayak, raft), size, shape, weight, depth \\
\hline Degree of difficulty & $\begin{array}{l}\text { Identification of the intended use—whether kayak, canoe, or whitewater } \\
\text { raft—as this will determine the design hydraulics }\end{array}$ \\
\hline Characteristics of person on vessel & Weight, age, experience \\
\hline
\end{tabular}

\section{D.3.2 Functional Relationships}

The functional relationships important to the design of a recreation passage module are summarized in Table 23, along with a brief rationale for the importance of each functional relationship.

Table 23. Summary of key functional relationships necessary for recreation passage module design

\begin{tabular}{|c|c|c|}
\hline Relationship of & To & Rationale/importance \\
\hline $\begin{array}{l}\text { Module size, shape, } \\
\text { number of drops, } \\
\text { slope, and discharge }\end{array}$ & $\begin{array}{l}\text { Type of hydraulic } \\
\text { jump }\end{array}$ & $\begin{array}{l}\text { A hydraulic jump occurs when high-velocity flow transitions to } \\
\text { low-velocity flow. These conditions will be present at abrupt } \\
\text { drops within the module and at the point of discharge from the } \\
\text { module into the tailwater. Hydraulic jumps that maintain a } \\
\text { positive downstream velocity at all times are desirable, whereas } \\
\text { those that create recirculating rollers are not }\end{array}$ \\
\hline Range of discharges & $\begin{array}{l}\text { 1. Water velocity } \\
\text { through module } \\
\text { 2. Water depth } \\
\text { through module } \\
\text { 3. Regulation of water } \\
\text { velocity and depth }\end{array}$ & $\begin{array}{l}\text { The relationship between discharge and depth/velocity through } \\
\text { the module should be known to ensure the module is passable } \\
\text { under most flow conditions. If safe passage cannot be } \\
\text { guaranteed, mechanical regulation of the inflow may be } \\
\text { necessary, although this may not prove economically feasible. }\end{array}$ \\
\hline Gross head at site & $\begin{array}{l}\text { Minimum module } \\
\text { length, gradient, and } \\
\text { flow }\end{array}$ & $\begin{array}{l}\text { Recreational craft require a safe gradient to bridge the abrupt } \\
\text { drop required for hydroelectric generation. This is accomplished } \\
\text { through a single downstream sloping module or through a series } \\
\text { of drops. A relationship predicting the length and gradient } \\
\text { associated with each type based on the gross head at a site is } \\
\text { necessary. The range of flow rates that can be sustained through } \\
\text { the module based on this gradient must be considered }\end{array}$ \\
\hline $\begin{array}{l}\text { Size, velocity, and } \\
\text { location of eddies } \\
\text { around and in the } \\
\text { module }\end{array}$ & $\begin{array}{l}\text { Travel path of } \\
\text { recreational craft }\end{array}$ & $\begin{array}{l}\text { Eddies dissipate turbulent kinetic energy, resulting in } \\
\text { recirculation and swirling flows that could trap a small } \\
\text { watercraft or a capsized paddler. }\end{array}$ \\
\hline $\begin{array}{l}\text { Module exit } \\
\text { hydraulics }\end{array}$ & $\begin{array}{l}\text { 1. Changes in } \\
\text { downstream flow } \\
\text { depth } \\
\text { 2. Scour }\end{array}$ & $\begin{array}{l}\text { A downstream depth that rises and falls during periods of } \\
\text { variable discharge will have an effect on the hydraulics of the } \\
\text { module exit, an area that is vulnerable to recirculating flow } \\
\text { patterns. The flow exiting the module may also result in some } \\
\text { scour downstream. This relationship should be understood and } \\
\text { scour minimized }\end{array}$ \\
\hline
\end{tabular}

All recreation passage downstream of an SMH facility will require a hydraulic drop to connect a craft from the headwater to the tailwater. This is generally achieved using either boulders or a series of drops (Caisley and Garcia 1999). In the case of boulders, there is large uncertainty in maintaining and controlling a safe flow under a variety of conditions, owing to the roughness of the boulder surfaces and the presence of holes between boulders, which create highly unsteady flow. When drops are used, they must be carried out in series, with sufficient length between them to ensure there is no interference from 
the backwater profile extending upstream from the next drop. Determining this length requires a physical model study or simulation. An appropriate depth of drop is based on two conditions: it must be shallow enough that large waves do not submerge the front of the craft (if designing for a canoe), and it must be sized to avoid the creation of a recirculating hydraulic jump.

The behavior of a hydraulic jump at an abrupt drop is a widely studied phenomenon, as summarized in Caisley and Garcia (1999). The complex hydrodynamics are a function of discharge, hydraulic head, water depth, and the geometry of the channel. As proposed by Hsu (1950), a hydraulic jump can be classified into five regions based on the approach flow Froude number and the depth downstream of the abrupt drop (Figure 34). The jump begins to travel upstream in Region 1, when the toe of the jump is upstream of the drop. This region also produces the highest tailwater elevation. In Region 5, the toe travels downstream past the drop, and the tailwater elevation is at a minimum. At regions 2 and 4, the jump is stable and the drop controls the location of the jump. In these regions, breaking, recirculating surface waves are created. In Region 3, undulating waves (i.e., waves that do not break) travel downstream and there is no zone of recirculation. Based on guidelines developed by Taggart et al. (1984), a boat chute design should ensure a jump remains in Region 3, or the lower or upper portion of Region 2 or Region 4, respectively. These regions will carry boaters downstream while minimizing the risk of a roller that can trap them underwater.

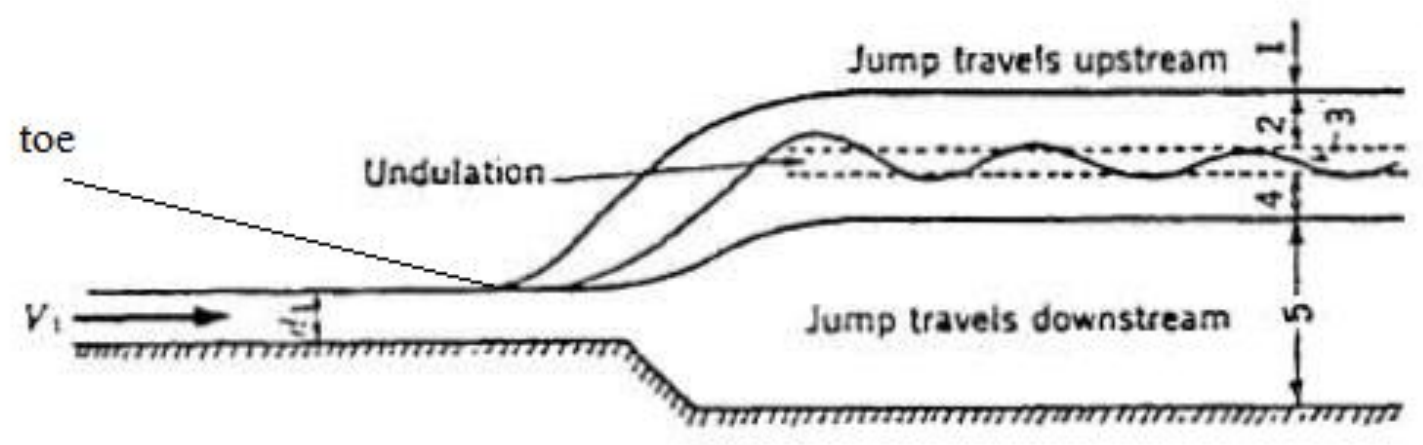

Figure 34. Hydraulic jump behavior at an abrupt drop. (Caisley et al. 1999 as adopted from Hsu et al. 1950)

The hydraulic jump is also classified as an A-jump, a B-jump, or a wave jump, loosely corresponding to Regions 1 and 2, Regions 4 and 5, and Region 3, respectively. A prediction of the type of jump to be formed at an abrupt drop is provided by Moore and Morgan (1959), who base their estimate on a Froude number $\left(V_{1} /\left(g Y_{1}\right)^{0.5}\right)$, the ratio of downstream to upstream water depth (value of $\left.y_{2} / y_{1}\right)$, and the ratio of the depth of drop to the upstream water depth $\left(\Delta Z_{\mathrm{o}} / y_{1}\right)$, where the subscripts 1 and 2 refer to upstream and downstream of the toe of the jump, respectively. It is seen that a finite band of values exists for a range of potential Froude numbers where the desirable wave jump occurs (Figure 35). It is possible to design a variety of passage module shapes and sizes that will create favorable conditions for watercraft. However, these equations, among others that describe the hydraulic jump, have been derived using controlled hydrodynamic conditions in a flume; and in practice, the predicted outcomes may not match the results of physical model studies (Taggart et al. 1984). Computational and physical models provide valuable insights into hydraulic conditions under a variety of discharges that will be necessary for module design. 


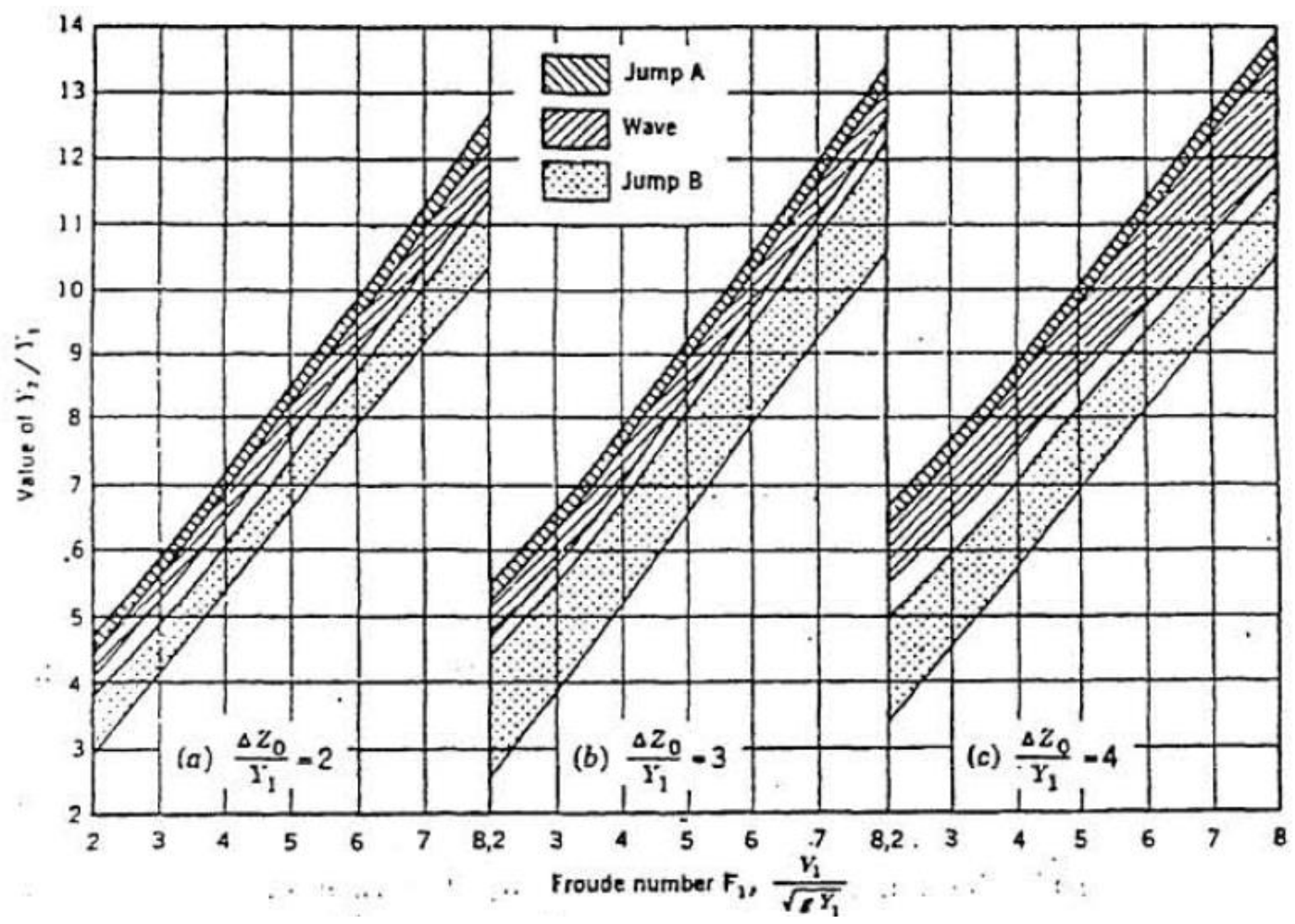

Figure 35. Prediction of hydraulic jump type. (Caisley and Garcia 1999 as found in Moore and Morgan 1959)

The presence of a hydraulic jump can also be mitigated with an inlet control structure that modulates the inflow discharge and velocity. Some boat chutes employ a hinged flap gate to regulate the flow through or into the passage channel (Figure 36). The flap is lifted and lowered based on upstream conditions, creating a change in velocity and water surface elevation. A particularly effective design incorporates a slotted apron as the downstream flap of the hinge, allowing water to pass under the crest of the hinge and resurface downstream (Caisley and Garcia 1999). This configuration helps create an undulating hydraulic jump with surface waves that travel continuously downstream. However, mechanical regulation adds cost and complexity to the design, which may compromise the overall feasibility of the module. The need for and method of flow control at the entrance of the module must be well understood and optimized for cost and efficiency of use over a wide operating range. 


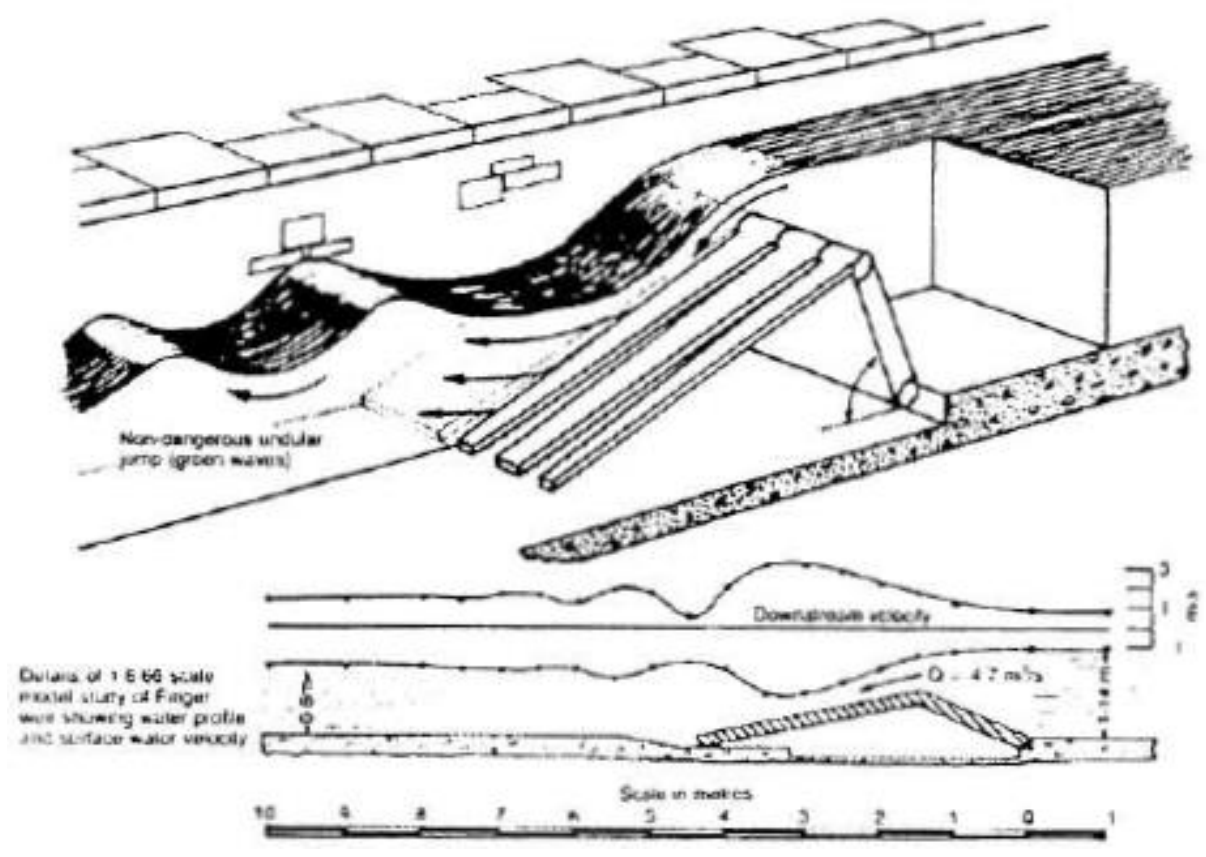

Figure 36. Inlet control structure designed with a slotted apron that creates an undular hydraulic jump with no recirculation. (Caisley and Garcia 1999)

A relationship between module length, gradient, head, and in-module flow at a site is critical to assessing the feasibility of a module design. This relationship will depend strongly on type of passage (e.g., sloping channel or abrupt drops), degree of difficulty desired, and site geometry. On a site scale, Simmons et al. (1977) offer a classification of whitewater difficulty for a range of channel slope and flow (Figure 37). It is seen that as flow increases at a given slope, the difficulty and class of rapids is also increased. Similar relationships are necessary for module designs to predict the navigation of a module or series of modules under various flows.

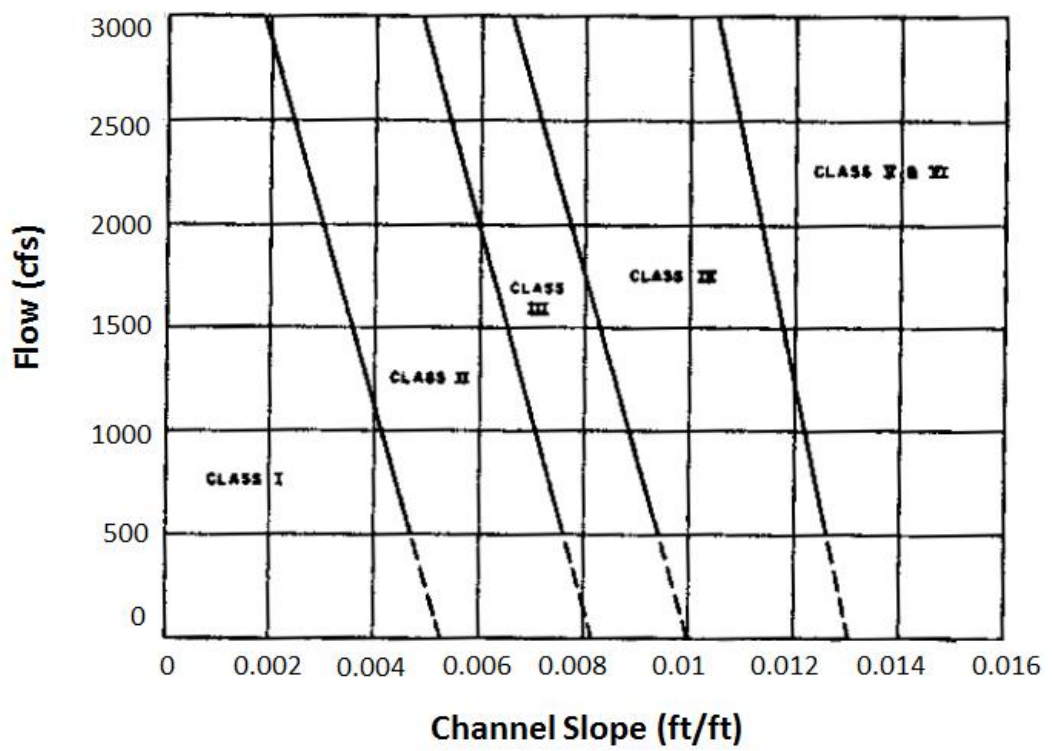

Figure 37. Whitewater classification versus slope and flow. (Simmons et al. 1977) 


\section{D.4 MEASURES OF PERFORMANCE}

The recreation passage module is intended to provide safe and consistent passage to small craft that wish to cross the hydropower facility. A variety of module types can accomplish this objective, and evaluation criteria are needed to quantify the difficulty of the module, the operational range of the regulating technology, flow velocity and depth, size, and cost (Table 24).

Table 24. Recreation passage module measures of performance

\begin{tabular}{|l|l|}
\hline \multicolumn{1}{|c|}{ Index } & \multicolumn{1}{c|}{ Status } \\
\hline Difficulty of module & Limits available-more research needed \\
\hline Hydraulic jump & Limits available-modeling needed \\
\hline Viable range of flow & More research needed \\
\hline Acceptable slope & More research needed \\
\hline Cost of operation & More research needed \\
\hline
\end{tabular}

The passage difficulty of the module should be clearly understood and communicated to paddlers, canoeists, and kayakers. In the United Kingdom, boat chutes on the Medway River are classified using a 1 to 3 rating system ${ }^{12}$ based on the slope of the chute. A more quantitative recreation performance index can be used to evaluate the potential for destination whitewater or boating recreation (Colorado Water Conservation Board 2008):

$$
\text { Recreation Performance Index }=\frac{\text { Hydraulic Drop }}{\text { Course Length }} * \text { Discharge } * 100
$$

A minimum performance index of 75 is the target for a "reasonable recreational experience" at a destination boating area, and a value of 500 reflects world-class whitewater or kayaking potential. While a similar approach could be applied to recreation passage modules, more research is necessary to classify module types and recreation opportunities.

Module performance with respect to the creation of a hydraulic jump is highly dependent on geometry and flow characteristics. For drop structures, Caisley et al. (1999) offer empirical predictions of hydraulic jump types based on the results of model studies (Figure 38). A clear dividing line between jump types is shown as the difference between tailwater depth, $h_{d}$, and the downstream height of the step, $h_{a}$, increases. This measure is applicable for a single type of structure; and more research, including physical testing, is necessary to fully categorize this behavior for different recreation passage module types.

\footnotetext{
${ }^{12} \mathrm{http} / / / \mathrm{www}$. rivermedwaycanoes.com/guid-to-canoe-passes-and-locks/
} 


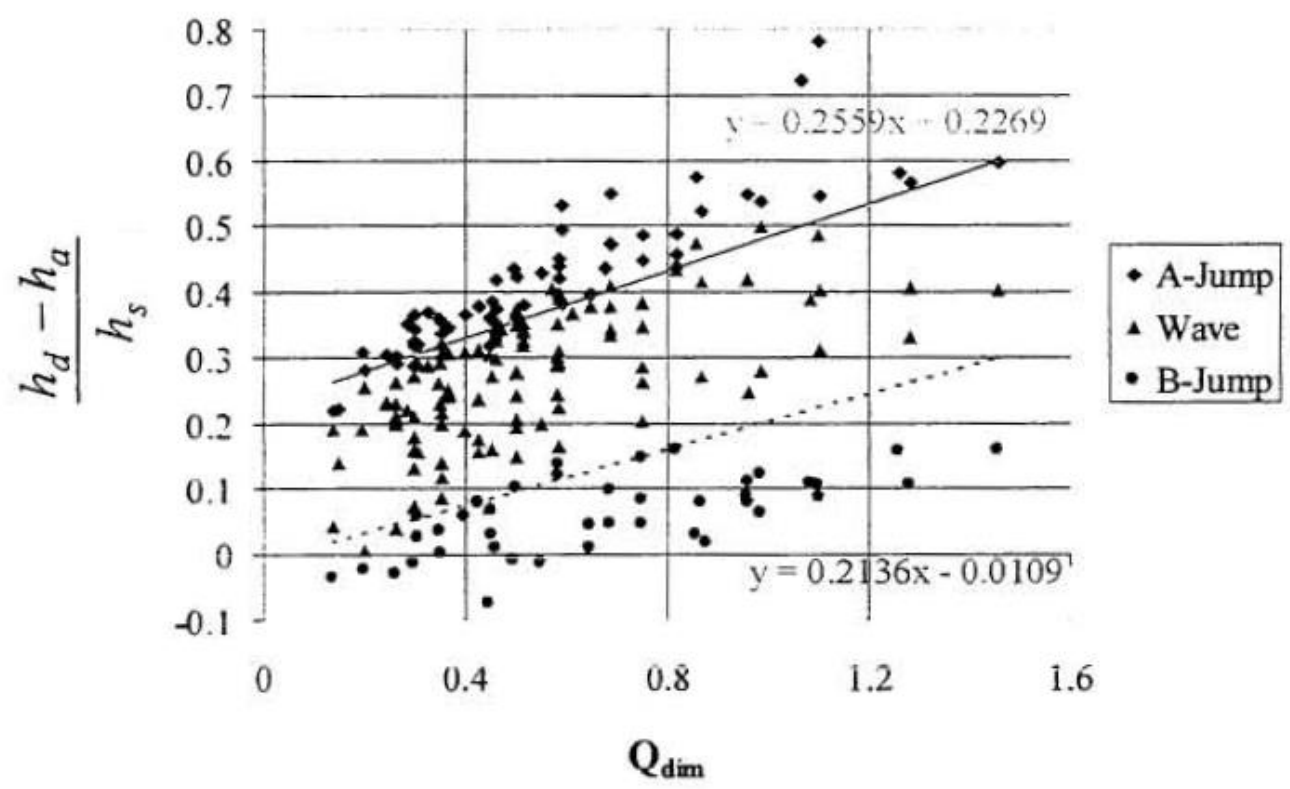

Figure 38. Empirical prediction of hydraulic jump type. (Caisley et al. 1999)

A measure of acceptable flow velocity and depth is required for different types of passage. Criteria can be developed similar to those of Hyra (1978), who provides optimum, acceptable, marginal, and unacceptable ranges of depth and velocity for different types of recreation based on safety minimum and maximum criteria and probabilities of use (Figure 39).

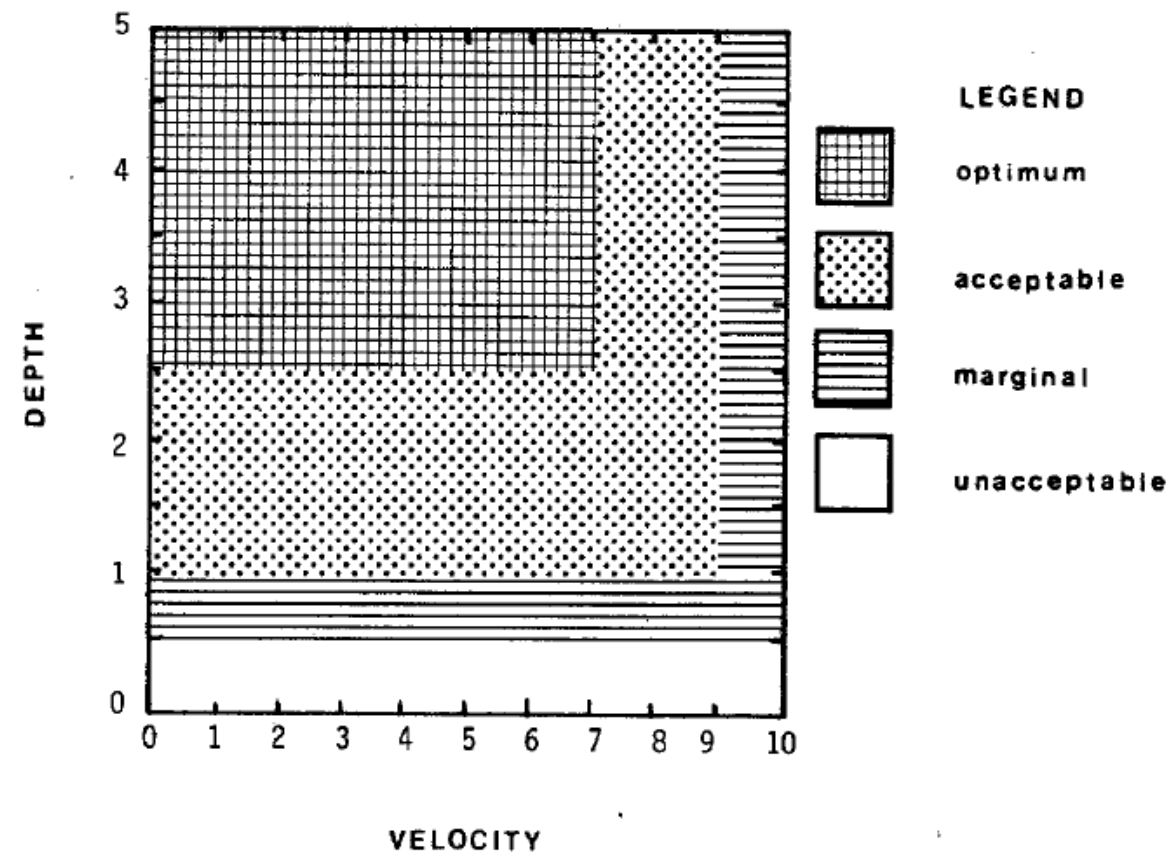

Figure 39. Suggested depth and velocity criteria for canoeing and kayaking. (Hyra 1978) 


\section{D.5 DESIGN CONSTRAINTS}

The analysis of the recreation passage module requirements (Appendix D.2) in conjunction with the functional relationships (Appendix D.3) allows the specification of design constraints for the recreation passage module (Table 25). These are considered the behaviors and features that the recreation passage module must exhibit to accomplish its primary technical objective of allowing small watercraft to pass consistently and safely through the SMH facility. The design constraints are not prescribed for a specific site or module type, but rather form a framework from which specific designs can be created and quantitative evaluation criteria developed. Design constraints are characterized as local when they pertain specifically to the recreation passage module and global when their validity can be extended to the other modules of the SMH facility.

Table 25. Recreation passage module design constraints

\begin{tabular}{|c|c|c|}
\hline Constraint & Formalization & $\begin{array}{c}\text { Scale } \\
(\mathbf{L}=\text { Local, } \\
\text { G= Global })\end{array}$ \\
\hline $\begin{array}{l}\text { Avoid creating a recirculating hydraulic } \\
\text { jump under normal conditions }\end{array}$ & $\begin{array}{l}\text { Safety is the primary consideration of the } \\
\text { recreation module, and the threat of a } \\
\text { recirculating hydraulic jump is the most } \\
\text { significant design challenge for passing small } \\
\text { craft. A basic design constraint is outlined in } \\
\text { Taggart et al. (1984): "any supercritical flow } \\
\text { must make the transition to subcritical flow } \\
\text { with the supercritical discharge on the } \\
\text { surface and on a horizontal attitude." A flow } \\
\text { control device at the module entrance may be } \\
\text { necessary if it cannot be ensured that a } \\
\text { hydraulic jump is prevented under a wide } \\
\text { range of flows. }\end{array}$ & $\mathrm{G}, \mathrm{L}$ \\
\hline $\begin{array}{l}\text { Mitigate all personal safety risks within } \\
\text { the module }\end{array}$ & $\begin{array}{l}\text { The risk of injury, drowning, or death is } \\
\text { present at all hydraulic structures intended } \\
\text { for use by recreationists. Recreation passage } \\
\text { module personal safety risks that must be } \\
\text { mitigated include but are not limited to sharp } \\
\text { edges or protrusions, holes or objects that } \\
\text { entrap arms or legs, pinning against objects } \\
\text { or walls, lack of an appropriate flow path } \\
\text { downstream, and entrapment into the } \\
\text { generation module region }\end{array}$ & $\mathrm{L}$ \\
\hline $\begin{array}{l}\text { Limit the maximum hydraulic drop of } \\
\text { individual drops within the module }\end{array}$ & $\begin{array}{l}\text { The recreation passage module may } \\
\text { incorporate a series of small drops to allow } \\
\text { passage across the hydropower facility within } \\
\text { a reasonable length. For open canoes, a } \\
\text { maximum drop or around } 1 \mathrm{ft} \text { is suggested } \\
\text { (Caisley and Garcia 1999). A maximum drop } \\
\text { height of } 4 \mathrm{ft} \text { is recommended before a } \\
\text { physical model study is necessary (Colorado } \\
\text { Water Conservation Board 2008). This } \\
\text { constraint may be relaxed if the passage } \\
\text { module is designed for a higher level of } \\
\text { difficulty }\end{array}$ & $\mathrm{L}$ \\
\hline
\end{tabular}


Table 24. Recreation passage module design constraints (continued)

\begin{tabular}{|l|l|c|}
\hline \multicolumn{1}{|c|}{ Constraint } & \multicolumn{1}{c|}{ Formalization } & $\begin{array}{c}\text { Scale } \\
\text { (L= Local, } \\
\mathbf{G =} \text { Global) }\end{array}$ \\
\hline $\begin{array}{l}\text { Limit the maximum velocity of water in } \\
\text { the module }\end{array}$ & $\begin{array}{l}\text { The maximum velocity in the module will be } \\
\text { related to the flow rate and slope through the } \\
\text { module. For destination whitewater type } \\
\text { courses, velocities of less than 15 ft/s are } \\
\text { recommended (Simmons et al. 1977). Lower } \\
\text { velocities are required for modules where } \\
\text { novice boaters are expected }\end{array}$ & L, G \\
\hline
\end{tabular}

\section{D.6 DESIGN ENVELOPE SPECIFICATION}

The human element of recreation passage entails safety as the primary design consideration. The mere presence of a recreation passage module reassures those in small craft that they can travel downstream with minimal risk of harm, capsizing, or drowning. Low-head hydraulic structures are notorious for creating unstable and fatal conditions; and extreme caution, foresight, and engineering expertise must be included in any recreation passage module design.

Recreation passage can also significantly enhance the multipurpose value proposition of an SMH facility by providing tourists and recreational enthusiasts with a unique instream experience. Recent boat chutes and water parks in Texas, ${ }^{13}$ Colorado, ${ }^{14}$ and the United Kingdom ${ }^{15}$ have received positive feedback from stakeholders. These examples demonstrate the value of incorporating recreation passage into the design phase, either as a challenging water feature or as a simple conveyance structure. Although these designs have been incorporated into existing non-powered low-head dams, the inclusion of recreation passage module-type facilities into small hydropower projects remains largely untested in practice. However, the requirements, constraints, and measures of performance laid out above are intended to create a bounded envelope for recreation passage module design innovation. Their implications can be summarized as follows:

- A recreation passage module can be designed with varying degrees of difficulty.

- Hydraulics and safety provisions must be appropriately matched to the desired type and difficulty of passage.

- Recirculating hydraulic jumps must be avoided under a range of flow conditions.

- Safe passage must be paramount under all flow conditions.

- The basic geometry of the stream and flow conditions should be known.

- Module cost and size should be optimized within the budget of a facility-longer passage modules help create appropriate passage hydraulics, although they require more materials and a longer foundation module, which will add cost.

- Module cost and operational flexibility should be optimized within the budget of a facility - the module intake must effectively pass a range of discharges while safely conveying recreationists downstream.

- The inclusion of natural features is desirable.

\footnotetext{
${ }^{13}$ http://www.mysanantonio.com/news/environment/article/Mission-Reach-is-open-to-paddling4042020.php\#photo-3726992

${ }_{14}$ http://www.chaffeecountytimes.com/free_content/redesign-of-silver-bullet-rapid-may-benefit-both-boatersand/article cb687376-a49e-11e3-a47e-0017a43b2370.html

15 http://www.medwaycanoetrail.co.uk/trail.php
} 


\section{D.6.1 State-of-the-Art Advances}

Novel designs in the United Kingdom have addressed the combined needs of upstream fish passage and downstream recreational passage through a single sloping chute structure (Figure 40). In these designs, artificial brushes are used to dissipate flow energy to create favorable conditions for fish and boats. One such structure, constructed using reinforced concrete and polysterene void formers to reduce the deadweight of concrete, was designed and installed in an existing bypass channel in less than 12 weeks at a cost of roughly $\$ 120,000(2010 £ 80,000)$.

A series of recreation chutes and slides on the River Medway in the United Kingdom have been incorporated into existing low-head dams (Figure 41). Many of these concrete structures are designed with steep gradients and low flows to enable consistent passage of canoes and kayaks. Flow control is achieved through the use of a regulating gate on the opposite side of the stream. This arrangement applies physical separation to ensure that dangerous, recirculating hydraulics do not occur near points of passage.

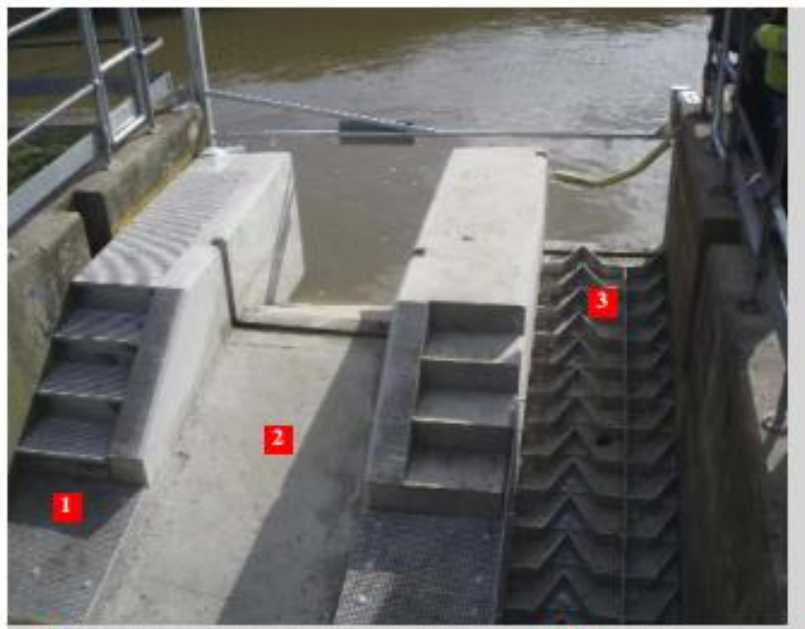

1 Elver (Eel) pass (under gruting)

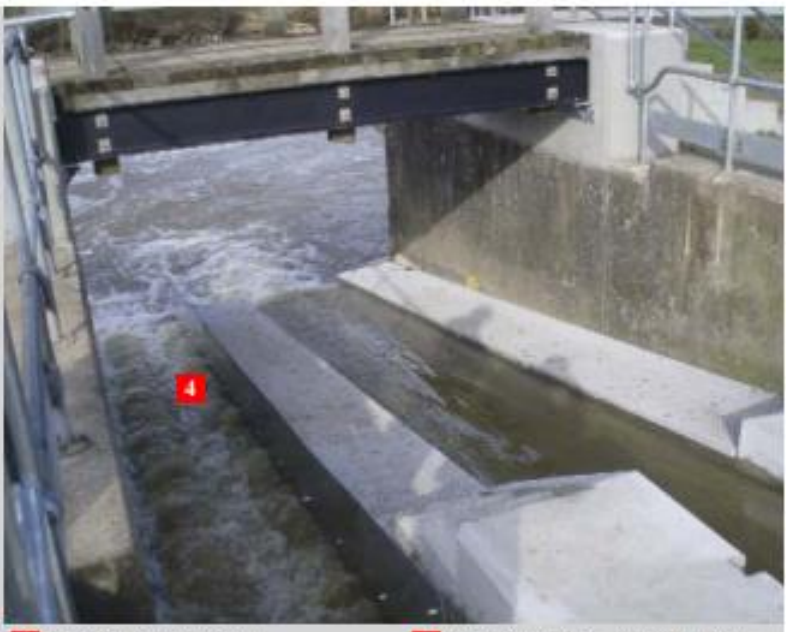

3 Fish Pass (note haffles)
4 Fish Pass baffles controlling flow

Figure 40. Combined canoe and fish pass in the United Kingdom. Both are constructed with a 1:6 gradient. (Photo courtesy of the UK Environment Agency and $\mathrm{CH} 2 \mathrm{M}$ ) 


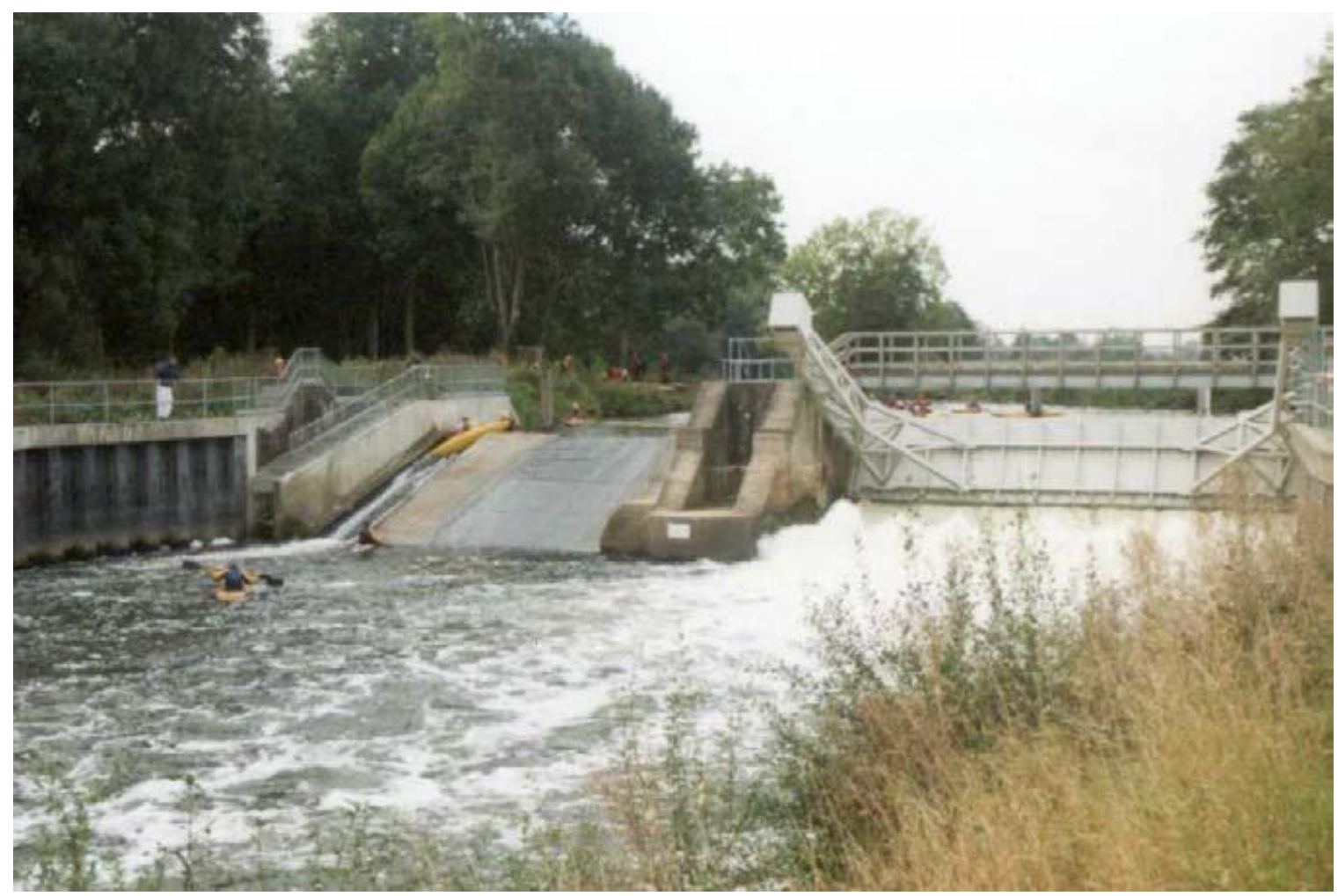

Figure 41. Canoe/kayak slide adjacent to a fish passage structure located at a gated weir. This canoe pass is the steepest gradient in the Medway canoe pass system. A gated weir can be seen on the right, while a canoe/kayak slide can be seen left-of-center. A fish passage channel can be seen to the left of the canoe/kayak slide. (Photo courtesy of the UK Environment Agency)

\section{D.6.2 Research Gaps}

Compared with fish passage, there are a very limited number of public studies, reviews, or design criteria for recreation passage at low-head hydropower facilities. Those present in the literature are generally focused on a single design at a single site, most often at a weir or non-powered dam. Although many of these reports strive to offer general design guidelines, the systematic development of important functional relationships for recreation passage design is a significant research gap.

The need for recreation passage modules at small hydropower dams is apparent, as is the need for additional research. Major research gaps include the following:

- Cost - The biggest challenge from a design perspective is anticipated to be cost. Recreation modules must mitigate the abrupt drop necessary for hydropower generation with a gradient acceptable for passing small watercraft. As head increases, the length of the module must grow disproportionately, adding not only to the module cost itself but also to the cost of a supporting foundation. The length of the module is generally unknown, and historically a model study has been used to estimate the tailwater elevation and backwater profile that create safe hydraulic conditions.

- The use of physical modeling and numerical simulations - In designing recreation passage structures, the current approach is to use customized physical model tests and simulations to analyze the overall hydraulic behavior of the structure; conditions that create a hydraulic jump; the need for and type of inlet control structure; the behavior of in-module structures that dissipate energy, slow the flow, and generate eddies; and conditions that lead to scour downstream. This approach is born out of both the 
lack of general design guidelines for a variety of recreation passage types, and the importance of mitigating personal safety risks. Recreation passage module designs will require the use of simulation and testing capabilities to improve their concept viability.

- Trade-offs between simplicity of design, safety, and aesthetics-Many existing boat chutes and other recreation passage structures are made of concrete, which enables simplicity of design, stability, and endurance, although it generally does not match the surrounding aesthetic. The use of boulders and natural materials may help the module blend into the surrounding environment, although sharp edges and irregular and protruding surfaces increase the complexity of in-module hydraulics and may compromise public safety. Additional research is needed to develop modules that incorporate a natural aesthetic while enabling simplicity of design.

- Desirable degree of difficulty-SMH facilities have the potential to create unique recreation opportunities with varying degrees of difficulty. It is unclear what level of difficulty will be generally accepted by stakeholders and, consequently, should be targeted by designers. Increased difficulty will generally mean steeper gradients, which may reduce overall material costs but increase the need for safety mitigation measures. 


\section{APPENDIX E. WATER PASSAGE MODULE}

Water is the primary resource for energy generation in a hydropower facility. In a strict sense, any flow not used for generation represents a reduction in revenue for the project. However, there is a need to pass water for non-generating purposes. Flood flows in excess of generation capacity must pass safely downstream to minimize upstream flooding and to avoid compromising the stability of the facility. Water is allocated toward fish, sediment, and recreational craft passage structures when needed (see Appendices B, C, and D of this report). Environmental minimum flows are passed through small turbines or conveyed over hydraulic structures to minimize the degradation of downstream fish habitat and river morphology and to mitigate adverse impacts on recreation. Furthermore, the water quantity and quality requirements for uses downstream of the hydropower facility — such as public consumption, irrigation, fishing, commercial use, waste treatment plants, and cooling plants - must be met in conjunction with generation needs. When water cannot flow elsewhere through the facility, it must flow over a water passage module.

\section{E.1 OBJECTIVES}

To minimize the effects of the disruption in the continuity of water passage due to the presence of an SMH facility on a waterway, non-generating water must be transported across the SMH facility. The primary technical objective of the water passage module of the SMH facility is to allow the conveyance of non-generating water through the facility.

\section{Water Passage Module Primary Technical Objective}

Allow the conveyance of non-generating water through the SMH facility

To achieve the overall primary technical objective, the water passage module needs to achieve the following specific objectives (Figure 42):

1. Safely pass flows not usable by the generation module.

2. Support entrance hydraulics for the generation module.

3. Meet the water supply demands and the hydraulic requirements of other uses, such as human water supply, irrigation, commercial supply, wastewater treatment plants, and cooling plants.

4. Maintain hydraulics for sediment passage through the hydropower facility and sediment transport capacities downstream of the hydropower facility.

5. Maintain hydraulics for fish passage through the hydropower facility and for fish habitat upstream and downstream of the hydropower facility.

6. Maintain hydraulics for recreation passage and maintaining recreation quality downstream of the hydropower facility.

7. Integrate structurally into foundation module. 


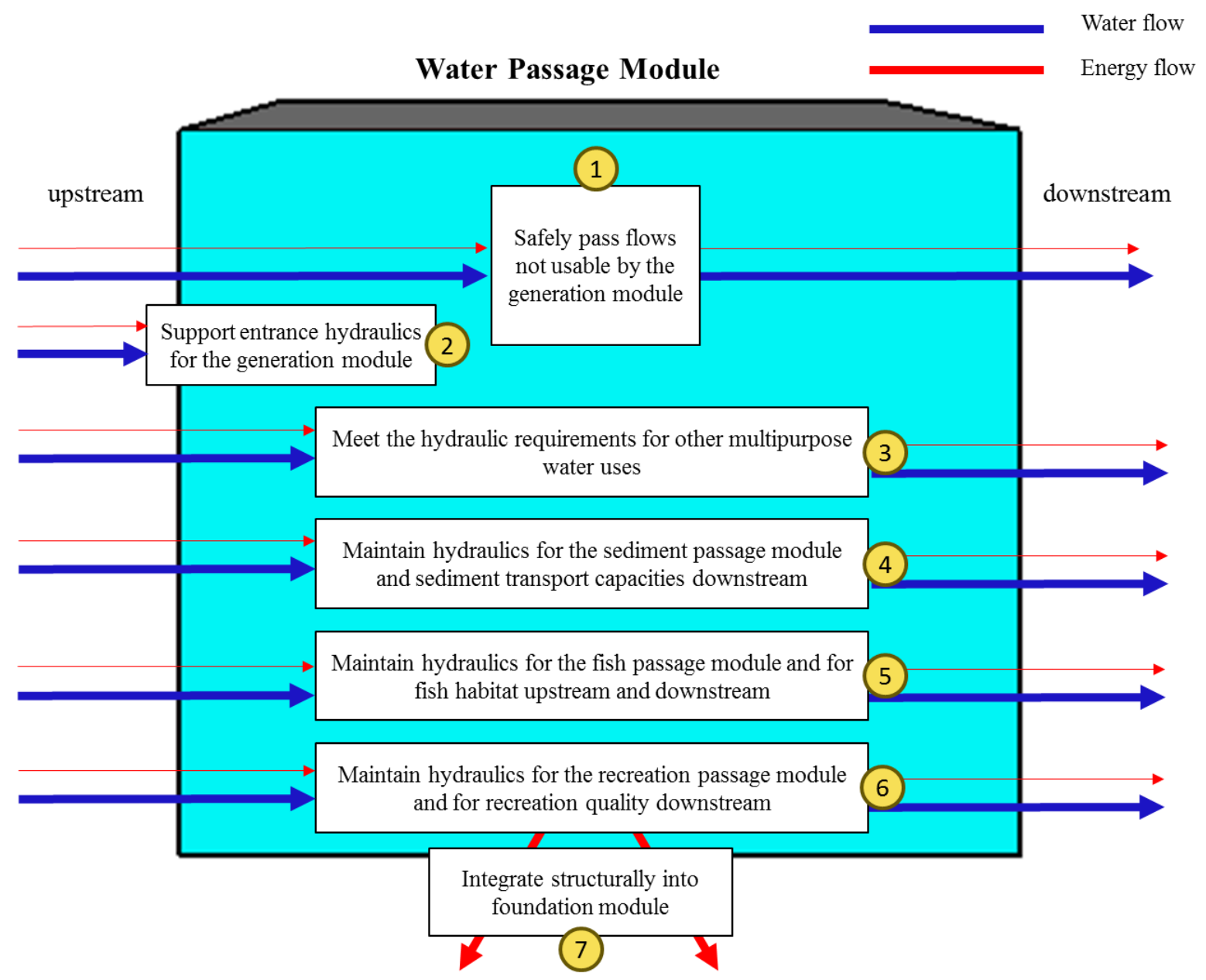

Figure 42. Conceptual schematic of the specific objectives of a water passage module.

\section{E.2 REQUIREMENTS}

The requirements for the water passage module are quantifiable characteristics or behaviors that the water passage module must exhibit to ensure its successful operation. Meeting these requirements ensures that the water passage module will achieve its specific objectives and thereby its primary technical objective. The requirements for the water passage module are summarized in Table 26, Table 27, and Table 28, where they are characterized as Functional, Performance, Interface, and Other, similar to the functional requirements of the fish, sediment, and recreation passage modules (Appendices B.2, C.2, and D.2, respectively). Furthermore, in these tables, the relationship of each requirement for the water passage module with the five constituents of the river continuum - water, sediment, energy, organisms and nutrients - is indicated in an analogous manner to the requirements for the other passage modules (Appendices B.2, C.2, and D.2, respectively). In Table 26, Table 27, and Table 28, the water passage module requirements are grouped by its specific objectives to indicate the close association between the water passage module requirements and specific objectives. 
Table 26. Water passage module requirements. In the fourth column: $F=$ Functional; $P=$ Performance; $I=$ Interaction; $\mathrm{O}=$ other. In columns $6-11$, an " $\mathrm{X}$ " denotes a relationship to the river continuum constituent indicated in the top row

\begin{tabular}{|c|c|c|c|c|c|c|c|c|c|c|}
\hline & & Requirement & $\begin{array}{c}\text { Type } \\
(\mathbf{F} / \mathbf{P} / \mathbf{I} / \mathbf{O})\end{array}$ & Formalization/rationale & 幽 & 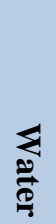 & 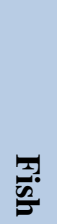 & 邑 & 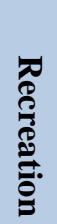 & 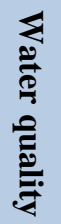 \\
\hline 1 & & $\begin{array}{l}\text { Safely pass flows not usable } \\
\text { by the generation module }\end{array}$ & & & & & & & & \\
\hline & $\mathrm{a}$ & $\begin{array}{l}\text { Route flows around the } \\
\text { generation module to } \\
\text { appropriately sized water } \\
\text { passage modules }\end{array}$ & $\mathrm{F}, \mathrm{I}$ & $\begin{array}{l}\text { Flows that cannot be used by } \\
\text { the generation module should } \\
\text { be passed downstream to } \\
\text { prevent overtopping of the } \\
\text { SMH facility }\end{array}$ & $\mathrm{X}$ & $\mathrm{X}$ & & & & \\
\hline 2 & & $\begin{array}{l}\text { Support entrance hydraulics } \\
\text { for the generation module }\end{array}$ & & & & & & & & \\
\hline & $\mathrm{a}$ & $\begin{array}{l}\text { Partition flows between the } \\
\text { water passage module and } \\
\text { the generation module }\end{array}$ & $\mathrm{F}, \mathrm{I}$ & $\begin{array}{l}\text { The generation module will } \\
\text { require a consistent flow of } \\
\text { water to ensure reliable and } \\
\text { efficient operation. The water } \\
\text { passage module should be } \\
\text { designed to ensure flows are } \\
\text { smoothly passed to the } \\
\text { generation module under } \\
\text { normal, low, and high water } \\
\text { conditions. }\end{array}$ & $\mathrm{X}$ & $\mathrm{X}$ & & & & \\
\hline & $\mathrm{b}$ & $\begin{array}{l}\text { Maintain sufficient head and } \\
\text { intake submergence for the } \\
\text { generation module }\end{array}$ & $\mathrm{F}, \mathrm{I}$ & $\begin{array}{l}\text { The generation module intake } \\
\text { should remain submerged to } \\
\text { avoid head losses, and the } \\
\text { head above the intake should } \\
\text { be maintained within the } \\
\text { design range of the generation } \\
\text { module to ensure reliable and } \\
\text { efficient power production. }\end{array}$ & & & & & & \\
\hline 3 & & $\begin{array}{l}\text { Meet the hydraulic } \\
\text { requirements for other } \\
\text { multipurpose water uses, } \\
\text { such as water supply, } \\
\text { irrigation, wastewater } \\
\text { treatment, and cooling water }\end{array}$ & & & & & & & & \\
\hline & $\mathrm{a}$ & $\begin{array}{l}\text { Route river flow to water } \\
\text { passage structures designed } \\
\text { to pass a predetermined flow } \\
\text { to meet demand }\end{array}$ & F, P & $\begin{array}{l}\text { Water should be routed to a } \\
\text { water passage structure that } \\
\text { supplies the required flows } \\
\text { downstream }\end{array}$ & & $X$ & & $X$ & & \\
\hline & b & $\begin{array}{l}\text { Maintain hydraulic } \\
\text { conditions required for } \\
\text { supplying these uses }\end{array}$ & $\mathrm{F}, \mathrm{P}$ & $\begin{array}{l}\text { In addition to the amount of } \\
\text { water flow, many uses, such as } \\
\text { cooling intakes, require certain } \\
\text { ranges of depth or flow } \\
\text { velocity downstream of the } \\
\text { facility, which must be } \\
\text { satisfied }\end{array}$ & & $\mathrm{X}$ & & $\mathrm{X}$ & & \\
\hline
\end{tabular}


The water passage module will consist of suitable structures to allow a portion of the flow to bypass the SMH facility, including spillways, weirs, and bypass channels. These structures will need to have intakes or crests that are appropriately sized to route the expected discharges (USBR 1977). For instance, an orifice used to convey non-generating flows downstream must have a sufficient diameter to allow the necessary discharges through the SMH facility. A broad-crested weir must have a length designed to pass non-generating flows. An important requirement is that the water passage module must allow the conveyance of predetermined discharges for a range of flow conditions; a stage-discharge relationship quantifying the volume of discharge to be passed for a given water depth during both the low and high flow levels expected at the SMH facility must be developed.

Many downstream water uses require that specific flow hydraulics be maintained around intakes to ensure the undisturbed operation of these facilities. Intakes for certain facilities, such as pumping stations, require a minimum level of submergence, which in turn requires maintaining a minimum required flow depth of the river (Yildirim and Kocabac 1995; Werth and Frizzel 2009). Other types of intakes may require the flow velocity or bed shear stress around the intake to be within certain ranges to prevent excessive scour (Maclean 1991; Nakato and Ogden 1998). The water passage module needs to account for the requirements of these various uses and supply water to fulfill them. It is likely, however, that the requirements of some of the various uses will conflict with one another; and it may not be feasible for all of them to be entirely satisfied. Therefore, a site assessment should be performed to establish acceptable performance levels to satisfy each type of water use.

During flood conditions, it is possible that the amount of water flow will exceed what the generation module can safely use. The excess water flow, especially during more extreme flood events, may overtop the SMH facility, threatening its stability. The water passage module must be able to convey any excess flood discharge safely downstream to prevent its compromising the stability and safety of the SMH facility. To ensure its capability to do so, the sizes of the water passage structures making up the water passage module must be appropriately selected so that they can handle these water flows.

As discussed in Appendix C, a suitable amount of water flow must be diverted to the sediment passage module to ensure the transport of sediment across the SMH facility. The water flow required by the sediment passage module to achieve its primary technical and specific objectives must be supplied by the water passage module (Table 27). This requirement entails that an interface between the water and sediment passage modules must be established in the SMH facility to ensure seamless operation of the sediment passage module. Furthermore, the presence of hydropower facilities is known to reduce the downstream competent flows required for transporting sediment (Brandt 2000; Graf 2006; Schmidt and Wilcock 2008; Magilligan et al. 2013). Researchers have documented that disruption of the stream competence often leads to undesired morphologic changes, such as armoring, channel narrowing, and excess bank erosion (Appendix C). To minimize such changes, the water passage module must allow flows through the SMH facility that are competent to transport the range of sediment sizes encountered at the SMH facility (Table 27). 
Table 27. Water passage module functional requirements. In the fourth column: $\mathrm{F}=$ Functional; $\mathrm{P}=$ Performance; $\mathrm{I}=$ Interaction; $\mathrm{O}=$ other. In columns 6-10, an " $\mathrm{X}$ " denotes a relationship to the river continuum constituent indicated in the top row

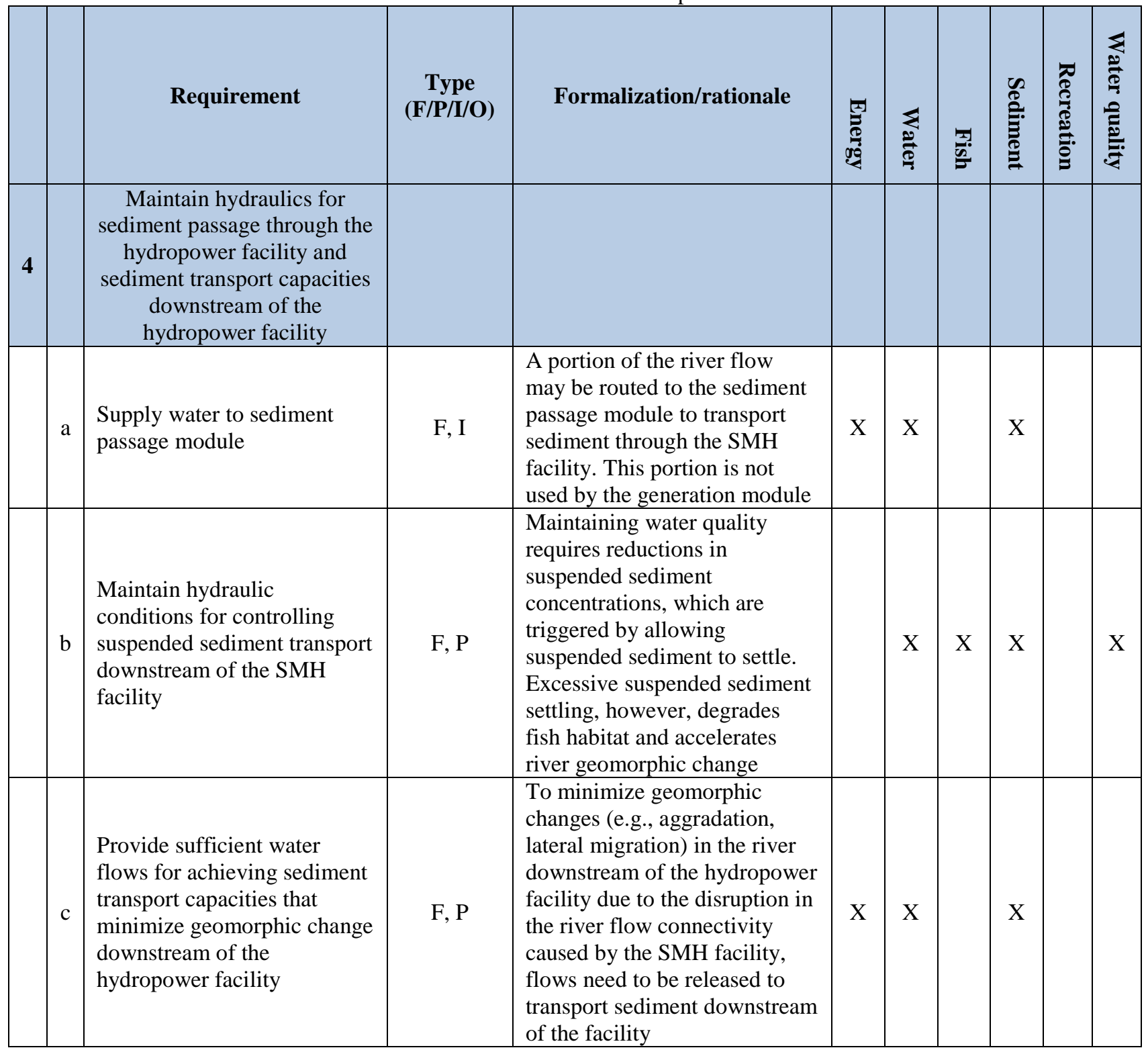

An important requirement for the water passage module is that it control the amount of suspended sediment transported within the water column downstream of the SMH facility. Suspended sediment is a key contributor to poor water quality; and its contributions to reducing water clarity, hindering water treatment, and impacting the health of aquatic organisms are well documented (Davies-Colley and Smith 2001; Owens et al. 2005; Bilotta and Brazier 2008). In addition, suspended sediments often transport contaminants such as heavy minerals, phosphorus, and nitrogen, which may be harmful to humans as well as to other organisms. Therefore, the flow conditions downstream of the SMH should promote the settling out of suspended sediment and minimize its resuspension (Table 27). At the same time, excessive settling of fine sediment promotes river aggradation and fine sediment intrusion into the river bed, which degrade fish habitat spawning gravels (Sear 1993; Kondolf 2000;). Therefore, the flow conditions downstream of the SMH facility need to be controlled by the water passage module so that the conflicting requirements 
are reconciled. Appropriate measures of performance, examined in Appendix E.5, should be established to quantify the degree to which each of these requirements is satisfied.

In addition, as noted in Appendix B.2, the water passage module needs to supply the fish passage module with water to maintain flow conditions that allow the fish passage module to achieve its specific and primary technical objectives (Table 28). As in the case of the sediment passage module, an appropriate interface between the fish passage and the water passage modules should be present to ensure that the appropriate flows are diverted to the fish passage module. At the same time, the water passage module must pass enough water to maintain fish habitat downstream of the SMH facility. As discussed in Appendix B, acceptable fish habitat requires certain mean and turbulent flow characteristics, including minimum flow depth, maximum velocity ranges, bed slope, and turbulence levels (Table 11). The water passage module therefore is required to convey sufficient flow discharge downstream to satisfy these requirements for maintaining acceptable fish habitat quality (Dermisis and Papanicolaou 2009; Reinfelds et al. 2010; Noonan et al. 2012).

Similar to the sediment and fish passage modules, the recreation passage module need to be supplied with water to achieve its primary technical objective of passing recreational craft through the SMH facility (Table 28). Therefore, an important requirement for the water passage module is to interface with the recreational passage module and supply the necessary water flows, as determined in Appendix D of the present report. In addition, the water passage module is required to supply sufficient flows downstream of the facility to maintaining the hydraulics necessary to recreation. For example, recreational craft have specific depth and flow discharge requirements for different recreational activities, such as kayaking and whitewater rafting (Vandas et al. 1990, BLM 2016). At the same time, an additional requirement for the water passage module is to minimize the likelihood of occurrence of excessive flow velocities that might compromise the safety of recreational craft.

Table 28. Water passage module functional requirements. In the fourth column: $\mathrm{F}=$ Functional; $\mathrm{P}=$ Performance; $\mathrm{I}=$ Interaction; $\mathrm{O}=$ other. In columns 6-10, an " $\mathrm{X}$ " denotes a relationship to the river continuum constituent indicated in the top row

\begin{tabular}{|c|c|c|c|c|c|c|c|c|c|c|}
\hline & & Requirement & $\begin{array}{c}\text { Type } \\
(\mathbf{F} / \mathbf{P} / \mathbf{I} / \mathbf{O})\end{array}$ & Formalization/rationale & 멀 & 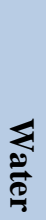 & $\frac{3}{\underline{n}}$ & 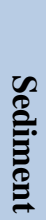 & 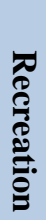 & 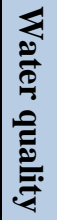 \\
\hline 5 & & $\begin{array}{l}\text { Maintain hydraulics for fish } \\
\text { passage through the } \\
\text { hydropower facility and for } \\
\text { fish habitat upstream and } \\
\text { downstream of the } \\
\text { hydropower facility }\end{array}$ & & & & & & & & \\
\hline & $\mathrm{a}$ & $\begin{array}{l}\text { Supply water to the fish } \\
\text { passage module }\end{array}$ & $\mathrm{F}, \mathrm{I}$ & $\begin{array}{l}\text { A predetermined amount of } \\
\text { water should be diverted to the } \\
\text { fish passage module to allow } \\
\text { fish migration along the river. } \\
\text { This portion is not used by the } \\
\text { generation module }\end{array}$ & & $X$ & $X$ & & & \\
\hline & $\mathrm{b}$ & $\begin{array}{l}\text { Provide sufficient water } \\
\text { flows for maintaining fish } \\
\text { habitat hydraulics upstream } \\
\text { and downstream of the } \\
\text { hydropower facility }\end{array}$ & $\mathrm{F}, \mathrm{P}$ & $\begin{array}{l}\text { Predetermined flows need to } \\
\text { be passed downstream to } \\
\text { maintain fish habitat } \\
\text { conditions and prevent loss of } \\
\text { biodiversity }\end{array}$ & & $X$ & $\mathrm{X}$ & & & \\
\hline
\end{tabular}


Table 27. Water passage module functional requirements (continued)

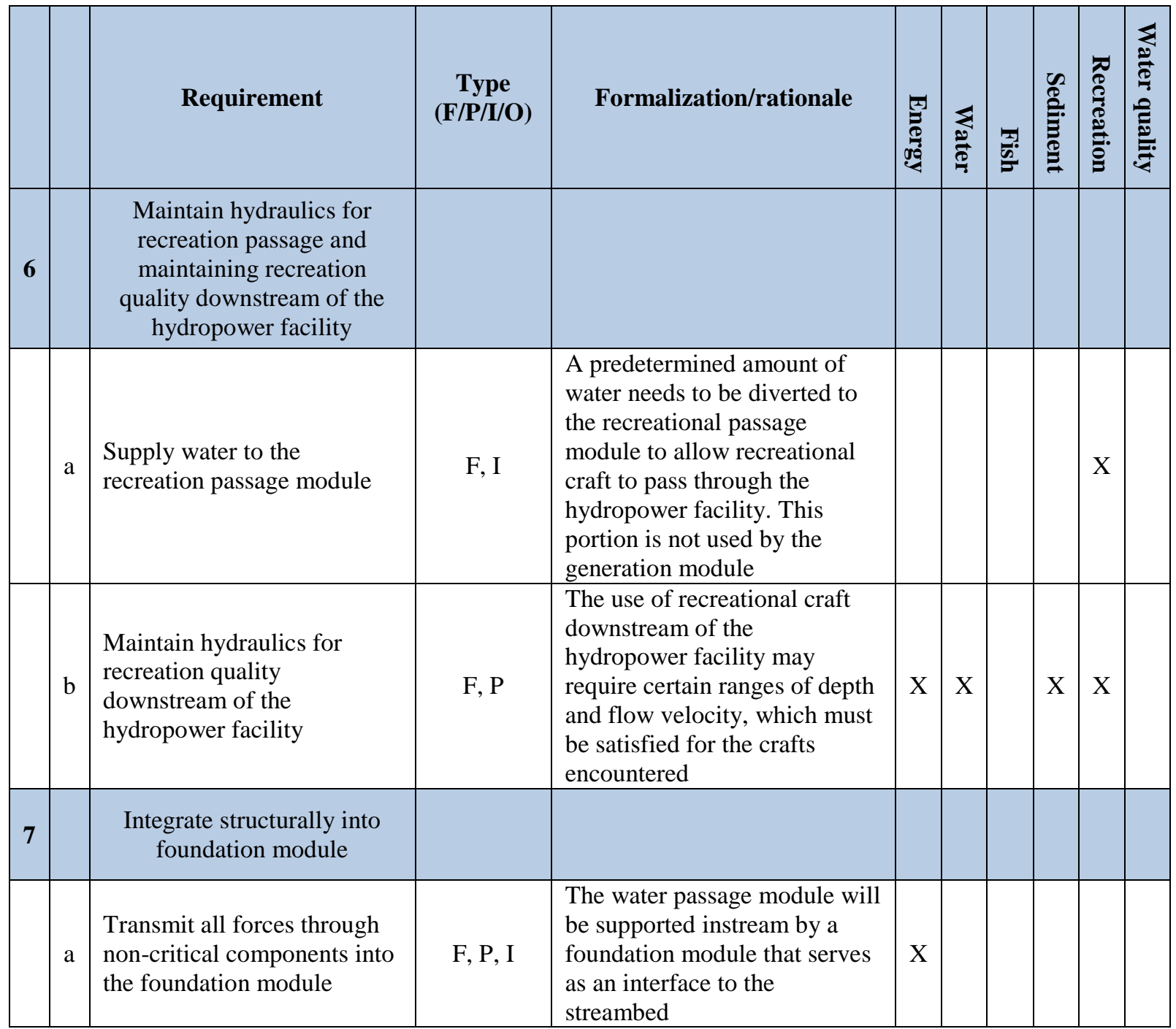

\section{E.3 INPUTS, FUNCTIONAL RELATIONSHIPS AND PROCESSES}

This section identifies the processes that govern the operation and behavior of the water passage module. These processes are quantified with functional relationships, which are also listed in this section for the water passage module. Knowledge of these processes and functional relationships is a prerequisite for understanding the function and predicting the behavior of the water passage module. Therefore, the functional relationships provide the basis for the water passage module design, so that it accomplishes its primary and secondary technical objectives. Before examining the water passage module functional relationships, it is important to identify the key variables, which are the inputs to these functional relationships.

\section{E.3.1 Necessary Inputs}

The key variables that are inputs to the water passage module functional are presented in Table 29. These variables are divided into five categories, depending on their relation to sediment, flow, geomorphologic 
or chemical processes, or geometry. This categorization further allows systematic investigation of the functional relationships to which these inputs relate.

Table 29. Water passage module necessary inputs

\begin{tabular}{|l|l|}
\hline \multicolumn{1}{|c|}{$\begin{array}{c}\text { Identification of } \\
\text { key inputs }\end{array}$} & \multicolumn{1}{c|}{ Formalization } \\
\hline Flow variables & $\begin{array}{l}\text { Range of flow discharges encountered, watershed hydrologic } \\
\text { characteristics, climate, land use/land cover, flow depth, turbulent } \\
\text { shear stress, water temperature, friction factor, flood frequency and } \\
\text { magnitude, tailwater depth, flow needs of other modules, flow needs of } \\
\text { other multipurpose uses }\end{array}$ \\
\hline Geometric variables & $\begin{array}{l}\text { Geometry and shape of passage module, elevation difference upstream } \\
\text { and downstream of facility, passage module slope, passage module } \\
\text { length, stream cross-sectional geometry upstream and downstream of } \\
\text { SMH facility, geometry of other modules }\end{array}$ \\
\hline Geomorphologic variables & $\begin{array}{l}\text { River bed slope, bed topography, friction factor, channel sinuosity, } \\
\text { bank geometry, bank soil composition }\end{array}$ \\
\hline Sediment characteristic variables & $\begin{array}{l}\text { Sediment grain size distribution (e.g., median grain diameter, } \\
\text { geometric standard deviation), friction factor, sediment fall velocity, } \\
\text { sediment angularity, sediment shape, relative protrusion, suspended } \\
\text { sediment concentration }\end{array}$ \\
\hline
\end{tabular}

\section{E.3.2 Functional Relationships}

The functional relationships related to the operation of the water passage module, along with a brief statement of the importance of each one, are tabulated in Table 30. The river flow discharge at the location of an SMH facility is intimately related to the water surface runoff, which is the amount of water from precipitation, snowmelt, or other sources that does not infiltrate into the soil but is conveyed into the river (Figure 43). The surface runoff in a watershed is a function of the watershed hydrologic characteristics, including the climatic conditions at the watershed, the watershed drainage area, the land use and land cover of the watershed, its topography, and its soil type (Maidment 1993; Papanicolaou and Abban et al. 2016). The most important climatic condition influencing surface runoff and thus river flow is precipitation, which quantifies the amount of water contributed to the watershed by the rainfall. It is often characterized by the rainfall intensity, which is the volume of precipitated water per unit of time, the duration of rainfall, and its distribution over the watershed. It is well documented (Figure 44) that river discharge is related via a power functionality to the drainage area of the watershed, with larger watersheds yielding higher river discharges (Maidment 1993; Mulvihill and Baldigo 2012).

Table 30. Functional relationships governing water passage module operation

\begin{tabular}{|l|l|l|}
\hline \multicolumn{1}{|c|}{ Relationship of } & \multicolumn{1}{|c|}{ To } & \multicolumn{1}{c|}{ Rationale/importance } \\
\hline Flow discharge & $\begin{array}{l}\text { 1. Watershed } \\
\text { contributions } \\
\text { 2. Passage module } \\
\text { geometry } \\
\text { 3. Available head } \\
\text { 4. Tailwater elevation }\end{array}$ & $\begin{array}{l}\text { The flow rate that needs to be passed depends on the flow that is } \\
\text { conveyed by the river upstream of the SMH facility, which } \\
\text { depends on the contributing watershed characteristics. The flow } \\
\text { rate that can be passed through the SMH facility is dependent on } \\
\text { the size of the passage structure (e.g., weir, spillway) and the } \\
\text { available head }\end{array}$ \\
\hline $\begin{array}{l}\text { Flow velocity } \\
\text { downstream of } \\
\text { facility }\end{array}$ & $\begin{array}{l}\text { Flow discharge, } \\
\text { slope, friction factor, } \\
\text { river cross-sectional } \\
\text { geometry, river } \\
\text { geomorphology, } \\
\text { grain size distribution }\end{array}$ & $\begin{array}{l}\text { The flow velocities downstream of the hydropower facility are } \\
\text { predominantly a function of the flow rate conveyed, and the } \\
\text { river cross-sectional geometry, which dictates the available flow } \\
\text { area. The river bed morphology as well as the sizes of the } \\
\text { sediment grains making up the river bed, determine the friction } \\
\text { factor, which is a measure of the bed the resistance to the flow }\end{array}$ \\
\hline
\end{tabular}


Table 29. Functional relationships governing water passage module operation (continued)

\begin{tabular}{|c|c|c|}
\hline Relationship of & To & Rationale/importance \\
\hline $\begin{array}{l}\text { Flow depth } \\
\text { downstream of } \\
\text { facility }\end{array}$ & $\begin{array}{l}\text { Flow discharge, } \\
\text { slope, friction factor, } \\
\text { river cross-sectional } \\
\text { geometry, river } \\
\text { geomorphology, } \\
\text { grain size distribution }\end{array}$ & $\begin{array}{l}\text { Similar to the flow velocity, the flow depth at a river cross- } \\
\text { section depends on the flow discharge and river cross-sectional } \\
\text { geometry. Flow depth also depends on the resistance to the flow, } \\
\text { which is governed by the river geomorphology and the sizes and } \\
\text { types of the river bed material }\end{array}$ \\
\hline $\begin{array}{l}\text { Turbulence } \\
\text { characteristics } \\
\text { downstream of } \\
\text { facility }\end{array}$ & $\begin{array}{l}\text { Flow discharge, } \\
\text { slope, river } \\
\text { geometry, river } \\
\text { geomorphology, } \\
\text { grain size distribution }\end{array}$ & $\begin{array}{l}\text { Turbulence is generated broadly from the interaction of the } \\
\text { mean flow with the roughness elements on a river bed. As a } \\
\text { result, the turbulent flow patterns are governed from the mean } \\
\text { flow quantities, e.g., flow discharge, velocity, depth, and the } \\
\text { river geomorphologic characteristics, such as river slope, bed } \\
\text { sediment sizes and the presence of large-scale geomorphologic } \\
\text { features such as bedforms }\end{array}$ \\
\hline $\begin{array}{l}\text { Sediment transport } \\
\text { capacity }\end{array}$ & $\begin{array}{l}\text { Flow discharge, flow } \\
\text { depth, bed slope, } \\
\text { grain size distribution }\end{array}$ & $\begin{array}{l}\text { The capacity for transport of expected sediment loads stems } \\
\text { from the balance between flow shear and resisting forces. The } \\
\text { former are dependent broadly on flow discharge, depth and } \\
\text { slope, whereas the latter are dependent mostly on the sediment } \\
\text { sizes to be transported, the interaction between these sizes, and } \\
\text { the large-scale geomorphology of the river, e.g., the existence of } \\
\text { bedforms }\end{array}$ \\
\hline $\begin{array}{l}\text { Suspended sediment } \\
\text { concentration }\end{array}$ & $\begin{array}{l}\text { 1. Mean flow } \\
\text { characteristics and } \\
\text { patterns } \\
\text { 2. Turbulent flow } \\
\text { characteristics } \\
\text { 3. Supplied sediment } \\
\text { 4. Settling velocity }\end{array}$ & $\begin{array}{l}\text { 1. The mean flow velocity is the main driver for the } \\
\text { transportation of suspended sediment downstream } \\
\text { 2. Turbulence causes diffusion and mixing of the transported } \\
\text { sediment concentration } \\
\text { 3. The amount of sediment transported downstream in } \\
\text { suspension is dependent on the amount of sediment supplied } \\
\text { from upstream } \\
\text { 4. The sediment settling velocity quantifies the tendency of } \\
\text { sediment to deposit or remain in suspension. }\end{array}$ \\
\hline
\end{tabular}

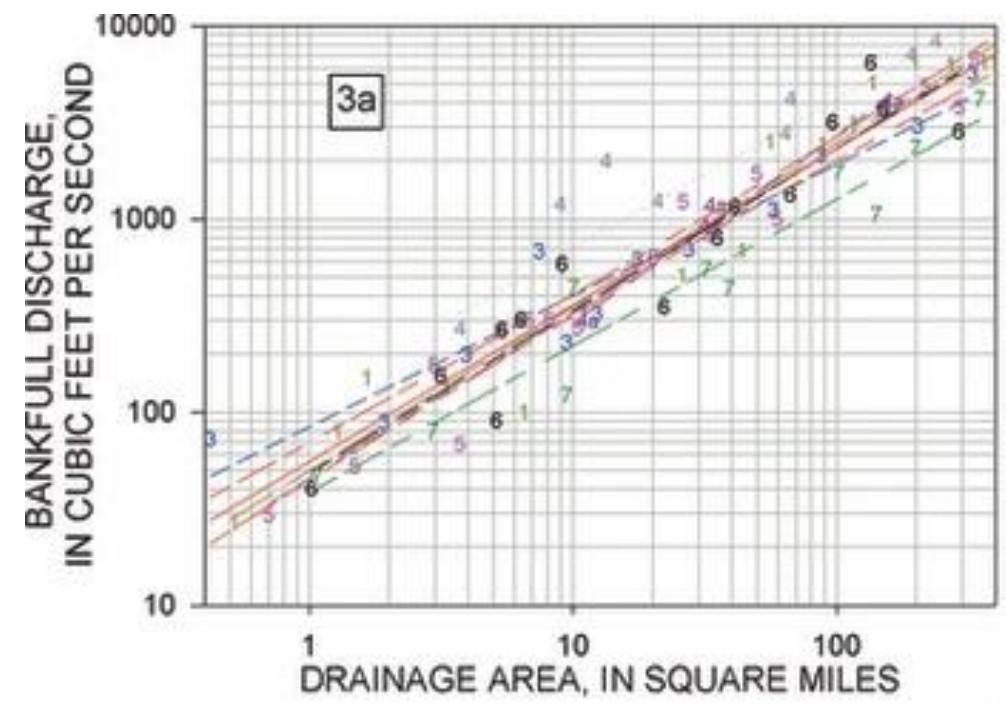

Figure 43. Dependence of the bankfull discharge on the watershed drainage area for different hydrologic units in New York state. (Mulvihill and Baldigo 2012) 
(a)
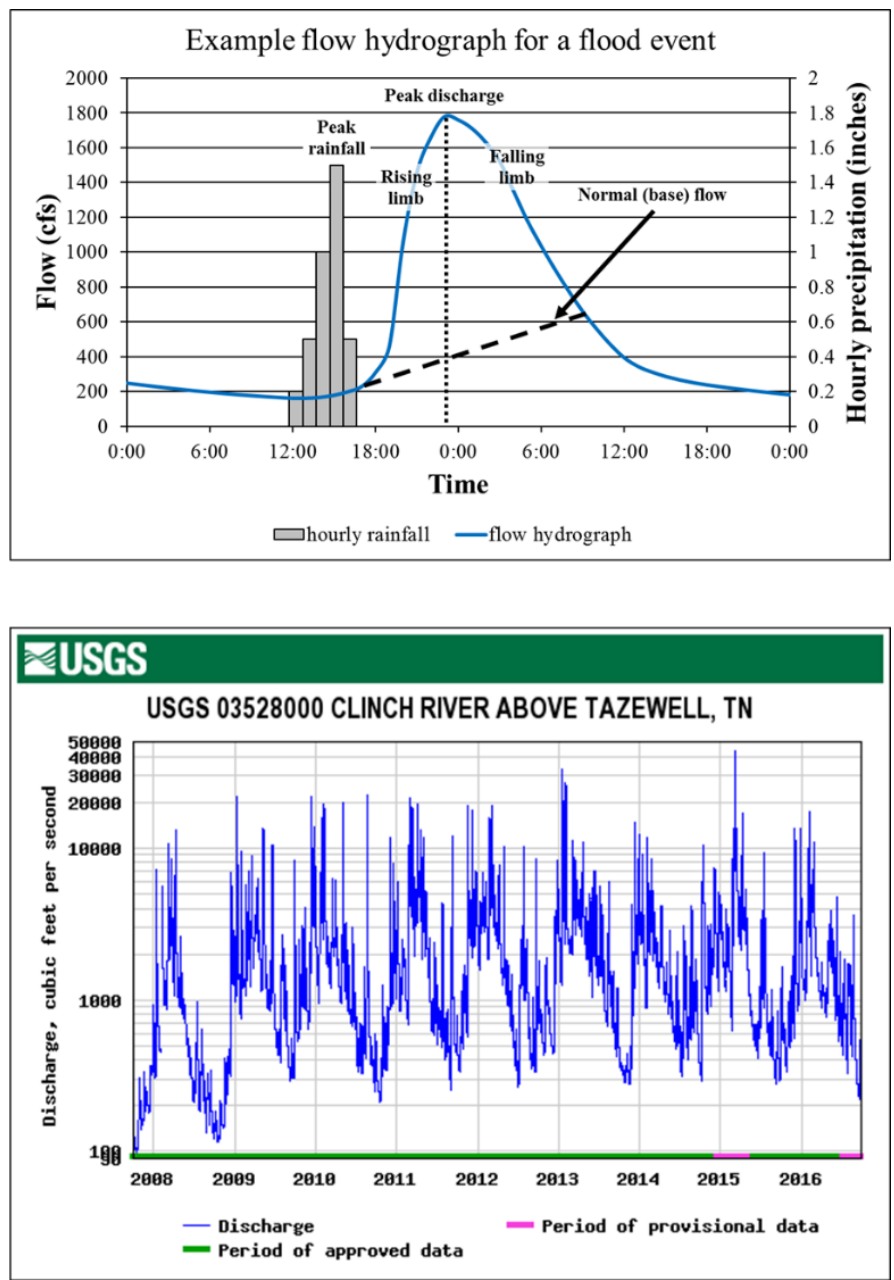

Figure 44. (a) Example of a typical hydrograph indicating the flow response (blue curve) to precipitation (gray bars). (b) Example hydrograph for the past 9 years for the Clinch River near Tazewell, Tennessee.

The topography of the watershed also plays an important role in surface runoff. Typically, the effects of the watershed topography are considered through the average slope of the watershed and a characteristic length, which is representative of the watershed shape and quantifies the average distance that water must travel within the watershed before reaching the river. For instance, watersheds with more elongated shapes tend to yield smaller river discharges, as water needs to travel further before reaching the river. Furthermore, the land use and land cover of the watershed play an important role, as they determine the amount of precipitation that infiltrates into the soil and does not generate runoff. The presence of denser vegetative cover minimizes infiltration and accelerates water runoff. The presence of impervious surfaces, such as paved roads and buildings, effectively eliminates infiltration, thus increasing surface runoff and river discharge. Along the same lines, the type of soil in the watershed controls water infiltration and therefore the amount of runoff. Soils with higher clay content exhibit smaller infiltration and therefore higher runoff.

The variability in climatic conditions, land use, land cover, and soil type in a watershed leads to temporal variations in surface runoff and thus in river flow. This temporal variability in water flow is depicted by the flow hydrograph (Figure 44a), which gives the river discharge at a point along the river as a function of time. The construction and analysis of hydrographs allow a determination of the flood magnitude and frequency at the location of the $\mathrm{SMH}$, which in turn allows prediction of the flows that will be encountered by the SMH facility (Figure 44b). 
The water passage module typically consists of a water conveyance structure, such as a spillway, an orifice, or an open channel (USBR 1977). For all these types of structures, the flow discharge that can be conveyed across the structure is a function of the available head, which is the difference between the water surface elevations upstream and downstream of the conveyance structure (Chaudhry 2008). In general, for a weir-type device, the flow, $Q$, and water levels or head, $h$, are generally related as follows:

$$
Q \propto f\left(G, C, h^{a}\right)
$$

The parameter $G$ refers to the geometry of the mechanism structure used to pass flow, such as the width of a sill over which flow passes (for a weir-type device), length over which the flow passes (for a weirtype device), width of channel, slope, and bed roughness (for open channel flow), or diameter of conduit (for a conduit flow). The parameter $C$ is a coefficient used to align empirical formulations with actual flow.

In the case of a spillway, for example, the conveyed discharge is a function of the shape of the spillway weir and the spillway length. The dependence of the conveyed spillway discharge on the weir shape is depicted by the discharge coefficient (Figure 45). For orifices and open channels used for passing water, the discharge through the structure is a function of the structure cross-sectional geometry, slope, and bed roughness. Knowledge of these characteristics allows the prediction of the discharges that can be conveyed through the orifice or open channel. Conversely, these functional relationships allow estimation of the structure dimensions required to allow the conveyance of a given discharge.

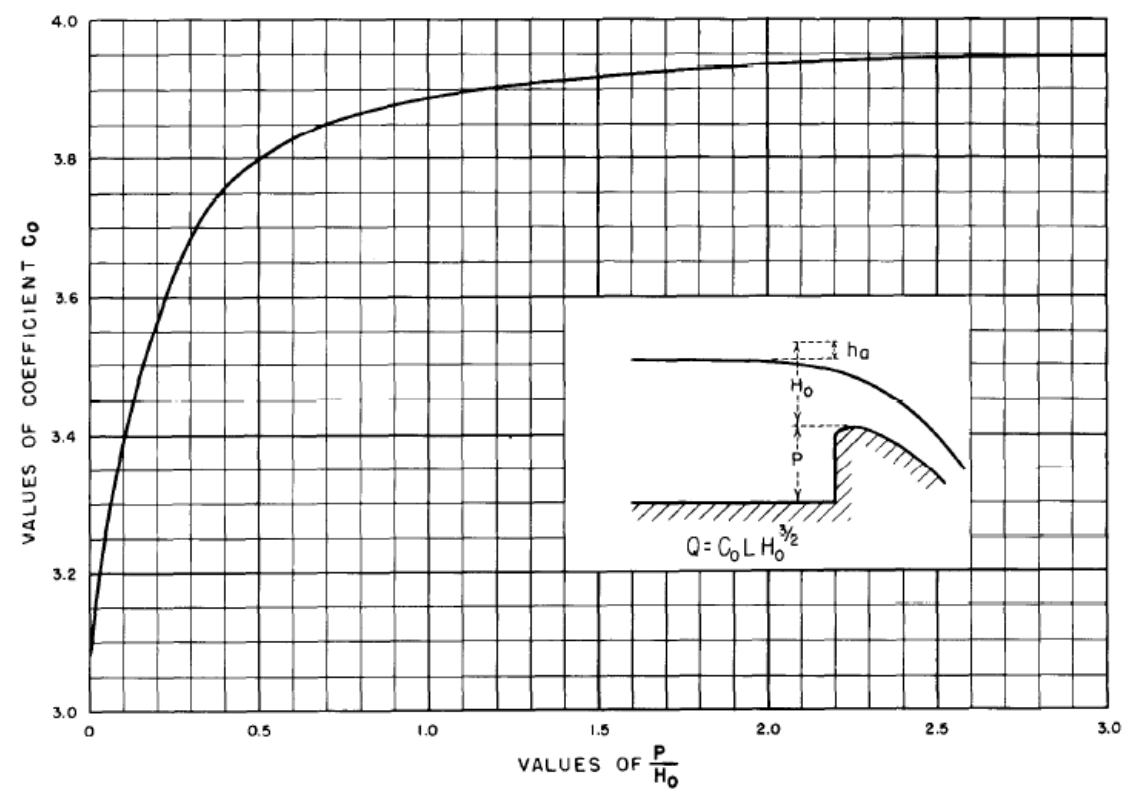

Figure 45. Relationship between the weir discharge coefficient (vertical axis) and the available water head (horizontal axis) for an ogee-shaped weir. (USBR 1977)

Downstream of the SMH facility, the prevailing flow depth in a river is a function of the dischargewhich in this case is controlled by the water passage module of the SMH facility - as well as of the river bed slope, the cross-sectional geometry of the river, and the resistance that the flow encounters on the river bed and banks. The resistance of the river bed and banks to the flow has long been an object of study. This resistance has typically been quantified by the friction factor, which has been related to a 
characteristic length scale representative of the sediment sizes making up the bed. However, the friction factor is also a function of the relative submergence, which expresses the ratio of the flow depth to the characteristic height of the sediment making up the bed. For most rivers, the relative submergence is larger than one, indicating that the river bed material is deeply submerged. For such cases, the friction factor depends only upon the characteristic bed sediment height. However, in rivers with large boulders and other large bed features, such as sand dunes, it is possible that the diameters of these elements may become comparable to or even larger than the flow depth, so that they may protrude through the water free surface. This is a condition known as "low relative submergence," where the friction factor increases significantly and becomes also a function of the relative submergence ratio (Millar 1999; Ferguson 2007; Rickenmann and Recking 2011). The flow velocity is a function of the discharge and the cross-sectional area of the flow, which is in turn a function of the flow depth, width, and shape of the cross-sectional area. Therefore, the flow velocity is directly related to the same parameters that determine the flow depth.

Broadly, turbulence is produced by the interaction of high-speed fluid with the roughness elements that make up the river bed (Nezu and Nakagawa 1993; Strom and Papanicolaou 2007; Hardy 2011; Detert et al. 2010). This interaction of the flow with the roughness element leads to the generation of vortices around these roughness elements, which increase the turbulence levels in their vicinity. Some research has shown (Shamloo et al. 2001; Sadeque et al. 2008; Lacey and Rennie 2011; Papanicolaou et al. 2012) that different vortices form under different relative submergence regimes, and that the relative submergence also affects the turbulence levels of the flow. At the same time, the levels of turbulence in the flow depend on the bulk flow characteristics, including the flow velocity and therefore the flow discharge, flow depth, and bed slope.

Although the primary technical objective of the water passage module is the conveyance of water rather than sediment through the SMH facility, it provides the water supply required for the transport of sediment in the river reaches downstream of the SMH facility. It is pertinent, therefore, to briefly outline the key functional relationships that govern the transport of sediment to the extent that they relate to sediment transport in the context of the water passage module specific objective. In general, coarser sediment is transported in proximity to the bed and constitutes the bedload (Yalin 1977). As discussed in detail in Appendix $\mathrm{C}$ of this report, the bedload transport capacity is typically expressed as a function of the difference in the force applied by the flow and the threshold force required to set a coarse sediment grain of given size in motion (Yalin 1977). The applied flow force, also called "bed shear stress," is a function of the flow depth, the river bed slope, and the density and the sizes of the sediment grains to be transported. The threshold stress, or critical bed shear stress for incipient motion, is broadly dependent on the heterogeneity of the bed material grains, their packing density, their shapes, and the degree to which they protrude into the flow (Yalin 1977; Wiberg and Smith 1987; Papanicolaou et al. 2002). Finer sediment, on the other hand, is typically transported in suspension. The suspended sediment is considered to settle out of suspension and deposit when a characteristic velocity length scale of the flow called "friction velocity" is less than the settling velocity of the suspended sediment. The flow shear velocity depends on the flow depth and bed slope within the water passage module, while the fall velocity is determined from the sediment size and water temperature (Raudkivi 1998).

\section{E.4 MEASURES OF MODULE PERFORMANCE}

Assessing the efficiency of the water passage module in meeting the requirements listed in Appendix E.2 requires a set of quantifiable indices (Table 31). The indices will, in turn, allow evaluation of the efficiency with which the water passage module accomplishes its specific and primary technical objectives. 
Table 31. Water passage module measures of performance

\begin{tabular}{|l|l|}
\hline \multicolumn{1}{|c|}{ Index } & \multicolumn{1}{c|}{ Status } \\
\hline Index of Hydrologic Alteration & More research and modeling needed \\
\hline Indices of Schmidt and Wilcock (2008) & Limits available_modeling needed \\
\hline Indices of Grant et al. (2003) & Limits available_modeling needed \\
\hline River width & Limits available \\
\hline Flow depth & Limits available \\
\hline Flow velocity & Limits available \\
\hline Bed slope & Limits available \\
\hline Turbulence kinetic energy & Limits available \\
\hline Energy dissipation function & Limits available \\
\hline Suspended sediment concentration & Limits available \\
\hline Subsurface flow hydraulic gradient & Limits available \\
\hline River bed sediment and suspended sediment size distribution & Limits available \\
\hline
\end{tabular}

The most comprehensive suite of indices for assessing the effects of hydropower facilities on the hydrology of a river is the Indicators of Hydrologic Alteration (IHA) (Richter et al. 1996; Magilligan and Nislow 2005; Magilligan et al. 2013) The IHA considers 32 hydrologic variables that quantify the alterations caused by the SMH to five aspects of the hydrologic regime: (1) magnitude of monthly flow conditions; (2) magnitude and duration of annual water conditions; (3) timing of annual extreme conditions; (4) magnitude duration and frequency of pulses in river flow; and (5) rate at which hydrologic conditions change. Summary statistics for these variables are compared for periods before and after the installation of the SMH facility to allow assessment of the impacts of the SMH facility. To assess the performance of water passage module designs before the placement of an SMH facility, the hydrology in the post-construction period would need to be projected via the SMH simulation capability.

Assessment of the water passage module performance with respect to maintaining sufficient sediment transport capacity in the river reaches downstream of the SMH facility needs to involve measures quantifying the river geomorphic change. Such measures are the three indices proposed by Schmidt and Wilcock (2008), which quantify (1) the potential for river aggradation or degradation, (2) the bed incision potential, and (3) the magnitude of flood reduction under the conditions before and after the installation of the SMH facility. As discussed in Appendix D.4, acceptable limits for these indices are provided by Schmidt and Wilcock (2008), who compile ranges of values for the three indices for hydropower facilities with minimal geomorphic changes. Alternately, the simpler two indices of Grant et al. (2003) could be used; they are expressed by (1) the ratio of the sediment supply upstream and downstream of the SMH facility and (2) the ratio of the fractions of sediment-transporting flows before and after the placement of the SMH facility. As in the case of the IHA, the indices of Schmidt and Wilcock (2008) and of Grant et al. (2003) require knowledge of key input variables following the installation of the SMH facility. Ranges of their values for this condition can be obtained through the simulation capability of the SMH.

For assessing fish habitat hydraulics in the river reaches downstream of the SMH facility, the optimal metrics are the ones considered for the assessment of the fish passage module (Appendix B.4). These metrics include the flow depth, flow velocity, TKE, and EDF (OTA 1995; Maxwell and Papanicolaou 2000; Liu et al. 2006; Dermisis and Papanicolaou 2009). In addition, the suspended sediment concentration could be a useful measure for assessing the amount of infiltration of suspended sediment in the natural stream beds downstream of the SMH facility. A more rigorous method is proposed by Kondolf (2000), which considers the grain size distribution of the river bed material and of the fine sediment as well as the hydraulic gradient for subsurface flow.

The performance of the water passage module with respect to the recreation quality and water supply for various uses downstream of the SMH facility can be assessed by considering the flow depth, discharge velocity, and flow velocity in the river reaches downstream. Finally, the performance of the water passage 
module for maintaining water quality in the downstream reaches can be assessed by considering the suspended sediment concentration, for which limits are available from the Environmental Protection Agency (EPA 2016).

\section{E.5 DESIGN CONSTRAINTS}

The analysis of the water passage module requirements (Appendix E.2) in conjunction with the functional relationships (Appendix E.3) allows the specification of design constraints for the water passage module (Table 32). These are considered the behaviors and features that the water passage module must exhibit to accomplish its primary technical objective of conveying non-generating flows across the SMH facility. At present, strict quantitative criteria are not specified for each of the design constrains, as the development of such criteria is beyond the scope of the present document. Instead, the identifications of the water passage module performance measures outlined in Appendix E. 4 are used as initial building blocks for formalizing technical design constraints. The design constraints examined in Table 32 are characterized as local when they pertain specifically to the water passage module and global when their validity can be extended to the other modules of the SMH facility.

Table 32. Water passage module design constraints

\begin{tabular}{|l|l|c|}
\hline \multicolumn{1}{|c|}{ Constraint } & \multicolumn{1}{c|}{ Formalization/rationale } & \multicolumn{1}{|c|}{$\begin{array}{c}\text { Scale } \\
\text { (L= local, } \\
\mathbf{G}=\text { global })\end{array}$} \\
\hline $\begin{array}{l}\text { The water passage module must be } \\
\text { able to intake water for a range of } \\
\text { conditions }\end{array}$ & $\begin{array}{l}\text { The water passage module must be able to intake } \\
\text { water for conveyance downstream for a range of } \\
\text { approach flow conditions upstream of the SMH } \\
\text { facility }\end{array}$ & $\mathrm{L}$ \\
\hline $\begin{array}{l}\text { The water passage module must } \\
\text { convey enough water flow } \\
\text { downstream to meet the demands for a a } \\
\text { variety of uses }\end{array}$ & $\begin{array}{l}\text { There are a variety of uses, such as human } \\
\text { consumption, industrial use, cooling plants, and } \\
\text { wastewater treatment plants, that must be satisfied; } \\
\text { and none of these uses may be excluded }\end{array}$ & $\mathrm{L}$ \\
\hline $\begin{array}{l}\text { The water passage module must be } \\
\text { able to pass flood flows to prevent } \\
\text { overtopping of the SMH facility }\end{array}$ & $\begin{array}{l}\text { Failure to pass flood flows may lead to overtopping } \\
\text { of the SMH facility and compromise of its structural } \\
\text { stability }\end{array}$ & $\mathrm{L}$ \\
\hline $\begin{array}{l}\text { The water passage module must be } \\
\text { able to convey flows sufficient to } \\
\text { prevent significant river } \\
\text { morphological changes }\end{array}$ & $\begin{array}{l}\text { The flows conveyed by the water passage module } \\
\text { must ensure sufficient transport capacity in the } \\
\text { downstream river reaches to prevent significant } \\
\text { alterations in the river morphology }\end{array}$ & $\mathrm{L}$ \\
\hline $\begin{array}{l}\text { The flow discharge conveyed must } \\
\text { maintain fish habitat in the } \\
\text { downstream river reaches }\end{array}$ & $\begin{array}{l}\text { The flows conveyed by the water passage module } \\
\text { must ensure acceptable ranges of flow depth, } \\
\text { velocity, and turbulence, and minimize fine } \\
\text { sediment intrusion into spawning gravels }\end{array}$ & $\mathrm{L}$ \\
\hline $\begin{array}{l}\text { The water passage module must } \\
\text { successfully interface with the fish, } \\
\text { sediment, and recreation passage } \\
\text { modules }\end{array}$ & $\begin{array}{l}\text { The water module must be able to supply the other } \\
\text { modules with sufficient water to achieve their } \\
\text { primary technical objectives }\end{array}$ & $\mathrm{G}$ \\
\hline
\end{tabular}


Table 31. Water passage module design constraints (continued)

\begin{tabular}{|l|l|c|}
\hline \multicolumn{1}{|c|}{ Constraint } & \multicolumn{1}{c|}{ Formalization/rationale } & $\begin{array}{c}\text { Scale } \\
\text { (L= local, } \\
\text { G= global) }\end{array}$ \\
\hline $\begin{array}{l}\text { Module components cannot be heavier } \\
\text { than the lift capacity of available } \\
\text { cranes and transport vehicles or } \\
\text { vessels }\end{array}$ & $\begin{array}{l}\text { The module components must not exceed the } \\
\text { capacity of transport vehicles or vessels and } \\
\text { available cranes so that they can be transported to } \\
\text { the SMH site and placed }\end{array}$ & G \\
\hline $\begin{array}{l}\text { Module components cannot exceed in } \\
\text { size the size of available transport } \\
\text { vehicles or vessels }\end{array}$ & $\begin{array}{l}\text { The module components must be smaller than the } \\
\text { transport vehicle or vessel to allow their } \\
\text { transportation to the SMH site }\end{array}$ & G \\
\hline $\begin{array}{l}\text { Module components must be } \\
\text { compatible with one another }\end{array}$ & $\begin{array}{l}\text { The module components must connect with one } \\
\text { another and offer structural stability to the module. }\end{array}$ & $\mathrm{G}$ \\
\hline $\begin{array}{l}\text { Module components must be } \\
\text { compatible with foundation modules } \\
\text { the foundation module to ensure the structural } \\
\text { stability of the module from the SMH facility } \\
\text { foundation }\end{array}$ & $\begin{array}{l}\text { Because the water passage module needs to convey } \\
\text { flood discharges, it must be able to withstand the } \\
\text { forcing caused by the flood water }\end{array}$ & $\mathrm{G}$ \\
\hline $\begin{array}{l}\text { Module components must be able to } \\
\text { withstand the water forces under } \\
\text { conditions of flood }\end{array}$ & $\mathrm{G}$ \\
\hline
\end{tabular}

\section{E.6 DESIGN ENVELOPE SPECIFICATION}

The systematic examination of the water passage module for an SMH facility in this section has generated a list of design constraints for the water passage module, the fulfillment of which ensures that the water passage module accomplishes its primary technical objective of conveying non-generating flows across the SMH facility. As is the case for the other modules of the SMH facility, the design constraints identified in Table 32 may alternately be viewed as a design envelope for characteristics and behaviors that a successful water passage module design must exhibit to accomplish its primary technical objective. Note that multiple water passage module designs could fulfill these design constraints, but it is not the goal of the present report to identify the optimal design. To identify the optimal designs for the water passage module, the present report provides measures, identified in Appendix E.4, that allow assessment of the performance of potential designs and identification of the optimal design.

Specification of the water passage module design envelope requires the identification of limits for the water passage module performance measures provided in Appendix E.4. Identification of these performance measure limits allows the exclusion of potential water passage module designs that do not perform within the identified limits. For instance, a design for the water passage module that allows water to overtop the SMH facility during a possible flood condition cannot be considered. Identification of such performance measure limits is tied to specific characteristics at the SMH facility site, including the hydrologic regime of the watershed in which the SMH facility site is located. It is possible to classify potential SMH sites with respect to some key, recurring characteristics, such as the watershed hydrology, that are pertinent to the design envelope specification of the water passage module. Similarly, potential SMH sites will need to be classified in terms of the types of sediments (coarse vs. fine) and fish species to derive water passage module designs that are optimal for the specific sediment and fish species common in a class of SMH sites. The outcome of such classification schemes will be the establishment of limits and designs that are applicable to a class of SMH sites with similar characteristics, thereby enhancing SMH standardization. Site classification is therefore of paramount importance to identifying the limits of the water passage module design envelope.

The concept of scale is particularly important for the water passage module, as the water conveyed by the water passage module is used to minimize the effects of the SMH facility in the river reaches 
downstream. It is necessary, therefore, to delineate the spatial and temporal scales of the effects of the SMH facility on water quantity, sediment transport, and fish habitat. For instance, Schmidt and Wilcock (2008), in the case of larger dams, considered river reaches as far as 180 miles downstream to test their proposed indices of geomorphic change. Of paramount importance to the identification of appropriate spatiotemporal scales are testing and simulation capabilities, which can be used to measure or model potential effects of the SMH facility in the river continuum.

A limitation of the current analysis is that all of the functional relationships examined in Appendix E.3 are deterministic in nature. The deterministic nature of these relationships implies that a given input to a process can have only the specific outcome predicted by the functional relationship. This may be the case when the process in question is considered in an average sense, but the complexity and randomness in nature often causes variability in the predicted outcome which is not accounted for by the deterministic relationship. To address this limitation of the deterministic approach, the functional relationships for the processes outlined in Appendix E.3 should ultimately be considered from a probabilistic perspective. 


\section{APPENDIX F. FOUNDATION MODULE}

A foundation is the element of an architectural structure that connects the structure to the ground and transfers weight loads from the structure and/or external forces around it to the subsurface. The foundation module is the structural interface that anchors the generation module and passage modules to the streambed. It must support the loads of instream modules and the environment, minimize disruptions to habitat and sediment, and ensure stability for the entire SMH facility. Although the role of the foundation module within the SMH concept is similar to that of the foundations of conventional hydropower facilities, a conceptual design of the foundation module herein represents possibly the most radical departure from conventional hydropower thinking. The need for a foundation module is borne out of the lack of environmentally compatible, modern methods to safely, reliably, and cost-effectively anchor generation and passage modules to the stream subsurface. The conventional approach to hydropower foundation design entails a combination of site specificity and extensive civil works construction activities: sophisticated field studies to characterize the subsurface; diversion of water to allow for excavation, leveling, and construction; and the pouring of large quantities of concrete to produce massive, heavy structures that resist forces imposed upon the facility. Foundation module design operates under the assumptions that these methods do not achieve efficiency of design, they do not complement the modular nature of generation and passage modules, and innovation in foundation methods would accelerate the deployment of SMH facilities.

The other departure that SMH makes from conventional thinking is that full impoundment of a river is not considered. A large dam that fully obstructs the flow provides stability and resistance, but it does not represent efficiency of design and it creates a natural barrier that can have negative environmental implications. New, environmentally compatible methods and technologies are required that provide the same functionality as traditional dams without the size, cost, immensity, inflexibility, and permanence. However, a modular approach fundamentally alters how forces are resisted in a structure-conventional gravity dams have a primary plane of contact between the subsurface and the base of the dam, and the stresses throughout the body of the structure remain low (FERC 2003). A modular approach will introduce a new plane of contact between generation/passage modules and the foundation module. The implications of this configuration must be considered in the design phase.

To economically justify the feasibility of an SMH project, it is necessary to minimize costs associated with civil works in the foundation module design. For example, the module would need to be designed in a way that minimizes ground excavation if possible; minimizes disturbances in river connectivity during installation, operation, and maintenance (e.g., avoids the use of coffer dams where appropriate); minimizes benthic habitat disturbances by reducing the footprint of the module structure; reduces overall installation times; facilitates ease of installation; and uses advanced materials rather than concrete. In some cases, the foundation module may be designed with a simple anchoring system connected to other module structures without a conventional concrete-type foundation. For example, either a foundation module or the passage/generation modules may be anchored into the streambed using steel wires or beams, if the rock or soil foundations have enough bearing capacity to resist weight loads and external forces. A well-designed foundation module provides stability for other module structures by preventing slipping, overturning, seepage, uplift, sinking, and excessive sediment deposition and scour for both normal operating conditions and extreme environmental conditions (e.g., earthquakes and floods) without a significant impact on the surrounding stream environment. 


\section{F.1 OBJECTIVES}

The primary technical objective of the foundation module is to provide stability and support for SMH infrastructure (e.g., passage and generation modules) by anchoring the foundation module into the streambed and banks.

\section{Foundation Module Primary Objective}

Anchor passage and generation modules to the streambed and banks.

To achieve this primary technical objective, the following specific objectives need to be accomplished:

1. Provide structural resistance against imposed loads.

2. Ensure stability of the SMH facility.

3. Minimize the mechanical impacts of moving water and sediment on the streambed.

4. Integrate structurally into generation and passage modules.

A conceptual example of the foundation module design is displayed in Figure 46 and Figure 47 . While it is represented as a black box foundation structure, the foundation module could be a simple anchoring system that consists of driven piles and a prefabricated box caisson, or it may consist of more complex structural members.

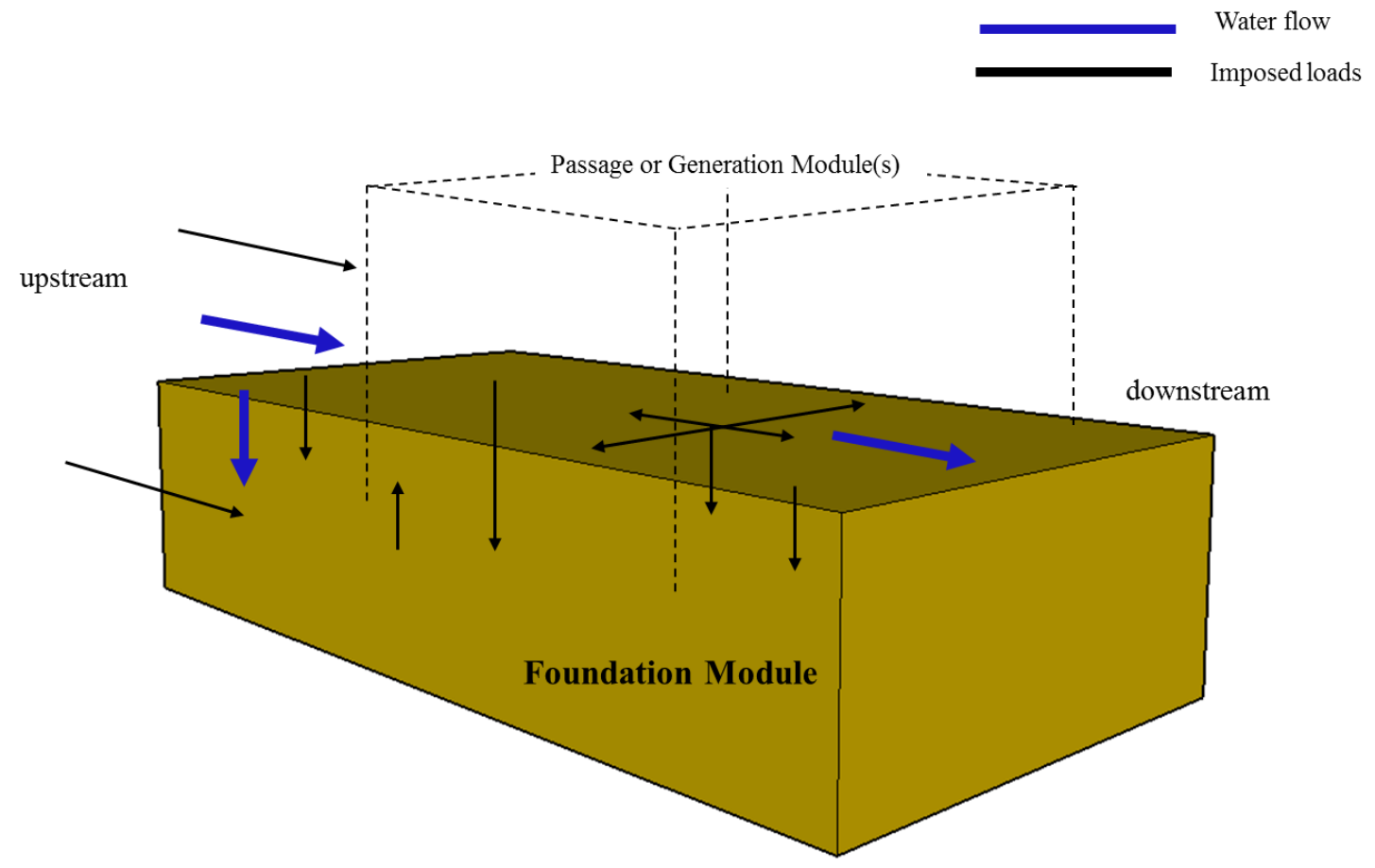

Figure 46. Conceptual schematic of the imposed loads a foundation module must resist. 


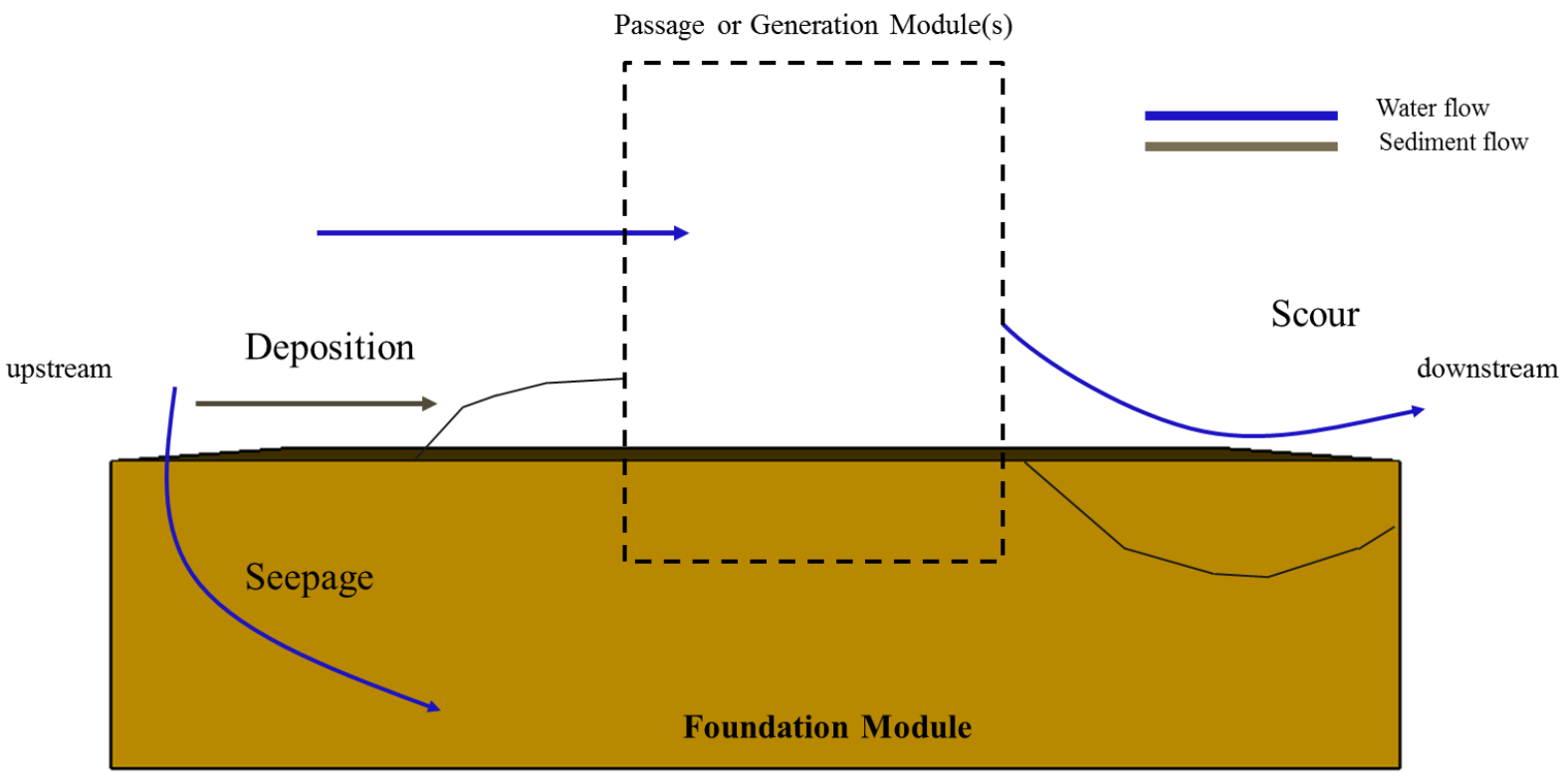

Figure 47. Conceptual schematic of the environmental mechanics a foundation module must resist.

\section{F.2 REQUIREMENTS}

Foundation module requirements further describe the specific objectives an installed module should achieve (Table 33).

Table 33. Foundation module requirements. In the fourth column: $F=$ Functional; $P=$ Performance; $I=$ Interaction; $\mathrm{O}=$ other. In columns 6-11, an " $\mathrm{X}$ " denotes a relationship to the river continuum constituent indicated in the top row

\begin{tabular}{|c|c|c|c|c|c|c|c|c|c|c|}
\hline & & Requirement & $\begin{array}{c}\text { Type } \\
(\text { F/P/I/O) }\end{array}$ & Formalization/rationale & 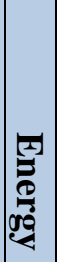 & $\begin{array}{l}\sum_{2}^{2} \\
\stackrel{2}{9}\end{array}$ & 굴 & 垈 & 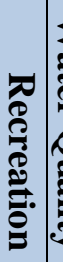 & 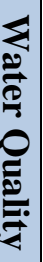 \\
\hline 1 & & $\begin{array}{l}\text { Provide structural } \\
\text { resistance against imposed } \\
\text { loads }\end{array}$ & $\mathrm{F}, \mathrm{P}, \mathrm{I}$ & & $\mathrm{x}$ & $x$ & & $x$ & & \\
\hline & $a$ & $\begin{array}{l}\text { Resist maximum static } \\
\text { loads from the general and } \\
\text { passage modules }\end{array}$ & $\mathrm{F}, \mathrm{P}, \mathrm{I}$ & $\begin{array}{l}\text { The foundation module (FM) } \\
\text { should be able to bear the } \\
\text { static loads of the generation } \\
\text { and passage modules to } \\
\text { prevent sinking, while the } \\
\text { bearing capacity of the } \\
\text { subsurface must be adequate } \\
\text { to support all modules }\end{array}$ & $x$ & $x$ & & & & \\
\hline
\end{tabular}


Table 32. Foundation module requirements (continued)

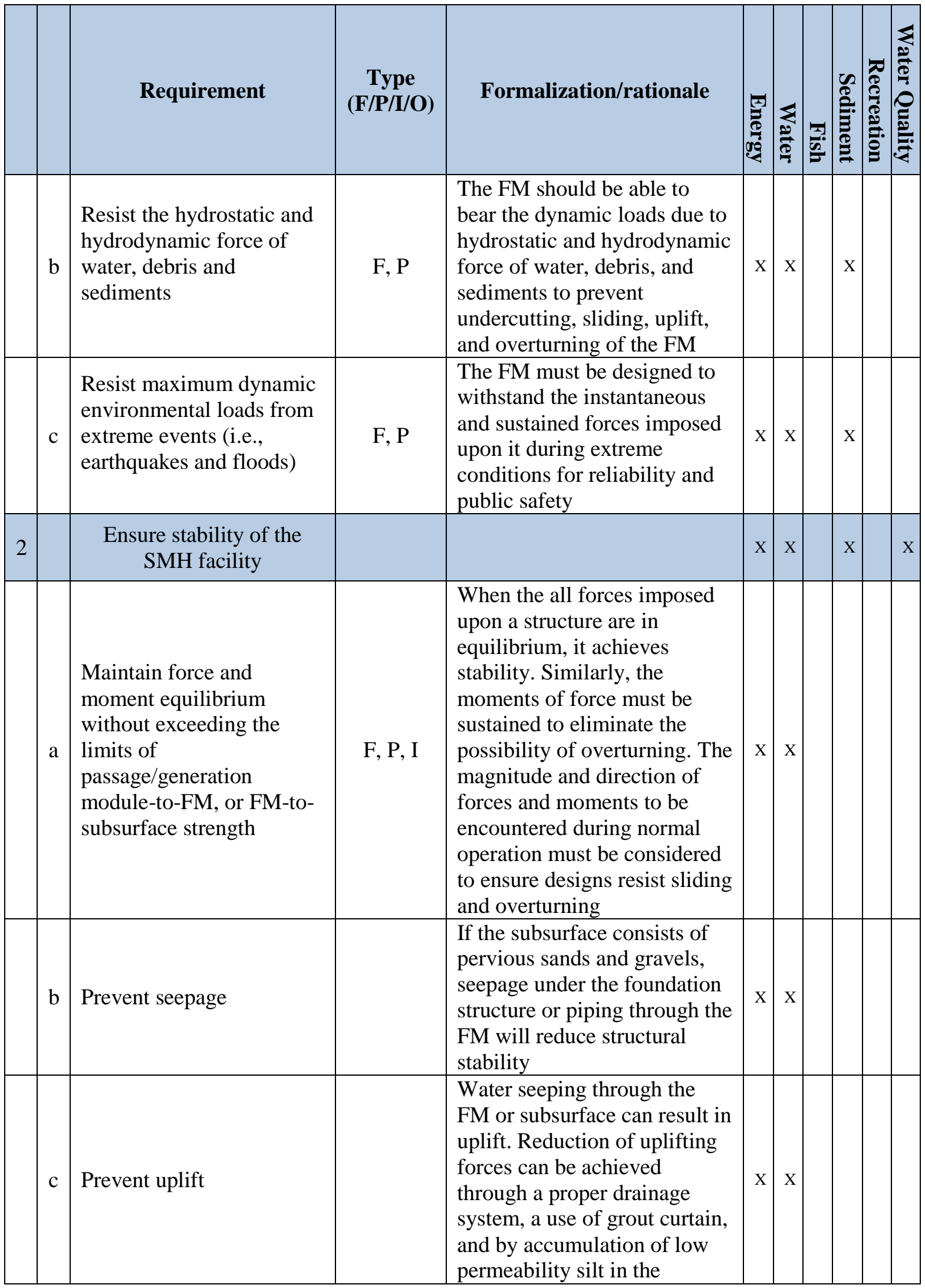


Table 32. Foundation module requirements (continued)

\begin{tabular}{|c|c|c|c|c|c|c|c|c|c|c|}
\hline & & Requirement & $\begin{array}{c}\text { Type } \\
(\mathbf{F} / \mathbf{P} / \mathbf{I} / \mathbf{O})\end{array}$ & Formalization/rationale & 赵 & \} $&{\frac{7}{2}} &{\text { ֻ }} &{\text { 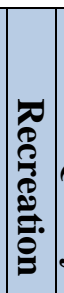 }} &{\text { : }} \\
{\hline} &{ } &{ } &{ } &{\text { upstream side }} &{ } &{ } &{ } &{ } &{ } &{ } \\
{\hline} &{\text { d }} &{\begin{array}{l}\text { Resist erosion or scour of } \\
\text { the surrounding streambed }\end{array}} &{ } &{\begin{array}{l}\text { The energy of water leaving } \\
\text { the generation of passage } \\
\text { modules will impose a load } \\
\text { on the downstream portion of } \\
\text { the FM that could lead to } \\
\text { erosion of foundation } \\
\text { materials over time or } \\
\text { scouring of soils. Erosion and } \\
\text { scour may cause instability of } \\
\text { foundation structure due to } \\
\text { reduced structural integrity } \\
\text { and undercutting of soils, } \\
\text { respectively }\end{array}} &{\mathrm{X}} &{\mathrm{X}} &{ } &{\mathrm{X}} &{ } &{\mathrm{X}} \\
{\hline} &{\mathrm{e}} &{\begin{array}{l}\text { Prevent settling, } \\
\text { subsidence, and downward } \\
\text { migration of the SMH } \\
\text { facility }\end{array}} &{ } &{\begin{array}{l}\text { Conventional dam } \\
\text { foundations and subsurfaces } \\
\text { are extensively scoped for } \\
\text { fissures, caverns, and settling } \\
\text { and subsidence potential. } \\
\text { Foundation treatments, } \\
\text { compaction, and fill are } \\
\text { applied to optimize stability. } \\
\text { A foundation module must } \\
\text { incorporate a high strength } \\
\text { and geotechnically } \\
\text { appropriate interface with the } \\
\text { subsurface and with modules } \\
\text { overhead to minimize settling } \\
\text { and subsidence of the facility. } \\
\text { The installation module will } \\
\text { play a critical role in } \\
\text { identifying subsidence } \\
\text { hazards. }\end{array}} &{\mathrm{X}} &{\mathrm{x}} &{ } &{\mathrm{x}} &{ } &{ } \\
{\hline 3} &{ } &{\begin{array}{l}\text { Minimize the mechanical } \\
\text { impacts of moving water } \\
\text { and sediment on the } \\
\text { streambed }\end{array}} &{ } &{ } &{\mathrm{x}} &{\mathrm{x}} &{ } &{\mathrm{x}} &{ } &{\mathrm{x}} \\
{\hline} &{\mathrm{a}} &{\text { Resist scour downstream }} &{\mathrm{F}, \mathrm{P}} &{\begin{array}{l}\text { The energy of water leaving } \\
\text { generation or passage } \\
\text { modules may be carried } \\
\text { downstream past the FM, } \\
\text { resulting in scouring of soils } \\
\text { over time. The FM may need }\end{array}} &{\mathrm{x}} &{\mathrm{x}} &{ } &{\mathrm{X}} &{ } &{ } \\
$\hline
\end{tabular}


Table 32. Foundation module requirements (continued)

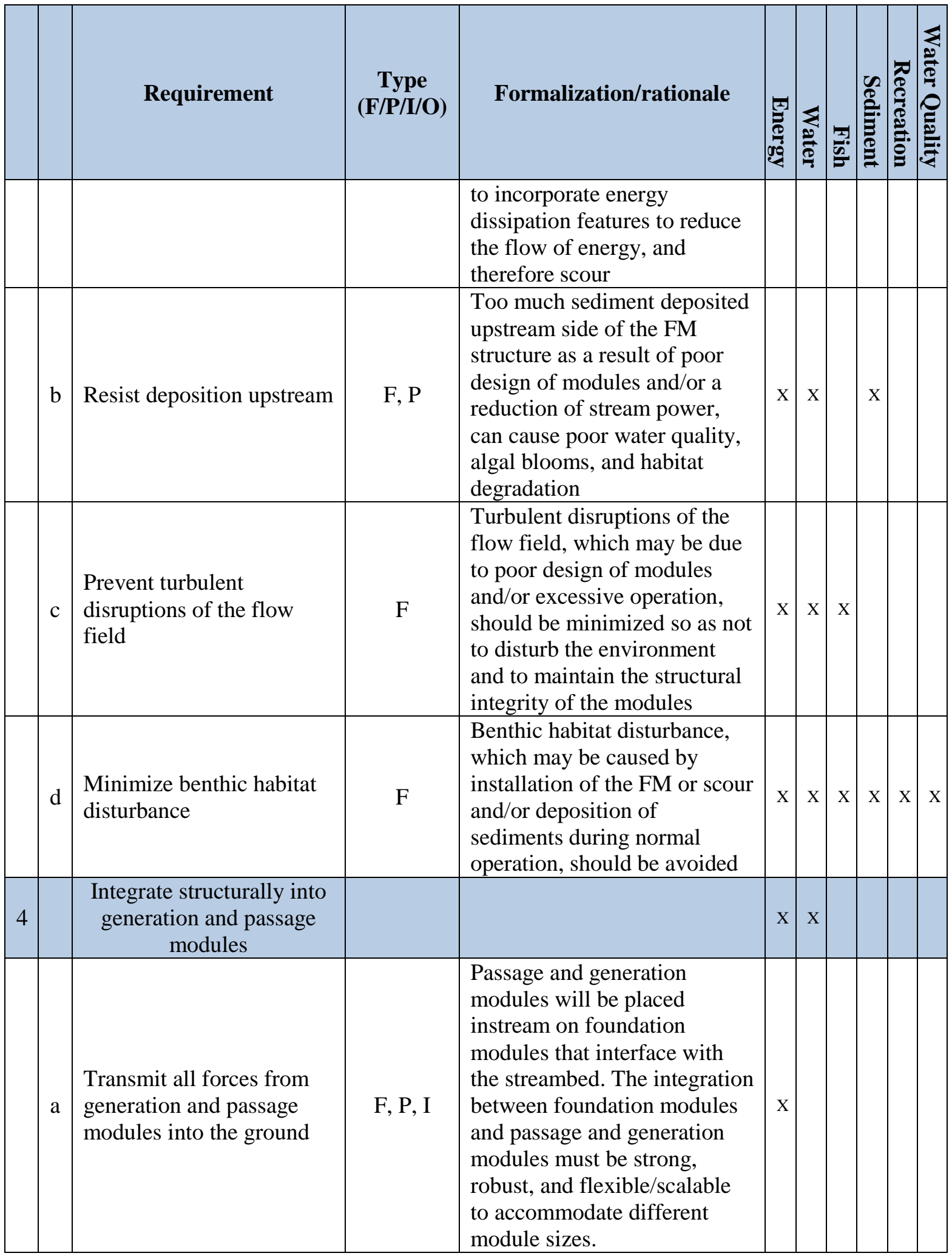




\section{F.3 INPUTS, FUNCTIONAL RELATIONSHIPS, AND PROCESSES}

A good foundation module design should eliminate the possibility of failure from overturning, uplift, sliding, and tilting that might occur if the forces imposed upon the foundation exceed the module strength or the bearing capacity of the underlying subsurface. Proper design requires knowledge of the forces, loads, and combinations thereof that will be imposed on the module in normal operating conditions and during extreme events, the bearing capacity of the subsurface and the structural rigidity of the module, and the material properties of the subsurface and the module. Many of the forces imposed on a hydraulic foundation structure are difficult to quantify with precision; engineering judgment, simulations, and/or testing are used to estimate the location, intensity, and direction of these forces and their impact on overall foundation performance.

\section{F.3.1 Necessary Inputs}

Table 34 lists necessary inputs for foundation module design.

Table 34. Foundation module necessary inputs for module design

\begin{tabular}{|c|c|}
\hline $\begin{array}{l}\text { Identification of } \\
\text { key inputs }\end{array}$ & Formalization \\
\hline Flow variables & $\begin{array}{l}\text { Range of flow rates, average hydraulic head, water depth, velocity, } \\
\text { turbulence parameters, friction factor, watershed hydrologic } \\
\text { characteristics, flood frequency and magnitude, inflow design flood }\end{array}$ \\
\hline Head & Average hydraulic head, hydraulic head at flood conditions \\
\hline $\begin{array}{l}\text { Generation module and passage } \\
\text { module loads }\end{array}$ & $\begin{array}{l}\text { Envelope of loads (static and dynamic) resulting from normal operation of } \\
\text { the generation and passage modules }\end{array}$ \\
\hline Geomorphologic variables & $\begin{array}{l}\text { River bed slope, bed topography, friction factor, channel sinuosity, } \\
\text { substrates, soil type, depth to bedrock, structure of strata (strength, } \\
\text { thickness, inclination, fracturing, porosity, gradation, angularity, shape, } \\
\text { moisture, shear strength, permeability }\end{array}$ \\
\hline Sediment characteristic variables & $\begin{array}{l}\text { Sediment grain size distribution (e.g., median grain diameter, geometric } \\
\text { standard deviation), friction factor, sediment fall velocity, sediment } \\
\text { angularity, sediment shape, relative protrusion }\end{array}$ \\
\hline Stream cross sectional area & Bottom width, wetted perimeter, depth, side slope \\
\hline Location of potential failure planes & $\begin{array}{l}\text { The most vulnerable areas where imposed loads will cause modules to } \\
\text { slide along a plane, resulting in module failure }\end{array}$ \\
\hline Externally imposed force variables & $\begin{array}{l}\text { Hydrostatic forces, hydrodynamic force, earth and silt forces, magnitude } \\
\text { of these forces expected to occur during failure }\end{array}$ \\
\hline $\begin{array}{l}\text { All module dimensions } \\
\text { (foundation, generation, and } \\
\text { passage modules) }\end{array}$ & Length, width, height \\
\hline $\begin{array}{l}\text { Foundation module construction } \\
\text { material }\end{array}$ & Density, strength, stiffness, porosity, permeability, erodibility \\
\hline Foundation anchor design & Material properties, dimensions, installation method \\
\hline
\end{tabular}




\section{F.3.2 Functional Relationships}

Table 35 lists functional relationships for foundation module operation and their rationales.

Table 35. Functional relationships governing foundation module operation

\begin{tabular}{|c|c|c|}
\hline Relationship of & To & Rationale/importance \\
\hline $\begin{array}{l}\text { Static and dynamic } \\
\text { loading of the } \\
\text { foundation module }\end{array}$ & $\begin{array}{l}\text { Bearing pressure } \\
\text { and mechanical } \\
\text { properties of the soil } \\
\text { and subsurface }\end{array}$ & $\begin{array}{l}\text { The bearing pressure of the subsurface is related to the geology, } \\
\text { bed material, topography, and bathymetry, with consideration of } \\
\text { their evolution throughout the life of the project. These features } \\
\text { must be identified and classified for the most common } \\
\text { deployment scenarios, with emphasis placed on both streambeds } \\
\text { and stream banks, to determine viable foundation module (FM) } \\
\text { designs }\end{array}$ \\
\hline $\begin{array}{l}\text { Static and dynamic } \\
\text { loading of the FM }\end{array}$ & $\begin{array}{l}\text { Strength of } \\
\text { foundation module } \\
\text { materials }\end{array}$ & $\begin{array}{l}\text { The deformation, displacement, vibration, compression, and } \\
\text { material failure characteristics of the FM material must be } \\
\text { understood with respect to the envelope of static and dynamic } \\
\text { loads to be encountered. A relationship predicting the shear } \\
\text { friction within the module and at the modular interface with the } \\
\text { subsurface and other modules is necessary }\end{array}$ \\
\hline Module designs & $\begin{array}{l}\text { 1. Undercutting } \\
\text { 2. Uplift } \\
\text { 3. Sliding } \\
\text { 4. Overturning } \\
\text { 5. Benthic habitat } \\
\text { disturbance } \\
\text { 6. Scour and } \\
\text { deposition of } \\
\text { sediments } \\
\text { 7. Erosion of the } \\
\text { FM }\end{array}$ & $\begin{array}{l}\text { 1. Effective design of the FM may prevent undercutting } \\
\text { 2. Effective design of the FM (e.g., the use of proper drain } \\
\text { system) may prevent uplift } \\
\text { 3. Effective design of the FM will minimize the excessive shear } \\
\text { stresses caused by dead and live loads } \\
\text { 4. Effective design of the FM will prevent overturning } \\
\text { 5. The footprint of the FM designs may determine the degree of } \\
\text { benthic habitat disturbance } \\
\text { 6. Effective design of the FM may prevent excessive scour and } \\
\text { deposition of sediments around the structure } \\
\text { 7. Effective design of the FM may prevent the erosion of the } \\
\text { structure }\end{array}$ \\
\hline $\begin{array}{l}\text { Flow depth } \\
\text { upstream of facility } \\
\text { and FM material } \\
\text { composition }\end{array}$ & Seepage potential & $\begin{array}{l}\text { Seepage under the FM and subsurface erosion must be } \\
\text { considered a possibility at all sites. The use of new and } \\
\text { innovative foundation methods and materials will require new } \\
\text { relationships to identify seepage potential, and the best means to } \\
\text { incorporate seepage mitigation measures into the FM }\end{array}$ \\
\hline $\begin{array}{l}\text { Generation and } \\
\text { passage module } \\
\text { flow energy }\end{array}$ & $\begin{array}{l}\text { Energy dissipation } \\
\text { requirements }\end{array}$ & $\begin{array}{l}\text { The energy carried by water flow out of the generation and } \\
\text { passage modules may require dissipation by the FM to reduce the } \\
\text { possibility of scour past the downstream end of the FM. }\end{array}$ \\
\hline
\end{tabular}

\section{F.4 MEASURES OF PERFORMANCE}

The primary foundation module measures of performance are the ability to provide structural resistance and stability against the imposed static and dynamic loads in a safe and reliable manner (Table 36). However, these primary performance measures are difficult to gauge in a prototype until the module is stressed or fatigued to failure. Therefore, structural performance measures must be modeled and/or tested in a more controlled environment (i.e., a test facility) to ensure that the module design can satisfy all functional requirements. In addition, module scalability, size of the module, installed cost per module, estimates of module useful life (durability), and environmental disturbance are additional performance measures to be qualitatively and/or quantitatively gauged. 
Table 36. Foundation module measures of performance

\begin{tabular}{|l|l|}
\hline Index & Status \\
\hline Stability against sliding & More research and modeling/testing needed \\
\hline Strength of foundation module materials & More research and modeling/testing needed \\
\hline Scalability & More research needed \\
\hline Size & More research needed - minimize instream and subsurface volume \\
\hline Cost & More research needed - long-term facility target of $<\$ 6,000 / \mathrm{kW}$ \\
\hline Environmental disturbance & More research needed - deposition and scour minimized \\
\hline
\end{tabular}

A foundation module should maintain stability during normal and extreme flow conditions, such as a 100year flood event. Stability criteria may vary for a particular combination of imposed loads, based on the knowledge of inter-module interactions and interactions between the foundation module and the site subsurface. In most conventional dams, stability is achieved by using the weight of a large, heavy structure to resist the horizontal force of water. Acceptance criteria for the stability of existing gravity dams are based on factors of safety - the ultimate strength of the foundation materials is divided by a safety factor to determine the allowable stresses that can be safely sustained under various static and dynamic loading conditions (FERC 1999). An additional factor of safety characterizes the actual shear plane resistance, which must be some factor higher than the shear plane resistance that would initiate sliding. There is generally a large uncertainty associated with this analysis, as the cohesive bond between the dam structure and the subsurface interface is difficult to quantify. A modular approach does not rely on a massive gravity structure for stability but instead strives for low-profile, ecological compatibility, minimized designs that can transmit horizontal loads directly into the subsurface through innovative means. Additional research, modeling, and testing are necessary to determine the optimal configuration, inter-module cohesion mechanisms, and foundation module-to-streambed interface that will maximize stability.

The material properties of the foundation module - most important, the shear and tensile strength of the materials used - are important to assessing the overall strength and stability of the module. In conventional small dams, the shear strength along the dam-foundation interface, comprising the friction angle and cohesion of the material(s) interface, is the most important variable to understand in a stability analysis (Paxson et al. 2011). These values are well known for conventional dams, but additional research, modeling, and testing of foundation module designs is necessary to develop acceptable performance measures.

The foundation module must be designed in such a way that it can be well coupled with various sizes of other modules to effectively and economically achieve the specific objectives under a range of flow conditions, head, site topography, and subsurface geology. The foundation module can be assessed based on the number of modules required to support a given supply of kilowatts, or cubic feet second of flow, or number of foundation modules per generation or passage module. A building-block style foundation technology could use precast segments with interlocking elements to provide rapid in-field installation and removal. A scalable module will need a high-strength interface that can sustain the stresses identified in the stability analysis; thus more research to quantify the tradeoff between scalability and strength is necessary. However, module installation, replacement, refurbishment, and administration can be streamlined and made more cost-effective if a common module can be scaled across multiple sites.

A foundation module should be sized to safely and economically support other modules while remaining amenable to standard transportation methods and/or ease of fabrication on sites with minimum civil works construction. An exemplary module will reduce the overall footprint of the SMH facility and minimize the need for access, dewatering, excavation, leveling, or grading, which will not only reduce costs but also minimize environmental disruption associated with construction activities. Although this concept is new in the hydropower industry, the construction industry is rife with innovative environmentally 
compatible and minimal-size designs and techniques. Soil nailing, for example, is a technique used as a retaining wall alternative for either permanent or temporary construction. Compared with traditional retaining walls, soil nailing offers multiple advantages, including elimination of excavation and backfill, reduced material and cost requirements, smaller footprints and right-of-way requirements, and improved safety. (FHWA 1998).

There is a large degree of uncertainty in setting a specific target installed cost for a foundation module, as is also the case for other SMH module structures:

- A site may consist of a generation module and a foundation module, or it may require several passage modules and foundation modules. Depending on the settings of the sites, the installed cost of the foundation module would vary in each case.

- The cost to precast, deliver, and install a foundation module may be greater than the cost of existing construction technologies; but the modular development of a project may reduce civil works and other project soft costs, improving project feasibility.

- The use of innovative methods and advanced materials may further reduce the costs associated with the foundation module fabrication and installation.

Based on these uncertainties, it is most instructive to set an upper bound on installed cost, under which a foundation module should strive to fit. The immediate target for an SMH project should be less than $\$ 6,000 / \mathrm{kW}$, including all modules necessary at a site. Over time, this number should be reduced as module deployment increases.

The degree of environmental disturbance associated with foundation module installation and operation may be minimized by establishing a strategic design plan. This strategic plan may include a smart design that can minimize the mechanical impacts of moving water and sediment on the streambed, enabling minimal scour and deposition or self-cleaning of sediments upstream and downstream. It also may include an effective design that can minimize the foundation module footprint, which may directly affect benthic habitats. An index of performance should be established to categorize the installation disturbance and instream functionality with respect to sediment and scouring associated with a foundation module.

\section{F.5 CONSTRAINTS}

Table 37 lists design constraints for foundation module design.

Table 37. Foundation module design constraints

\begin{tabular}{|c|c|c|}
\hline Constraint & Formalization & $\begin{array}{c}\text { Scale } \\
(\mathbf{L}=\text { local }, \\
\text { G = global })\end{array}$ \\
\hline Type of subsurface & $\begin{array}{l}\text { Subsurface soil/bedrock characteristics } \\
\text { should be stable enough not to require } \\
\text { extensive treatment. The bearing pressure } \\
\text { exerted by the facility must not exceed the } \\
\text { limiting shear resistance of the subsurface, } \\
\text { and soils that lead to excessive settlement } \\
\text { must be avoided }\end{array}$ & $\mathrm{G}$ \\
\hline $\begin{array}{l}\text { Module must not require extensive } \\
\text { excavation }\end{array}$ & $\begin{array}{l}\text { In combination with limiting the type of } \\
\text { subsurface where a foundation module } \\
\text { should be applied, the excavation needs to } \\
\text { install and sustain a foundation module must } \\
\text { be minimized }\end{array}$ & G \\
\hline
\end{tabular}


Table 38. Foundation module design constraints (continued)

\begin{tabular}{|l|l|c|}
\hline \multicolumn{1}{|c|}{ Constraint } & \multicolumn{1}{c|}{ Formalization } & \multicolumn{1}{|c|}{$\begin{array}{c}\text { Scale } \\
\text { (L= local, } \\
\text { G= global) }\end{array}$} \\
\hline $\begin{array}{l}\text { Dewatering of a stream-reach for module } \\
\text { installation is not allowed }\end{array}$ & $\begin{array}{l}\text { Environmentally compatible installation } \\
\text { methods must be used for the foundation } \\
\text { module, meaning a cofferdam or full } \\
\text { dewatering of a given stream cross-section is } \\
\text { not allowed }\end{array}$ & $\mathrm{G}$ \\
\hline $\begin{array}{l}\text { Foundation module (in combination with } \\
\text { passage and generation module) cannot } \\
\text { fully impound a stream-reach }\end{array}$ & $\begin{array}{l}\text { An SMH facility must maintain the flow of } \\
\text { water, energy, sediment, fish, and small } \\
\text { watercraft throughout a stream-reach. This } \\
\text { facility level objective is best achieved by } \\
\text { ensuring the stream-reach is not fully } \\
\text { impounded }\end{array}$ & $\mathrm{G}$ \\
\hline $\begin{array}{l}\text { Unit stresses of foundation module } \\
\text { materials cannot be exceeded under normal } \\
\text { static loading }\end{array}$ & $\begin{array}{l}\text { Foundation module materials with shear and } \\
\text { tensile strengths that sustain the combined } \\
\text { normal and maximum dynamic and static } \\
\text { loads must be used }\end{array}$ & $\mathrm{G}$ \\
\hline \multirow{2}{\text{Safetyfactors}}{} & $\begin{array}{l}\text { The existing safety factors for low-hazard } \\
\text { dams may not be applicable to modular } \\
\text { foundation structures, although they can } \\
\text { serve as a starting point for estimating the } \\
\text { strength and stability parameters that must be } \\
\text { maintained. They generally relate to usual, } \\
\text { unusual, and extreme loading, and the } \\
\text { probability of occurrence of each condition }\end{array}$ & $\mathrm{G}$ \\
\hline
\end{tabular}

\section{F.6 DESIGN ENVELOPE SPECIFICATION}

A foundation module is necessary to enable the installation of generation and passage modules and to ensure the success of an SMH facility. This module is perhaps the most unique and most challenging of the SMH modules. Conventional approaches to hydropower development have relied on massive concrete structures for stability and support, whereas future SMH facilities will require minimized foundation designs, materials, and configurations that are strong and stable yet flexible and scalable, and installations that limit overall environmental disturbance.

It is clear that the environmentally compatible, low-profile, efficient foundation modules described in this section can be realized only through innovative and superior design strategies. The objectives, requirements, constraints, and measures of performance outlined represent a first attempt at identifying the functionalities that designers must target to produce an exemplary foundation module. Given the variety of potential known and unknown development site characteristics, environmental attributes, subsurface types, and potential new foundation materials and techniques to be employed, the list is not exhaustive; and a large degree of uncertainty persists in the module design envelope. The following points summarize the topic.

- The foundation module must resist static and dynamic loads without the use of massive concrete structures.

- High-strength designs are necessary that transmit horizontal loads into the subsurface while minimizing the use of materials. 
- The foundation module must provide stability for the entire SMH facility. Additional research, modeling, and testing are necessary to characterize how interlocking and scalable foundation modules can sustain the stresses of operation at modular interfaces.

- Environmental disturbance must be minimized through environmentally compatible, low-profile designs that minimize the need for access, dewatering, excavation, leveling, and grading.

- The foundation module must extend upstream and downstream and act to minimize the impact of sedimentation and scour, respectively.

- The use of advanced modeling and testing capabilities is critical to ensuring the success of future SMH facilities and foundation module configurations. 


\section{APPENDIX G. TERMINOLOGY}

The definitions in Appendix G are subject to change.

This report includes references to both new and conventional terminology with respect to small hydropower. Key terms and concepts, and their respective definitions, are provided below for reference throughout the report.

Design Constraint: a limitation on the value of a design parameter or a limitation on an effect of deployment or operation that must be satisfied and verifiable to ensure feasibility of a module or facility. They are characterized as local when they pertain specifically to an individual module, and global when their validity can be extended to the other modules of the SMH facility.

Design Specification: the objectives, requirements, constraints, and measures of performance of a module that developers will need to address in their design.

Environmental Disturbance: disruption to the flow, exchange, or transfer of water, energy, fish and aquatic species, sediment, and water quality in a river system.

Fit-for-Purpose: a design philosophy intended to produce a solution that is cheap, fast, and meets the intended need for which it is developed.

Foundation Module (FM): a module situated between the streambed and passage and/or generation modules dedicated to resisting the forces of operation and supporting or bearing the loads imparted by modules and the environment.

Functional Analysis: the method of developing and analyzing functional requirements, functional relationships, constraints, and exemplary characteristics on a module and facility level and determining how they are accounted for in facility design.

Functional Decomposition: the process of developing and analyzing facility and module objectives, requirements, functional relationships, constraints, and measures of performance and determining how they are accounted for in facility design.

Generation Module (GM): a module with dedicated functionality for hydroelectric power generation.

Measure of Performance: a set of quantifiable indices or metrics that enable the evaluation of a module with respect to how well it accomplishes specific and primary technical objectives.

Modules: an independently operable unit with dedicated functionality from which an SMH facility can be constructed. Modules discussed in this report have dedicated generation, passage, and foundation functionalities, and will be described in terms of functional requirements, constraints, and module characteristics, rather than a discrete physical form. SMH modules are conceptualized to be independently interchanged to achieve a configuration appropriate for the scale and environmental context of the site selected for development.

Modular Interface: the mechanism through which a module connects to other modules.

Module Enclosure: the outer surface of a generation module that seals inner equipment and systems. 
Module Standardization: the predictable and scalable development of generation, passage, and foundation modules. An individual module must incorporate all intended purposes and form a single unit that reliably interfaces with the same type and other types of modules.

Passage Module (PM): a module with dedicated functionality for the upstream to downstream passage of water, sediment, recreational craft, and fish, or the downstream to upstream passage of fish.

Primary Objective(s): the ideal goal(s) of an installed and operational module or SMH facility.

Requirement: a feature of a module or facility that (1) is essential to achieving the primary objective, (2) is verifiable through testing, measurement, or observation, and (3) in combination with other requirements indicates that the module or facility is achieving its primary objective. They are characterized as Functional, Performance, Interface and Other, based on the following criteria:

- Functional requirement: The requirement is a behavior or function that needs to be performed for successful module operation.

- Performance requirement: The requirement is quantified by how well a function is accomplished.

- Interface requirement: The requirement involves interaction of the fish passage module with other modules, e.g., water passage, generation.

- Other: There is a lack of knowledge regarding the requirement at present.

Specific Objective(S): a set of goals or actions that must be accomplished to ensure the primary objective is achieved.

Stakeholders: a person, entity, business, organization, or agency with an interest in hydropower. Key stakeholder categories identified in the SMH MYRP include Water Management and Allocation, Regulatory and Standards Agencies, Resource Managers, Advocacy and Outreach, Standards and Certification Entities, Electric Utilities, Hydropower Asset Owners, Project Development Interests, and Technology Developers.

Sub-Modules: a smaller sub-set of a larger module. For example, a generation module may be comprised of an intake sub-module, a hydraulic chamber and hydraulic water turbine sub-module, an electrical generator sub-module, and a draft tube sub-module. 


\section{APPENDIX H. REFERENCES}

Abban, B., A. N. Papanicolaou, M. K. Cowles, C. G. Wilson, O. Abaci, K. Wacha, K. Schilling, and D. Schnoebelen. 2016. "An enhanced Bayesian fingerprinting framework for studying sediment source dynamics in intensively managed landscapes." Water Resources Research 52.

doi:10.1002/2015WR018030

Annandale, G. W. 2013. Quenching the Thirst: Sustainable Water Supply and Climate Change. CreateSpace, North Charleston, S.C.

ASME PTC (Performance Test Codes). 1993. The Guide to Hydropower Mechanical Design. HCI Publication, 374.

Baines, N.C. 2010. "Turbomachinery in renewable energy applications.” Power Engineering 114(4). Available at http://www.power-eng.com/articles/print/volume-114/issue-4/Features/turbomachineryin-renewable-energy-applications.html. Accessed October 2016.

Bevelhimer, M.S., M. Schramm, and C. DeRolph. 2015. Non-Federal Hydropower Mitigation Database. Oak Ridge National Laboratory. Available at http://nhaap.ornl.gov/environmental-mitigation. Accessed October 2016.

Bilotta, G. S. and R. E. Brazier. 2008. "Understanding the influence of suspended solids on water quality and aquatic biota." Water Research 42(12), 2849-2861.

Bishop, N. and D. Linke. 2015. New Pathways for Hydropower: Getting Hydropower Built-What Does It Take? ORNL/TM-2015/48, Oak Ridge National Laboratory.

BLM (Bureau of Land Management) 2016. "River segments, Rio Grande and Rio Chama." US Department of the Interior, Bureau of Land Management. At http://www.blm.gov/nm/st/en/ prog/recreation/taos/river_segments_rio.html\#RioChama. Accessed October 2016.

Bombardelli, F., M. Guala, C. García, B. Briskin, and M. García, M. 2002. "Mean flow, turbulence, and free-surface location in a canoe chute physical model. Pp. 1-12 in Hydraulic Measurements and Experimental Methods 2002, Estes Park, Colo., July 28-August 1, 2002. American Society of Civil Engineers. Available at http://dx.doi.org/10.1061/40655(2002)12. Accessed October 2016.

Bonnet, M., A. Witt, K. Stewart, B. Hadjerioua, and M. Mobley. 2015. The Economic Benefits of Multipurpose Reservoirs in the United States-Federal Hydropower Fleet, ORNL/TM-2015/550. Oak Ridge National Laboratory.

Brandt, S. A. 2000. "Classification of geomorphological effects downstream of dams." Catena, 40(4), 375-401.

Bratrich, C., B. Truffer, K. Jorde, J. Markard, W. Meier, A. Peter, M. Schneider, and B. Wehrli. 2004. "Green hydropower: A new assessment procedure for river management." River Research and Applications 20(7), 865-882.

Brune, G. M. 1953. “Trap efficiency of reservoirs.” Eos, Transactions American Geophysical Union. 34(3), 407-418. doi: 10.1029/TR034i003p00407.

Bunt, C. M. 2001. "Fishway entrance modifications enhance fish attraction." Fisheries Management and Ecology 8(2), 95-105. 
Bunt, C. M., T. Castro-Santos, and A. Haro. 2012. "Performance of fish passage structures at upstream barriers to migration." River Research and Applications 28(4), 457-478.

Cada, G. F. 1997. Efforts to Reduce the Impacts of Hydroelectric Power Production on Reservoir Fisheries in the United States. Report No CONF-9708103. Oak Ridge National Laboratory.

Cada, G. F. 2001. "The development of advanced hydroelectric turbines to improve fish passage survival." Fisheries 26(9), 14-23.

Caisley, M. E. and M. Garcia. 1999. Canoe Chutes and Fishways for Low-Head Dams: Literature Review and Design Guidelines. Hydraulic Engineering Series 60. Illinois Department of Water Resources, Office of Water Resources. Available at http://hdl.handle.net/2142/12219. Accessed October 2016.

Caisley, M.E., F. A. Bombardelli, and M. H. Garcia. 1999. Hydraulic Model Study of a Canoe Chute for Low-head Dams in Illinois, Hydraulic Engineering Series 63. Illinois Department of Water Resources, Office of Water Resources. Available at http://hdl.handle.net/2142/12214. Accessed October 2016.

Chanson, H. 2009. "Turbulent air-water flows in hydraulic structures: Dynamic similarity and scale effects.” Environmental Fluid Mechanics 9(2), 125-142.

Chaudhry, M. H. 2008. Open Channel Flow. 2nd ed., Springer, New York.

CNRA (California Natural Resources Agency). 2013. Technologies for Passing Fish at Large Dams. State of California, Department of Water Resources. Available at http://www.water.ca.gov/fishpassage/docs/lg_dam.pdf. Accessed October 2016.

Colorado Water Conservation Board. 2008. Floodplain and Stormwater Criteria Manual, Chapter 13, "Hydraulic Analysis and Design"; Section 7, "Recreational Structures." Colorado Department of Natural Resources.

Cooke, S. J. and S. G. Hinch. 2013. "Improving the reliability of fishway attraction and passage efficiency estimates to inform fishway engineering, science, and practice." Ecological Engineering $58,123-132$.

Coombs, S., P. Görner, and H. Münz. 1989. The Mechanosensory Lateral Line Neurobiology and Evolution. Springer-Verlag, New York.

Cordova. M. M., E. C. Finardi, F. A. Carmago Ribas, and F. A. Brown do Coutto. 2013. “A system to optimize plant production." Hydroworld.com. Available at

http://www.hydroworld.com/articles/print/volume-21/issue-5/articles/plant-optimization/a-system-tooptimize-plant-production.html. Accessed October 2016.

Davies-Colley, R. J. and D. G. Smith. 2001. "Turbidity, suspended sediment, and water clarity: A review." Journal of the American Water Resources Association, 37, 1085-1101. doi: 10.1111/j.17521688.2001.tb03624.x

Deng, Z., G. R. Guensch, C. A. McKinstry, R. P. Mueller, D. D. Dauble, and M. C. Richmond. 2005. "Evaluation of fish-injury mechanisms during exposure to turbulent shear flow." Canadian Journal of Fisheries and Aquatic Sciences 62(7), 1513-1522.

Dermisis, D. and A. Papanicolaou. 2009. "Fish passage over hydraulic structures in Midwestern streams." International Journal of River Basin Management 7(4), 313-328. 
Detert, M., V. Weitbrecht, and G. H. Jirka. 2010. "Laboratory measurements on turbulent pressure fluctuations in and above gravel beds." Journal of Hydraulic Engineering 136, 779-789.

Draut, A. E., J. B. Logan, and M. C. Mastin. 2011. "Channel evolution on the dammed Elwha River, Washington, USA.” Geomorphology 127(1), 71-87.

EPA (Environmental Protection Agency) 2016. Code of Federal Regulations, Title 40, "Protection of Environment, Chapter 1, Subchapter D, Part 131, "Water Quality Standards." Available at http://www.ecfr.gov/cgi-bin/text-idx?SID=454a7b51118b27f20cef29ff071c1440\&node $=40: 22 \cdot 0.1 \cdot 1.18 \& r g n=d i v 5$. Accessed October 2016 .

ESHA (European Small Hydropower Association). 2004. Guide on How to Develop a Small Hydropower Plant. Available at http://www.canyonhydro.com/images/Part_1_ESHA_Guide_on_how_to_develop_a_small_hydropow er_plant.pdf. Accessed October 2016.

Farell, C., J. Arroyave, N. Cruz, and J. S. Gulliver. 1983. Hydromechanics of Variable Speed Turbines. Report 225. Prepared by the University of Minnesota for the Minnesota Department of Natural Resources, St. Paul. Available at https://conservancy.umn.edu/bitstream/handle/11299/110086/ pr225.pdf?sequence=1. Accessed October 2016.

FERC (Federal Energy Regulatory Commission). 1999. "Gravity Dams." Chapter 3 in Engineering Guidelines for the Evaluation of Hydropower Projects. Washington, DC. Available at https://www.ferc.gov/industries/hydropower/safety/guidelines/eng-guide.asp. Accessed October 2016.

FERC (Federal Energy Regulatory Commission). 2003. "Gravity Dams.” Chapter 3 in Engineering Guidelines for the Evaluation of Hydropower Projects. Washington, DC. Available at https://www.ferc.gov/industries/hydropower/safety/guidelines/eng-guide/chap3.pdf. Accessed October 2016.

Ferguson, J. W., R. F. Absolon, T. J. Carlson, and B. P. Sandford. 2006. "Evidence of delayed mortality on juvenile Pacific salmon passing through turbines at Columbia River dams." Transactions of the American Fisheries Society 135(1), 139-150. doi.org/10.1577/T05-080.1

Ferguson, R. 2007. "Flow resistance equations for gravel-and boulder-bed streams." Water Resources Research 43(5).

FHWA (Federal Highway Administration). 1999. Manual for Design and Construction Monitoring of Soil Nail Walls. FHW A-SA-96-069R. US Department of Transportation. Available at http://isddc.dot.gov/OLPFiles/FHWA/010571.pdf. Accessed October 2016.

Ficke, A. D., C. C. Myrick, and N. Jud. 2011. "The swimming and jumping ability of three small great plains fishes: Implications for fishway design.” Transactions of the American Fisheries Society, 140(6), 1521-1531. doi: 10.1080/00028487.2011.638579. Accessed October 2016.

Fuller, M. R., M. W. Doyle, and D. L. Strayer. 2015. "Causes and consequences of habitat fragmentation in river networks." Annals of the New York Academy of Sciences 1355(1), 31-51.

Gaeuman, D., J. C. Schmidt, and P. R. Wilcock. 2005. "Complex channel response to changes in stream flow and sediment supply on the lower Duchesne River, Utah.” Geomorphology 64, 185-206. 
Grabowski, R. C., I. G. Droppo, and G. Wharton. 2011. "Erodibility of cohesive sediment: The importance of sediment properties." Earth-Science Reviews 105(3), 101-120.

Graf, W. L. 2006. "Downstream hydrologic and geomorphic effects of large dams on American rivers." Geomorphology 79, 336-360.

Grams, P. E., J. C. Schmidt, and D. J. Topping. 2007. "The rate and pattern of bed incision and bank adjustment on the Colorado River in Glen Canyon downstream from Glen Canyon Dam, 19562000." Geological Society of America Bulletin 119(5/6), 556-575.

Grant, G. E., J. C. Schmidt, S. L. Lewis. 2003. “A Geological Framework for Interpreting Downstream Effects of Dams on Rivers.” In A Peculiar River, American Geophysical Union, pp. 209-225. Available at http://wpg.forestry.oregonstate.edu/sites/wpg/files/bibliopdfs/03Grantetal Deschutes.pdf. Accessed October 2016.

Guenther, P., S. Felder, and H. Chanson. 2013. "Flat and pooled stepped spillways for overflow weirs and embankments: cavity flow processes, flow aeration and energy dissipation. Pp. 77-86 in International Workshop on Hydraulic Design of Low-Head Structures (IWLHS 2013), Aachen, Germany, February 20-22, 2013. Bundesanstalt fur Wasserbau (BAW).

Gulliver, John S., and R.E.A. Arndt. 1991. Hydropower Engineering Handbook. McGraw-Hill.

Hardy, R. J., J. L. Best, S. N. Lane, and P. E. Carbonneau. 2010. "Coherent flow structures in a depthlimited flow over a gravel surface: The influence of surface roughness." Journal of Geophysical Research 115, F03006. doi: 10.1029/2009JF001416

Hsu, E. Y. S. Kolupaila, C. Jaeger, L. M. Laushey, M. Viparelli, R. M. Weaver, S. M. Woodward, and F. M. Yates. 1950. "Discussion on 'Control of the Hydraulic Jump by Sills' by John W. Forster and Raymond A. Skrinde.” Transactions of the American Society of Civil Engineers 1(15), 988-991.

Hughes, A. 2009. Electric Motors and Drives, 3rd ed., Elsevier, Burlington, Massachusetts.

Hyra, R. 1978. Methods of Assessing Instream Flows for Recreation. FWS/OBS-78/34, US Fish and Wildlife Service, Department of the Interior. National Technical Information Service, US Department of Commerce, 78(26).

ICPDR (International Commission for the Protection of the Danube River). 2013. Hydropower Case Studies and Good Practice Examples. Annex to Guiding Principles on Sustainable Hydropower Development in the Danube Basin. ICPDR, Vienna. Available at https://www.icpdr.org/main/sites/ default/files/nodes/documents/annex_-_case_studies_and_good_practice_examples_final.pdf. Accessed October 2016.

IEA (International Energy Agency). 2000. IEA Assessment of Further Opportunities for R\&D-Summary Report. Available at http://www.ieahydro.org/media/2bf10d98/Assessment\%20of\%20Further $\%$ 20Opportunities\%20for\%20R\&D\%20-\%20Summary\%20Report.pdf. Accessed October 2016

Kao, S. C., McManamay, R. A., Stewart, K. M., Samu, N. M., Hadjerioua, B., DeNeale, S.T., Yeasmin, D., Pasha, M.F.K., Oubeidillah, A. A., Smith, B. T. 2014. New Stream-reach Development: A Comprehensive Assessment of Hydropower Energy Potential in the United States. GPO DOE/EE1063.Washington, DC: Wind and Water Power Program, US Department of Energy.

Katopodis, C. 1992. Introduction to Fishway Design: Working Document. Department of Fisheries and Oceans. Winnipeg, Manitoba, Canada. Available at http://www.wra.gov.tw/public/attachment/41110254871.pdf. Accessed October 2016. 
Kiger, K. T., and J. H. Duncan. 2012. "Air-entrainment mechanisms in plunging jets and breaking waves.” Annual Review of Fluid Mechanics 44, 563-596.

Kinloch, D. B. 2015. Demonstration of Variable Speed Permanent Magnet Generator at Small, LowHead Hydro Site. Final report, DE-EE0005429. Shaker Landing Hydro Associates for the US Department of Energy.

Kleinhans, M. G., and L. C. van Rijn. 2002. "Stochastic prediction of sediment transport in sand-gravel bed rivers." Journal of hydraulic engineering 128(4), 412-425.

Klumpp, C. C., C. A. Pugh, and J. R. Fitzwater. 1989. Union Avenue Dam Boatchute Study, R-89-12. US Bureau of Reclamation, Denver, Colo.

Kondolf, G. M., Y. Gao, G. W. Annandale, G. L. Morris, E. Jiang, J. Zhang, ... C. T. Yang. 2014. "Sustainable sediment management in reservoirs and regulated rivers: Experiences from five continents." Earth's Future 2(5), 256-280.

Kondolf, G. M. 2000. “Assessing salmonid spawning gravel quality.” Transactions of the American Fisheries Society 129(1), 262-281.

Lacey, R. J. and C. D. Rennie. 2011. "Laboratory investigation of turbulent flow structure around a bedmounted cube at multiple flow stages." Journal of Hydraulic Engineering 138(1), 71-84.

Lane, E. W. 1955. The importance of fluvial geomorphology in hydraulic engineering," Proceedings of the ASCE, 81(745), 1-17.

Langendoen, E. and A. Simon. 2008. "Modeling the evolution of incised streams. II: Streambank erosion.” J. Hydraul. Eng. 10.1061/(ASCE)0733-9429(2008)134:7(905), 905-915.

Langendoen, E. J. and C. V. Alonso. 2008. "Modeling the evolution of incised streams: I. Model formulation and validation of flow and streambed evolution components." Journal of Hydraulic Engineering 134(6), 749-762.

Larinier, M. 2000. Dams and Fish Migration. World Commission on Dams, Toulouse, France.

Leyland, B. 2014. Small Hydroelectric Engineering Practice. CRC Press Boca Raton, Florida. Available from https://www.crcpress.com/Small-Hydroelectric-Engineering-Practice/Leyland/9781138000988. Accessed October 2016.

LIHI (Low Impact Hydropower Institute) 2014. Revised LIHI Certification: A Proposed New Approach for 2014. Available at http://lowimpacthydro.org/assets/files/Criteria/Revised\%20LIHI\%20 Criteria\%20-\%20public\%20release\%20-\%2008192014\%20-\%20FINAL.pdf. Accessed October 2016.

Liu, M., N. Rajaratnam, and D. Z. Zhu. 2006. "Mean flow and turbulence structure in vertical slot fishways." Journal of Hydraulic Engineering 132(8), 765-777.

Maclean, A. 1991. "Bed shear stress and scour over bed-type river intake." Journal of Hydraulic Engineering 10.1061/(ASCE)0733-9429(1991)117:4(436), 436-451.

Magilligan, F. J. and K. H. Nislow. 2005. "Changes in hydrologic regime by dams." Geomorphology 71(1), 61-78. 
Magilligan, F. J., K. H. Nislow, and C. E. Renshaw. 2013. "Flow Regulation by Dams.” In J. Schoder, editor in chief, E. Wohl, ed., Treatise on Geomorphology. Academic Press, San Diego, Calif, vol. 9, Fluvial Geomorphology, 794-808.

Maidment, D. 1993. Handbook of Hydrology. McGraw-Hill Professional Publishing.

Marriner, B. A., A. B. M. Baki, D. Z. Zhu, J. D. Thiem, S. J. Cooke, and C. Katopodis 2014. "Field and numerical assessment of turning pool hydraulics in a vertical slot fishway." Ecological Engineering $63,88-101$.

Maxwell, A. and A. Papanicolaou. 2000. "Geometric characteristics of step-pool streams." Building Partnerships, pp. 1-10. doi: 10.1061/40517(2000)293

McManamay, R. A., M. S. Bevelheimer, and S.-C. Kao. 2013. "Updating the US hydrologic classification: An approach to clusterine and stratifying ecohydrologic data." Ecohydrology 7, 903926. Available at http://hydropower.ornl.gov/docs/pubs/Updating_the_US_hydrologic_classification _an_approach_to_clustering_and_stratifying_ecohydrologic_data.pdf. Accessed October 2016.

Meixler, M. S., M. B. Bain, and M. T. Walter. 2009. "Predicting barrier passage and habitat suitability for migratory fish species.” Ecological Modelling 220(20), 2782-2791.

Millar, R. G. 1999. "Grain and form resistance in gravel-bed rivers," Journal of Hydraulic Research 37(3), 303-312.

Milliman, J. D., and K. L. Farnsworth. 2013. River Discharge to the Coastal Ocean: A Global Synthesis. Cambridge University Press.

Montgomery, J. C., C. F. Baker, and A. G. Carton. 1997. "The lateral line can mediate rheotaxis in fish." Nature 389, 960-963.

Moore, M. C. 1994. Bedload Transport: The Effects of Particle Shape and an Investigation of a Wide Range of Transport Rates, M. S. Thesis, Virginia Polytechnic Institute and State University, Blacksburg, Va.

Moore, W. L., and C. W. Morgan. 1959. "Hydraulic jump at an abrupt drop." Transactions of the American Society of Civil Engineering 124(2991), 507-524.

Mulvihill, C. I. and B. P. Baldigo. 2012. "Optimizing bankfull discharge and hydraulic geometry relations for streams in New York State." Journal of the American Water Resources Association 48(3): 449463. doi: 10.1111/j.1752-1688.2011.00623.x

Nakato, T. and F. Ogden. 1998. "Sediment control at water intakes along sand-bed rivers." Journal of Hydraulic Engineering 10.1061/(ASCE)0733-9429(1998)124:6(589), 589-596.

Nezu, I., and H. Nakagawa. 1993. Turbulence in Open-Channel Flows, Balkema, Rotterdam.

Noonan, M. J., J.W.A. Grant, and C. D. Jackson. 2012. "Quantitative assessment of fish passage efficiency." Fish and Fisheries 13, 450-464.

NRCS (Natural Resources Conservation Service). 2007. National Engineering Handbook, Part 654Stream Restoration Design, Technical Supplement 14N, Fish Passage and Screening Design. US Department of Agriculture.

O'Connor, P., Q. F. Zhang, S. T. DeNeale, D. R. Chalise, and E. Centurion. 2015. Hydropower Baseline Cost Modeling. ORNL/TM-2015/14. Oak Ridge National Laboratory. 
Opsahl, E. 2013. "CleanPower Turbinator: Hydropower without a dam, Tjeldbergodden, Norway." Proceedings of HydroVision International 2013, Denver, Colo. July 23-26, 2013. Available at http://www.turbinator.no/Portals/0/Presentasjoner/HydroVision2013_CleanPower\%20

Turbinator.pdf. Accessed October 2016.

OTA (Office of Technology Assessment). 1995. Fish Passage Technologies: Protection at Hydropower Facilities. OTA-ENV-641. US Government Printing Office, Washington, DC. Available at http://ota.fas.org/reports/9519.pdf. Accessed October 2016.

Owens, P. N., R. J. Batalla, A. J. Collins, B. Gomez, D. M. Hicks, A. J. Horowitz, G. M. Kondolf, M. Marden, M. J. Page, D. H. Peacock, E. L. Petticrew, W. Salomons, and N. A. Trustrum. 2005. "Finegrained sediment in river systems: Environmental significance and management issues." River Research Applications 21, 693-717. doi: 10.1002/rra.878

Papanicolaou, A. N., P. Diplas, N. Evaggelopoulos, and S. Fotopoulos. 2002. "Stochastic incipient motion criterion for spheres under various bed packing conditions." Journal of Hydraulic Engineering 128(4), 369-380.

Papanicolaou, A. N., and A. Maxwell. 2000. "Hydraulic performance of fish bypass-pools for irrigation diversion channels." Journal of Irrigation and Drainage Engineering 126(5), 314-321.

Papanicolaou, A. N., and B. K. Abban. 2016. "Channel Erosion and Sediment Transport." Chapter 65 in Handbook of Applied Hydrology, 2nd ed. V. P. Singh, ed., McGraw-Hill. ISBN-13:978-0071835091

Papanicolaou, A. N., C. M. Kramer, A. G. Tsakiris, T. Stoesser, S. Bomminnayuni, and Z. Chen. 2012. "Effects of a fully submerged boulder within a boulder array on the mean and turbulent flow fields: Implications to bedload transport." Acta Geophysica 60(6), 1502-1546.

Papanicolaou, A. N., and B. D. Barkdoll. 2011. Sediment Dynamics upon Dam Removal. ASCE Manuals and Reports on Engineering Practice No. 122, 1st ed. American Society of Civil Engineers, Reston, Virginia. ISBN-13:978-0784411360.

Parker, G. 1991. "Selective sorting and abrasion of river gravel. I: Theory." Journal of Hydraulic Engineering 117(2), 131-149.

Parker, G. 2008. "Transport of Gravel and Sediment Mixtures." Chapter 3 in Sedimentation Engineering: Processes, Measurements, Modeling, and Practice, ASCE Manual of Practice110, V. A. Vanoni, ed. $165-252$.

Paxson, G. S., D. B. Campbell, M. C. Canino, and M. E. Landis. 2011. "Dam Safety: Stability and rehabilitation of 'smaller' gravity dams." HydroWorld.com. Available at http://www.hydroworld.com/articles/hr/print/volume-30/issue-6/articles/dam-safety-stability-andrehabilitation-of-smaller-gravity-dams.html. Accessed October 2016.

Poff, N. L. and J.K.H. Zimmerman. 2010. "Ecological responses to altered flow regimes: A literature review to inform the science and management of environmental flows." Freshwater Biology 55(1), 194-205. Available at http://www.wrb.state.ri.us/documents/Poff_Zimmerman_2009_FWB.pdf. Accessed October 2016.

Pracheil, B. M., C. R. DeRolph, M. P. Schramm, and M. S. Bevelhimer. 2016. "A fish-eye view of riverine hydropower systems: The current understanding of the biological response to turbine passage." Reviews in Fish Biology and Fisheries, 26(153), 1-15. doi: 10.1007/s11160-015-9416-8 
Puertas, J., L. Pena, and T. Teijeiro. 2004. "Experimental approach to the hydraulics of vertical slot fishways." Journal of Hydraulic Engineering 130(1), 10-23.

Raudkivi A. J. 1998. Loose Boundary Hydraulics, A. A. Balkema Publishers, Rotterdam, The Netherlands.

Reinfelds, I., M. Lincoln-Smith, T. Haeusler, D. Ryan, and I. Growns. 2010. "Hydraulic assessment of environmental flow regimes to facilitate fish passage through natural riffles: Shoalhaven river below Tallowa Dam, New South Wales, Australia." River Research and Applications 26(5), 589-604.

Renöfält, B. M., R. Jansson, and C. Nilsson. 2010. "Effects of hydropower generation and opportunities for environmental flow management in Swedish riverine ecosystems." Freshwater Biology 55, 49-67. doi:10.1111/j.1365-2427.2009.02241.x

Richmond, M. C., Z. Deng, C. A. McKinstry, R. P. Mueller, T. J. Carlson, and D. D. Dauble. 2009. "Response relationships between juvenile salmon and an autonomous sensor in turbulent flow." Fisheries Research 97(1), 134-139.

Richter, B. D., J. V. Baumgartner, J. Powell, and D. P. Braun. 1996. "A method for assessing hydrologic alteration within ecosystems." Conservation Biology 10(4), 1163-1174.

Rickenmann, D. and A. Recking. 2011. "Evaluation of flow resistance in gravel-bed rivers through a large field data set." Water Resources Research 47(7).

Roscoe, D. W., and S. G. Hinch. 2010. "Effectiveness monitoring of fish passage facilities: Historical trends, geographic patterns and future directions." Fish and Fisheries 11(1), 12-33.

Sadeque, M. A., N. Rajaratnam, and M. R. Loewen. 2008. "Flow around cylinders in open channels." Journal of Engineering Mechanics 134(1), 60-71.

Santucci Jr, V. J., S. R. Gephard, and S. M. Pescitelli. 2005. "Effects of multiple low-head dams on fish, macroinvertebrates, habitat, and water quality in the Fox River, Illinois." North American Journal of Fisheries Management 25(3), 975-992.

Schilt, C. 2007. "Developing fish passage and protection at hydropower dams." Applied Animal Behaviour Science 104, 295-325.

Schmidt, J. C., and P. R. Wilcock. 2008. "Metrics for assessing the downstream effects of dams." Water Resources Research 44(4).

Schramm, M. P., M. S. Bevelhimer, and C. R. DeRolph. 2016. "A synthesis of environmental and recreational mitigation requirements at hydropower projects in the United States." Environmental Science \& Policy 61, 87-96.

Schwartz, F. H. and M. Shahidehpour. 2006. "Small hydro as green power." Pp. 1-6 in 2006 IEEE EIC Climate Change Conference, Ottawa, Ontario, Canada, May 10-12, 2006.

Sear, D. A. 1993. "Fine sediment infiltration into gravel spawning beds within a regulated river experiencing floods: Ecological implications for salmonids." Regulated Rivers: Research and Management 8, 373-390. doi: 10.1002/rrr.3450080407

Shamloo, H., N. Rajaratnam, and C. Katopodis. 2001. "Hydraulics of simple habitat structures." Journal of Hydraulic Research 39(4), 351-366. 
Simmons, W. P., R. J. Brown, R. A. Simonds, and T. H. Logan. 1977. "Model Studies of Denver Whitewater Channel." Journal of the Hydraulics Division 103(7), 763-775.

Skvarenina, T. L., and W. E. DeWitt. 2004. Electrical Power and Controls, 2nd ed., Pearson Prentice Hall, Upper Saddle River, New Jersey.

Smith, B. T., A. Witt, K. M. Stewart, K. Lee, S. DeNeale, and M. Bevelhimer. 2017. A Multi-Year Plan for Research, Development, and Prototype Testing of Standard Modular Hydropower Technology/R1 ORNL/TM-2016/102, Oak Ridge National Laboratory.

Smith, B. T., H. I. Jager, and P. Marsh. 2008. "Prospects for combining energy and environmental objectives in hydropower optimization." Waterpower XI, 2007. Available at https://www.researchgate.net/publication/228634825_Prospects_for_combining_energy_and_environ mental_objectives_in_hydropower_optimization. Accessed October 2016.

Strom, K. B., and A. N. Papanicolaou. 2007. "ADV measurements around a cluster microform in a shallow mountain stream." Journal of Hydraulic Engineering. ASCE 133(12), 1379-1389. doi: 10.1061/(ASCE)0733-9429(2007)133:12(1379).

Sutarto, T., A. N. Papanicolaou, C. G. Wilson, and E. J. Langendoen. 2014. "Stability analysis of semicohesive streambanks with concepts: Coupling field and laboratory investigations to quantify the onset of fluvial erosion and mass failure." Journal of Hydraulic Engineering 140(9), 04014041.

Taggart, W. C., J. M. Pflaum, and J. H. Sorensen. 1984. Modifications of Dams for Recreational Boating. Pp. 781-785 in Water for Resource Development, Coeur d'Alene, Idaho, August 14-17, 1984. American Society for Civil Engineering.

Tarrade, L., A. Texier, L. David, and M. Larinier. 2008. "Topologies and measurements of turbulent flow in vertical slot fishways." Hydrobiologia 609(1), 177-188.

TN SHP (Thematic Network on Small Hydro Power). 2005. Proposals for a European Strategy of Research, Development and Demonstration $(R D \& D)$ for Renewable Energy from Small Hydropower.

Trussart, S. et al., 2002. Hydropower projects: A review of most effective mitigation measures. Energy Policy, 30(14), pp.1251-1259.

USBR (US Bureau of Reclamation). 1977. Design of Small Dams. Government Printing Office, Washington. DC.

van Rijn, L. C. 1993. Principles of Sediment Transport in Rivers, Estuaries and Coastal Seas. Aqua Publications, Amsterdam, The Netherlands.

Vandas, S., 1990. Dolores River Instream Flow Assessment: Project Report. US Department of the Interior, Bureau of Land Management. Denver Service Center, Denver, Colo.

Viparelli, E., O. Sequeiros, A. Cantelli, P. R. Wilcock, and G. Parker. 2010. "Modeling of river morphodynamics with creation/consumption of grain size stratigraphy. Part 2: Numerical model." Journal of Hydraulic Research 48(6), 727-741.

Wang, R. W., L. David, and M. Larinier. 2010. "Contribution of experimental fluid mechanics to the design of vertical slot fish passes." Knowledge and Management of Aquatic Ecosystems (396), 02.

Werth, D. and C. Frizzell. 2009. "Minimum pump submergence to prevent surface vortex formation." Journal of Hydraulic Research 47(1), 142-144. 
Whitehead, M., and R. Albertani. 2015. "How composite materials can be used for small hydro turbines." Hydro Review and HydroWorld.com. 34(2), 56-63.

Wiberg, P. L., and J. D. Smith. 1987. "Calculations of the critical shear stress for motion of uniform and heterogeneous sediments." Water Resources Research. 23, 1471-1480. doi:10.1029/WR023i008p01471

Wild, T., D. Loucks, G. Annandale, and P. Kaini. 2015. "Maintaining sediment flows through hydropower dams in the Mekong River Basin." Journal of Water Resources Planning and Management 42(1). doi: 10.1061/(ASCE)WR.1943-5452.0000560.

Wong, M., and G. Parker. 2006. "Reanalysis and correction of bed-load relation of Meyer-Peter and Müller using their own database." Journal of Hydraulic Engineering, 132(11), 1159-1168.

Yalin, M.S. 1977. “Mechanics of Sediment Transport,”2nd ed. Pergamon Press.

Yildirim, N. and F. Kocabaş. 1995. "Critical submergence for intakes in open channel flow." Journal of Hydraulic Engineering 10.1061/(ASCE)0733-9429(1995) 121:12(900), 900-905.

Zhang, Q.F.K., B. Smith, and W. Zhang. 2012. Small Hydropower Cost Reference Model. ORNL/TM2012/501. Oak Ridge National Laboratory. Available at http://info.ornl.gov/sites/publications/files/ pub39663.pdf. Accessed October 2016. 